\title{
REDIQ - A Computer Program for Estimating Health Effects from Inhalation and Ingestion of Radionuclides
}

December 1976

Prepared for the

Nuclear Regulatory Commission 


\title{
NOTICE
}

This report was prepared as an account of work sponsored by the United States Government. Neither the United States nor the United States Nuclear Regulatory Commission, nor any of their employees, nor any of their contractors, subcontractors, or their employees, makes any warranty, express or implied, or assumes any legal liability or responsibility for the accuracy, completeness or usefulness of any information, apparatus, product or process disclosed, or represents that its use would not infringe privately owned rights.

PACIFIC NORTHWEST LABORATORY

operated by

BATTELLE

for the

ENERGY RESEARCH AND DEVELOPMENT ADMINISTRATION

Under Contract EY-76-C-06-1830

\author{
Printed in the United States of America \\ Available from \\ National Technical Information Service \\ U.S. Department of Commerce \\ 5265 Port Royal Road \\ Springfield, Virginia 22151 \\ Price: Printed Copy $\$$ _; Microtiche $\$ 3.20$
}

$\begin{array}{cc}\text { P Pages } & \begin{array}{c}\text { NTIS } \\ \text { Selling Price }\end{array} \\ 007-025 & \$ 4.50 \\ 026-050 & \$ 5.00 \\ 051-075 & \$ 5.50 \\ 076-100 & \$ 5.00 \\ 101-125 & \$ 6.50 \\ 126-150 & \$ 7.00 \\ 15--775 & \$ 7.75 \\ 176-200 & \$ 8.50 \\ 201-225 & \$ 8.75 \\ 226-250 & \$ 9.00 \\ 251-275 & \$ 10.00 \\ 275-300 & \$ 10.25\end{array}$


BNWL-2 110

NRC-1

ERRATA

DECEMBER 1977

The following corrections should be made.

1) Page A.9: The last line for equation (12) should be

$$
+\frac{c_{h}^{\prime}}{\left(\lambda_{i}-\lambda_{n}\right)}\left\{\frac{e^{-\lambda_{n} T_{2}}-e^{-\lambda_{i} T_{2}}}{\lambda_{j}-\lambda_{n}}-T_{2} e^{-\lambda_{i} T_{2}}\right\}
$$

2) Pages D.38 and D.39: The organ data library presented in Appendix D contains outdated $f_{w}$ values for uranium. The values should be: ${ }^{(2)}$ for total body, $1 \times 10^{-2}$; for kidneys, $1.1 \times 10^{-3}$; and for bone, $1.1 \times 10^{-3}$. 
BNWL -2110

$\mathrm{NRC}-1$

\title{
33679000626699
}

REDIQ - A COMPUTER PROGRAM FOR ESTIMATING HEALTH EFFECTS FROM INHALATION AND

INGESTION OF RADIONUCLIDES
by
D. L. Strenge
E. C. Watson
W. E. Kennedy

December 1976

\author{
BATTELLE \\ Pacific Northwest Laboratories \\ Richland, Washington 99352
}




\section{SUMMARY}

The computer program REDIQ calculates the risk equivalence of dosage from internally deposited radionuclides to dosage from external whole-body irradiation. The calculation gives an estimate of the microcurie intake per nuclide that would result in a risk equivalent to receiving 1 rem of external whole-body irradiation. The program allows for internal deposition resulting from either inhalation of radioactive aerosols or ingestion of contaminated food. The inhalation portion of REDIQ was taken from the computer program DACRIN, ${ }^{(1)}$ which uses the models of the respiratory tract adopted by the Task Group on Lung Dynamics. ${ }^{(2)}$ REDIQ also uses a simple exponential model for retention by an organ of interest, and the gastrointestinal tract model of the International Commission on Radiological Protection (ICRP).

For each nuclide specified, the program first calculates the radiation dose per microcurie intake by inhalation or ingestion to any of 23 organs and tissues. A maximum of 10 organs may be specified for any one case. The values for dose per microcurie intake are then coupled with relative risk values for each organ being considered, to arrive at the estimated intake equivalent to 1 rem of external whole-body irradiation. 


\section{CONTENTS}

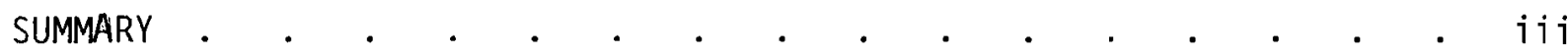

FIGURES • . . . . . . . . . . . . . . . . . . . . . . . . vii

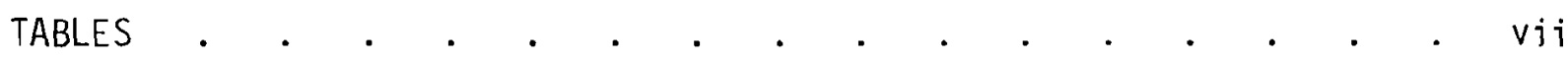

INTRODUCTION .

MATHEMATICAL MODELS AND METHODS . . . . . . . . . . . . . . 2

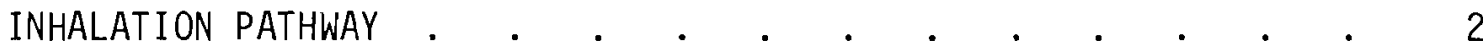

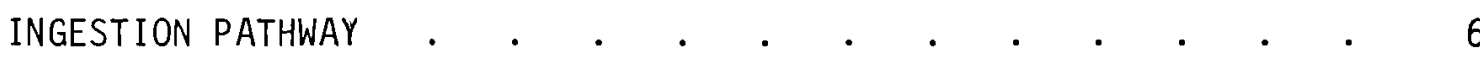

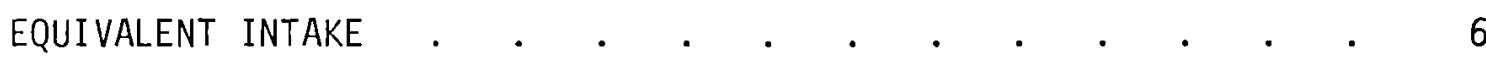

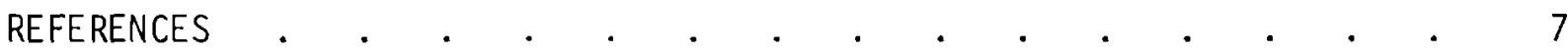

APPENDIX A - Description of Mathematical Models . . . . . . . . A.l

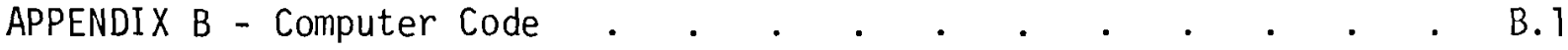

APPENDIX C - Code Flow Diagram . . . . . . . . . . . . . . . .

APPENDIX D - Data Libraries . . . . . . . . . . . . . . . . D. 1

APPENDIX E - Program Listing . . . . . . . . . . . . . . . . . . E.1

APPENDIX F - Input Preparation . . . . . . . . . . . . . . F.1

APPENDIX G - Sample Problem . . . . . . . . . . . . . . G. G 


\section{FIGURES}

1 Schematic Diagram of the Task Group Lung Model . . . . . . 3

2 Schematic Diagram of the REDIQ Metabolic Model . . . . . . 4

3 Schematic Diagram of the G.I. System Mode1 . . . . . . . 5

C-1 Program Module Linkage . . . . . . . . . . . . . C.1

C-2a Main Program Flow Diagram . . . . . . . . . . . C.2

$\mathrm{C}-2 \mathrm{~b}$ Main Program Flow Diagram . . . . . . . . . . . C.3

C-2C Main Program Flow Diagram. . . . . . . . . . . C.4

C-3a Subroutine ORDOSE Flow Diagram . . . . . . . . . . C.5

C-3b Subroutine ORDOSE Flow Diagram . . . . . . . . . . C.6

C-3C Subroutine ORDOSE Flow Diagram . . . . . . . . . . C.7

C-3d Subroutine ORDOSE Flow Diagram . . . . . . . . . . C.8

D-1 Radionuclide Data Library . . . . . . . . . . . D.4

D-7 Organ Data Library. . . . . . . . . . . . . . . . D.7

E-1 FORTRAN Listing of REDIQ . . . . . . . . . . . . . . . E.2

G-1 Input Card Listing for Sample Problem . . . . . . . . G.3

G-2 Sample Problem Output . . . . . . . . . . . . . . . . G.4

\section{$\underline{T A B L E S}$}

A-1 Values of the Clearance Parameters for the Task Group

Lung Model . . . • • . . . . . • . . . . A.2

A-2 G.I. Tract Data . . . . . . . . . . . . . A.14

F-1 Namelist Variables for Cards 2 to $N$. . . . . . . . F.3

F-2 Numerical Index of Organs. . . . . . . . . . . F.4

G-1 Assumed Values Used in Calculating Estimates of Risk . . . . G.2 
REDIQ - A COMPUTER PROGRAM FOR ESTIMATING HEALTH EFFECTS FROM INHALATION AND INGESTION OF RADIONUCLIDES

\section{INTRODUCTION}

People are continually exposed to radiation from many sources (e.g., cosmic radiation, $x$-ray machines, television sets and radionuclides in the environment) that results in receipt of an external dose. Internal exposure, resulting in dose receipt by individual organs within the body, occurs when radionuclides are assimilated through respiration of air and ingestion of food and water. The purpose of this report is to describe a computer program for estimating the radionuclide intake that produces an internal exposure equivalent to 1 rem of whole-body external exposure.

The "intake equivalent" is expressed as the microcuries total intake of a given nuclide, via inhalation or ingestion (not both), that produce a risk equivalent to that from 1 rem of external whole-body irradiation. "Risk" means the danger that a particular effect, such as death from cancer, may occur. The intake equivalent is established using risk factors to weight the dose for each organ, and equating the total risk to the external whole-body exposure risk. The computer program REDIQ was developed to calculate the values for organ dose per microcuries of intake, and to use these values to estimate the equivalent intake amounts.

The program makes no assumptions about the values to be used for risk factors; these must be supplied by the user. The Advisory Committee on Biological Effects of Ionizing Radiation(a) (the BEIR Committee) has reported its best estimates of the cancer death risk for the U.S. population from exposure to ionizing radiation. (4) Use of this information is discussed in Appendix $G$ as part of the sample problem.

(a) Of the National Academy of Sciences--National Research Council. 


\section{MATHEMATICAL MODELS AND METHODS}

The mathematical models used by REDIQ are those of the computer program

DACRIN ${ }^{(1)}$ plus the ingestion pathway model presented in ICRP Publication 2. ${ }^{(3)}$ These models are used to determine the dose to specific organs per microcurie intake via inhalation or ingestion. A detailed discussion of each model is given in Appendix A. The normalized organ dose values are used to determine the equivalent intake values for each nuclide of interest, using the method that is described below following a general discussion of the inhalation and ingestion models.

\section{INHALATION PATHWAY}

The model of the respiratory tract adopted by the Task Group on Lung Dynamics forms the general basis for the mathematical models developed to calculate the dose from the inhalation of radionuclides. (1) In the Task Group's model, the respiratory tract is divided into three regions, the nasopharyngeal (NP), the tracheobronchial (TB), and the pulmonary (P), as shown in Figure 1. Deposition is assumed to vary with the aerodynamic properties of the aerosol distribution for each inhaled radionuclide, and is described by the three parameters $D_{3}, D_{4}$, and $D_{5}$. These parameters represent the fraction of the inhaled material, $Q_{I}$, initially deposited in each of the three regions.

The NP, TB and $P$ regions of deposition are further subdivided into two or more subcompartments. Each subcompartment represents the fraction of a compartment's initial radionuclide content that is subject to a particular clearance process. This fraction is represented by $f_{j}$, where $j$ indicates the clearance pathway. For example, the quantity of material in the TB region that is cleared by process $(c)$ is represented by the product ${ }_{C} D_{4} Q_{I}$. For each clearance process in the three translocation or aerosol solubility groups, the values of $f_{j}$ and $T_{j}$ (the clearance half-time) are those suggested by the ICRP ${ }^{(5)}$ (see Appendix A, Table A-1). Values of the deposition fractions $D_{3}, D_{4}$, and $D_{5}$ have been published in graphic form ${ }^{(2)}$ as a function of activity median aerodynamic diameter (AMAD). 


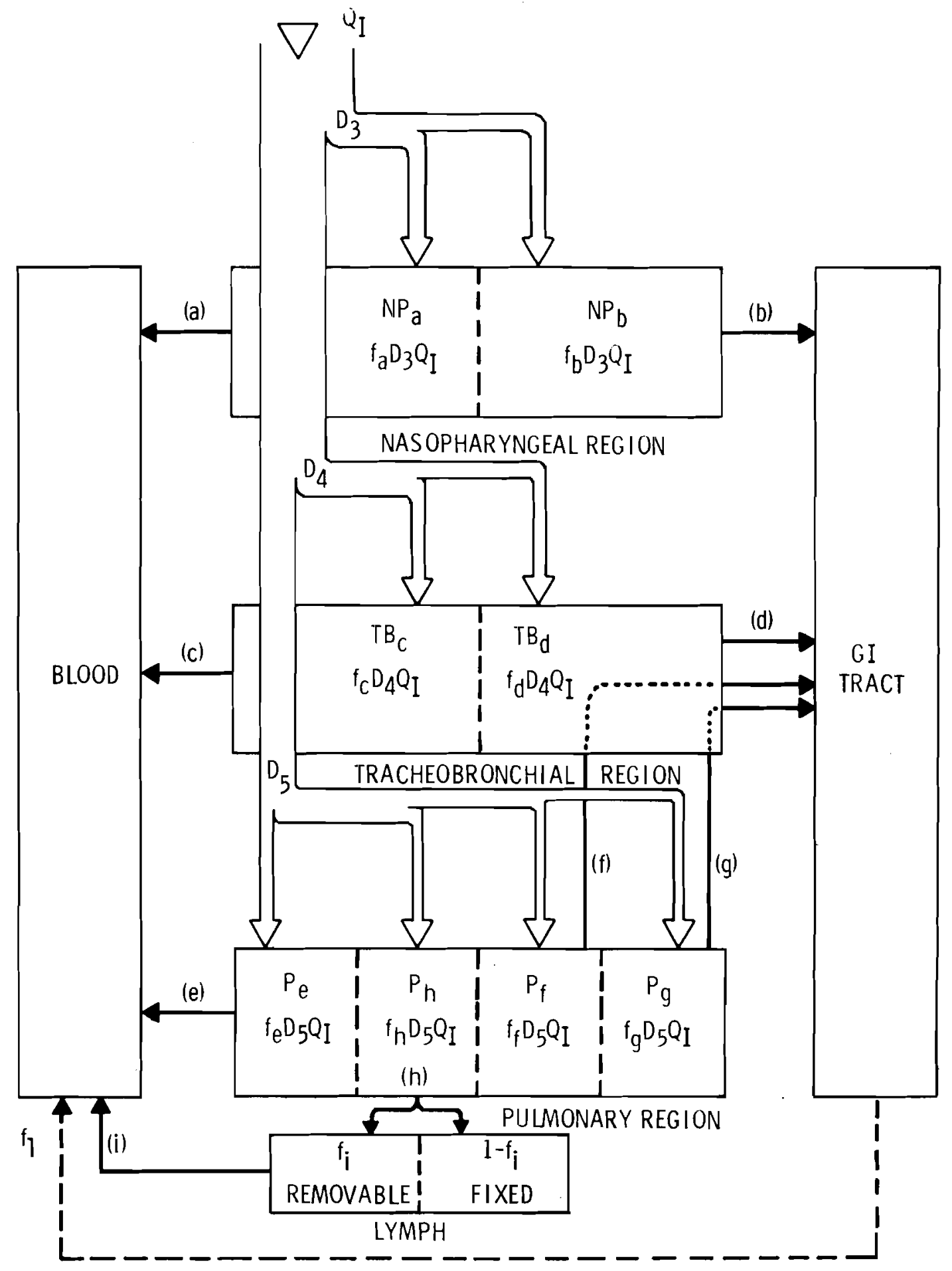

FIGURE 1. Schematic Diagram of the Task Group Lung Model 
Routines to generate these values directly from the AMAD have been included in the code and yield essentially the same values as those presented by the Task Group.

REDIQ expands the Task Group lung model to include calculation of organ doses, using the lung model to describe entry of radioactive materials into the body. Radionuclides are assumed to be transported via the blood, moving from the respiratory tract, the lymphatic system, and the gastrointestinal (GI) tract to other organs and tissues where significant accumulations of inhaled radionuclides occur. This translocation from the respiratory tract and lymphatic system to the blood has been described in some detail by the Task Group. of the material clearing from the respiratory tract through the GI tract, a constant fraction, $f_{1}$, is assumed to be taken up by the blood. The portion moving to the $n^{\text {th }}$ organ or tissue is assumed to be a constant fraction, $f_{2}^{\prime}$, of the amount that enters the blood stream at any time $t$. Once in the $n^{\text {th }}$ organ, the radioactive material is assumed to clear the organ (and the body) at a constant rate, $\lambda_{n}$. This expanded model can thus be used to determine organ doses at any time following acute or chronic exposures. A schematic representation of the REDIQ metabolic model described above is shown in Figure 2.

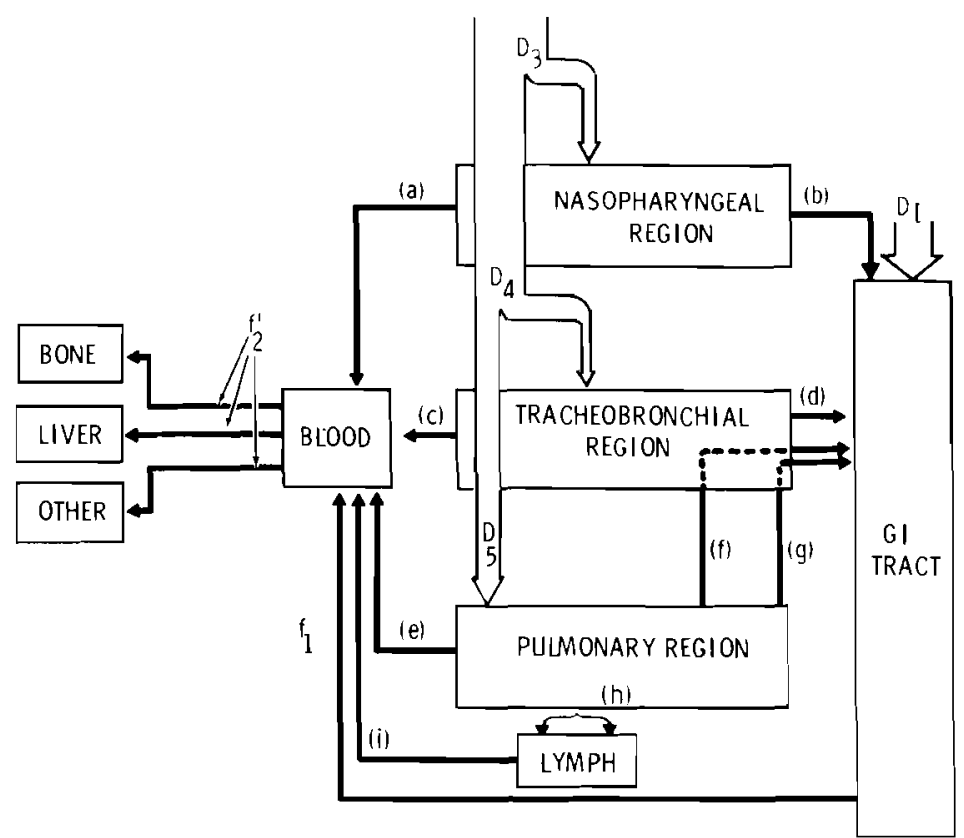

FIGURE 2. Schematic Diagram of the REDIQ Metabolic Model 
Material entering the GI tract from the respiratory system can cause portions of the GI tract to be exposed to radiation. The ICRP GI tract model ${ }^{(3)}$ is used to describe movement of material within the tract's compartments. A diagram of this model is given in Figure 3. Material from the respiratory tract enters the G.I. tract through the stomach $(S)$, which is assumed to be uniformly irradiated for a mean residence time of 1 hour. Absorption of material into the blood is assumed to occur from the small intestine (SI) only. Using an exponential absorption model, the rate constant is defined so that a fraction $f_{1}$ is absorbed during passage through the SI. Values of $f_{1}$ are those recommended by the ICRP. (3)

The dose contribution to the pulmonary portion of the lung includes radiations from daughter nuclides formed there. The daughter contributions are computed indirectly using weighted values of the effective energy emitted by the daughter nuclides in the chain. Weighted values were calculated for each of the decay chains tabulated by the $\operatorname{ICRP}(3,6)$ for residence half-times of 1 day, 50 days and 500 days. These values are included in the organ data library discussed in Appendix D.

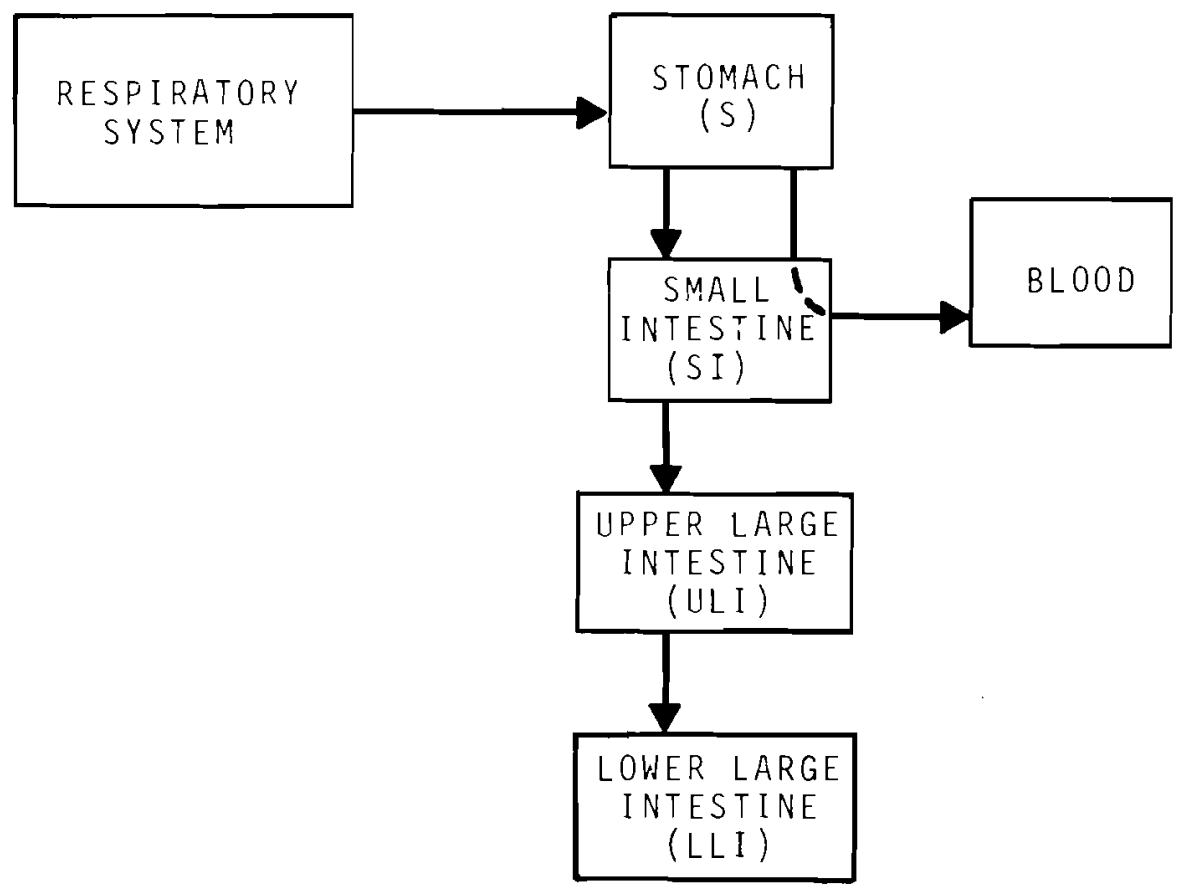

FIGURE 3. Schematic Diagram of the GI System Model 


\section{INGESTION PATHWAY}

The ICRP GI tract model described above is also the basis for the ingestion pathway model used by REDIQ. Material is assumed to enter the body via ingestion to the stomach (arrow $D_{I}$ in Figure 2). Transfer to other organs is assumed to occur through absorption of material from the small intestine.

\section{EQUIVALENT INTAKE}

The calculation of equivalent intake values depends on a careful determination of relative risk values. All risk values must be related to the same biological effect, for example, death from cancer. Values are determined for the risk from 1 rem of whole-body irradiation, plus the risk per rem for each organ to which a nuclide contributes a significant dose. Risk values are expressed as events per rem. The equivalent intake is then calculated as the ratio of the whole-body exposure risk to the sum of the products of organ dose times the organ risk factor. The equivalent intake is expressed as microcuries per rem of whole-body exposure. Details of the calculation are given in Appendix $A$. 


\section{REFERENCES}

1. J. R. Houston, D. L. Strenge and E. C. Watson, DACRIN - A Computer Program for Calculating Organ Dose from Acute or Chronic Radionuclide Inhalation. BNWL-B-389; Rep. BNWL-B-389 Supp, Battelle, Pacific Northwest Laboratories, Richland, WA 99352, 1975.

2. Task Group on Lung Dynamics for Committee II of the International Commission on Radiological Protection, "Deposition and Retention Models for Internal Dosimetry of the Human Respiratory Tract." Health Phys. 12:173, 1966.

3. The International Commission on Radiological Protection, Report of Committee II on Permissible Dose for Internal Radiation. ICRP Publication 2, Pergamon Press, Oxford, 1972.

4. The Advisory Committee on Biological Effects of Ionizing Radiation, The Effects on Populations of Exposure to Low Levels of Ionizing Radiation. National Academy of Sciences - National Research Council, Washington, DC 20006, 1972.

5. The International Commission on Radiological Protection, The Metabolism of Compounds of Plutonium and Other Actinides. ICRP Publication 19, Pergamon Press, 0xford, 1972.

6. The International Commission on Radiological Protection, Recommendations of the International Commission on Radiological Protection. ICRP Publication 6, Pergamon Press, 0xford, 1962. 
APPENDIX A

DESCRIPTION OF MATHEMATICAL MODELS 
DESCRIPTION OF MATHEMATICAL MODELS

This appendix describes mathematical models used to calculate inhalation and ingestion doses and the risk equivalence values: Equations are presented for both acute and chronic uptake modes.

\section{INHALATION DOSE MODEL}

The mathematical model for calculating the dose to an organ of interest via inhalation, using the ICRP Task Group Lung Model (TGLM), $(1,2)$ is described here. In the TGLM, the respiratory tract is divided into three regions, the nasopharyngeal (NP), the tracheobronchial (TB), and the pulmonary (P). The schematic representation of this model is shown in Figure 1 of the main text. Deposition of inhaled nuclides is assumed to vary with the aerodynamic properties of the aerosol distribtuion for each nuclide, and is described by the three parameters $D_{3}, D_{4}$, and $D_{5}$. These parameters represent the fraction of the inhaled material $Q_{I}$ initially deposited in the NP, TB, and $P$ regions, respectively. Each of the three regions of deposition is further subdivided into two or more subcompartments, each representing the fraction of material initially in a compartment that is subject to a certain clearance process. This fraction is represented by $f_{j}$, where $j$ indicates the clearance pathway. For example, the quantity of material in the TB region cleared by process (c) is represented by the product ${ }_{C} D_{4} Q_{I}$. Material from pulmonary compartment (h) clears through the lymphatic system (LM).

Table A-1 ${ }^{(2)}$ shows the values of $f_{j}$ and the clearance half-times $T_{j}$ for each clearance process in the three translocation classes of aerosols. The three translocation classes indicate the extent to which material is retained in the respiratory compartments: for days (D), weeks $(W)$, or years $(Y)$. Values of the deposition fractions $D_{3}, D_{4}$, and $D_{5}$ as a function of activity median aerodynamic diameter (AMAD) have been published in the form of a graph. (1)

Radionuclides are assumed to be transported via the blood, moving from the respiratory tract, lymphatic systems, and GI tract to other organs and 
TABLE A-1. Values of the Clearance Parameters for the Task Group Lung Model

\begin{tabular}{|c|c|c|c|c|c|c|c|}
\hline \multirow{3}{*}{ COMPARTMENT } & & \multicolumn{6}{|c|}{ TRANSLOCATION CLASS } \\
\hline & \multirow[b]{2}{*}{$j^{(a)}$} & \multicolumn{2}{|c|}{ D } & \multicolumn{2}{|l|}{ W } & \multicolumn{2}{|l|}{ Y } \\
\hline & & $\mathrm{T}_{\mathrm{j}}(\mathrm{b})$ & $f_{j}(c)$ & $T_{j}$ & $f_{j}$ & $T_{j}$ & $f_{j}$ \\
\hline NP & a & 0.01 & 0.5 & 0.01 & 0.1 & 0.01 & 0.01 \\
\hline & $b$ & 0.01 & 0.5 & 0.40 & 0.9 & 0.4 & 0.99 \\
\hline $\mathrm{TB}$ & c & 0.01 & 0.95 & 0.01 & 0.5 & 0.01 & 0.01 \\
\hline & $d$ & 0.2 & 0.05 & 0.2 & 0.5 & 0.2 & 0.99 \\
\hline$P$ & e & 0.5 & 0.8 & 50 & 0.15 & 500 & 0.05 \\
\hline & $f$ & n.a. & n.a. & 1 & 0.4 & 1 & 0.4 \\
\hline & g & n.a. & n.a. & 50 & 0.4 & 500 & 0.4 \\
\hline & $h$ & 0.5 & 0.2 & 50 & 0.05 & 500 & 0.15 \\
\hline LM & $i$ & 0.5 & 1 & 50 & 1 & 1000 & 0.9 \\
\hline
\end{tabular}

(a) Metabolic pathways from lung.

(b) Half-time (in days) for removal from compartment via pathway $j$.

(c) Fraction removed from compartment via pathway $j$.

tissues where significant accumulations of inhaled radionuclides occur. This translocation from the respiratory tract and lymphatic system to the blood has been described in considerable detail. (1) of the material clearing from the respiratory tract through the GI tract, a constant fraction is assumed to be taken up by the blood. Uptake by the $n^{\text {th }}$ organ or tissue is assumed to be a constant fraction of the amount entering the blood stream at any time. Once in the $n^{\text {th }}$ organ, the activity is assumed to clear the organ and the body at a constant rate. 
Notation for the equations found in this section is as follows:

$D_{1 n}\left(T_{1}\right)$ - is the dose in rem received by the $n$th organ or tis sue by time $\mathrm{T}_{1}$ during continuous uptake of radioactive material.

$D_{2 n}\left(T_{2}\right)$ - is the dose in rem received by the $n$th organ or tissue by time $T_{2}$ following the termination of continuous uptake of radioactive material.

$Q_{1 n}\left(T_{1}\right)$ - is the quantity of radioactive material in $\mu C i$ present in the nth organ or tissue as a function of time during continuous uptake of radioactive material.

$\mathrm{Q}_{2 \mathrm{n}}\left(\mathrm{T}_{2}\right)$ - is the quantity of radioactive material in $\mu \mathrm{Ci}$ present in the nth organ or tissue following the termination of continuous uptake of radioactive material.

$\mathrm{E}_{\mathrm{n}} \quad$ - is the effective absorbed energy per disintegration in $\frac{\mathrm{MeV} \cdot \text { rem }}{\mathrm{dis} \cdot \text { rad }}$ for the nth organ or tissue.

$M_{n} \quad$ - is the mass in grams of the nth organ or tissue over which the dose is to be averaged.

- is the biological removal rate constant per sec for the jth subcompartment of the respiratory tract.

$\lambda$ - is the radiological decay constant of the nuclide of interest, per sec.

$\lambda_{j} \quad$ - is the total removal rate constant per sec for the $j$ th subcompartment of the respiratory tract. Note: $\lambda_{j}=\lambda_{j}^{b}+\lambda$.

- is the biological removal rate constant per sec for the $n$th organ or tissue.

- is the total effective removal rate constant per sec for the nth organ or tissue. Note: $\lambda_{n}=\lambda_{n}^{b}+\lambda$.

- is the fraction of material in the blood that reaches the organ of interest. 
$f_{1}$ - is the fraction of material in the GI tract that reaches the blood.

$f_{w} \quad$ is the fraction of material ingested that reaches the organ of interest.

$\mathrm{P}_{0} \quad-$ is the rate at which the radioactive material is inhaled, in $\mu \mathrm{Ci} / \mathrm{sec}$.

$f_{j}$ - is the fraction of the material in a deposition region (NP, TB, P), that clears by the $j$ th pathway.

$D_{k} \quad$ - is the fraction of the inhaled material deposited in the kth compartment of the respiratory tract.

$k=3$ for the nasopharyngeal (NP) compartment.

$k=4$ for the tracheobronchial (TB) compartment.

$k=5$ for the pulmonary (P) and lymph (LM) compartments.

$\mathrm{T}_{1} \quad$ - is the total uptake time, in sec.

$\mathrm{T}_{2} \quad$ - is the time interval following termination of uptake, in sec.

The development of equations to describe the lung clearance model is divided into two parts: the first deals with organ burdens and doses in the time interval during which the inhalation of radionuclides takes place; and the second considers the contiguous time interval following the cessation of radionuclide intake.

Intake Period

For the intake stage, the quantity of radionuclide in the eight subcompartments $(j)$ of the three compartments $(k)$ of the respiratory tract is computed by the equation

$$
Q_{j, k}(t)=f_{j} D_{k} Q_{I} \frac{1-e^{-\lambda} t^{t}}{\lambda_{j}}
$$

The equations for the removable quantity in the pulmonary lymph nodes are complicated: the rate of radionuclide transfer into the lymph system 
$\left(\lambda_{h}\right)$ may be either equal or unequal to the rate of transfer out of the system $\left(\lambda_{j}\right)$, depending on the solubility class of the radionuclide. Thus, two equations are needed to compute the quantity of radionuclide in the lymph compartment. For the case $\lambda_{h} \neq \lambda_{i}$, i.e., Class $Y$ solubility in the current version of the mode1,

$$
Q_{L M i}(t)=\frac{\lambda_{h}^{b}{ }_{i} f_{h} P_{0} D_{5}}{\lambda_{h}}\left[\frac{\left(1-e^{-\lambda_{i} t}\right)}{\lambda_{i}}-\frac{\left(e^{-\lambda_{i} t}-e^{-\lambda_{h} t}\right)}{\lambda_{h}-\lambda_{i}}\right]
$$

and for the case $\lambda_{h}=\lambda_{i}$, i.e., Class $D$ and $W$ in the current version of the model,

$$
Q_{L M i}(t)=\frac{\lambda_{h}^{b} f_{i} f_{h} P_{0} D_{5}}{\lambda_{h}}\left[\frac{\left(1-e^{-\lambda_{i} t}\right)}{\lambda_{i}}-t e^{-\lambda_{i} t}\right]
$$

Using the preceding equations, the equations describing the quantity of radionuclide in the $n$th organ as a function of time during uptake can be derived by

where

$$
Q_{\ln }(t)=P_{0}\left\{\sum_{j=a}^{g} f_{2}^{\prime} c_{j}\left[\frac{\left(1-e^{-\lambda_{n} t}\right)}{\lambda_{n}}-\frac{\left(e^{-\lambda_{n} t}-e^{-\lambda_{j} t}\right)}{\left(\lambda_{j}-\lambda_{n}\right)}\right]+L\right\}
$$

$L$ - is the contribution to the organ burden from material passing through the lymphatic system,

and

$$
\begin{aligned}
& c_{a}=\lambda_{a}^{b} f_{a} D_{3} / \lambda_{a} \\
& c_{b}=\lambda_{b}^{b} f_{b} D_{3} f_{1} / \lambda_{b} \\
& c_{c}=\lambda_{c}^{b} f_{c} D_{4} / \lambda_{c} \\
& c_{d}=\lambda_{d}^{b} f_{d} D_{4} f_{1} / \lambda_{d} \\
& c_{e}=\lambda_{e}^{b} f_{e} D_{5} / \lambda_{e}
\end{aligned}
$$




$$
\begin{aligned}
& c_{f}=\lambda_{f}^{b_{f}} D_{5} f_{1} / \lambda_{f} \\
& C_{g}=\lambda{ }_{g}^{b} f_{g} D_{5} f_{1} / \lambda_{g}
\end{aligned}
$$

The lymph pathway contributions to the $n^{\text {th }}$ organ burden for the two situations are calculated as follows:

$$
\begin{aligned}
& L= f_{2}^{\prime} c_{h}\left\{\frac{1}{\lambda_{i}}\left[\frac{\left(1-e^{-\lambda_{n} t}\right)}{\lambda_{n}}-\frac{\left(e^{-\lambda_{n} t}-e^{-\lambda_{j} t}\right)}{\left(\lambda_{i}-\lambda_{n}\right)}\right]\right. \\
&\left.-\frac{1}{\left(\lambda_{h}-\lambda_{j}\right)}\left[\frac{\left(e^{-\lambda_{n} t}-e^{-\lambda_{j} t}\right)}{\left(\lambda_{i}-\lambda_{n}\right)}-\frac{\left(e^{-\lambda_{n} t}-e^{-\lambda_{h} t}\right)}{\left(\lambda_{h}-\lambda_{n}\right)}\right]\right\} \text { for } \lambda_{h} \neq \lambda_{i} \\
& L=f_{2}^{\prime} C_{h}\left\{\frac{1}{\lambda_{i}}\left[\frac{\left(1-e^{-\lambda_{n} t}\right)}{\lambda_{i}}-\frac{\left(e^{-\lambda_{n} t}-e^{-\lambda_{j} t}\right)}{\left(\lambda_{i}-\lambda_{n}\right)}\right]-\frac{e^{-\lambda_{n} t}-\left[\left(\lambda_{i}-\lambda_{n}\right) t+1\right] e^{-\lambda_{i} t}}{\left(\lambda_{i}-\lambda_{n}\right)^{2}}\right\} \\
& \text { for } \lambda_{h}=\lambda_{i}
\end{aligned}
$$

where

$$
C_{h}=\frac{\lambda_{j}^{b}{ }_{h}^{b_{h}} f_{i} f_{h} D_{5}}{\lambda_{h}}
$$

The calculation of the dose to organs burdened by the radionuclide is based on the following:

$$
D_{1 n}(t)=\frac{5.92 \times 10^{-4} E_{n}}{M_{n}} \int_{0}^{t} Q_{1 n}(\tau) d \tau
$$

where the constant is a combination of the conversion factors

$$
3.7 \times 10^{4}\left(\frac{\mathrm{dis} / \mathrm{sec}}{\mu \mathrm{Ci}}\right) 1.6 \times 10^{-6}\left(\frac{\mathrm{ergs}}{\mathrm{MeV}}\right) 10^{-2}\left(\frac{\mathrm{rads}}{\mathrm{erg} / \mathrm{g}}\right)=5.92 \times 10^{-4}
$$


The dose to the pulmonary lung at the end of inhalation intake of a radionuclide is determined by

$$
D_{1 p}\left(T_{1}\right)=\frac{5.92 \times 10^{-4} E_{p}}{M_{p}} P_{0} D_{5} \sum_{j=e}^{h} \frac{f_{j}}{\lambda_{j}}\left(T_{1}-A_{j}\right)
$$

where

$$
M_{p} \text { - is the mass of the lung in grams }
$$

and

$$
A_{j}=\frac{1-e^{-\lambda_{j} T_{1}}}{\lambda_{j}}
$$

For the $n^{\text {th }}$ organ or tissue, the dose is computed for $\lambda_{h} \neq \lambda_{i}$ by

$$
\begin{aligned}
D_{1 n}\left(T_{1}\right)= & 5.92 \times 10^{-4} \frac{E_{n} P_{0} f_{2}^{\prime}}{M_{n}}\left\{\sum_{j=a}^{g} C_{j}\left[\frac{T_{1}-A_{n}}{\lambda_{n}}-\left(\frac{A_{n}-A_{j}}{\lambda_{j}-\lambda_{n}}\right)\right]\right. \\
& +\frac{C_{h}}{\lambda_{i}}\left[\frac{T_{1}-A_{n}}{\lambda_{n}}-\frac{A_{n}-A_{i}}{\left(\lambda_{j}-\lambda_{n}\right)}\right]-\frac{C_{h}}{\left(\lambda_{h}-\lambda_{i}\right)}\left[\frac{A_{n}-A_{i}}{\left(\lambda_{i}-\lambda_{n}\right)}\right. \\
& \left.\left.-\frac{A_{n}-A_{h}}{\lambda_{h}-\lambda_{n}}\right]\right\}
\end{aligned}
$$

$$
\begin{aligned}
& \text { or for } \lambda_{h}=\lambda_{i} \text { by } \\
& D_{1 n}\left(T_{1}\right)=5.92 \times 10^{-4} \frac{E_{n} P_{0} f_{2}^{\prime}}{M_{n}}\left(\sum_{j=a}^{g} C_{j}\left(\frac{T_{1}-A_{n}}{\lambda_{n}}-\frac{A_{n}-A_{j}}{\lambda_{j}-\lambda_{n}}\right)\right. \\
& +\frac{C_{h}}{\lambda_{i}}\left(\frac{T_{1}-A_{n}}{\lambda_{n}}-\frac{A_{n}-A_{i}}{\lambda_{i}-\lambda_{n}}\right)+\frac{C_{n}}{\left(\lambda_{i}-\lambda_{n}\right)^{2}}\left\{A_{i}-A_{n}\right. \\
& \left.\left.+\frac{\left(\lambda_{i}-\lambda_{n}\right)}{\lambda_{i}^{2}}\left[1-\left(\lambda_{i} T_{1}+1\right) e^{-\lambda_{i} T_{1}}\right]\right\}\right)
\end{aligned}
$$


where

$$
\begin{aligned}
& A_{n}=\frac{1-e^{-\lambda} n^{\top} 1}{\lambda_{n}} \\
& A_{i}=\frac{1-e^{-\lambda_{i}{ }^{\top} 1}}{\lambda_{i}} \\
& A_{h}=\frac{1-e^{-\lambda_{h}{ }^{\top} 1}}{\lambda_{h}}
\end{aligned}
$$

and $C_{j}$ and $C_{h}$ are as previously defined.

\section{Post-Intake Period}

For the time following cessation of radionuclide inhalation, the equations used to calculate the respiratory tract burden become

$$
Q_{2 j}\left(T_{2}\right)=Q_{1 j}\left(T_{1}\right) e^{-\lambda_{j} T_{2}}
$$

where $Q_{2 j}\left(T_{2}\right)$ - is the burden in the respiratory tract subcompartment at a time $T_{2}$ following the termination of inhalation uptake $Q_{1 j}\left(T_{1}\right)$ - is the burden in the respiratory tract subcompartment at the end of inhalation uptake for a time $T_{1}$.

The burden in the $n^{\text {th }}$ organ at time $T_{2}$ can be described for $\lambda_{h} \neq \lambda_{i}$ by

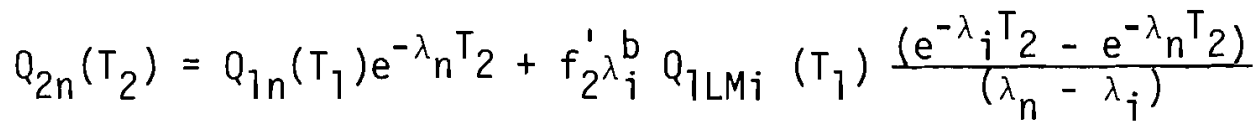

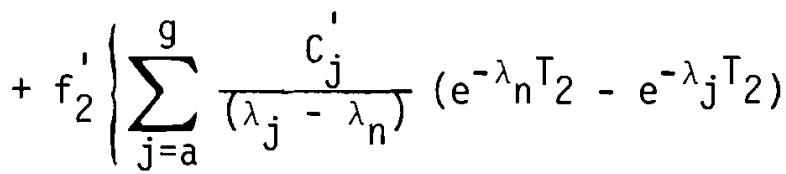

$$
\begin{aligned}
& \left.+\frac{c_{h}^{\prime}}{\left(\lambda_{h}-\lambda_{i}\right)}\left[\frac{\left(e^{\left.-\lambda_{n} T_{2}-e^{-\lambda_{i} T_{2}}\right)}\right.}{\left(\lambda_{i}-\lambda_{n}\right)}-\frac{\left(e^{-\lambda_{n} T_{2}}-e^{\left.-\lambda_{h} T^{\top} 2\right)}\right.}{\left(\lambda_{h}-\lambda_{n}\right)}\right]\right)
\end{aligned}
$$


or for $\lambda_{h}=\lambda_{i}$ by

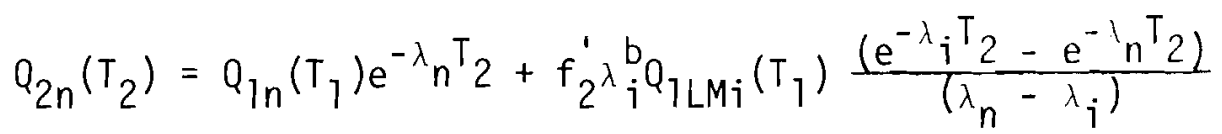

$$
\begin{aligned}
& +f_{2}^{\prime}\left(\sum _ { j = a } ^ { g } \frac { c _ { j } ^ { \prime } } { ( \lambda _ { j } - \lambda _ { n } ) } \left(e^{-\lambda_{n}{ }^{\top} 2}-e^{\left.-\lambda_{j}{ }^{\top} 2\right)}\right.\right. \\
& \left.+\frac{C_{n}^{\prime}}{\left(\lambda_{i}-\lambda_{n}\right)}\left\{e^{-\lambda_{n} T_{2}}-\left[\left(\lambda_{i}-\lambda_{n}\right) T_{2}-1\right] e^{-\lambda_{i} T_{2}}\right\}\right)
\end{aligned}
$$

where

$$
\begin{aligned}
& c_{a}^{\prime}=\lambda_{a}^{b} a_{1 a}\left(T_{1}\right) \\
& c_{b}^{\prime}=\lambda_{b}^{b} a_{1 b}\left(T_{1}\right) f \\
& c_{c}^{\prime}=\lambda_{c}^{b} a_{1 c}\left(T_{1}\right) \\
& c_{d}^{\prime}=\lambda_{d}^{b} Q_{1 d}\left(T_{1}\right) f \\
& c_{e}^{\prime}=\lambda_{e}^{b} a_{1 e}\left(T_{1}\right) \\
& c_{f}^{\prime}=\lambda_{f}^{b} a_{1 f}\left(T_{1}\right) f_{1} \\
& c_{g}^{\prime}=\lambda_{g}^{b} Q_{1 g}\left(T_{1}\right) f_{1} \\
& c_{h}^{\prime}=f_{j} \lambda_{h}^{b} \lambda_{j}^{b} a_{1 h}\left(T_{1}\right)
\end{aligned}
$$

The pulmonary lung dose from inhalation of a radionuclide for a time $T_{1}$ followed by no additional radioactive intake for a time $T_{2}$ is determined by

$$
D_{p}=D_{1 p}\left(T_{1}\right)+5.92 \times 10^{-4} \frac{E_{p} P_{0} D_{5}}{M_{p}} \sum_{j=e}^{h} f_{j} A_{j} B_{j}
$$


where

$$
B_{j}=\frac{1-e^{-\lambda} j^{T} 2}{\lambda_{j}}
$$

and $D_{1 p}\left(T_{1}\right)$ and $A_{j}$ are as defined by Equation (7).

The effective dose to the $n^{\text {th }}$ organ as a result of inhalation uptake for a time $T_{1}$ followed by no additional radioactive intake for a time $T_{2}$ is determined by

$$
\begin{gathered}
D_{n}=D_{1 n}\left(T_{1}\right)+5.92 \times 10^{-4} \frac{E_{n}}{M_{n}}\left\{Q_{1 n}\left(T_{1}\right) B_{n}+f_{2}^{\prime}\left[\frac{\lambda_{i}^{b} Q_{1 L M i}\left(T_{1}\right)}{\left(\lambda_{n}-\lambda_{j}\right)}\left(B_{i}-B_{n}\right)\right.\right. \\
\left.\left.+G\left[\frac{\left(B_{n}-B_{j}\right)}{\left(\lambda_{i}-\lambda_{n}\right)}-z\right]+\sum_{j=a}^{g} \frac{C_{j}^{\prime}}{\left(\lambda_{j}-\lambda_{n}\right)}\left(B_{n}-B_{j}\right)\right]\right\} \quad(14)
\end{gathered}
$$

where

$$
\begin{aligned}
& B_{n}=\frac{1-e^{-\lambda} n^{\top} 2}{\lambda_{n}} \\
& B_{h}=\frac{1-e^{-\lambda} h^{\top} 2}{\lambda_{h}} \\
& B_{i}=\frac{1-e^{-\lambda} T^{\top} 2}{\lambda_{i}} \\
& B_{j}=\frac{1-e^{-\lambda}{ }_{j} T_{2}}{\lambda_{j}}
\end{aligned}
$$

Also, for $\lambda_{h} \neq \lambda_{i}$

$\mathrm{D}_{\ln }\left(\mathrm{T}_{1}\right)$ is determined by Equation (8)

$Q_{1 n}\left(T_{1}\right)$ is determined by Equations $(4,5 a)$

$$
\begin{aligned}
& G=\frac{C_{h}^{\prime}}{\left(\lambda_{h}-\lambda_{j}\right)} \\
& Z=\frac{B_{n}-B_{h}}{\left(\lambda_{h}-\lambda_{n}\right)}
\end{aligned}
$$


and for $\lambda_{h}=\lambda_{i}$

$$
\begin{aligned}
& D_{1 n}\left(T_{1}\right) \text { is determined by Equation (9) } \\
& Q_{1 n}\left(T_{1}\right) \text { is determined by Equations }(4,5 b) \\
& G=\frac{C_{h}^{\prime}}{\left(\lambda_{i}-\lambda_{n}\right)} \\
& Z=\lambda_{i}^{-2}\left[1-\left(\lambda_{i} T_{2}+1\right) e^{\left.-\lambda_{i} T_{2}\right]}\right.
\end{aligned}
$$

The code provides for calculation of the dose to the pulmonary lung as a result of both primary deposition (that occurring directly on the lung surfaces during inhalation) and secondary deposition (that occurring as a result of solubilization and redeposition in the lung tissue itself). For the second case, the pulmonary lung is treated like any other organ.

Weighted values of the effective energy, $\varepsilon_{j}$, of daughter radionuclides are calculated using the ICRP equations ${ }^{(3)}$ for three biological clearance half-times of 1 day, 50 days and 500 days. The effective energy of the $i^{\text {th }}$ daughter is determined by

$$
\varepsilon_{i}=\sum_{i} F_{i}[E(R B E) n] i
$$

where

$$
F_{i}=\frac{\prod_{j=1}^{i} T_{j} / T_{j}^{r}}{1-e^{-\lambda_{0} t}} \sum_{n=1}^{i} \frac{T_{n}^{i}\left(1-e^{-\lambda}{ }_{n}{ }^{i}\right)}{\prod_{\substack{p=0 \\ p \neq n}}^{i}\left(T_{n}-T_{p}\right)}
$$


and

$\mathrm{F}_{i}$ - is the ratio of the number of disintegrations of daughter atoms to the number of disintegrations of parent atoms in the lung over a time $t$

$\lambda_{0}$ - is the effective decay constant of the parent (the subscript zero refers to the parent)

$\lambda_{i}$ - is the effective decay constant of the $i^{\text {th }}$ daughter in the lung

$T_{i}$ - is the effective half life of the $i^{\text {th }}$ daughter in the lung

$T_{i}^{r}$ - is the radioactive half 1 ife of the $i^{\text {th }}$ daughter

$t$ - is the time over which the dose is to be calculated

E - is the total energy absorbed in the organ per disintegration of the radionuclide

RBE - is the relative biological effectiveness of the radiation

$\mathrm{n}$ - is the relative damage factor for radionuclides deposited in the bone.

\section{G.I. TRACT MODEL}

The ICRP GI tract model ${ }^{(3)}$ is used to describe movement of material within the GI tract compartments, with input to the GI model described by the lung model (see Figure 1 of main text). A diagram of the GI tract model is given in Figure 3 of the main text. Material from the respiratory tract enters the GI tract through the stomach, which is assumed to be uniformly irradiated for a mean residence time of 1 hour. Absorption into the blood is assumed to occur from the small intestine (SI) only. An exponential absorption model is used, with the rate constant defined so that a fraction $f_{1}$ is absorbed during passage through the SI. Values of $f_{1}$ are those recommended by the ICRP. (3)

To determine the amount of a radionuclide reaching the GI tract, it is necessary to know the radionuclide concentration in each compartment of the lung ( $b, d, f$ and $g$ in text Figure 1 ) as a function of time. For the uptake period, this concentration is given by Equation (1). 
The rate of material entering the GI tract from the respiratory system (in $\mu \mathrm{Ci} / \mathrm{sec}$ ) is calculated from Equation (15) as

$$
q_{1 G}(t)=\sum_{j=b, d, f, g} \lambda_{j}^{b} Q_{1 j}(t)
$$

The total amount of radionuclide entering the GI tract during the uptake period is

$$
Q_{1 G}=\int_{0}^{T} q_{1 G}(t) d t=P_{0} \sum_{j=b, d, f, g} \frac{\lambda_{j}^{b} f_{j} D_{i}}{\lambda_{j}}\left[T_{1}-\frac{1-e^{-\lambda_{j} T_{T}}}{\lambda_{j}}\right]
$$

Where $T_{1}$ - is the uptake period in sec.

Equation (16) can be reduced to

$$
Q_{1 G}=P_{0} \sum_{j=b, d, f, g} c_{j}\left[T_{1}-\frac{1-e^{-\lambda_{j} T_{1}}}{\lambda_{j}}\right]
$$

where

$$
\begin{aligned}
& c_{b}=\frac{\lambda_{b}^{b_{f}} f_{b} D_{3}}{\lambda_{b}} \\
& c_{d}=\frac{\lambda_{d}^{b} f_{d} D_{4}}{\lambda_{d}} \\
& c_{f}=\frac{\lambda_{f}^{b} f_{f} D_{5}}{\lambda_{f}} \\
& c_{g}=\frac{\lambda_{g}^{b} f_{g} D_{5}}{\lambda_{g}}
\end{aligned}
$$


The amount of a radionuclide (in ${ }_{\mu} \mathrm{C} i$ ) in each lung compartment during the second period (i.e., from the time uptake stops to the dose time) is given by Equation (10)

$$
Q_{2 j}(t)=Q_{1 j}\left(T_{1}\right) e^{-\lambda_{j} t}
$$

The rate at which a nuclide enters the GI tract during the second period (in $\mu \mathrm{Ci} / \mathrm{sec}$ ) is then

$$
q_{2 G}(t)=\sum_{j=b, d, f, g} \lambda_{j}^{b} a_{1 j}\left(i_{1}\right) e^{-\lambda_{j} t}
$$

and the total amount (in $\mu \mathrm{C} i$ ) for the second period is

$$
Q_{2 G}=\int_{0}^{T_{2}} q_{2 G}(t) d t=P_{o} \sum_{j=b, d, f, g} \frac{c_{j}}{\lambda_{j}}\left(1-e^{-\lambda_{j} T_{1}}\right)\left(1-e^{-\lambda_{j} T_{2}}\right)
$$

The total amount of radionuclide entering the GI tract from the start of uptake to the dose time is

$$
Q_{G}=Q_{1 G}+Q_{2 G}
$$

This amount can give a radiation dose to each of the four GI tract compartments: stomach (S), small intestine (SI), upper large intestine (ULI) and lower large intestine (LLI). The dose is a function of residence time and absorption into the blood stream. According to the ICRP GI tract model (text Figure 3), absorption occurs only in the small intestine. Data for this model are given in Table A.2.

\section{TABLE A.2. GI Tract Data}

GI Tract

Residence

Time for Material

Mass of Compartment Time, Hours to Reach Compartment, Hours Contents, Grams

$\begin{array}{rrrr}S & 1 & -- & 250 \\ \text { SI } & 4 & 1 & 1100 \\ \text { ULI } & 8 & 5 & 135 \\ \text { LLI } & 18 & 13 & 150\end{array}$




\section{Stomach Dose}

Material leaving the lung goes first to the stomach, where it is assumed to remain for a mean time of $1 \mathrm{hr}$ before passing to the small intestine. The dose to the stomach is

$$
D_{S}=2.96 \times 10^{-4} \frac{E_{S} Q_{G}}{m_{S}} \frac{\left(1-e^{-\lambda} r^{\tau} S\right)}{\lambda_{r}}
$$

where

$E_{S}$ - is the effective energy per disintegration for the radionuclide in the stomach, in $\mathrm{MeV} / \mathrm{dis}$

$m_{S}$ - is the mass of the contents of the stomach, in grams

${ }^{T} S$ is the mean residence time in the stomach, in sec

$Q_{G}$ - is the total input to the $G I$ system, in $\mu \mathrm{Ci}$

and

$2.96 \times 10^{-4}=(1 / 2) \times 3.7 \times 10^{4}\left(\frac{\mathrm{dis} / \mathrm{sec}}{\mu \mathrm{Ci}}\right) 1.6 \times 10^{-6}\left(\frac{\mathrm{ergs}}{\mathrm{MeV}}\right) 10^{-2} \frac{\mathrm{rads}}{\mathrm{erg} / \mathrm{g}}$

The factor $(1 / 2)$ is included because the dose to the walls of the GI system is about one-half the dose to its contents.

Small Intestine

Of the material entering the SI, a fraction $f_{1}$ is absorbed into the blood. The amount of material leaving the SI is then $1-f_{1}$. If the material entering the blood is assumed to be absorbed at constant rate $\left(\lambda_{a}\right)$, the following expression holds:

$$
1-f_{1}=e^{-\lambda} a^{\tau} S I
$$

This can be solved for $\lambda_{a}$ using the equation

$$
\lambda_{a}=\frac{1}{{ }^{\tau} S I} \ln \frac{1}{1-f_{1}}
$$


where

$\lambda_{a}$ - is the absorption rate constant per sec for a given element

$\tau_{S I}$ - is the residence time in the SI, in sec.

Equation (19) requires $f_{1}$ to be less than unity. Where $f_{1}$ for an element has been listed as unity in ICRP Publication 2, it is set to 0.95 . This is consistent with the ICRP assumption in calculating the dose to the ULI and LLI that at least $5 \%$ of al1 elements passing through the G.I. system reach the large intestines.

The dose to the SI is calculated as

$$
D_{S I}=2.96 \times 10^{-4}\left(\frac{E_{S I}}{m_{S I}}\right)\left(e^{-\lambda} r^{\tau} S\right)\left(\frac{1-e^{-\lambda} S I{ }^{\top} S I}{\lambda_{S I}}\right) Q_{G}
$$

where and

$$
\lambda_{\text {SI }}=\lambda_{\mathrm{a}}+\lambda_{r}
$$

$\lambda_{\text {SI }}$ - is the effective removal constant per sec for the nuclide in the small intestine

$E_{S I} \quad-\quad$ is the effective energy per disintegration for the radionuclide in the SI, in $\mathrm{MeV} / \mathrm{dis}$

$m_{S I}$ - is the mass of the contents of the SI, in grams

$e^{-\lambda r^{\tau} s} \cdot$ is the decay of $Q_{G}$ in passing through the stomach

\section{Upper Large Intestine}

The material leaving the SI enters the upper large intestine. The amount of material is $Q_{G}$ reduced by decay in passing through the $S$ and $S I$ and by absorption in the SI. The material is assumed to flow linearly through the ULI so that the dose is given by

$$
D_{U L I}=2.96 \times 10^{-4} \tau_{U L I} e^{-\lambda r\left({ }^{\tau} S+{ }^{\tau} S I\right)}\left(\frac{E_{U L I}}{m_{U L I}}\right) Q_{G}\left(1-f_{1}\right)
$$


where

$\tau_{U L I}$ - is the mean residence time in the ULI, in sec

$m_{U L I}$ - is the mass of contents of the ULI, in grams

$E_{U L I}$ - is the effective energy per disintegration for the radionuclide in the ULI, in MeV/dis.

\section{Lower Large Intestine}

The equation for dose to the LLI is similar to the ULI dose equation except that decay during passage through the ULI is included.

$$
D_{L L I}=2.96 \times 10^{-4} \tau_{L L I} e^{-\lambda_{r}\left(\tau_{S}+\tau_{S I}+\tau_{U L I}\right)}\left(\frac{E_{L L I}}{m_{L L I}}\right) Q_{G}\left(1-f_{1}\right)
$$

where

$\tau_{L L I}$ - is the mean residence time in the LLI, in sec

$m_{L L I}$ - is the mass of contents of the LLI, in grams

$E_{L L I}$ - is the effective energy for the radionuclide in the $L L I$, in $\mathrm{MeV} / \mathrm{dis}$.

The above equations for ULI and LLI calculate the dose at the entrance to the compartment as recommended by the ICRP. (3)

\section{REDIQ INGESTION MODEL}

Ingestion doses are calculated in two steps: first, the dose to the GI tract is calculated using the four compartment model shown in text Figure 3; and second, the organ dose is calculated from the fraction of the ingested radioactivity reaching the organs through the blood.

\section{GI Tract Dose}

Since the time for transfer of material through the GI tract is short compared to the dose times for most radionuclides, all of the ingested activity $\left(Q_{G}\right)$ is assumed to enter the stomach at time zero. The equations for dose to the GI tract compartments are those defined in Equations 18-22. 


\section{Organ Dose}

Equations are given below for both acute and chronic ingestion.

\section{Acute Ingestion}

For a single ingestion of radionuclides, the radionuclide quantity reaching an organ at any time $t$ is given by the equation

$$
Q=Q_{0} f_{w} e^{-\lambda}{ }^{t}
$$

where

$$
\lambda_{j}=\lambda_{r}+\lambda_{b}
$$

and

$f_{W}$ - is the fraction of the ingested material reaching the organ of interest

$Q_{0}$ - is the total radioactivity ingested during the uptake period, in $\mu \mathrm{Ci}$.

The total dose to an organ at any time $T_{2}$ after a single ingestion is the time integral of this quantity as follows:

$$
D=\frac{5.92 \times 10^{-4} t_{n}}{M_{n}} \int_{0}^{T_{2}} Q d t=\frac{5.92}{M_{n}} \times 10^{-4 E_{n}} Q_{0} f_{w} \int_{0}^{T} e^{-\lambda} j{ }^{t} d t
$$

so that

$$
D=\frac{5.92 \times 10^{-4} E_{n} Q_{0} f_{w}}{M_{n}}\left[\frac{1-e^{-\lambda} t}{\lambda_{j}}\right]
$$

Chronic Ingestion

For chronic ingestion of radionuclides, the ingestion rate is defined as

$$
P_{0}=\frac{Q_{0}}{T_{1}}
$$


Computation of the quantity of radionuclides present in the organ of interest during continuous ingestion is given by the following equation:

$$
Q_{1}(t)=\frac{f_{w} P_{0}\left(1-e^{-\lambda_{j} t}\right)}{\lambda_{j}}
$$

The dose to any organ during the ingestion period is calculated from the integral of Equation (27).

$D_{1 n}=\frac{5.92 \times 10^{-4} E_{n}}{M_{n}} \int_{0}^{T_{1}} Q_{1}(t) d t=\frac{5.92 \times 10^{-4} E_{n}}{M_{n}} f_{w} P_{0} \int_{0}^{T_{1}} \frac{\left(1-e^{-\lambda_{j} t} \cdot j\right.}{\lambda_{j}} d t$

or

$$
D_{1 n}=\frac{5.92 \times 10^{-4} E_{n} f_{w o} P_{0}}{M_{n} \lambda_{j}}\left[T_{1}-\frac{1-e^{-\lambda j} T_{1}}{\lambda_{j}}\right]
$$

The quantity of radionuclide found in any organ at a time after the ingestion period is found by correcting the expression in Equation (10) for physical and biological decay. This quantity is expressed as

$$
Q_{2}\left(t_{2}\right)=Q_{1}\left(t_{1}\right) e^{-\lambda_{j} t_{2}}
$$

or

$$
Q_{2}\left(t_{2}\right)=\frac{f_{w} P_{0}\left(1-e^{-\lambda_{j} T_{1}}\right)}{\lambda_{j}} e^{-\lambda_{j} t_{2}}
$$

The expression is based on the assumption that at time $t_{2}=0, Q_{2}(0)=$ $Q_{1}\left(T_{1}\right)$. The dose then is the time integral of this activity given by the following equation:

$$
D_{2 n}=\frac{5.92 \times 10^{-4} E_{n}}{M_{n}} \int_{0}^{T_{2}} Q_{2}\left(t_{2}\right) d t
$$


or

$$
D_{2 n}=\frac{5.92 \times 10^{-4} E_{n}}{M_{n}} \frac{f_{w o} P_{0}}{\lambda_{j}}\left(1-e^{-\lambda_{j} T_{1}}\right) \int_{0}^{T_{2}} e^{-\lambda_{j} t_{d}}
$$

The solution of this integral is

$$
D_{2 n}=\frac{5.92 \times 10^{-4} E_{n}}{M_{n}} \frac{f_{w o} P_{0}}{\lambda_{j}}\left(1-e^{-\lambda_{j} T_{1}}\right)\left(\frac{1-e^{-\lambda_{j} T_{2}}}{\lambda_{j}}\right)
$$

The total dose to any organ is given by the sum of $D_{1 n}$ [Equation (29)] and $D_{2 n}$ [Equation (34)]. The total dose $D_{T n}$ is found by the equation

$$
\begin{aligned}
D_{T n}= & D_{1 n}+D_{2 n}=\frac{5.92 \times 10^{-4} E_{n}}{M_{n}} \frac{f_{w_{0}} P_{0}}{\lambda_{j}}\left[\left(T_{1}-\frac{1-e^{-\lambda_{j} T_{1}}}{\lambda_{j}}\right)\right. \\
& \left.+\left(1-e^{-\lambda_{j} T_{1}}\right)\left(\frac{1-e^{-\lambda_{j} T_{2}}}{\lambda_{j}}\right)\right]
\end{aligned}
$$

\section{RISK EQUIVALENCE CALCULATION}

The organ dose commitments described above are used by REDIQ to estimate the intake in microcuries, via inhalation or ingestion, that yields the same health risk as 1 rem of whole-body external exposure. The resulting values are referred to as "intake equivalents" $\left(I_{e}\right)$. The intake equivalent is calculated as

$$
I_{e}=\frac{R_{W B}}{\sum_{n} R_{n} D_{n}}
$$

where

$I_{e}$ - is the intake equivalent that yields the same health risk as 1 rem of whole-body dose, in $\mu \mathrm{Ci} /$ rem 
$\mathrm{R}_{\mathrm{WB}}$ - is the whole-body health risk factor, in events/rem

$R_{n}$ - is the health risk factor for organ $n$, in events/rem

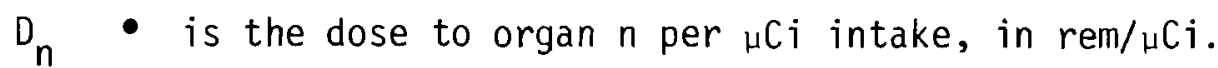

A11 risk factors must be based on the same health effect, for example, death from cancer. 
1. Task Group on Lung Dynamics for Committee II of the International Commission on Radiological Protection, "Deposition and Retention Models for Internal Dosimetry of the Human Respiratory Tract." Health Phys. 12: $173,1966$.

2. The International Commission on Radiological Protection, The Metabolism of Compounds of Plutonium and Other Actinides. ICRP Publication 19, Pergamon Press, Oxford, 1972.

3. The International Commission on Radiological Protection, Report of Committee II on Permissible Dose for Internal Radiation. ICRP Publication 2, Pergamon Press, Oxford, 1972. 
APPENDIX B

COMPUTER CODE 


\section{COMPUTER CODE}

The models described in Appendix $A$ have been incorporated into a computer code programmed for a CDC CYBER Computer. The modules of this program are described below. A listing of the program is given in Appendix $E$.

MAIN

MAIN is the main program and calls the other routines as needed to perform the calculations requested by the user. The data library reading subroutines are called by the main program, and all other input data are read in this program. Required input data is explained in detail in Appendix F. As an example, if the aerosol AMAD is supplied, the routine to generate the deposition fractions is called. The ORDOSE subroutine is then called to calculate the doses per $\mu \mathrm{Ci}$ uptake for each nuclide and organ chosen, and the equivalent intake values.

ORDOSE

Subroutine ORDOSE controls the routines that generate the necessary values for organ dose calculation (in rem/ $\mu \mathrm{Ci}$ uptake). The individual nuclide contributions to the organ dose values are printed in this routine. ORDOSE also determines output page format according to the number of organs chosen at execution time (up to a maximum of 10). Where no data exist for a nuclide-organ combination, the output page shows a blank rather than a zero. ORDOSE uses the rem per $\mu \mathrm{Ci}$ values to calculate the equivalent risk values.

$\underline{\text { DEP }}$

Subroutine DEP is used to calculate the deposition fraction for each compartment $\left(D_{3}, D_{4}\right.$ and $\left.D_{5}\right)$ when the AMAD is supplied as input. The error function is integrated numerically over appropriate limits to produce the necessary fractions. 


\section{SIMPS}

Function SIMPS performs the numerical integration of the error function using Simpson's rule.

ERFXP

Function ERFXP is the error function $e^{-x^{2}}$ that is integrated by SIMPS.

UNIT

Subroutine UNIT converts input time in seconds to more convenient units, depending on the magnitude of the value supplied. The appropriate units, i.e., minutes, hours, days, etc., are also returned for use in the printed output.

ORDOT1

Function ORDOT1 calculates the dose to an organ for the time $T_{1}$ during which inhalation of radioactivity occurs at a continuous rate.

ORDOT2

Function ORDOT2 calculates the dose to an organ during a time $\mathrm{T}_{2}$ following the termination of inhalation of radioactivity at a continuous rate. The equations used take into account any continuing movement of material from the respiratory compartments and the lymph to the organ during this period.

QLUNT1

Function QLUNT1 calculates the radioactivity in each lung subcompartment following continuous inhalation for a time $T_{1}$.

QLMIT1

Function QLMIT1 calculates the removable quantity of a nuclide present in the pulmonary lymph following continuous uptake for a time $T_{1}$. 
QNT1

Function QNTI calculates the quantity of a nuclide present in an organ following continuous uptake for a time $T_{1}$.

The results from the preceding three routines are used in calculating the dose that follows cessation of inhalation uptake.

$\underline{\text { LIBB }}$

Subroutine LIBK reads the radiological data library (see Appendix D) and converts some values to other units.

$\underline{\text { LIBK }}$

Subroutine LIBK reads the radiological data library and converts some values to other units.

G.IDOT

Function GIDOT controls calculation of doses to the GI tract compartments over the time periods for uptake and dose (periods $T_{1}$ and $T_{2}$ in Appendix A). GIDOT uses functions QUINT1 and QUINT2 (described below); the use of GIDOT is similar to that of ORDOT1 and ORDOT2.

QUINT1

Fucntion QUINTI calculates the time integral of material entering the GI system over the uptake period $T_{1}$.

QUINT2

Function QUINT2 calculates the time integral of material entering the GI system over the second time period, $\mathrm{T}_{2}$, following cessation of uptake.

$\underline{\text { IGOR1 }}$

Function IGORI calculates the dose to an organ for the time $\mathrm{T}_{1}$ during which ingestion of radioactivity occurs at a continuous rate. 
IG0R2

Function IGOR2 calculates the dose to an organ during time $T_{2}$ following ingestion of radioactivity at a continuous rate. The equations used account for physical decay and biological removal from the organ.

B. 4 
APPENDIX C

CODE FLOW DIAGRAM 


\section{CODE FLOW DIAGRAM}

A general outline of the code operation is given in this appendix. The relationship between the main program and the subroutines used by the code is shown in Figure $\mathrm{C}-1$. The code flow diagrams (Figures $\mathrm{C}-2$ and $\mathrm{C}-3$ ) cover in some detail the logic in both the main program and subroutine ORDOSE. Code flow diagrams for the auxilliary routines are not shown; however, their functions are included in blocks at the appropriate places within the flow diagrams given.

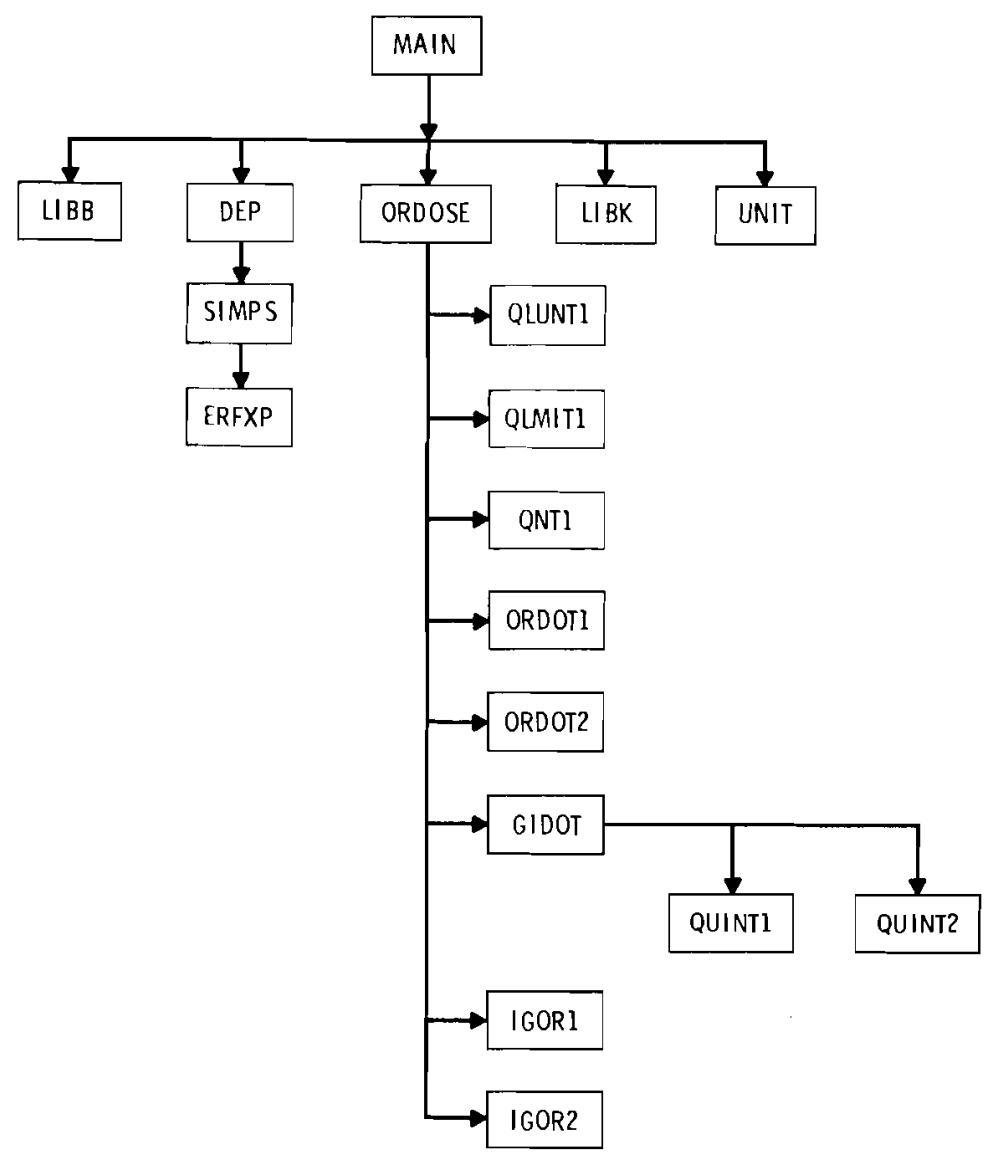

FIGURE C-1. Program Module Linkage

C. 1 


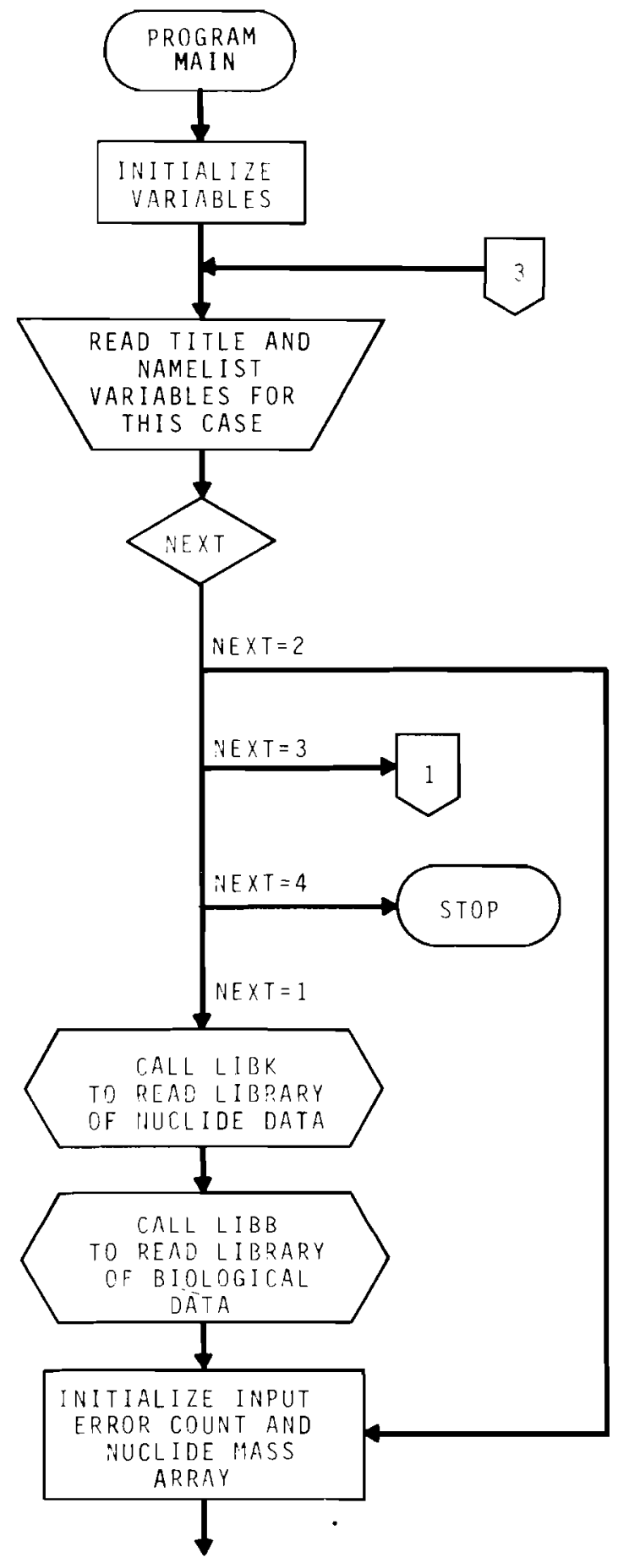

FIGURE C-2(a). Main Program Flow Diagram 


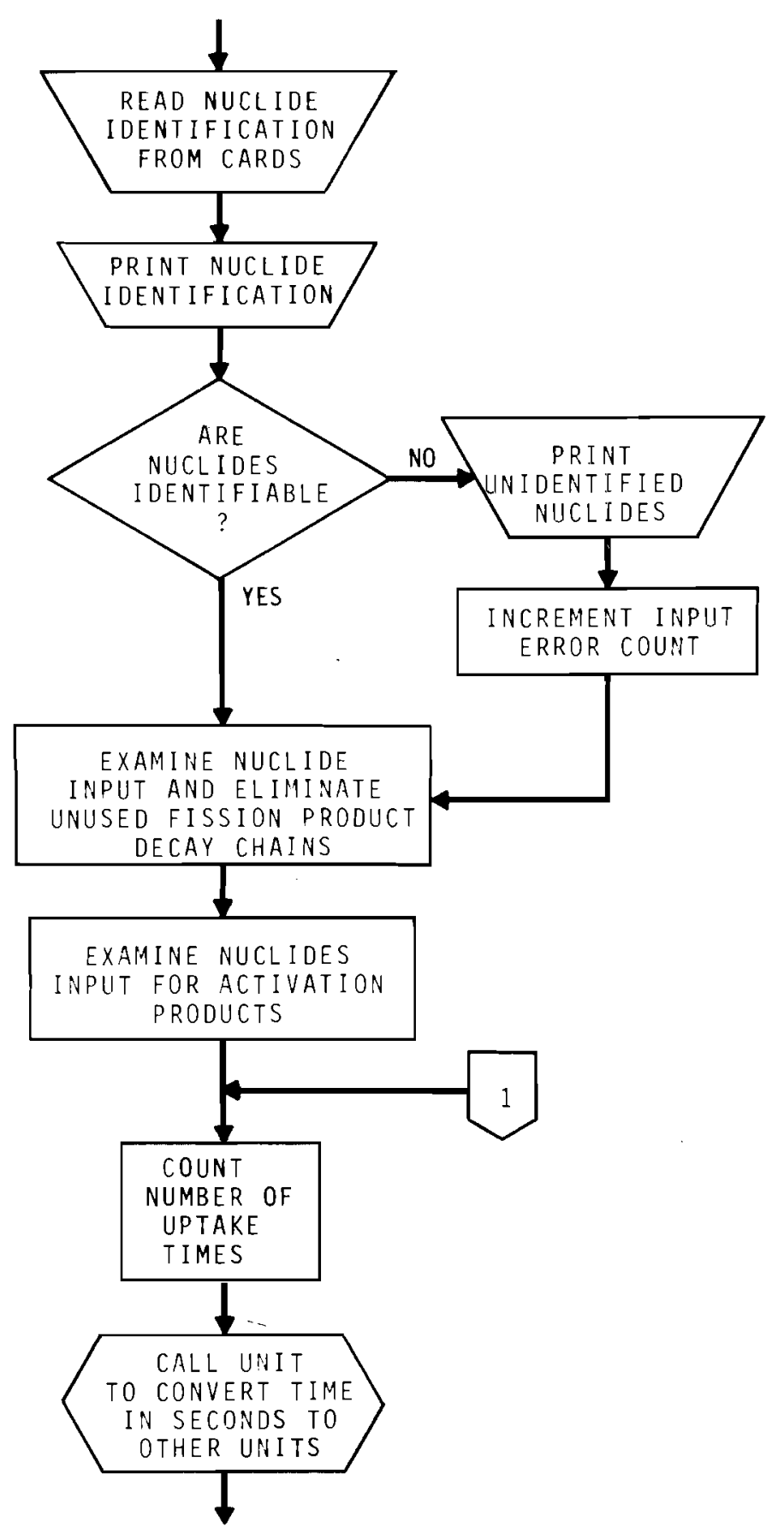

FIGURE C-2(b). Main Program Flow Diagram

C. 3 


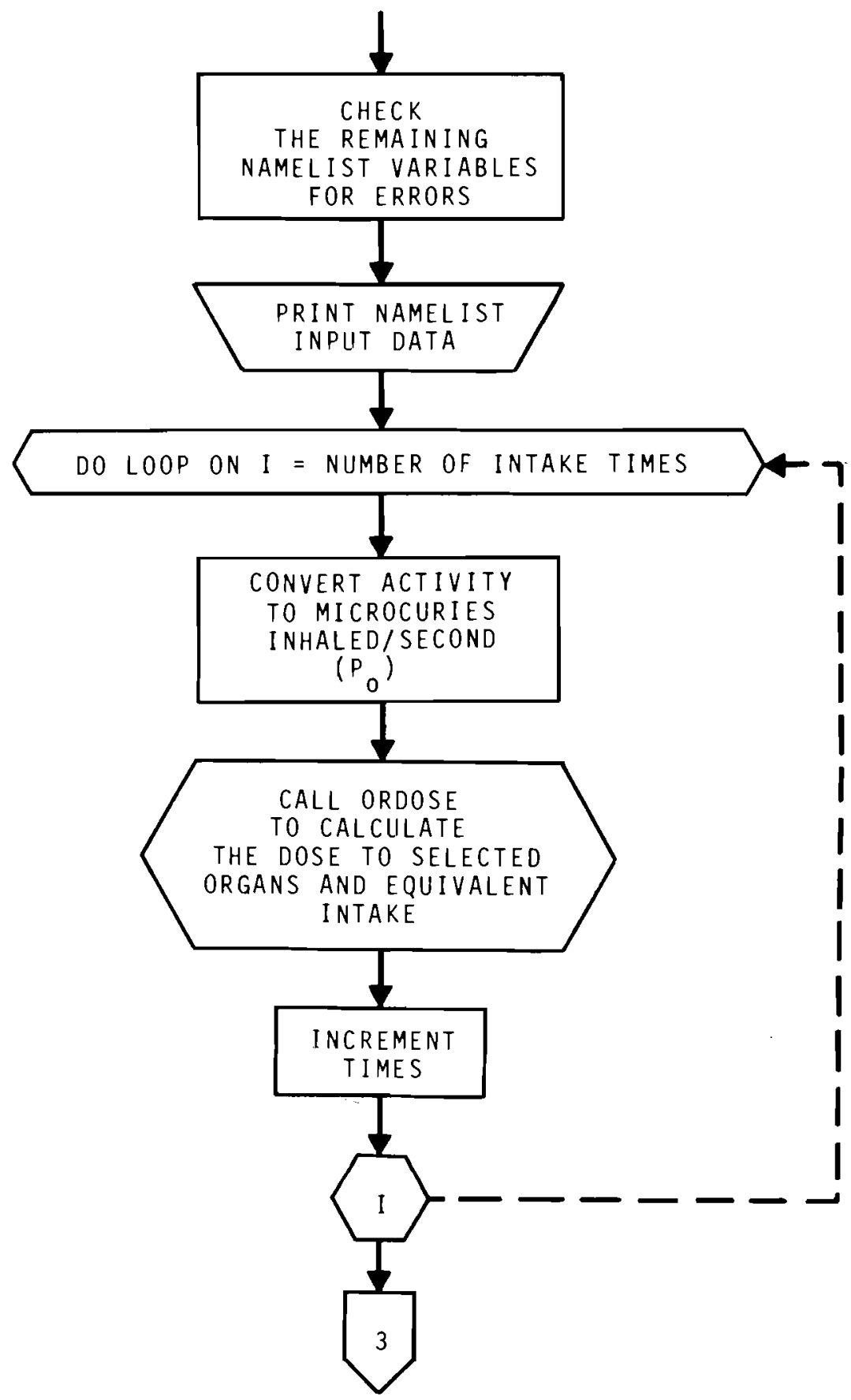

FIGURE C-2(c). Main Program Flow Diagram 


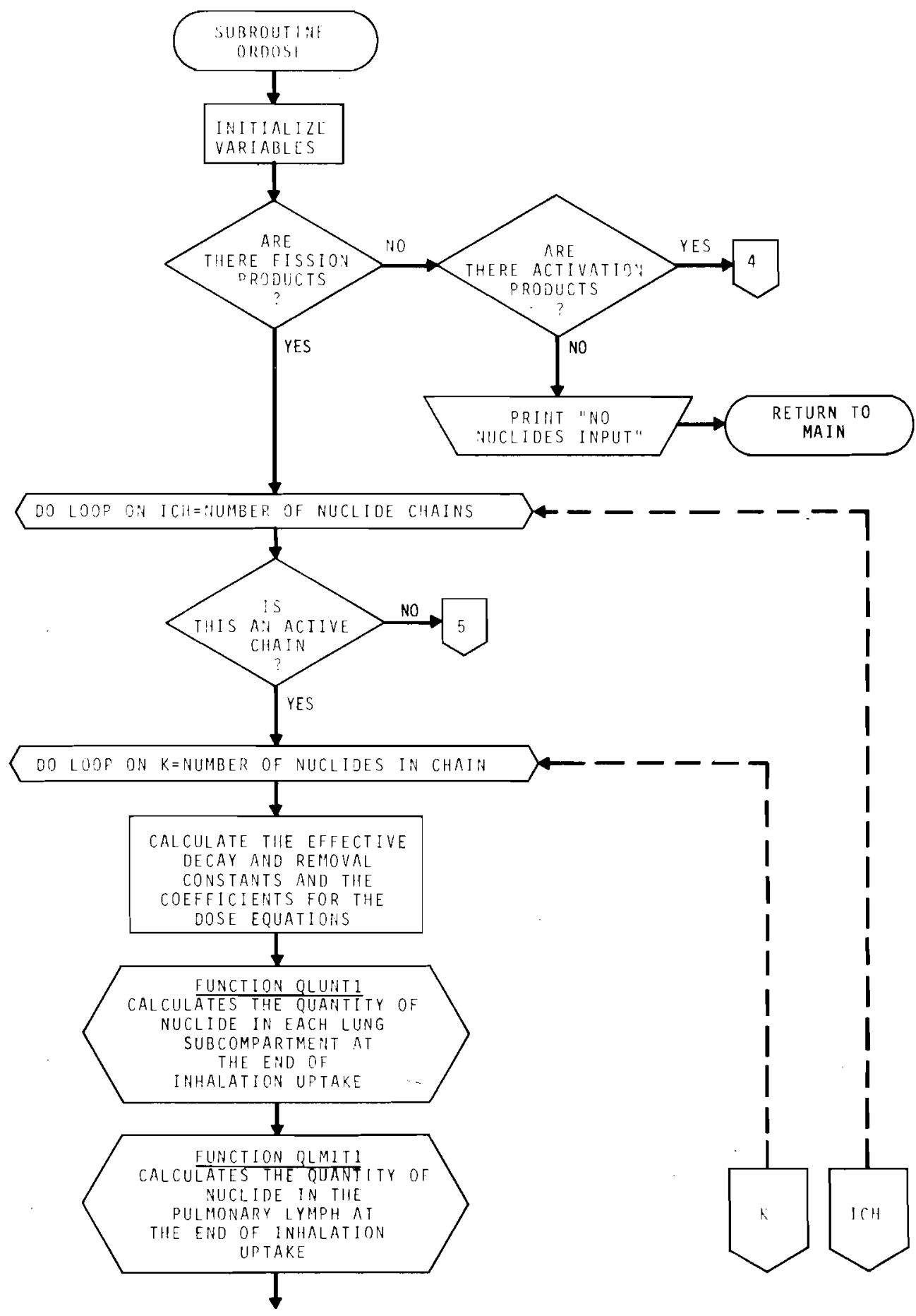

FIGURE C-3(a). Subroutine ORDOSE Flow Diagram 


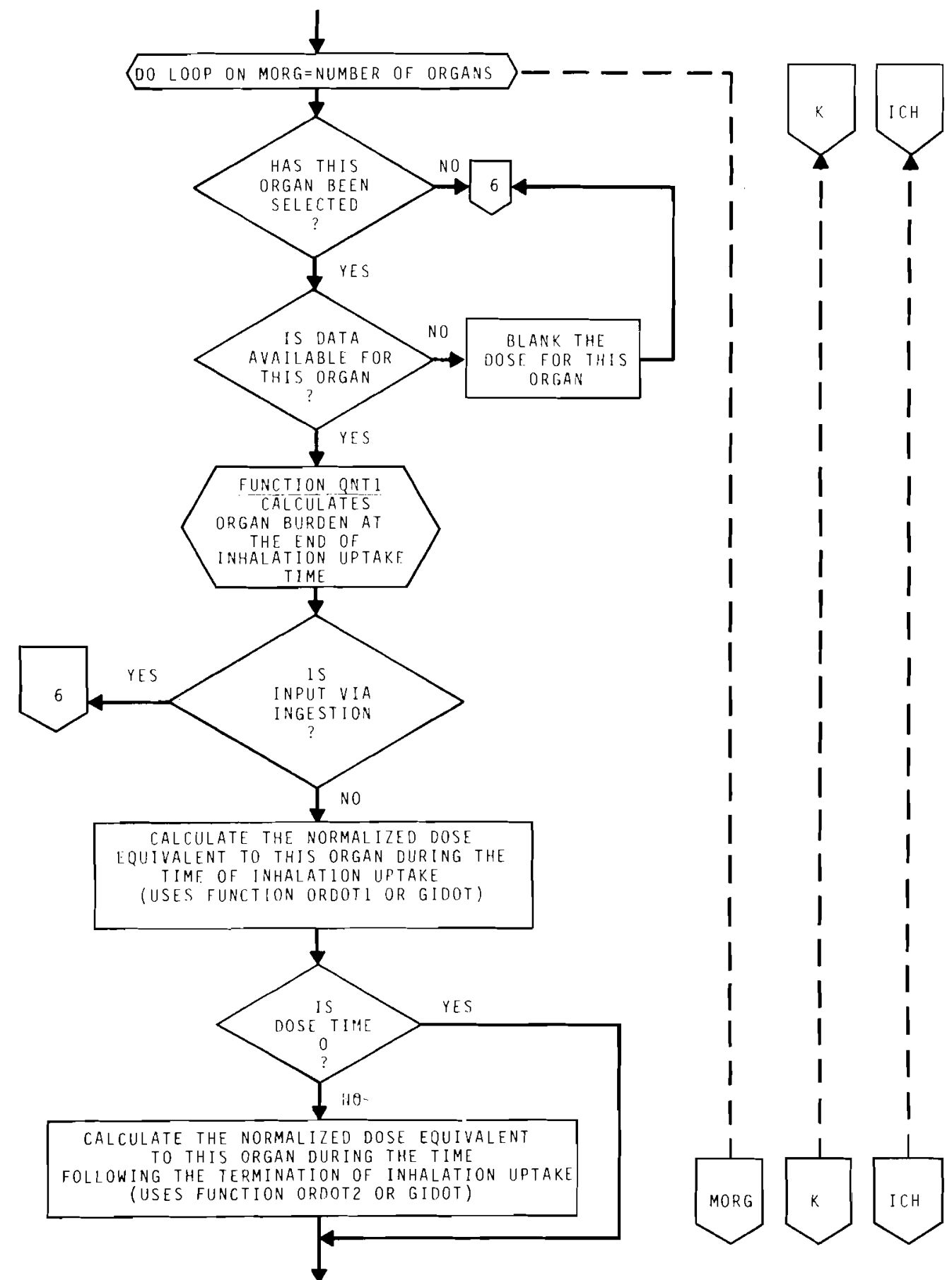

FIGURE C-3(b). Subroutine ORDOSE Flow Diagram

C. 6 


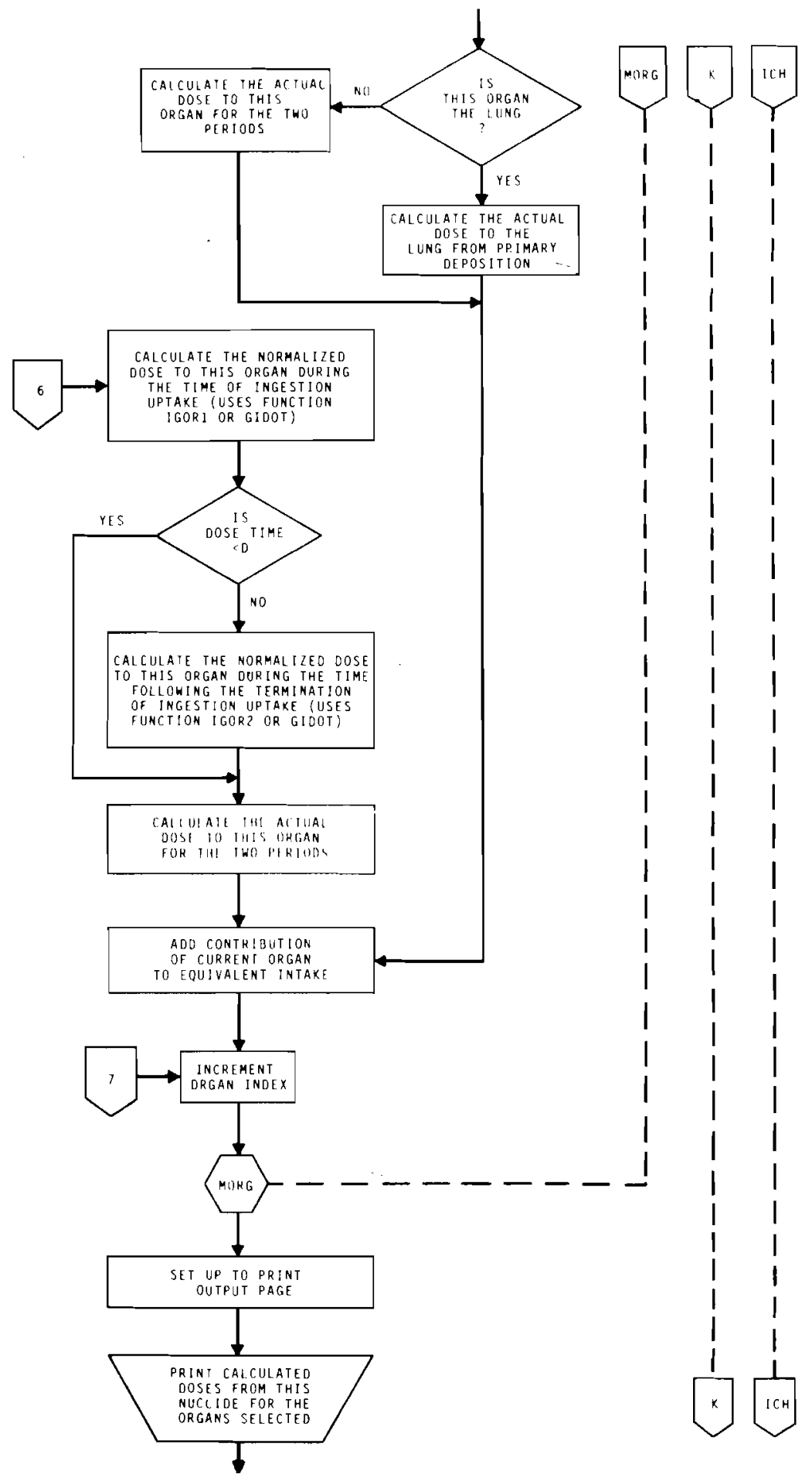

FIGURE C-3(c). Subroutine ORDOSE Flow Diagram 


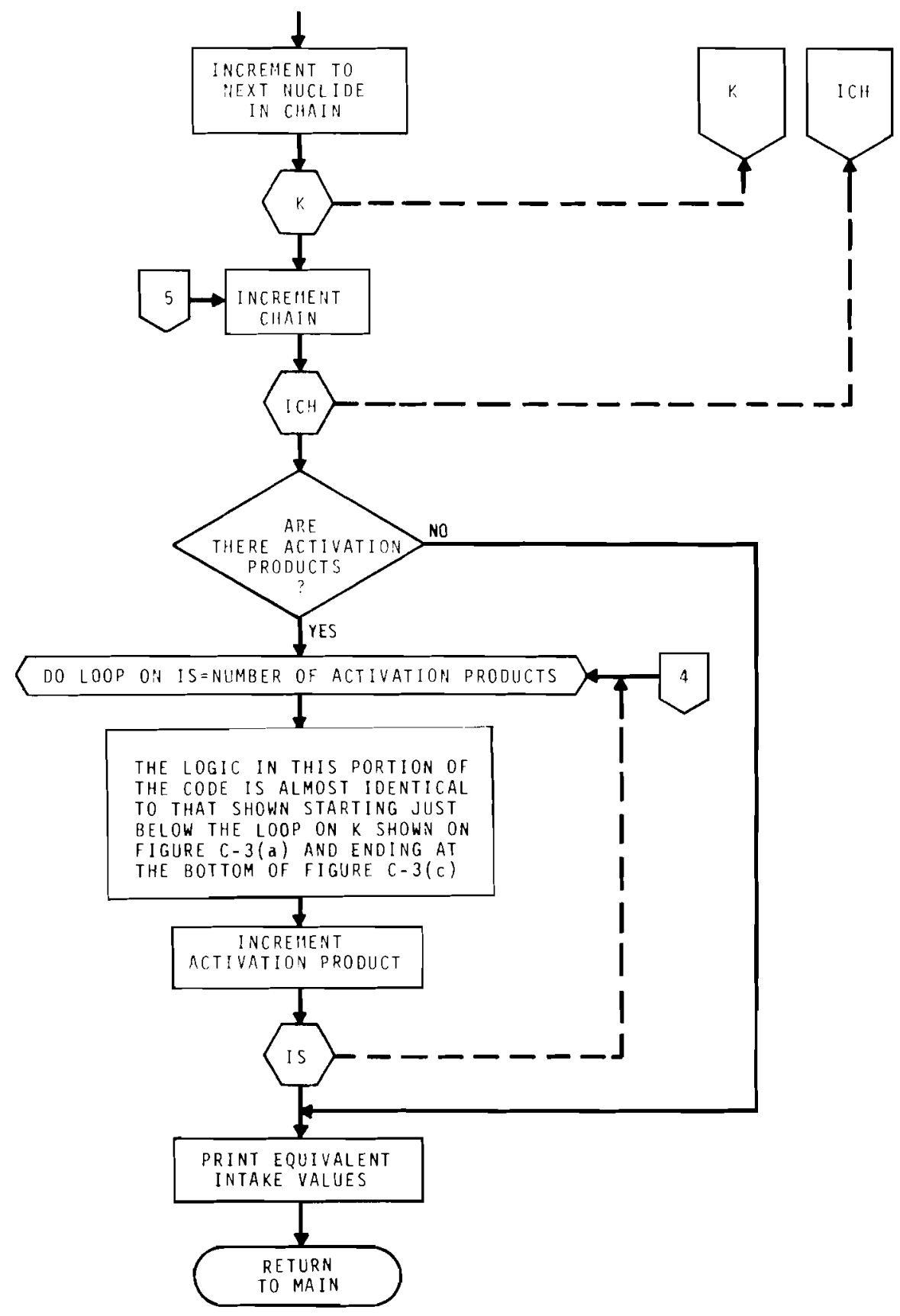

FIGURE C-3(d). Subroutine ORDOSE Flow Diagram

C.8 
APPENDIX D

DATA LIBRARIES 


\section{DATA LIBRARIES}

Two data libraries are used by the code:

1. Radionuclide data library

2. Organ data library

The organization and purpose of the data libraries are described below. Each library's data structure has been arranged so that additions or changes can be made with a minimum of effort.

Radionuclide Data Library

This library contains a master list of nuclide identification symbols and physical half lives. Nuclides supplied on input cards are compared to the master identification list.

The first card of the isotope library contains the number of fission products in the library, with 13 format used in the first three columins. The library has one card for each fission product, arranged in ascending atomic number order within an ascending atomic mass sequence. Currently, the library contains data on 331 fission products.

The card following that for the last fission product contains the number of activation products, using 13 format in the first three columns. A card follows for each of the 162 activation product nuclides currently in the library.

Each card for nuclide data has the following structure:

Column Format

$1-3$

$4-5$

$6-8$

9

$10-18$
I3

I2

A3

I1

E9.2
Variable

Atomic mass number

Atomic number

Nuclide symbol, with isomeric states indicated by an asterisk (i.e., KR*), left justified.

Integer to indicate isomeric state:

1 - isomeric state

2 - ground state

Physical half life in days 
A listing of the radionuclide data library is given in Figure $D-1$, page D.4.

\section{ORGAN DATA LIBRARY}

This library contains most of the data required by ORDOSE to calculate the effective dose to an organ. Data in the library are based on recommendations of the ICRP. $(1,2,3)$

The first card contains the total number of data cards in the library, using I4 format in the first four columns. The present limit on the data base is 2400 cards, and 2176 entries are currently in the library. One card is given for each radionuclide-organ combination. Entries are arranged in ascending organ number, within an ascending atomic mass sequence, within an ascending atomic number order.

The structure of each data card is indicated below. A listing of the organ data library is given in Figure D-2, page D. 7 . 
COLUMN

1-3

4-6

7

8-9

10-11

12-19

20-27

28-35

$36-43$

44-51

52-59

$60-65$

66-71
FORMAT

I3

13

I1

A2

12

E8. 3

E8.3

E8.3

E8. 3

E8.3

E8.3

E6.2

E6.2
VARIABLE

Atomic number

Atomic mass number

Isotope type: blank - ground state 1 - isomeric state

Element name

Organ code number

Physical half life, in days

Biological half life in the organ or tissue, in days

*Fraction of material taken into the body by ingestion that is retained in the organ ( $f_{w}$ in the initial ICRP lung mode1)

** Fraction of material taken into the body by inhalation that arrives in the organ ( $f_{a}$ in the initial ICRP lung model)

Fraction of the nuclide in the blood that reaches the organ $\left(f_{2}^{\prime}\right)$ Effective absorbed energy per disintegration of the radionuclide and daughters in the organ ( $E$, in MeV). For the lung, this is for a 1-day half-residence time

Weighted value of the effective absorbed energy per disintegration of the radionuclide and its daughters in the lung for a 50-day half-residence time Same as previous field except for a $500-$ day half-residence time

* Used for extracting $f_{1}$, the fraction of the ingested nuclide that reaches the blood.

** Not used by code. 
FIGURE D-1. Radionuclide Data Library 
339

$72302 N \geq 1.04 F+O A$ $73316425 . A R E-01$ $733 \cap 2 \mathrm{~V} ? 1.30 \mathrm{E}=\mathrm{n} 3$ 733164 ? ?. OOE=0! $743164>5.50 F=07$ $7531 G A ? 1.30 E \ldots 13$ 7532GE+1 $5.075-0 ! 1$ 7532GE ? 5.hOE-C? $7,3164 ? 3.705-04$ $7633 \mathrm{AS} ? 1.10 \mathrm{~F} . \mathrm{\cap n}$ $7732 G E+10.23 E-\cap 4$ $7732 G E ? 4.71 E-01$ $773345 ? 1.63 F+0 n$ $77345 E$ \& $2.0 A E=\cap 4$ 7R3गGE $2 \mathrm{~h} .11 \mathrm{~F}-\mathrm{NO}$ 7R33AS $2 \mathrm{~A}$. उ? F $=13$ $7033 \Delta S ? n .75 F=03$ 703 ISE*1 2.71F-03 703 USE $>2.50 E+07$ $803345 \geq 1.74 \mathrm{~F}=04$ 8035BR+1 1.R5F=n9 Bก353R? $1.25 E-02$ 8,334s? 3.R2F-nU 8134SE*1 3.OLE-0? व $1345 E ? 1.25 F-n$ ? $8,36 K R \geq 7.67 E+07$ $8,353 R ? 1.47 E+00$ $83345 E$ : $7.09 F=04$ $83345 F ? 1.745-02$ $8335 Q R 21.00 E-01$ $8336 k 2 \div 17.75 \mathrm{~F}=02$ $8434 S E$ ? 2.03E_ก $843552 * 1 \mathrm{~J} .17 F .03$ $8435 A$ ? ?.?2E-0? $8533 A S ? 4.9 A E-0 \mathrm{~m}$ B53पSE? $4.51 E-04$ 8535RQ ? 2. तAE.ก3 $8536 K 2+1,1 . A 3 E=01$ $853 E K R$ ? $3.93 E+03$ $8634 S E 21.85 E-14$ ${ }^{8}{ }^{3} 5^{80} ? 0.25 \mathrm{E}-\mathrm{O}_{4}$ 8637RA\#1 0.94F. 04 $8637 R E ? 1.87 F+01$ $87345 F 21.95 E-04$ $8735 A R ? 6.37 F-04$ $8736 K D>5.2 A F-02$ 8737RA $21.80 E+13$ Q73ESP.1 1.17E-01 8.3530? $1.85 E-n_{4}$ 8Q36KD? $1.17 E-01$ $8037 R A \geq 1.25 E-0$ ? $8035 B R \geq 5.21 E=05$ $8030 k 0 ? ? 2.52 E=03$ $8037 R 2 ? 1.04 E$. 2 803A5R ? 5.ARE+01 BO3OY. $11.25 E=04$ $9035 B D ? 1.25 F-05$ $9036 \times 9 ? 3 . R 2 E=04$ $903722 ? 2.01 E .03$
$0,3^{2} 52 \geq 1.05 E+04$ $9030 y+11.33 E=01$ $9030 Y$ ? ?. SHE+0O Q130KR ? 1.1DF-nG $9,37 R F+10.72 F=07$ 9, 370a ? R. TUE.กU

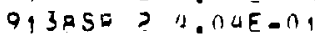
$9,30 Y \cdot 13.47 E-n 2$ $9,30 \mathrm{r} z 5.00 \mathrm{~F}+01$ $9>36 k R \geq 3.47 E-05$ $9237 R A ? 5.79 E .05$ $92385 R ? 1.13 E=01$ 933ar z 1.4TE-01 $9336 \times R ? 2.32 E-05$ $93372 A ?$ B. OUE. त5 03385R ? $9.70 F-03$ $9330 Y ? 4.21 E-01$ $9 x 40 Z 2 \geq 3.47 E+02$ $9341 N F * 11.35 E+03$ $9436 K 2 ? 1.155-05$ $9437 R R$ ? $3.47 E=09$ 9L3ASR? $9.33 E-04$ 943QY $? 1.39 E-0 ?$ $Q_{\triangle} \triangle 1 N A+1 \quad 4.38 E-03$ Q $\triangle \triangle N A ? 7,30 E .0 K$ $9536 \times 2 ? 1.16 E=05$ $9537 R A \geq 2.315 .05$ 953 ASR ? $5.54 E-04$ $9530 Y$ ? $7.64 \mathrm{E}-0 \mathrm{X}$ $9540 Z R ? 6.50 E+01$ 954 INA $3.75 \mathrm{~F}$.On $95+1 N A ? 3.50 E+01$ $9,39 Y ? 1.60 E-03$ 96 I INA $20.5 A F-01$ 9736 KR $21.10 E-05$ $9737 R A ? ? 32 F-05$ $97385 R ? 3.47 E=05$ $9730 Y 20.94 E-05$ $974029 \geq 7.07 E-01$ $9741 N^{9}+1 \quad 6,94 E-\cap 4$ $9741 \mathrm{Na}$ ? $5.00 \mathrm{OO}-02$ 9.40Zद 2 h.94E-04 QR 4 NA* 1 1. $3_{1} E-0$, QR ING $23.58 E$ O $904 \cap 29 ? 1: 35 E .05$ $9041 \mathrm{Na} 21.74 \mathrm{~F} .03$ $904 \geq 40 ? 2.70 E+n_{n}$ $9043 T C * 2.50 E-n$, $9043 T C ? 7.67 E+07$ IOnHINA 2 ?. OAF:n $10043 T C$ ?, $.07 E-04$ $10141 \mathrm{Ng}$ ? $0.04 \mathrm{E}-0 \mathrm{~A}$ $10,42 M 021.01 E-0$ ? 10143 IC ? $0.72 E-03$ $10>42 M 027.64 E_{-03}$ $10243 T C ? 5.70 E-05$ $10343 T_{C} ? 5.70 \mathrm{~F}=0 \mathrm{C}$ 103 पLRIJ 2 A. NOE+01 $103452 W+13.90 E-n$ ? 1044 टMO ? $1.11 E .03$
10443TE $21.205 F-n$ ? $10 \Delta 45 K+13.00 E=n_{3}$ $10445 R H ? 4.96 F . n Q$ $1054 ? M 0 ? 4.53 E-\cap 0$

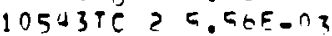
$10544 R U 21.25 F=01$ $10545 R H+13.47 F-O_{4}$ $10545 R H ? 1.50 E+00$ $10644 R U ? 3.65 E+02$ $106452 H+10.17 E=02$ $10645 R M 23.47 E=04$ $10743 T E 23.30 E-n, 4$ $107442 ! 1>2.02 F=03$ $107452 \mathrm{~N} 21.51 \mathrm{E}-02$ $1074000 ? ? .905+00$ $\left.10844 R_{1}\right) ? 3.13 E-03$ 1OR45RH 2 1. QTE-ก $1084745 \% 13.05 F+04$ $100474521.07 F=n 7$ $10045^{R A}$ ? $3.47 E-n_{4}$ $10046 P \cap+13.335-03$ $10040 P$ ? $?$. $53 E-01$ $10047 A 5$ प $4.53 E-04$ $11047 A_{G} * 1$ 2.60E+I) $11047 \Delta 5 ? 2.7 A E-14$

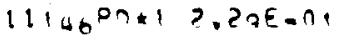
$1114 h P D>1.53 E-0>$ $111474 G, 19.575=04$ $111474 G$ Z $7.50 E+1) n$ $11148 C n+1$ 3.41)E-n2 $11>_{46}$ की $23.75^{E-01}$ $11347 A C 21.33 E-n 1$ $11340 P 22$ 1. OUEE-O3 $11347 \Delta G * 1$ \& $33 E-04$ $11347 \Delta C$ C ?.?1E-01 $1134 R C D+15,11 E+03$ $11446 P D ? 1.67 E-O_{3}$ $114474 C_{9}$ ? $5.79 E-n_{5}$ $11449 I N * 1=0.0 E+n$ I $11449 I N ?$ P. $33 E-04$ $1154600 ? 5.21 E-\cap 4$ $11547 \Delta G * 12.32 E=04$ $11547 A G 21.40 E-n ?$ $11548 C D * 1$ 4.30E +01 $115486022.30 E+0 n$ $11540 I N+1+23 E-01$ 11540 IN? 2.20E+17 1164600 ? $3.47 F-14$ $11647 \Delta G ? 1.74 E-93$ $11640 I N$ 1 $3.75 E-n>$ $11 \mathrm{~h} 49 ! \mathrm{N} 21 . \mathrm{n} 2 \mathrm{E}-\mathrm{n} 1$ $11747 A G 2$ 7. SUE-01 $11748 C D * 1 \quad 1.33 E=01$ $117486021.04 E-01$ $11740 I N * 1$ T.92E-OP $11740 I N ? 3.13 E-0$ ? $1175 n 5 N * 1 \quad 1.4 n E+n 1$ $11243 C D ? 3.47 E-n>$ 11340 IN $25.00 E-05$ $11 Q^{4} 8 C D+1 \quad 1.8 B E=03$
1104RCO ? h.OUF-nK $11040[N=11.25 E-0$ ? $110401 N 21.30 E=103$ $910505 \% 1>.50 E+?$ ? $12 n+9 I N ? 5.045-14$ 1 र. $48 C D ? ? .45-12$ $12140 I N * 1$ ?.15E-ก $12140 I N ? 3.47 E-00$ $121505 N+10.13 E+03$ $121505 N 21.11 E+0 n$ 12 रुOIN ? $3.6 \mathrm{dE}-05$ $1225159+1$ 2.25E-02

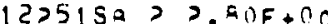
12340 IN 2 1. TOF-OA $123505 \mathrm{~V}+1$ ?. 7 NF $=n 2$ $123505 \mathrm{~N} 21,29 \mathrm{E}+\mathrm{O}$, 1 I35?TEस 1.17F+C? $1245152 * 11.405=0 ?$ 12151SR 2 h.O2E+01 $12550 \mathrm{SN}+1+.7 \mathrm{JF}=0 \mathrm{Z}$ $125505 N 20.425+n n$ $125515^{2} ? 0.465+n ?$ $12552 T E * 1$ S.MOE+ ח1 $1265054 ? 3.455+07$ $1265152.1,1.32 E-02$ $1265152 ? 9.25 E+n 1$ $127505^{N} 29.75 E=0$ ? $127515 R \geq 3.00 F+10$ $12752 T E * 11.05 E+02$ 12752152 3.RAE-ก। $12 R 5 \cap S N ? 4.31 E-0$ ? $12551 S R+14 ., O F=n 1$ 1295159 ? $6.04 E=03$ $122531 ? 1.74 E=0$ ? $120515921.25 E=0$ $12052 T E * 13.40 E+01$ $12052 T 5 ? 4.45 F .0 ?$ $12053125.24 F+n O$ $13 n 505 N 21.21=-03$ $13 \cap 515 B ? 2.71 E-0>$ 13,531 ? $5 . \geq 1 E-n !$ $1315159 ? 1,72 E-0 ?$

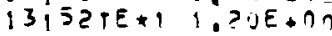
13,5 TE ? $1.01 \varepsilon-n ?$ $13153 I ? 2.05 E+03$ $13,54 \times E+1 ;$ ? Oก E+O $13>5159 \geq 1,40 F$ त 13 उ5शT5? $3: 255+10$ $1 S 253 I ? 0.5 A_{F} \cap>$ 1335159 ? ?.25E-? $13352 T E * 13.47 F=n$ $13353 T E \geq 1.30 \mathrm{OE} \cap 3$ 133531 2 $9.75 E-01$ $13354 X_{F}+12.30 E+0 n$ $13354 \times E \geq 5 . ? 7 E+n \cap$ $134515 \% ? 1.74 E-15$

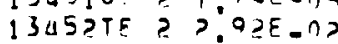
$13453 I ? 3.08 E-n$ ? $13055 C S+1$ 1.21E-n1 $13455 \mathrm{C} 5 ? 7.67 \mathrm{~F}+1 \mathrm{C}$ 
135SISA? 2.5UF-nE $13552 T E ? 3.30 E-11$ $135331>2.79 E-n 1$ $13554 x=41.116-02$ $13554 \times E>3.23 E-n$, $13555 C 5$ ? 7 ? $0+0$ $1355 n A \Delta+1: .21 E+00$ $134531 ? 7.01 E-04$ $13655 C S ? 1.30 E+01$ $13753122.78 E=00$ $13754 \times 522.92 E-03$ $13,55 C S ? 1.10 E+04$ $1375684 \cdot 1$ ?. $81 E=0$ $13253127.29 E=05$ $13854 \times F ? ! 1$ ? 1 ? $=0$ ? $13955 \mathrm{CS} ? 2.24 E=0 ?$ 139533 ? $2.32 E-05$ $13051 x_{E}>4.75 E-14$ $13055 C 5>$ b.60E-0 1305684 ? $5.70 E-0$ ? $14054 \times E ? 1.95 E-01$ $14055 C 527.045004$ $140568421.25 E+01$ IUN57LA $21.0 B E+00$ $14,54 \times E ? ? .32 F-05$ $14155 \mathrm{CS} ? 2.78 E=n_{1}$ $14,56 B 4 ? 1.25 E-0 ?$ $14157 \mathrm{LA} ? 1,53 E=0$ ? $14158 C E ? 3.255+0$. $1 \triangle 254 \times E 21.74 E-n_{5}$ $14 \geq 55 C 5$ ? 2.46E-na 14ว56SA $27.04 F=n 3$ $14>57 L A ? 50^{\circ}$. $3 E=0 ?$ $14250 P 02$ R.กกE-01 $14354 \times E ? 1.10 E-105$ $14355 C S ? 2.32 E-05$ $1435680 ? 1.30 \mathrm{E}-01 \mathrm{~A}$ $14357 L A 20.72 E-03$ $1435 \times C E ? 1.38 E+0 n$ $143500021.37 E+0$, $14454 \times E 2 \quad 1,16 E-05$ $14 \triangle 55 C S 22: 32 E=05$ $14456 B \Delta ? 3.47 F-05$ $14457 L A ? 4.43 E-05$ 1445 ACE $22.855+02$ $14450 P 0 ? 1.20 E=n ?$ $14460 N D ? 7.30 E+n 7$ 1.5SRCF? 2. DSE-0R 1 $455002 ?$ ? $45 E-01$ $1455 R C E \geq 0.72 E-03$ $146590 R 21.67 F=02$ 1475 ACE ? $7.64 E-\cap 4$ $147500 R ?$ ? $33 E-\cap 3$ $14960 N \cap ? 1.11 E+01$ $14701^{\mathrm{PM}} 20.49 E+0 ?$ $1470>54 ? 4 . B_{0} E_{+} ! 3$

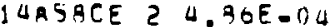
$14250 P Q 2 \cdot 4.30 E=03$ IUROIPM I I. IOF+OI $14 Q O, P M ? 5.4 n E+O \cap$
$14000 \mathrm{NO} ? 7.21 \mathrm{~F}-n>$ 1 $10 \mathrm{QbIPM} ? 2,21 E+\Pi 0$ $15460 \mathrm{NA} ? \mathrm{~A}, 13 \mathrm{~F}=03$ $15161 \mathrm{PH} ? 1.17 E+00$ $15,0254 ? 3.295+n 4$ $15>61042$ व.17F. 23 $15>03 E U * 1$ ?. R.RE $=01$ $15 \geq 03 E U ? 4.53 E+103$ $15361 \mathrm{PM} 23.32 \mathrm{E}-03$ $153625 M ? 1.96 E+00$ $151501 P M$ ? $1.74 E=03$ $15403 E U \geq 5.94 E+03$ $155625 \mathrm{M} \geq 1.53 \mathrm{~F}=02$ $15563 E 1126.57 E+0$ ? $156675 \mathrm{~m} ? 3.92 E-01$ 15क०3EU। $1.52 E+0$, 15763 EUI ? $6.33 F=01$ 15RG3EU? $3.10 E-0 ?$ $15963 E U 21.32 E-0$ ? $15904 G D>7.50 \mathrm{Em} 0$; $16003 E U ? 1.745-02$ $160659 a 27.20 E+01$ $16,046022.57 E=03$ $16,65 T A 26.00 E+0 n$ $16 \geq 046023.65 E+0>$ $10205 T 2 ? .33 E=0 ?$ $10305 T ?$ ? ?.71E=01 $165660 \times+19.73 E-01$ $165660 \mathrm{~V} 29.79 E=0 ?$ $166660 Y ? 3.42 E+00$ $16607 H O 21.13 E+00$ $16768 E A \cdot 1$ 2.89E-05 162

$31 \mathrm{H} 24.505+02$ 7 पSE $25.30 E+n 1$ IO $\triangle 8 E ?$ O $18 E$, OA 14 be $22.005+04$ 1 Q QF $27.80 E=0 ?$ 2211 NA ? $0.50 E+0 ?$ $2411 N A ? 6: 30 E-n i$ 3114SI? 1.!OE=01 $3215 P \geq 1.43 E+01$ $3516528.71 F+01$ $3617 \mathrm{CL} 21.20 E+0_{A}$ $3 \% 17 \mathrm{CL} 23.605=07$ पIIQAR? $7.63 E=0$ ? $4219 K$ ? $5.2 \cap E-n i$ $U_{1}$ INCA 2 ?. $07 E+n T$ $4520 C_{A} ? 1.04 E+0 ?$ $4720 C \Delta ? 4.90 E+0 i$ $46215 C ?$ S. $50 E+n_{1}$ $47215 C ? 3.43 E+n 0$ $4 \times 215 C ? 1.33 E+0 \cap$ पदट3V ? $1.01 E+01$ $5124 C E ? 2.78 E+n_{1}$ $5225 M N 25.55 F+00$ $5425 \mathrm{MN}$ ? 3.00E ก $5625 M N ? 1.10 E$ OI $5526 F E \cdot 2.10 E+03$ $5026 F E ? \triangle .51 E+01$
$5727 \mathrm{CO} 2>.70 \mathrm{~F}+\mathrm{n}$

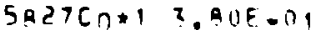
$5 \times 27 \mathrm{CO} ? 7.2 \cap E+n_{1}$ Gก $27 \mathrm{CO} ? 1.90 \mathrm{C}+03$ $\left.505 R^{2}\right\} ? 2.015+07$

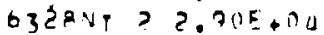
$6528 \mathrm{NI} \geq 1.11) \mathrm{F}=01$ 6U2AC:I? $2.30 E-01$ $653 n 2 N ? 2.45 E+0 ?$ $69302 N=1$ 5.ROE- II $603 \cap 2 N 23.00 E-0 ?$ 7.3?GE 2 1.20E+ 1 $733345 ? 7.60 E+n$ $7433 \Delta S ? 1.75 E+09$ $75345 E ? 1.275+n ?$ $853852+14.0^{\circ} \mathrm{F}=\mathrm{O}^{2}$ $85385=>6.505+01$ $934>M D ?: 10 E+n A$ $9643 T C=13.60 F=0 ?$ $9643 T r ? 4.315+0 n$ $9743 T E+1 ? .501 E-01$ 9743 TC ? 3.70E+0A 9744 ? ? 2.8OE+Oก $103460021.70 E+01$ $10547 \Delta, 24.00 E+n_{1}$ $10948 C_{D} ? 4.75 E+n>$ $11349 I N+17.30 E=0 ?$ $11350 \mathrm{SN} \geq 1.12 E+n ?$ $125531 ? 6.00 E+n 1$ $12653121.33 E+01$ $13,55 C 521: 00 E+01$ $131568 \Delta 21.16 F+n 1$ $153645022.36 E+n 2$ $16667 H 0+14.38 E+05$ $16968 E R$ ? $9.40 E+00$ ITIGRER 23 IOE-OT $17060 \% M 21.27 E+02$ $171697 \mathrm{M} 20.94 E+02$ $17570 Y 32$ I. 10E+ 10 $17771 L U 2$ G.AOE+ON $18 ; 7$ THE $20.00 E+n 1$ $18273 T A ? 21.12 E+0 ?$ $18,74 W$ ? $1.40 E+0 ?$ $18574 \mathrm{~W} 27.40 E+01$ $18774^{4} 21.00 E+0 n$ 1837545 ? $7.30 E+01$ $18675 R F 23.79 E+00$ $18775 R E ? 1.20 E+13$ ISATSRE? 7.1OE-N1 $185760 S ?$ Q $90 E+01$ $19,7605 \cdot 1$ 5.80E-01 $1917605 ? 1.60 E+C 1$ $19376105>1.30 E+0 n$ $10077 I R 21.20 E+01$ $1927712 ? 7.45 E+01$ $19477 I R 27.90 E-01$ 19178PT? 3.00E

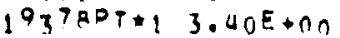
$19378 P T 21$. AOE +115 19778PT+1 5.9OE=0?

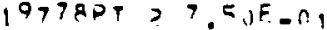

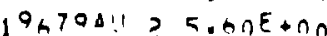
$19070 \Delta ! 1 ?>$ ? 20 . OO $19070 \Delta_{U} \geqslant 3.15 E+0 n$ $19750=6.11 .00 \mathrm{E}+0 n$ 19790 HE ? ?.7OF+n $2035 n \pi 5>0.52 E+n 1$ 20กHITL ? $1.13 E+0$ O 20, BITL $23 . \cap 0 E+n \cap$ 20>BITL $2, .20 E+n$, 20481TL $21.10 E+03$ $20385 \mathrm{~PB} ? 2.17 E+10$ $21085 P a \quad 5 \quad 10 E+03$

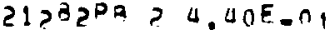
$204939 T ? 6.40 F+n$ त $207838 T 2 Z .00 E+03$ 21083BJ $25.00 E+0 n$ 21 PBST $24.20 E=0 ?$ 21 ก $4 P C ? 1.35 E+02$ $21,854 T 23,00 E=01$ $2238824 ? 1.17 E+01$ $22489 R A \geq 3.54 E_{+} 00$ $225880 \triangle \geq 1.48 E+01$ 22SORRA? $5.00 E+05$ 22月OARA $2 \geq .40 F+03$ $225 B 9 A C ? 1 . \cap 0 E+01$ $22780 \Delta C ? .00 E+03$ $22989 \Delta \mathrm{C} \geqslant 2.005 .01$ $22790 T H \geq 1.94 E+01$ 22 月OTH $>7.00 E+02$ 22970 TH ? ?.56E+106 $2300^{\circ} \mathrm{TH} ? 2: 00 \mathrm{TH}+07$ $23190 T H ? 1, n 7 E+n \cap$ $23 \geq 90 T$ T $25.10 F+1$ ? $2349014 ? 2.41 E+C 1$ $23 n^{9} P_{A} 21.77 F_{+}+01$ $23,91 P \Delta ? 1.30 E+07$ $233910022.74 E+01$ $23092 \mathrm{~V} 22.08 E+01$ $23 \geq 92 U \quad 2.70 E+04$ $233^{9} \mathrm{U}$ ? $5.90 E+07$ $23495 \mathrm{O}$ व.10E+07 235920 ? $2.60 E+11$ $23692 U>8.70 E+00$ $23792 U 26.75 E+0 n$ 23.920 ? $1.70 E+12$

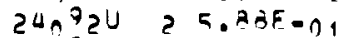
$23793 N D ? A . \cap O E+O R$ $23993_{N P} 22.33 F+01$ $236940 U>2.25 E+01$ $23,94 P_{\mathrm{J}} \geq 4.5_{h} E+n_{1}$ 23月9पPU $23.30 E+n_{4}$ 230940!J 2 a $90 E+16$ 24094PU $23040 E+06$ $24,94 P \cup ? 4.90 E+03$ 24>94PU $21.40 E+O R$ 24394PU 2 2. OBE-01 $24494 P U ? 2.92 E+10$ $24,954 M 21.70 E+15$ $24 \geq 954 * 15.60 E+04$ 


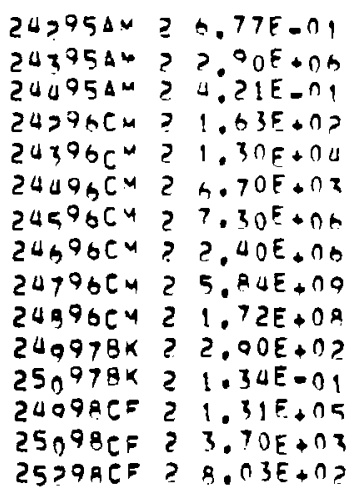


FIGURE D-2. Organ Data Library 
2170 ORGAN TATA LTFRARY PEVTSED AIIGIST 18.1070

\begin{tabular}{|c|c|c|c|c|c|c|c|}
\hline 3 & +1 & $.45 n+n a$ & $120+02$ & $100+n$ & .100 .01 & $100+01$ & $100-01$ \\
\hline 3 & in & $.45 n+n u$ & $\therefore 120+02$ & $\therefore \ln n+n$ & $.100+01$ & $.100+01$ & $.170=01$ \\
\hline 3 & $1 E$ & & & & & & $-100-01$ \\
\hline 7 & QE & $.536+102$ & $180+0 x$ & $\because \geq 00-11 ?$ & $.250=00$ & $.100+01$ & $.350-01$ \\
\hline 7 & SE & $.536+0 ?$ & $1>0+n_{3}$ & $-b^{n} 0=0 \mathrm{a}$ & $.750-(1 ?$ & $.300-01$ & $.12^{n-01}$ \\
\hline 7 & AF & $.53 n+n j$ & $270+103$ & $200-03$ & $.250=01$ & $.100+00$ & $.160-\pi 1$ \\
\hline 7 & AF & $.530+n ?$ & $.500+0.3$ & $.000-05$ & $.500=0.3$ & $.200-02$ & .120 .01 \\
\hline 7 & 356 & $.536+n ?$ & $.450+03$ & $.64 n=03$ & $.800=01$ & .320000 & .850 .01 \\
\hline 7 & SE & & & & & & $.160=01$ \\
\hline 7 & AE ? ? & $.536+02$ & & & & & .010 \\
\hline 7 & $8 F 21$ & $.536+02$ & & & & & .035 \\
\hline 7 & $9 E 22$ & $.536+02$ & & & & & 85 \\
\hline 7 & $3 E ? 3$ & $.530+0 ?$ & & & & & .0085 \\
\hline 10 & AE 1 & 5.8458 & IRn. & 002 & .2 .5 & & .209 \\
\hline 10 & EE 3 & $5.8 \triangle 5 ?$ & & $6 . F-5$ & .0075 & .03 & 200 \\
\hline 10 & BE & $5.8 \Delta 5 ?$ & & $? E-U$ & .025 & .1 & .200 \\
\hline 10 & $B E$ & 5.9458 & $\triangle 50$. & 6. $\triangle E=-4$ & .08 & .32 & 1.005 \\
\hline 10 & AE $R$ & $.584+n \theta$ & & & & & \\
\hline 10 & BE? & $.58<+n \theta$ & & & & & 200 \\
\hline 10 & AE? & $.58 \Delta+n 0$ & & & & & 200 \\
\hline 10 & $B E 22$ & $.584+0^{2}$ & & & & & 209 \\
\hline 10 & SF 23 & 5. AUEA & 0. & & & & .209 \\
\hline 94 & C I & $.20 n+07$ & $\because n \cap+n ?$ & $\therefore 1 n+n 1$ & $.750=00$ & $.100+01$ & $.500-01$ \\
\hline 14 & C & $.20 n+n 7$ & $400+0 ?$ & $250-01$ & $.200-01$ & $.250=0 !$ & $.270-00$ \\
\hline 14 & C 7 & $.20 n+n 7$ & $.120+12$ & $.500=0 n$ & $.380=00$ & $.500-00$ & .500 .01 \\
\hline 94 & 620 & $.200+07$ & & & & & .054 \\
\hline 10 & C 21 & $.200+07$ & & & & & .054 \\
\hline 14 & $C 22$ & $.200+07$ & & & & & .054 \\
\hline 14 & 023 & $.200+17$ & & & & & .054 \\
\hline 18 & F 1 & $.790=01$ & $\therefore 0 R+03$ & $.100+01$ & $.750-00$ & $.100+01$ & $.890-00$ \\
\hline 18 & $F 0$ & $.7 P \cap=n 1$ & $.145+04$ & $30=00$ & $.400-00$ & $.530=0 n$ & $.140+01$ \\
\hline 18 & $F \quad A$ & & & & & & $.540+00$ \\
\hline 18 & 520 & $.706-01$ & & & & & \\
\hline 18 & 521 & $.70 R=n 1$ & & & & & 89 \\
\hline 18 & F?? & $.709-01$ & & & & & 01 \\
\hline 18 & F 23 & $.708=01$ & & & & & \\
\hline 22 & $N \perp 1$ & $.850+03$ & $\because 110+02$ & $: 100^{\circ} 0$ & $.750=00$ & $.100+01$ & $.160+01$ \\
\hline 22 & NA 8 & & & & & & $=800+00$ \\
\hline $\begin{array}{l}22 \\
23\end{array}$ & $\begin{array}{ll}\mathrm{NA}^{\circ} \\
\mathrm{NA} \mathrm{S}^{\circ}\end{array}$ & $.950+03$ & & & & & \\
\hline 22 & NA? & $: 950+03$ & & & & & \\
\hline 22 & $N_{23}$ & $.950+133$ & & & & & 53 \\
\hline $\begin{array}{l}?_{4} \\
24\end{array}$ & $\begin{array}{ll}N A & 1 \\
N A & 9\end{array}$ & $.030=0 n$ & $\because 110+02$ & $\cdot 1^{n n+2}$ & $.750=00$ & $-100+01$ & $-2^{70+0}$ \\
\hline 24 & $N \Delta 20$ & $.630=00$ & & & & & \\
\hline 24 & $N \triangle 21$ & $.03 \cap 00 n$ & & & & & .7 \\
\hline 24 & $N .22$ & $.63 n=00$ & & & & & 1.0 \\
\hline 24 & $N \Delta 23$ & $.630=00$ & & & & & 0 \\
\hline 31 & SI 1 & $.110+0 n$ & $600+02$ & $850=0 n$ & $.690=00$ & $.100+01$ & $.590-00$ \\
\hline 31 & SI $R$ & $.110+00$ & $60 n+0 ?$ & $.900-01$ & $.700-01$ & $.100+00$ & $.590-00$ \\
\hline 31 & ST 9 & $.110+00$ & $600+n ?$ & $\therefore 85 n-03$ & $.700-03$ & $.100-0 ?$ & $.590-00$ \\
\hline 31 & 5110 & $.11 n+n 0$ & $600+02$ & $\therefore 30-03$ & .340 .03 & $.500-03$ & $.590-00$ \\
\hline 31 & $S I 11$ & $.110+00$ & $600+02$ & $.500=04$ & .400 .04 & $.000-03$ & $.590-00$ \\
\hline 31 & SII? & $.110+00$ & $.600+0 ?$ & $.300=01$ & $.300-01$ & $.400-01$ & $90-00$ \\
\hline 31 & 5920 & $.11 n=n n$ & & & & & \\
\hline 31 & $53 ? 9$ & $.11 n=0$ & & & & & 50 \\
\hline 31 & SI 22 & $.110=00$ & & & & & 59 \\
\hline 31 & $5 I 23$ & $.110-00$ & & & & & 59 \\
\hline 32 & 1 & $.143+n ?$ & $.257+03$ & $.75 n=0$ & $.63 n=0 n$ & $.100+01$ & $.6^{\circ} 0=00$ \\
\hline
\end{tabular}

$\sin 170$

E IOST

ORTLLIR

ORTLLIR

ORTLLIB

ORCLIS

ORCLLIA

ORTLIR

CRELLIS

ORPLLIS

ORPOOOR

DACOOR

070008

ORFOOB

OPCLIR

ORRLIR

ORRLLIS

DACLL IR

ORFOOI

OQReO01

ORe.001

ORP.0O1

ORPLI I

ORPLLIF

DACLIR

OPCLIA

OReOOI

ORroO 01

ORTOOL

OR P.OOI

OR CLLIB

ORPLIB

ORTLLI

ORFOOOI

ORCOOOI

OREOOOI

ORE.00!

CARLI I

ORFLIA

CRPODOI

OREOOOI

OR .001

020001

ORPLIR

ORFLIR

ORPOOI

ARPOOOI

DRि 00 !

OR r.0OI

ORELIB

ORPLI IB

ORPLIR

DPCLL I A

ODCLI I

ORALIR

ORe.001

ORe $0 \cap 1$

ORP 001

0 F 001

OPCLIA 


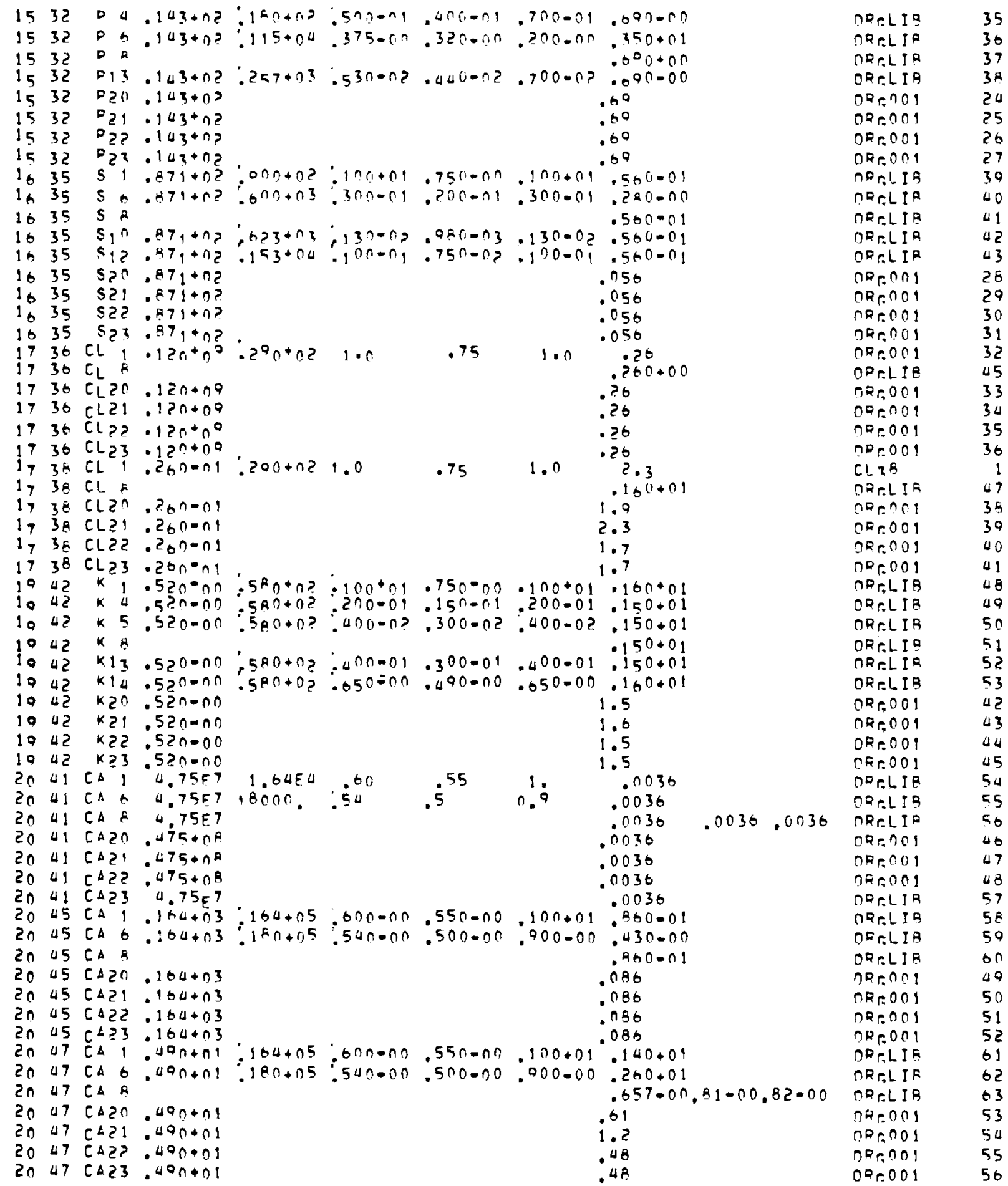




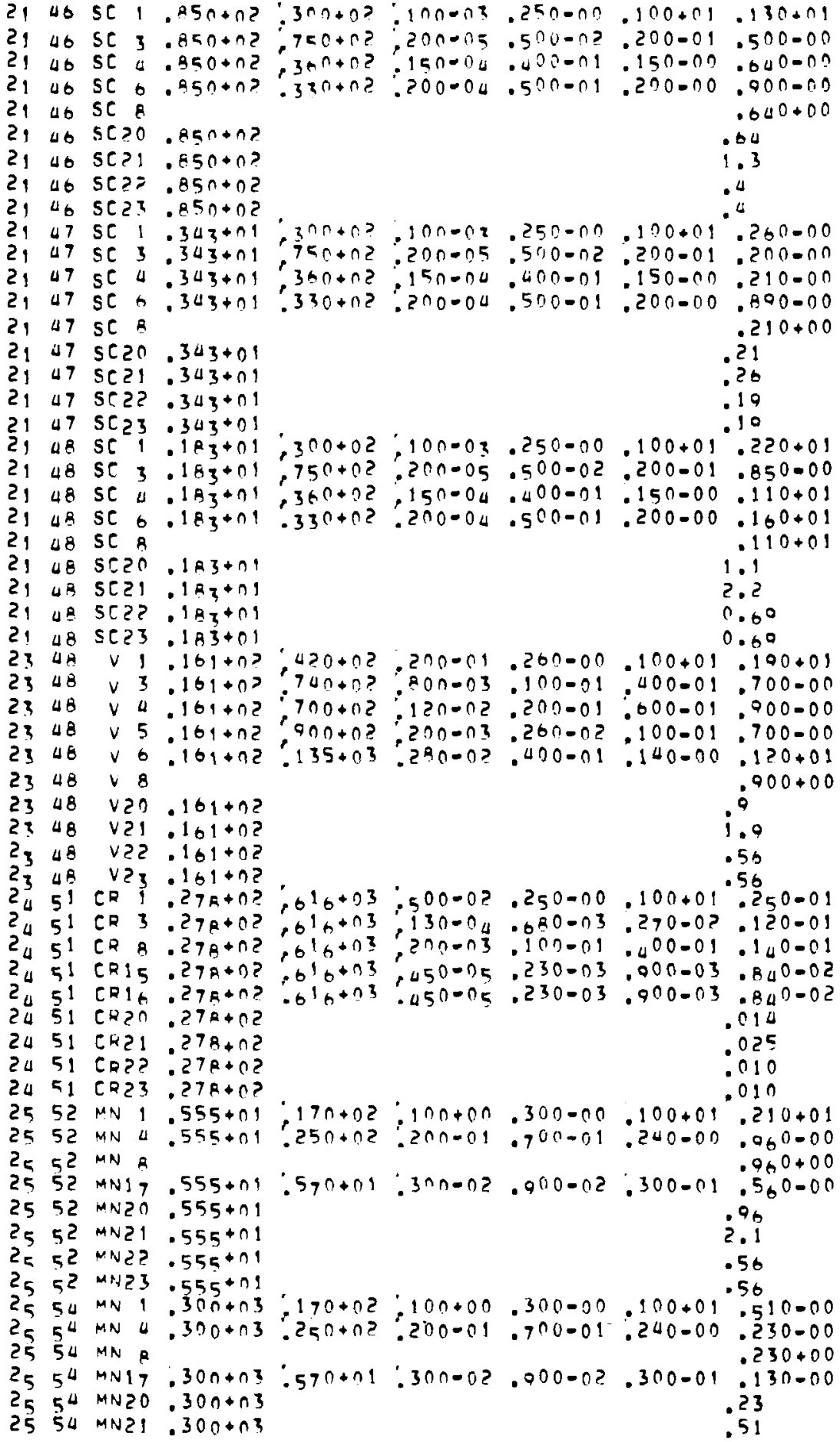

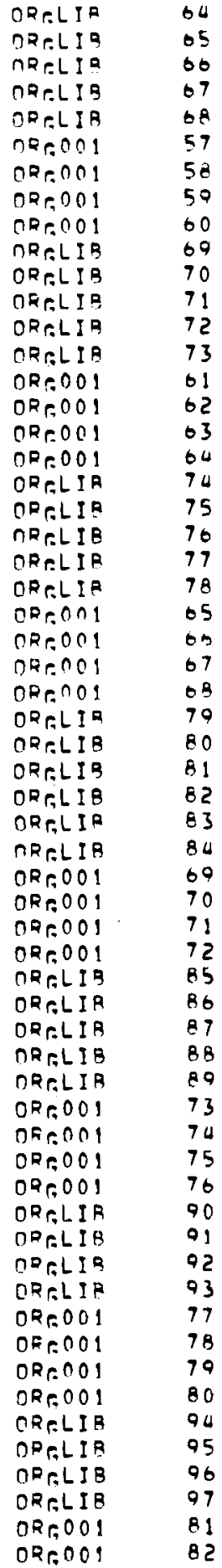




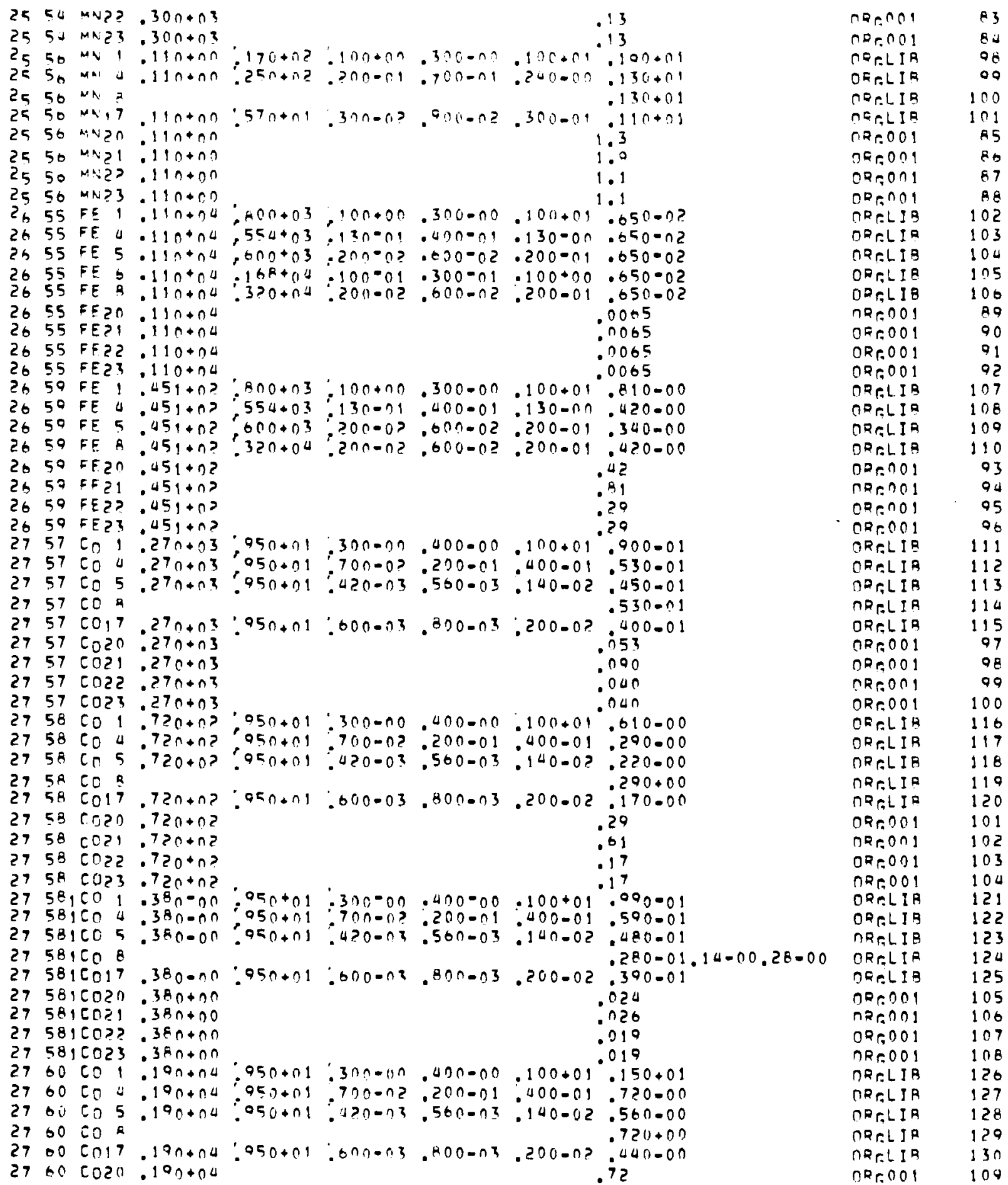




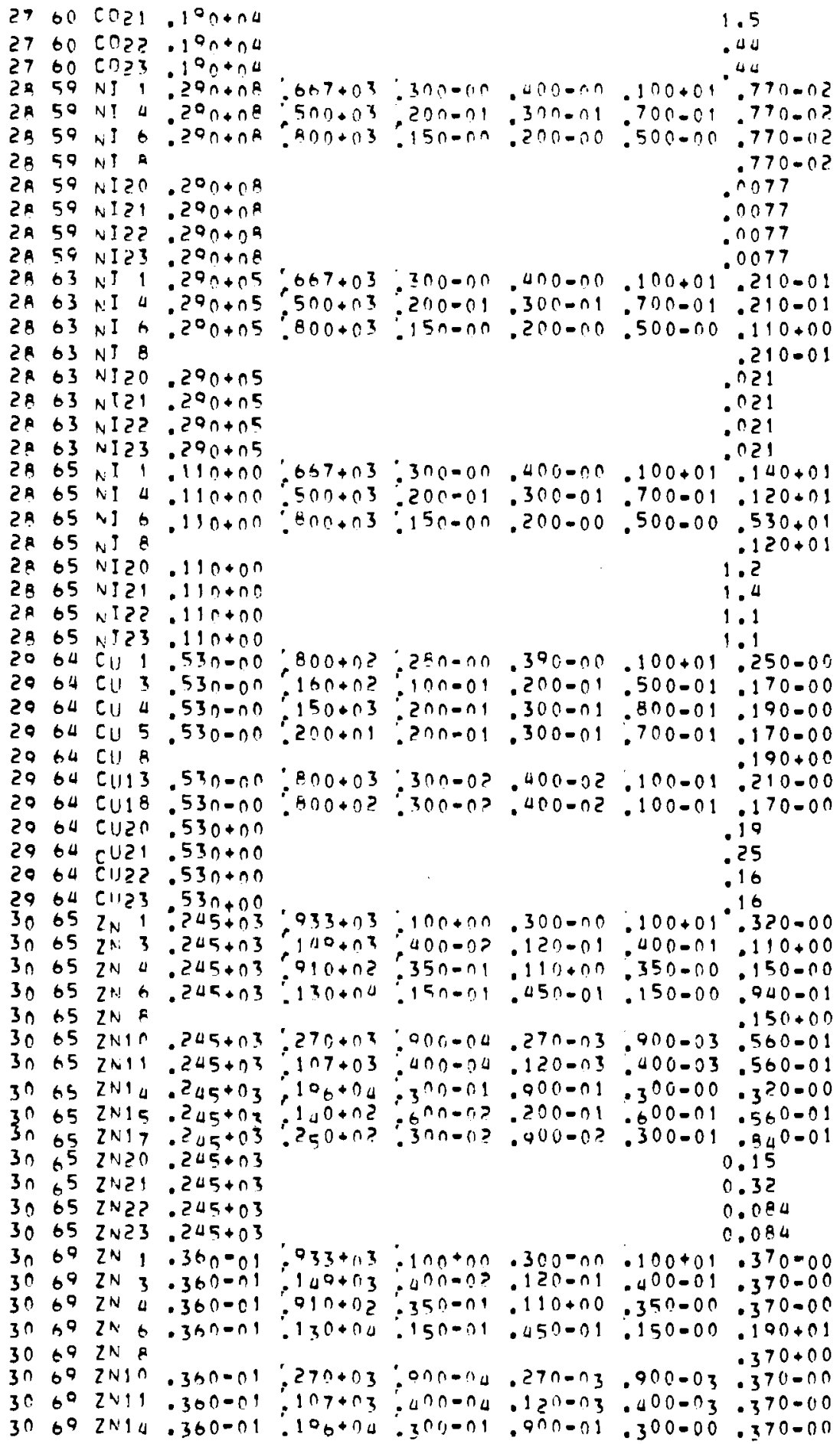

חRenत?

CRe 001

OREO01

ORPLIR

ORroL IR

ORTLLIR

ORRLL IR

ORroO

OQ0001

ORrOOL

0 Or. 001

ORRLLIR

OREL I

ORPLIA

ORHLIS

OPCOOLI

ORPOOI

OQR 001

ORroO

OPRLLIB

ORPLIE

ORRL I

ORCLIB

ORronol

neraO

ORr.cO

ORr.COI

ORPLIB

OPRLLIR

OROLIB

ORPL I B

ORELIR

OPr.LIA

ORr.LJR

OR $=001$

OPROOI

ORPOOI

ORr,OOI

ORr.L IR

CORLIR

ORPLIA

ORPLIIR

ORPLIS

ORPLIR

ORCLIA

ORRLIA

ORCLIE

ORTLIB

OR 001

DR 001

OR 001

OPfOOOI

DReL I

ORALIR

ORRLIR

ORPLIA

OPrLL IR

ORPL I

OPr.L It

DRr.LIR
110

111

112

131

132

133

134

113

114

115

116

135

136

137

138

117

$11 \mathrm{E}$

110

120

139

100

141

142

121

122

123

124

143

144

145

146

147

148

149

125

126

127

128

150

151

152

153

154

155

156

157

158

159

127

130

131

132

160

161

162

163

164

165

160

167 


\begin{tabular}{|c|c|c|c|c|c|c|c|c|c|c|}
\hline 30 & 69 & $2 \times 15$ & $.360-0 !$ & $\because 140+12$ & $\because n n n-\cap 2$ & $.20 n-n 1$ & $.000-01$ & $.37 \cup=00$ & OPr.LIR & 108 \\
\hline 30 & 69 & $20: 7$ & - $30 n=n 1$ & $.250+12$ & XnA-n? & $.9 n \cap-n z$ & $300-01$ & $.37 n-00$ & ORr,LIR & 100 \\
\hline $\begin{array}{l}39 \\
39\end{array}$ & $\begin{array}{l}69 \\
67\end{array}$ & $\begin{array}{l}\text { ZN20 } \\
2 \times 21\end{array}$ & $\begin{array}{l}36 n=n 1 \\
36 n=n 1\end{array}$ & & & & & 0.37 & ORTOCI & 133 \\
\hline 30 & 69 & ZN2? & $.36 n-n 1$ & & & & & 0.37 & GRe.001 & 135 \\
\hline 30 & $6^{\circ}$ & $2 \wedge 23$ & $.36 n-n !$ & & & & & 0.37 & ORroOI & 136 \\
\hline 30 & 699 & $2 \times 1$ & $.580-00$ & $: 033+03$ & $.100+00$ & $.300=00$ & $.100+01$ & $.040-00$ & ORPLIIB & 170 \\
\hline 30 & 609 & $2 N 3$ & $.58 n=n n$ & $.940+03$ & $\Delta \cap 0=1) ?$ & $.120-01$ & $.400-01$ & $.470-00$ & ORr,LIR & 171 \\
\hline 3 & 699 & $12 N a$ & $.58 n-n n$ & $.910+02$ & .350 .01 & $.110+00$ & $.350 .0 n$ & $.500-00$ & ORRLIS & 172 \\
\hline$n$ & 699 & $Z N 6$ & $.580=0 C$ & $130+04$ & $.150-01$ & $.450-01$ & $.150-00$ & $.210+01$ & ORP.LIR & 173 \\
\hline$n$ & 609 & $Z N R$ & & & & & & $.387-00.50=00.50=00$ & OPC L I B & 174 \\
\hline$n$ & $\begin{array}{l}691 \\
699\end{array}$ & $17 \times 10$ & $\begin{array}{l}-28 n=0 n \\
58 n=00\end{array}$ & $.27 n+03$ & $\therefore a n 0-00$ & $.270-03$ & .900 .03 & $.430-10$ & OROLLIR & 175 \\
\hline & 691 & $\begin{array}{l}12 N 11 \\
\text { IZNIU }\end{array}$ & $\begin{array}{l}-28 n=00 \\
28 n=0 n\end{array}$ & $.107+08$ & $\begin{aligned} 4000 \\
3000\end{aligned}$ & $-1 \geq n-03$ & $.400-03$ & $.030-00$ & ORRLIR & 176 \\
\hline 0 & 699 & $Z N 15$ & $.58 n=n 0$ & $140+02$ & $\begin{array}{l}\sin 0-n 1 \\
600-0,\end{array}$ & $\begin{array}{l}.210-01 \\
.200-01\end{array}$ & $\begin{array}{l}.500-00 \\
.600 .01\end{array}$ & $\begin{array}{r}.640 .00 \\
.430 .00\end{array}$ & $\begin{array}{l}\text { RPRLIIR } \\
\text { ORr.LIB }\end{array}$ & $\begin{array}{l}177 \\
178\end{array}$ \\
\hline & 691 & $2 N ! 7$ & $.580=0 n$ & $.250+02$ & $: 300=02$ & $.900-02$ & $.300-01$ & $.450-00$ & ORraL I I & 179 \\
\hline 0 & 691 & I ZN20 & $.580=00$ & & & & & 0.13 & $02 r 001$ & 137 \\
\hline 9 & $\begin{array}{l}691 \\
691\end{array}$ & $\begin{array}{l}2 N 21 \\
2 N 23\end{array}$ & $\begin{array}{r}-58 n=0 n \\
58 n=00\end{array}$ & & & & & 0.27 & QR $=001$ & $\begin{array}{l}138 \\
139\end{array}$ \\
\hline 0 & $60 \%$ & $2 N 23$ & $580=n n$ & & & & & $0.0 R_{1}$ & ORGOOI & 140 \\
\hline & 72 & 641 & $.59 n=00$ & $000+01$ & $: 100-0 ?$ & $.250-00$ & $.100+01$ & $180+01$ & narile & 180 \\
\hline 3 & $\begin{array}{l}72 \\
72\end{array}$ & $\begin{array}{ll}G \Delta & 3 \\
G \Delta & 4\end{array}$ & $\begin{array}{l}59 n-n n \\
59 n=n 0\end{array}$ & $\begin{array}{l}900+01 \\
480+01\end{array}$ & $\begin{array}{l}200-04 \\
250-03\end{array}$ & $\begin{array}{l}500-02 \\
630-01\end{array}$ & $\begin{array}{l}200-01 \\
250-00\end{array}$ & $\begin{array}{r}890-00 \\
110+01\end{array}$ & $\begin{array}{l}\text { ORRLL IP } \\
\text { OR L L I }\end{array}$ & $\begin{array}{l}181 \\
182\end{array}$ \\
\hline 3 & 72 & 6.5 & $.590=00$ & $=0 n+01$ & $\therefore 100-00$ & $.250-02$ & $.100-01$ & $\begin{array}{l}110+01 \\
890-00\end{array}$ & ORR R L I I R & $\begin{array}{l}102 \\
183\end{array}$ \\
\hline 31 & 72 & $G \Delta \quad 6$ & $.5^{\circ} n=n n$ & $\therefore 120+0 ?$ & $: 3 n \cap 0.03$ & $.750-01$ & $.300-00$ & $.260+01$ & $O R r_{0} L$ I $A$ & 184 \\
\hline 31 & 72 & GA & & & & & & $.110+01$ & ORRLIR & 185 \\
\hline 1 & 72 & $G \triangle 20$ & $.59 n=00$ & & & & & 1.1 & $0 R \times 001$ & 141 \\
\hline 1 & 72 & GA 21 & $.590=00$ & & & & & 1.8 & ORr. 001 & 142 \\
\hline 1 & $7 ?$ & G42Z & $.5^{\circ} n=00$ & & & & & 0.75 & $n R P 001$ & 143 \\
\hline 31 & 72 & GA23 & $.590=00$ & & & & & 0.78 & 020.001 & 144 \\
\hline $\begin{array}{l}3 ? \\
3 \\
3\end{array}$ & $\begin{array}{l}71 \\
71\end{array}$ & $\begin{array}{ll}\text { GE } & 1 \\
\text { GE } & 3\end{array}$ & & $\left\{\begin{array}{l}100+01 \\
120+02\end{array}\right.$ & $: \begin{array}{l}1000-01 \\
300-03\end{array}$ & $\begin{array}{l}260=00 \\
.500-02\end{array}$ & $\begin{array}{l}100+01 \\
300-01\end{array}$ & $\begin{array}{l}100-01 \\
100-01\end{array}$ & 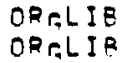 & $\begin{array}{l}186 \\
187\end{array}$ \\
\hline 2 & 71 & GE $\triangle$ & $.12 n+n 2$ & $.75 n+01$ & 200003 & $.500-02$ & $.200-09$ & $.100-01$ & ORrL L B & 188 \\
\hline $3 ?$ & 71 & GE $A$ & & & & & & .100001 & ORPLI I & 180 \\
\hline$?$ & 71 & GE 20 & $.120+02$ & & & & & 0.010 & ORr, 001 & 145 \\
\hline ? & 71 & 6521 & $.120+02$ & & & & & 0.010 & ORr.0O1 & 100 \\
\hline ? & 71 & GE22 & $-12 n+n ?$ & & & & & 0.010 & ORPOOOI & 147 \\
\hline 3 & $\begin{array}{l}71 \\
73\end{array}$ & 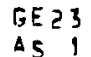 & $\begin{array}{l}120+n ? \\
760+n ?\end{array}$ & $=280+03$ & $3 \cap 0-01$ & $270=00$ & $100+09$ & $\begin{array}{l}n .010 \\
010-01\end{array}$ & $\begin{array}{l}n R=001 \\
O P O L\end{array}$ & $\begin{array}{l}148 \\
190\end{array}$ \\
\hline 3 & 73 & $\triangle S 3$ & $.760+n ?$ & $.550+03$ & $3 \cap 0-\cap 3$ & $.270-n ?$ & $100-01$ & $360-1$ & Darlia & 191 \\
\hline 3 & 73 & $\triangle S U$ & $.76 n+n ?$ & $.550+03$ & $: 000=03$ & $.800-12$ & $.300=01$ & .410 .01 & ORRLI IR & 102 \\
\hline 33 & 73 & AS $A$ & & & & & & $.410-01$ & ORPLI I & 193 \\
\hline 3 & 73 & $\triangle S 20$ & $.960+0 ?$ & & & & & 0.041 & ORron 01 & 149 \\
\hline 3 & 73 & $\Delta \leqslant 21$ & $.76 n+n ?$ & & & & & 0.061 & $0 R+C O S$ & 150 \\
\hline 3 & 73 & 45?2 & $.76 n+n z$ & & & & & 0.033 & $\cap R_{r}, 001$ & 151 \\
\hline 33 & 73 & $\triangle 523$ & $.760+102$ & & & & & 0.033 & $0 R \cap 001$ & 152 \\
\hline 33 & 74 & $\Delta S 1$ & $.175+0 ?$ & $290+n 3$ & $300-01$ & $.270-100$ & $.100+01$ & $.560-00$ & ORR LI I & 194 \\
\hline 3 & 74 & $\Delta S 3$ & $.175+02$ & $.550+03$ & $.300-03$ & $.2^{7} 0-02$ & $.100-01$ & $.340=00$ & ORALIB & 195 \\
\hline & 70 & AS 4 & $.175+02$ & $.550+03$ & $: 00 n-03$ & $.800-02$ & $300-01$ & $.380 \cdot 00$ & ORTIL I & 196 \\
\hline 33 & 74 & $\triangle S B$ & & & & & & $.380+00$ & ORr.LIA & 197 \\
\hline 3 & 74 & $\triangle S 20$ & $.175+0 ?$ & & & & & 0.38 & nRro001 & 153 \\
\hline 33 & 74 & $\Delta$ S21 & $.175+n ?$ & & & & & 0.56 & ORr, 001 & 150 \\
\hline 3 & 74 & $\triangle 522$ & $.175+02$ & & & & & 0.32 & ORr, 001 & 155 \\
\hline 3 & 74 & AS2 3 & $.175+02$ & & & & & 0.32 & $0 R+, 001$ & 156 \\
\hline 33 & 70 & $\Delta \mathbf{S} 1$ & $.111+n 1$ & $290+03$ & $: 300-01$ & $.270=00$ & $.100+01$ & $.130+01$ & $O^{R} r_{0} L$ I & 198 \\
\hline 33 & 70 & $\triangle S 3$ & $.119+n 1$ & $550+03$ & $: 3 \cap 0-03$ & .270 .02 & $.100-01$ & $.110+01$ & $\cap R r=L I R$ & 190 \\
\hline 3 & 76 & As 4 & $.119+01$ & $.5501+03$ & $.900-03$ & $.800-0 ?$ & $.300-01$ & $.110+01$ & ORP, L I & 200 \\
\hline 3 & 70 & $\Delta \leqslant$ & & & & & & $.110+01$ & OP.r.LIB & 201 \\
\hline : & 76 & A 520 & $-111+n 1$ & & & & & 1.1 & $O R r_{0} 001$ & 157 \\
\hline & 76 & A S 21 & $.111+01$ & & & & & 1.3 & $D R=001$ & 158 \\
\hline
\end{tabular}




\begin{tabular}{|c|c|c|c|c|c|c|c|c|c|c|c|c|}
\hline $3 ?$ & 70 & $\Delta \leqslant 2 ?$ & $.111+91$ & & & & & 9.1 & & & 020001 & 150 \\
\hline 33 & 70 & $\Delta \leq 23$ & $.111+01$ & & & & & 1.1 & & & nRPOOOI & 100 \\
\hline 33 & 77 & AS 1 & $.162+109$ & $.200+03$ & $\cdot 3 n n-01$ & $.270-00$ & $.100+01$ & $.240-00$ & & & ORCLII & 202 \\
\hline & 77 & $\Delta S ?$ & $.162+01$ & $55 n+n 3$ & $3 n c-03$ & $2^{7 n} n=?$ & $.100-01$ & $.240-00$ & & & DRCLIB & 203 \\
\hline 33 & 77 & $\Delta \leqslant U$ & $162+n 1$ & $.55 n+n 3$ & $\because 0_{0}-03$ & $.800=0 ?$ & $.300=01$ & $.240-00$ & & & ORCLIS & 204 \\
\hline 33 & 77 & $\triangle S D$ & & & & & & $.2<0+00$ & & & OPRLIB & 205 \\
\hline 33 & 77 & $\Delta S_{2}=0$ & $.16>+01$ & & & & & $n .24$ & & & ORFOOO1 & 161 \\
\hline 33 & 77 & 4529 & $.162+n 1$ & & & & & 0.24 & & & 00001 & 162 \\
\hline 33 & 77 & 4522 & $.162+01$ & & & & & $0 . ? 4$ & & & nReO0O4 & 163 \\
\hline 33 & 77 & 4523 & $.102+n 1$ & & & & & 0.20 & & & $n R=001$ & 164 \\
\hline 30 & 75 & SE 1 & $.127+03$ & $110+0 ?$ & $900-00$ & $.700=00$ & $.100+01$ & $.2 n 0-00$ & & & $D R C L I R$ & 206 \\
\hline $3 u$ & 75 & SE & $.127+\cap 3$ & $110+0 ?$ & $u n n=01$ & $.3 n 0=01$ & $.000-01$ & .720 .01 & & & ORTLIR & 207 \\
\hline 34 & 75 & SE 4 & $.127+03$ & $240+02$ & $.6 \cap 0-01$ & $.5^{n 01}-01$ & $.700-0 i$ & $.9 \Delta 0=01$ & & & ORCLIR & 208 \\
\hline 34 & 75 & SE 5 & $.127+03$ & $. \operatorname{len} n+n 2$ & $.45^{n-n} ?$ & $.350-02$ & $.500-02$ & $.720-01$ & & & ORALIA & 209 \\
\hline 34 & 75 & SE $B$ & & & & & & $.940+01$ & & & ORPLIR & 210 \\
\hline 34 & 75 & SE 20 & $-1 \geq 7+n 3$ & & & & & 0.094 & & & $O P C O 09$ & 165 \\
\hline 34 & 75 & SE2 I & $.127+03$ & & & & & 0.20 & & & $O P=001$ & 166 \\
\hline 30 & 75 & SE2Z & $.127+n 3$ & & & & & 0.056 & & & $0 R 0001$ & 167 \\
\hline 34 & 75 & SE23 & $.127+03$ & & & & & 0.056 & & & 090,001 & 168 \\
\hline 34 & 79 & SE 1 & $2.37 E 7$ & 11. & .9 & .7 & 1. & .042 & & & ORPLIB & 211 \\
\hline 30 & 79 & $S \varepsilon$ & $2.375 ?$ & 11. & .04 & .03 & .04 & .042 & & & OR RLLIB & 212 \\
\hline $\begin{array}{l}34 \\
34\end{array}$ & $\begin{array}{l}79 \\
70\end{array}$ & $\begin{array}{ll}\text { SE } & 4 \\
\text { SE } & 8\end{array}$ & $\begin{array}{r}2.3757 \\
2.3757\end{array}$ & 20. & .06 & .05 & .07 & .042 & $04 ?$ & 042 & OPRLLIB & 213 \\
\hline 30 & 70 & $S E 2 \cap$ & 2.3757 & & & & & 0.042 & . Oalc & & $\begin{array}{l}\text { ORPLLIS } \\
\text { ORPOOOI }\end{array}$ & $\begin{array}{l}21 \\
169\end{array}$ \\
\hline 34 & 79 & SEZ1 & 2.3757 & & & & & 0.042 & & & 08001 & 170 \\
\hline $\begin{array}{l}34 \\
34\end{array}$ & $\begin{array}{l}79 \\
79\end{array}$ & $\begin{array}{l}S E 22 \\
\text { SE } 23\end{array}$ & $\begin{array}{l}2.3757 \\
2.3757\end{array}$ & & & & & $\begin{array}{l}0.042 \\
.042\end{array}$ & & & 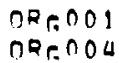 & 171 \\
\hline 35 & 82 & $B_{F} 1$ & $.15 n+01$ & $: 800+01$ & $.10 n+01$ & $.750-00$ & $.100+01$ & $.180+01$ & & & OPRLIR & 210 \\
\hline 35 & 82 & 6R R & & & & & & $.850+00$ & & & ORPLLIR & 217 \\
\hline 35 & 82 & FE2O & $.150+01$ & & & & & 0.85 & & & ORr, 001 & 172 \\
\hline 35 & 82 & HR2I & $.15 n+01$ & & & & & 1.8 & & & ORP, 001 & 173 \\
\hline 35 & 92 & Bम22 & $.150+01$ & & & & & 0.53 & & & $O R=001$ & 174 \\
\hline 35 & 82 & BR23 & $.15 n+01$ & & & & & 0.53 & & & $0 R R_{0} 001$ & 175 \\
\hline 37 & 80 & ER 1 . & $.186+02$ & $450+02$ & $100+n 1$ & $.750=00$ & $.100+01$ & $.700-00$ & & & ORr.LIB & 218 \\
\hline $\begin{array}{l}37 \\
37\end{array}$ & $\begin{array}{l}86 \\
86\end{array}$ & & $\begin{array}{l}186+02 \\
186+0 ?\end{array}$ & $\begin{array}{r}630+02 \\
450+02\end{array}$ & $\left\{\begin{array}{l}500-01 \\
400-0 ?\end{array}\right.$ & $\begin{array}{l}400-01 \\
300-02\end{array}$ & $\begin{array}{r}500-01 \\
400-0 ?\end{array}$ & $\begin{array}{l}.660000 \\
660-000\end{array}$ & & & $\begin{array}{l}O R C L I B \\
O R G L I B\end{array}$ & $\begin{array}{l}219 \\
220\end{array}$ \\
\hline 37 & 80 & RB 8 & & & & & & $.660+00$ & & & OPRLIR & 221 \\
\hline 37 & 86 & RE I U & $.18 b+0 ?$ & $800+02$ & $.450-00$ & $.340=00$ & $.450-00$ & $.700-00$ & & & ORPLIB & 222 \\
\hline 37 & 86 & $R B 17$ & $.18 n+02$ & $.600+0 ?$ & $300-02$ & $.230-02$ & $.300-02$ & $.650-00$ & & & ORGLIR & 223 \\
\hline 37 & 86 & QB? 0 & $.1 A_{n}+n 2$ & & & & & 0.66 & & & ORP, 001 & 176 \\
\hline 37 & $f 6$ & RE21 & $.18 n+12$ & & & & & 0.70 & & & $08 r, 001$ & 177 \\
\hline 37 & 80 & RRZ2 & $.1 a_{0}+0 ?$ & & & & & 0.65 & . & & OR=001 & 178 \\
\hline 37 & 86 & DBC3 & $.180+n ?$ & & & & & 0.65 & & & nProOs & 170 \\
\hline 37 & 87 & ES I & $.18 n+14$ & $0450+02$ & $100+01$ & $.750-00$ & $.100+01$ & $.900-01$ & & & DRELIB & 224 \\
\hline 37 & 87 & 28 & $.18 n+14$ & $1630+12$ & $500-01$ & $.4 \cap 0-01$ & $.5 .00-01$ & $.900=01$ & & & ORCLIB & 225 \\
\hline 37 & 87 & $R E$ & $.1801+14$ & $.45 n+n z$ & $400-\cap 2$ & $.300-02$ & $.400-02$ & $.900-01$ & & & ORr.LIR & 226 \\
\hline 37 & 67 & PR 8 & & & & & & $.900-01$ & & & DRrELIB & 227 \\
\hline 37 & 87 & REIS & $.98 n+! 4$ & $: 800+02$ & $450-100$ & $.300-00$ & $.450-00$ & $.9 \cap 0-01$ & & & ORPLLIB & 228 \\
\hline 37 & 87 & RR 97 & $.180+14$ & $.000+02$ & $30 n=n ?$ & $.230-02$ & $.300-02$ & $.900-01$ & & & ORPILIR & 229 \\
\hline 37 & 47 & $F R 20$ & $.180+10$ & & & & & 0.090 & & & $O R \cap \cap 01$ & 180 \\
\hline 39 & 87 & RA21 & $.18 n+14$ & & & & & 0.090 & & & ORe.001 & 181 \\
\hline 37 & 87 & RA2? & $.1^{a} 0+1^{4}$ & & & & & 0.090 & & & $0 R r, 009$ & 182 \\
\hline 37 & 87 & FR 23 & $.180+14$ & & & & & 0.090 & & & $D R R_{0} 001$ & 183 \\
\hline 30 & 85 & SR I & $.65 n+n ?$ & $130+05$ & $30 n=\cap n$ & $.400=00$ & $100 \div 01$ & $.330-00$ & & & ORPLLIR & 230 \\
\hline 38 & 65 & $S R$ & $.65 n+n 2$ & $.2 A O+05$ & $.900-01$ & $.120+00$ & $.175-00$ & $.910-01$ & & & DPRLLIA & 231 \\
\hline 39 & 95 & $S R \quad A$ & & & & & & $.160+00$ & & & $n R \cap L L I R$ & 232 \\
\hline 39 & 85 & SR2O & $.050+n 2$ & & & & & 0.16 & & & OPCOOI & 184 \\
\hline $3 R$ & 85 & SR? 1 & $.65 n+02$ & & & & & 0.33 & & & $\cap R+001$ & 185 \\
\hline 39 & 85 & SR2? & $.65 n+0 ?$ & & & & & 0.091 & & & $O R F=01$ & 186 \\
\hline $3 a$ & 85 & $5 \times 23$ & $.050+0 ?$ & & & & & 0. & & & DPחOOI & 187 \\
\hline
\end{tabular}




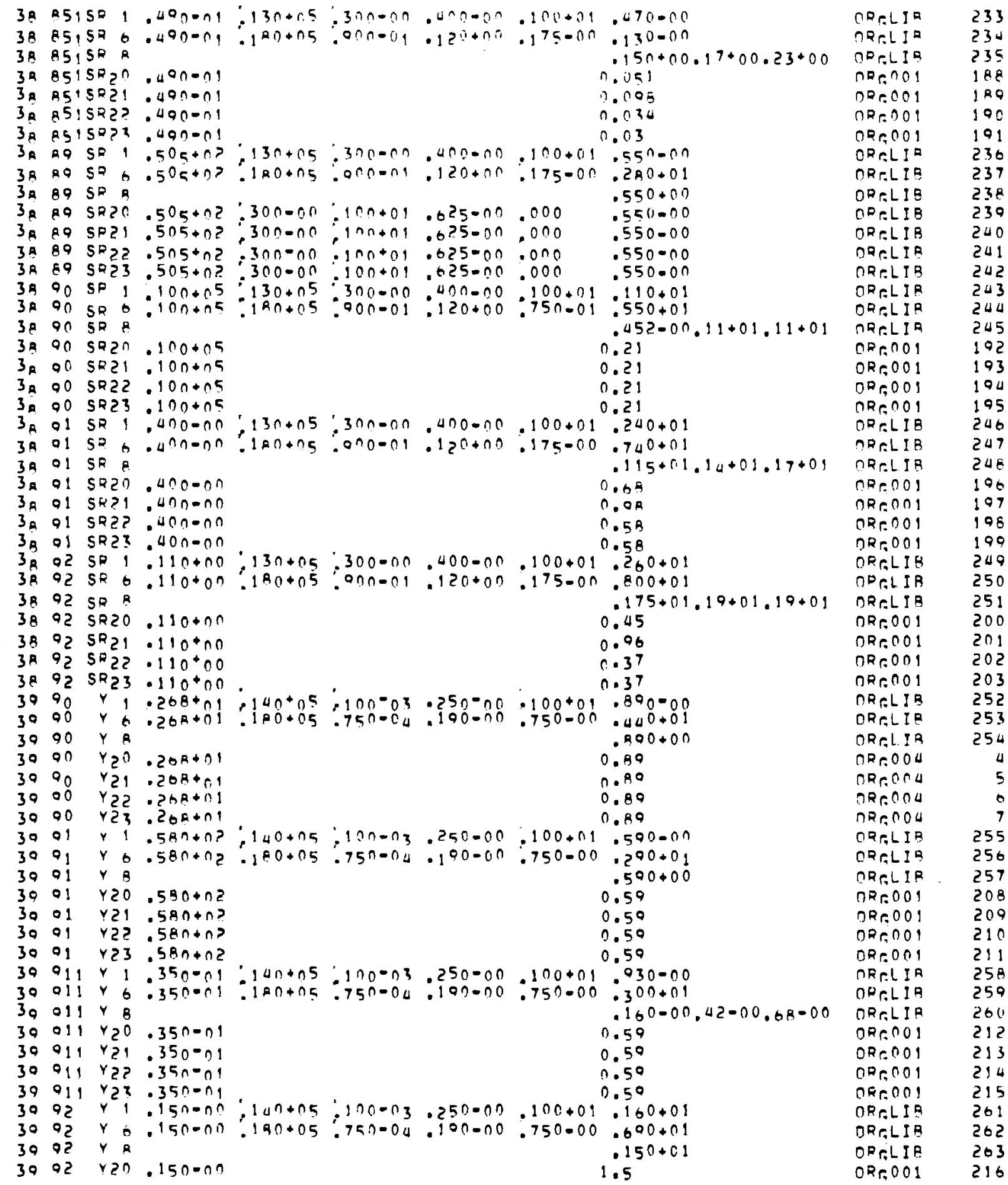




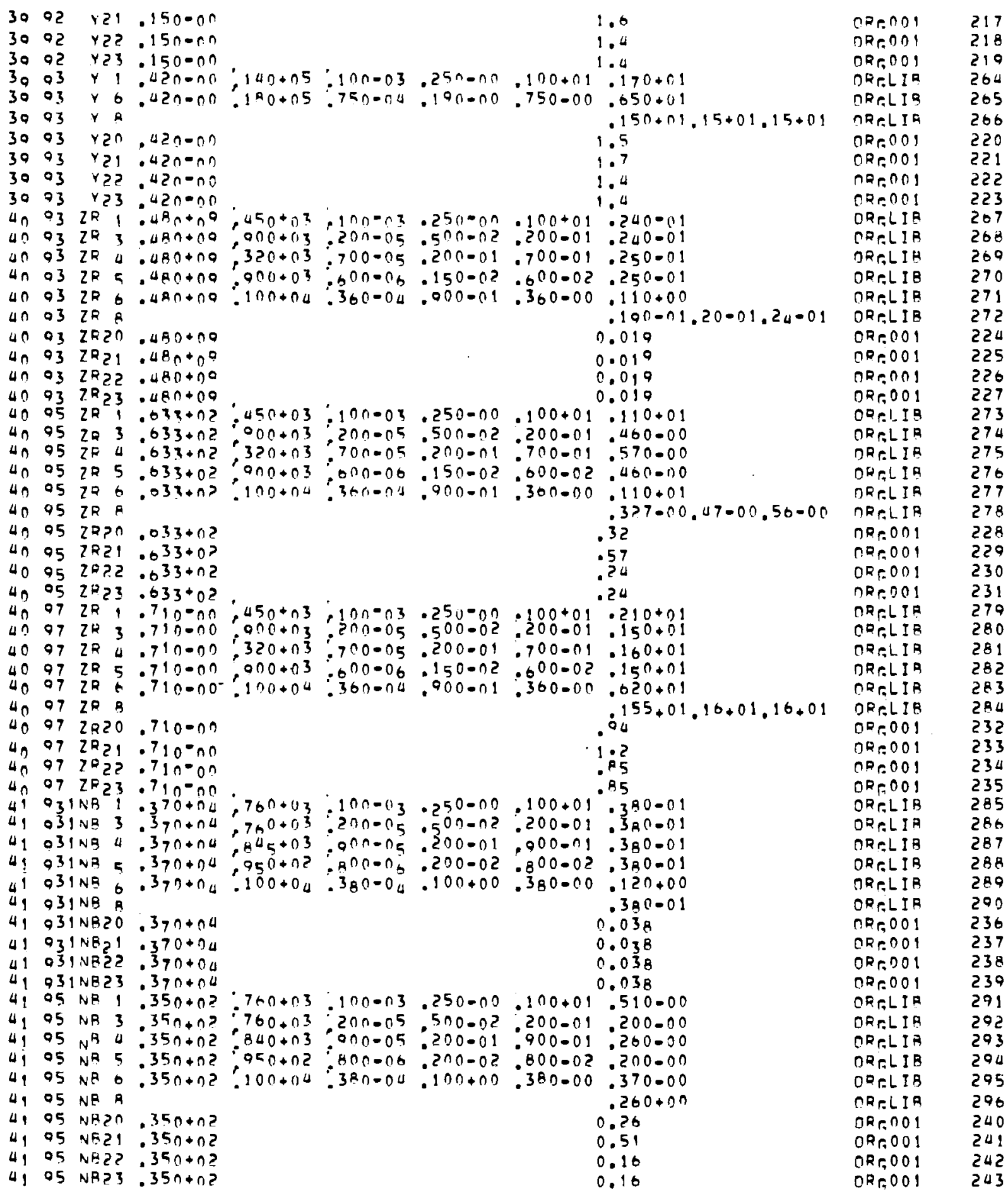




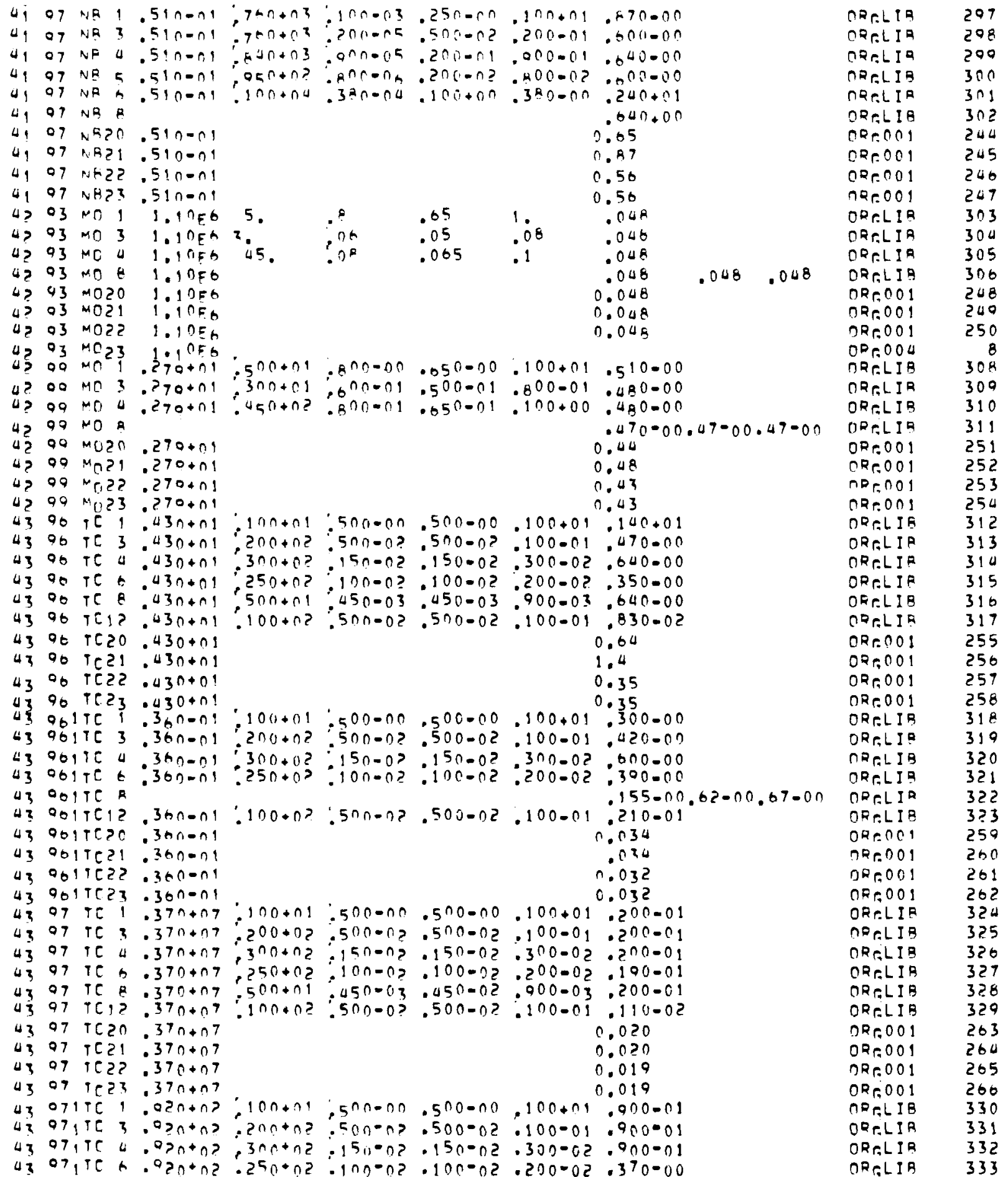









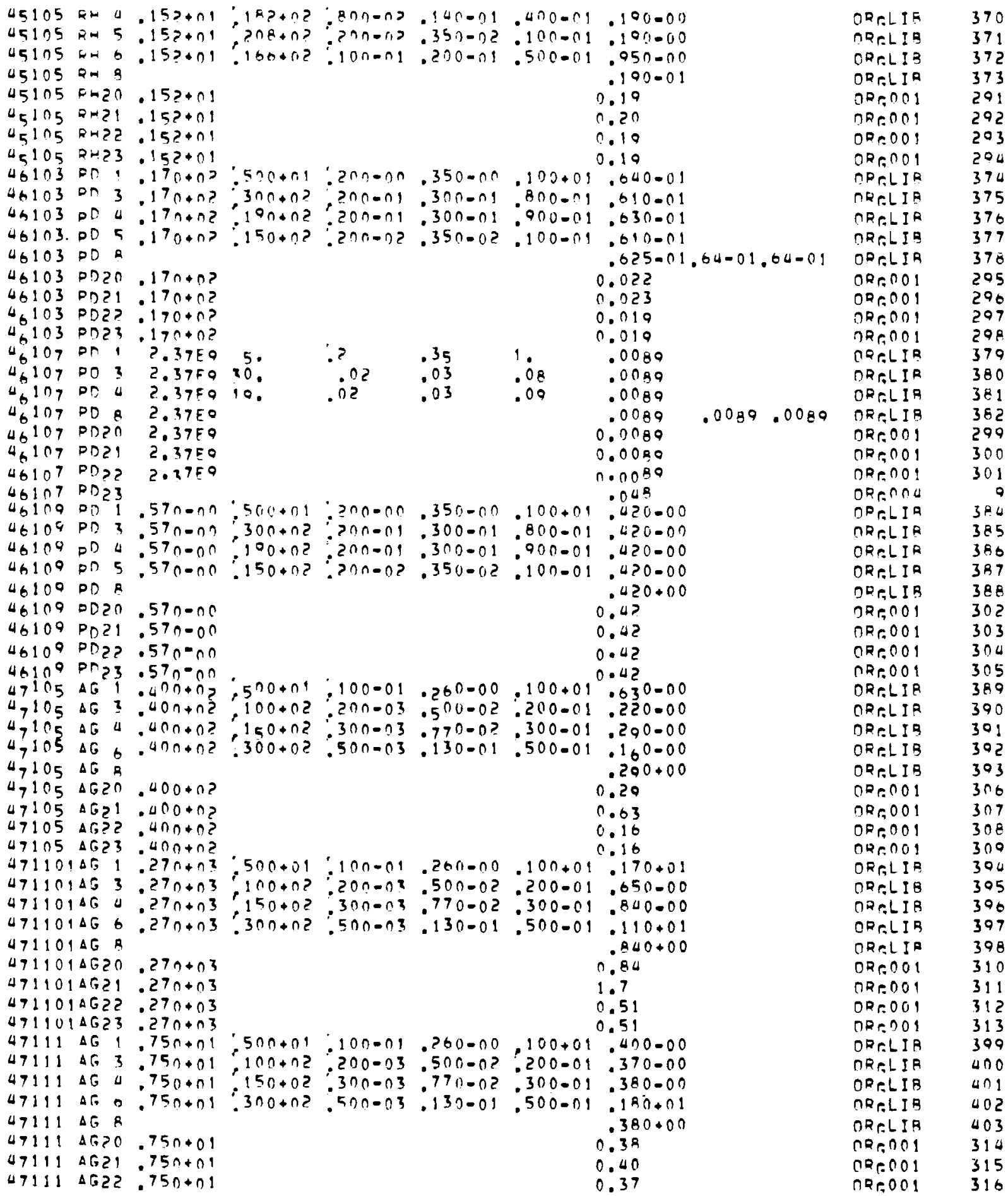




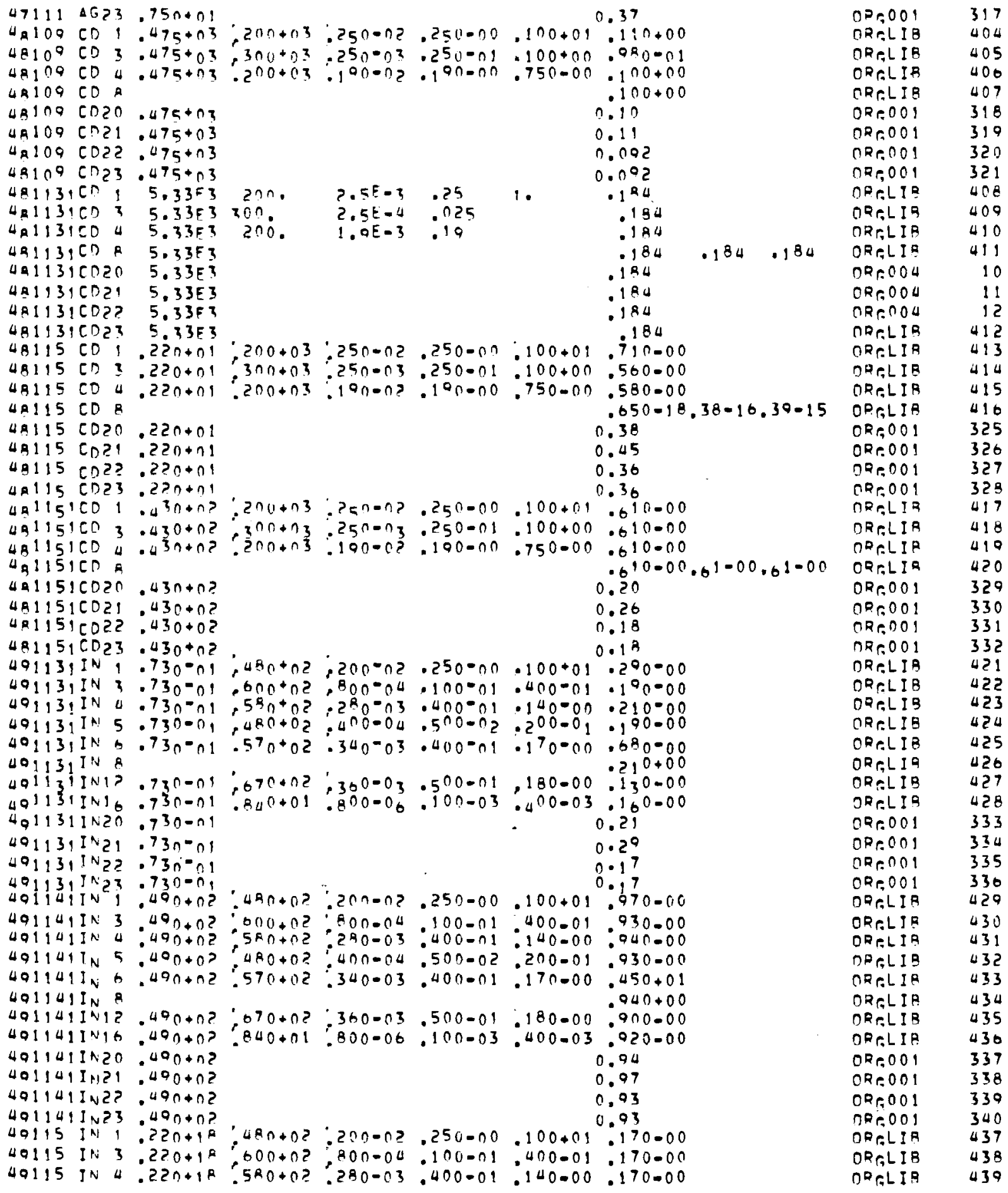




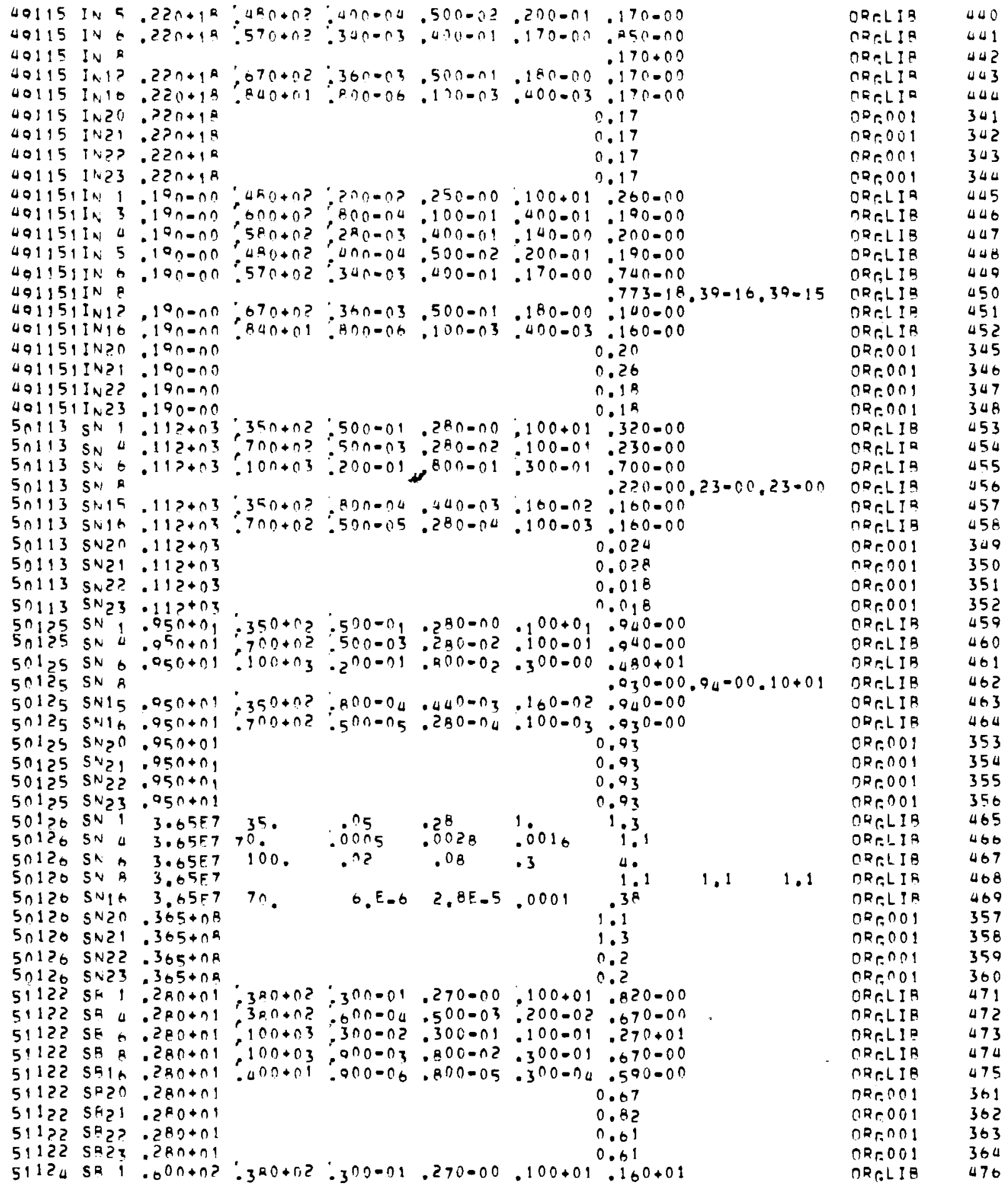




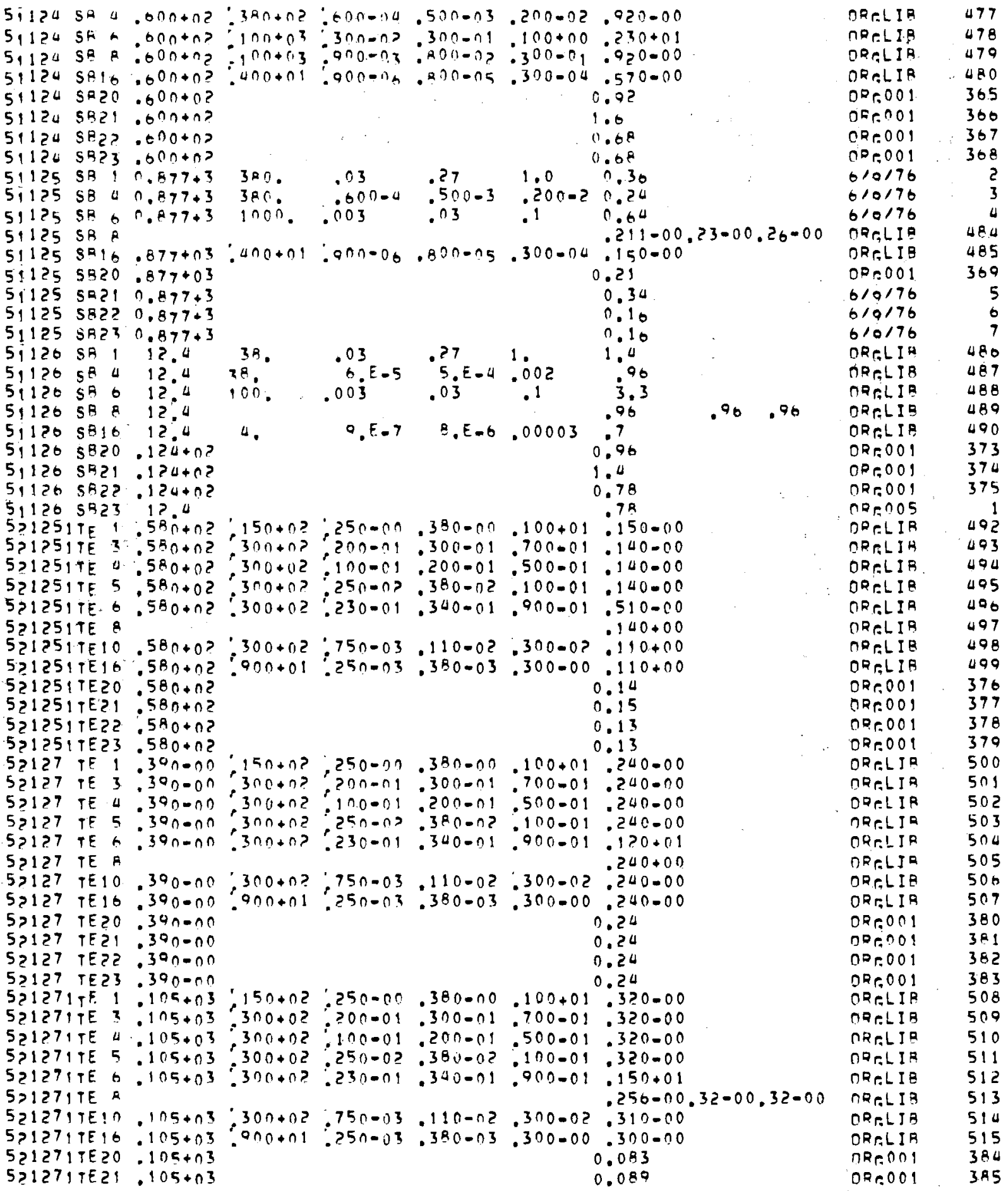




\begin{tabular}{|c|c|c|c|c|c|c|c|c|c|}
\hline & TF & & & & & & & & \\
\hline $\begin{array}{l}0 \\
0 \\
01579\end{array}$ & $\begin{array}{l}\text { TE? } \\
\text { TE }\end{array}$ & $-105+03$ & & & & & 0.070 & ORr.001 & $\begin{array}{l}386 \\
387\end{array}$ \\
\hline $\begin{array}{l}1271 \\
1320\end{array}$ & & $.105+13$ & & & & & 0.076 & CRenol & 387 \\
\hline $\begin{array}{l}1<2 \\
120\end{array}$ & TE 3 & $-5 ! n=0)$ & $-150+n ?$ & $=? 5 n=n n$ & - 3ancon & $.100+01$ & $.920=00$ & ORPLI IB & 516 \\
\hline 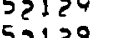 & If 3 & $.510-01$ & $.300+0 ?$ & $.2 n n-01$ & $.3 n 0-01$ & $.700-01$ & $.690=00$ & ORr.LIA & \\
\hline 2129 & TE \& & $.510-01$ & $300+02$ & $.100-04$ & $.200=01$ & $.5 \cap 0-01$ & $.730=00$ & ORr.LIE & 18 \\
\hline 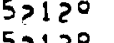 & TE 5 & $.51 n-01$ & $300+02$ & $.25 n-n ?$ & $.390-0 ?$ & $.100-01$ & $.580-00$ & ORPLLIR & 10 \\
\hline 32120 & & & & & & $.900-01$ & $. ? 80+01$ & DQR.LIA & 20 \\
\hline 2129 & TE & & & & & & $.730=00.73-00.73=00$ & ORPLIR & 21 \\
\hline $5>129$ & TE1O & $.5101-n 1$ & $.3 n 0+n 2$ & $.750-03$ & $.110-n 2$ & $.300-02$ & $.600=00$ & ORPLLIA & \\
\hline $5 ? 129$ & TEI6 & $.51 n-n 1$ & $.9 n n+n 1$ & $.25 n=03$ & $.380-03$ & $.300-00$ & $.000-00$ & ORPLLIE & \\
\hline $5 ? 1 ? 9$ & TEZO & $.510=01$ & & & & & 0.73 & 00,009 & 388 \\
\hline 2120 & TEZ1 & $.510-n 1$ & & & & & 0.98 & $0 \pi=n 01$ & 389 \\
\hline 2129 & TEZ? & $.510=01$ & & & & & 0.64 & $0 R+001$ & 390 \\
\hline 2129 & TEट3 & $.590-01$ & & & & & 0.64 & $02-009$ & 391 \\
\hline & & $.330+02$ & $150+02$ & $25 n=00$ & $.390-00$ & $.100+01$ & $.110+01$ & OPRLIR & \\
\hline 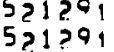 & $\begin{array}{ll}T E & 3 \\
T E & A\end{array}$ & $\begin{array}{l}-33 n+02 \\
330+0 ?\end{array}$ & $\begin{array}{l}-300+0 ? \\
300+02\end{array}$ & $\begin{array}{l}200-01 \\
100=01\end{array}$ & $\begin{array}{l}.300-01 \\
200-01\end{array}$ & $\begin{array}{l}.700-01 \\
500-01\end{array}$ & $\begin{array}{l}-00 \\
-00\end{array}$ & 0 orel IR & $\begin{array}{l}25 \\
26\end{array}$ \\
\hline 21291 & TE 5 & $.33 n+02$ & $300+02$ & $250-02$ & $.380-02$ & $.100-01$ & $.790-00$ & Oeritis & 27 \\
\hline 1299 & TE & $.33 n+02$ & .300 & .23 & .34 & $.900-01$ & $.3 ? 0+01$ & ORTIJB & 528 \\
\hline 299 & TE P & & & & & & $.795-00.93-00.83=00$ & ORCLIA & 529 \\
\hline $\begin{array}{l}21 ? 01 \\
21 ? 01\end{array}$ & $\begin{array}{l}T E: O \\
T E: 6\end{array}$ & $\begin{array}{l}33 n+n 2 \\
33 n+n ?\end{array}$ & $: \begin{array}{l}300+0 ? \\
900+01\end{array}$ & $\begin{array}{l}750=03 \\
250-03\end{array}$ & $\begin{array}{l}11 n=0 ? \\
3 R n=03\end{array}$ & $\begin{array}{r}300-02 \\
300=00\end{array}$ & $\begin{array}{l}.690-00 \\
680=00\end{array}$ & ORCLIA & $\begin{array}{l}530 \\
531\end{array}$ \\
\hline 21209 & TF.?O & $.33 n+n 2$ & & & & & 0.10 & ORT:001 & 392 \\
\hline 129 & TEZT & $.33 n+n ?$ & & & & & 0.11 & $O R=001$ & 303 \\
\hline$>1 \geq 91$ & TE?? & $.33 n+n ?$ & & & & & 0.093 & $n=0.001$ & 394 \\
\hline $5 ? 1 ? 91$ & TE23 & $.330+0 ?$ & & & & & 0.003 & $0 R+001$ & 305 \\
\hline $5>1311$ & TE 1 & $.1 \geq 5+01$ & $15 n+n ?$ & $.250-00$ & $.380-0 n$ & $.100+01$ & $.160+01$ & ORTLLIR & 532 \\
\hline 1311 & TE & $129+n 1$ & $300+n>$ & $=0 !$ & -01 & .700 & A 1 & OQPLIR & 533 \\
\hline $5 \geq 1311$ & TE & $.125+01$ & $300+0 ?$ & $100-01$ & $.200-01$ & $.500-01$ & $.970-00$ & ORPLII & 534 \\
\hline 521311 & $T E$ & $.12 .5+n 1$ & $.300+02$ & $250-0 ?$ & -02 & .100 .01 & .800 & DRFLIR & 535 \\
\hline $5 \geq 1311$ & & $.125+01$ & $.300+02$ & 230.01 & $.340-01$ & $.900-01$ & $.260+01$ & ORPLIE & 36 \\
\hline $5>1311$ & TE $B$ & & & & & & $.763-00.00-00.10+01$ & ORr:LIB & 537 \\
\hline $52 ! 3 ! 1$ & TE 16 & $.125+01$ & $: 900+01$ & $.250=03$ & $.380-03$ & $.300-00$ & .690 .00 & ORFLIR & 538 \\
\hline 521 & & $.125+01$ & & & & & 0.73 & ORr. 001 & 396 \\
\hline ? & $\begin{array}{ll}\text { TE } \\
\text { TE? }\end{array}$ & $.125+n 1$ & & & & & 1.2 & 006001 & $\begin{array}{l}397 \\
309\end{array}$ \\
\hline $5 ? 1311$ & TEZ3 & $\begin{array}{l}125+01 \\
125+n 1\end{array}$ & & & & & 0.35 & $0 R=001$ & 300 \\
\hline $5>132$ & TE ! & $320+01$ & $: 150+02$ & $\therefore 250-00$ & .350 & .100 & $.190+01$ & ORTLLIE & 530 \\
\hline 52132 & TE 3 & $.320+n 1$ & $300+02$ & $200-01$ & -01 & .700 & .06 & ORPLLIB & 540 \\
\hline $5>132$ & TE & $.320+01$ & $300+0 ?$ & $100-01$ & $.200-01$ & .500 & $110+01$ & CRRLIIR & 541 \\
\hline 52132 & TE & $.320+01$ & $3 n n+n 2$ & $.250-02$ & -02 & .10 & -00 & ORr LIB & 542 \\
\hline 132 & $T F$ & $.320+n !$ & .300 .02 & -01 & $-\cap 1$ & .01 & $.310+01$ & ORCLIR & 543 \\
\hline 52132 & TE $R$ & & & & & & .104 .01$. & $\partial R \cap L I R$ & $5 \Delta 4$ \\
\hline 52132 & $T E 10$ & $.320+n 1$ & $300+02$ & $.750-03$ & $.110=02$ & $.300-02$ & & ODPLI IB & 545 \\
\hline 52132 & TEIT & $.320+01$ & $: 900+01$ & $.25 n-03$ & $=03$ & .300 .00 & $.100-00$ & ORr:LIB & 540 \\
\hline 5?13? & $T E ? \cap$ & $.125+01$ & & & & & 0.13 & ORgO01 & 400 \\
\hline $5>132$ & TEZI & $.125+01$ & & & & & 0.21 & $02 r, 001$ & $\Delta 01$ \\
\hline $5>132$ & $T E \geq ?$ & $.125+n 1$ & & & & & 0.10 & ORTDOOI & $\triangle 02$ \\
\hline $5>132$ & $T E 23$ & $.125+01$ & & & & & 0.10 & 020.009 & 403 \\
\hline 53125 & $I$ & 00.2 & $.135+03$ & 1. & .75 & 1. & .053 & $I 1>5$ & \\
\hline 53125 & 18 & & & & & & .02 & $11>5$ & \\
\hline 5312.5 & I 16 & $60 . ?$ & $.130+03$ & .3 & .23 & .3 & .024 & $11>5$ & 3 \\
\hline 53125 & I 20 & on. 2 & & & & & .031 & 1155 & \\
\hline 53125 & I> & $b^{n} \cdot ?$ & & & & & .034 & $\div 1>5$ & \\
\hline 25 & 327 & Ho.? & & & & & .027 & $11 \geq 5$ & \\
\hline & 123 & $a^{n} \cdot 2$ & & & & & & $11>5$ & \\
\hline & 11 & $.133+02$ & $.13 a+03$ & $.100+$ & $.750-$ & .100 & $.230=00$ & ORELIB & 547 \\
\hline 53126 & If & & & & & & $.180+01$ & $O R r_{T} L I R$ & 548 \\
\hline 20 & 110 & $.133+02$ & $.1^{2} A+03$ & $.300=00$ & $.230=00$ & $.300-00$ & $1.160-00$ & ORPLIIR & 549 \\
\hline & $12 n$ & $.133+02$ & & & & & 0.18 & $O R \& 001$ & 404 \\
\hline
\end{tabular}




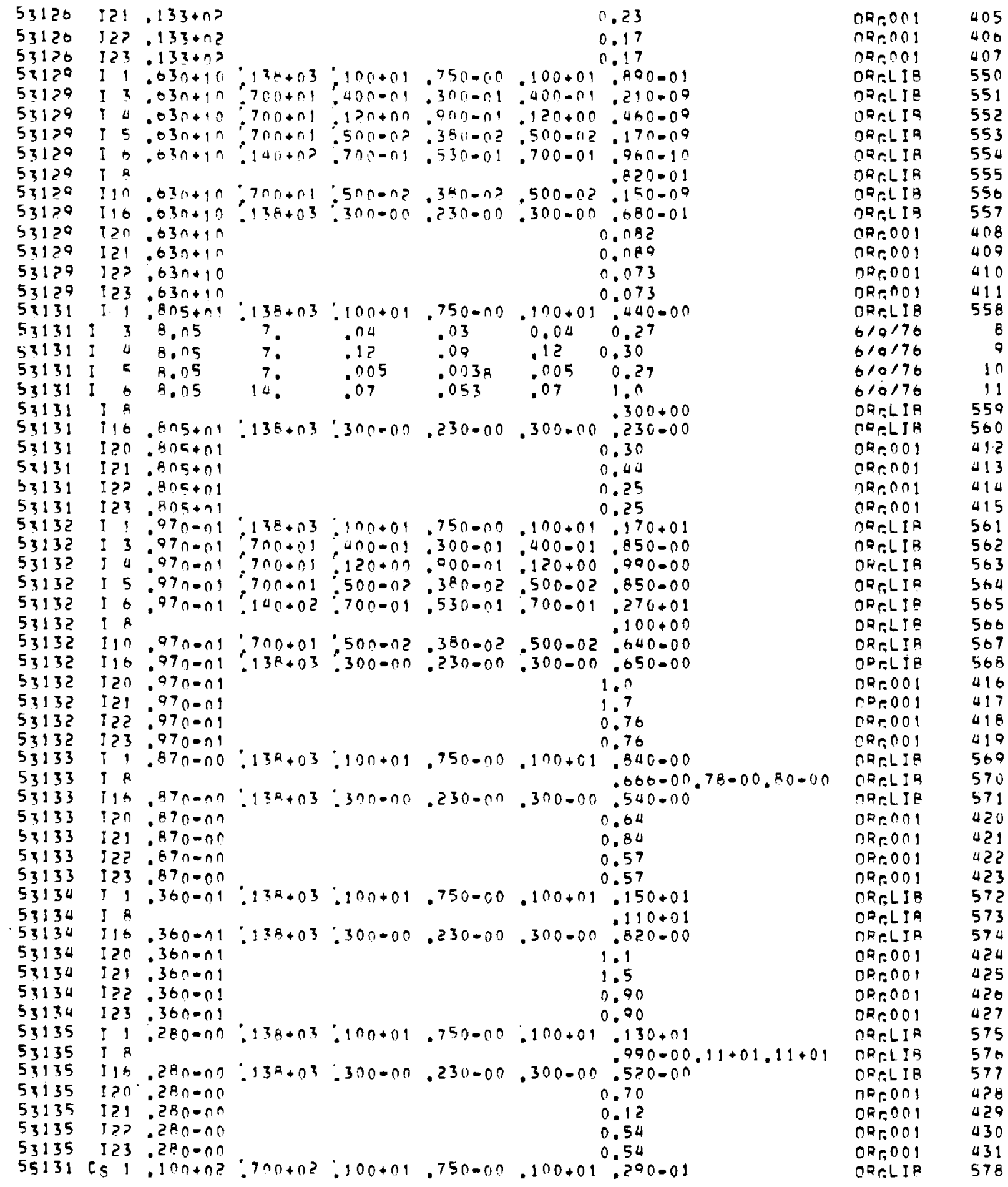




\begin{tabular}{|c|c|c|c|c|c|c|c|c|c|c|}
\hline 55131 & cs & $\underline{x}$ & $.10 n+n>$ & $420+0 ?$ & $.9 n n=01$ & $.750-0 ?$ & $.100-09$ & $.210-01$ & OQTELIR & 570 \\
\hline 55131 & cs & 4 & $.10 n+n ?$ & $a n n+n ?$ & $.7 n 0-11$ & $.50 n-n !$ & $.700-01$ & $.200-21$ & OPRLIIA & 580 \\
\hline $5513 !$ & cs & 5 & $.1 n n+n ?$ & OAOCOR? & $-5 \cap 0-\cap ?$ & $.390-02$ & $.500-0 ?$ & $.2\{0-1\}$ & ORr.LIR & 581 \\
\hline 55131 & cs & 6 & $.1 n n+n ?$ & $2120+03$ & $.400-01$ & $.300-01$ & . $\Delta \cap n=01$ & $.1>0-01$ & OROLIR & 582 \\
\hline 55131 & cs & ga & $.10 n+n ?$ & $140+\cap 3$ & $300-113$ & $.23 n-n ?$ & $.30 r_{1}=02$ & $.200-01$ & OPRLIR & 583 \\
\hline 5131 & CS: & & $.1 n n+0 ?$ & $.140+03$ & $\cdot a^{n} \cap 0, n n$ & $.300-00$ & $.200-00$ & $.200=01$ & ORYLIR & 584 \\
\hline 5131 & $\csc$ & & $.10 n+n z$ & & & & & $n . n>d$ & openos & 432 \\
\hline 5131 & C5? & & $.10 n+n 2$ & & & & & 0.029 & $O R$ r. 001 & 433 \\
\hline 55131 & $c \leq 2$ & & $.10 n+02$ & & & & & 0.017 & $O R r 001$ & 434 \\
\hline $\begin{array}{l}55131 \\
55134\end{array}$ & $\begin{array}{l}\mathrm{CS} 2 \\
\mathrm{cs}\end{array}$ & $\begin{array}{l}3 \\
1\end{array}$ & $\begin{array}{l}10 n+n 2 \\
00 n+n 3\end{array}$ & $700+0 ?$ & $\ln 0+01$ & $75 n=00$ & $100+01$ & 0.017 & OPROO I & $\begin{array}{r}435 \\
585\end{array}$ \\
\hline 55134 & CS & $z$ & $.84 n+03$ & $4 \geq 0+0 ?$ & $100-1$ & $.750-02$ & $100-01$ & $.400-00$ & ORPLIA & 586 \\
\hline 55134 & cs & 4 & $\therefore \Delta 0+\cap 3$ & $\because n 0+n ?$ & $700-01$ & $.500-01$ & $.700-01$ & $.570=00$ & OPRLLI & 587 \\
\hline 55134 & cs & 5 & $.840+n^{2}$ & $Q A D_{0}+n ?$ & $500-0 ?$ & $.380-02$ & $.500-02$ & $.460=00$ & ORRLLIB & 586 \\
\hline 55134 & cs & 6 & $.84 n+03$ & $1 \Delta 0+03$ & $400-01$ & $.300-01$ & $.400-01$ & .000000 & ORFLIB & 580 \\
\hline $\begin{array}{l}55134 \\
55134\end{array}$ & & & $\begin{array}{l}84 n+03 \\
844 n+n\}\end{array}$ & $\left\{\begin{array}{l}40+03 \\
140+03\end{array}\right.$ & $\begin{array}{l}3 \cap n-n ? \\
4 n 0=0 n\end{array}$ & $\begin{array}{l}230-02 \\
300-00\end{array}$ & $\begin{array}{l}300=02 \\
400=00\end{array}$ & $\begin{array}{l}570=00 \\
.110+01\end{array}$ & $\begin{array}{l}\text { ORELIS } \\
\text { ORELIIS }\end{array}$ & $\begin{array}{l}590 \\
591\end{array}$ \\
\hline 55130 & CS? & & $.940+03$ & & & & & 0.57 & $O R C 001$ & 436 \\
\hline $55 ! 34$ & CSE & & $.84 n+03$ & & & & & 1.1 & $O R+001$ & 437 \\
\hline 30 & $\mathrm{CS}$ & & $.500+0 ?$ & & & & & $10.3^{2}$ & OPROOOI & 438 \\
\hline 34 & 252 & & $.84 n+03$ & & & & & 0.38 & OREO 001 & 439 \\
\hline 5 & Cs & 1 & $.13 n=0 n$ & $-70(1+0 ?$ & $.100+01$ & $.750-00$ & $.100+01$ & $.100-00$ & OFrLIB & $50 ?$ \\
\hline $\begin{array}{l}301 \\
301\end{array}$ & C5 & 3 & $-13 n=0 n$ & $\therefore 430+0 ?$ & $=100=01$ & $-750-0 ?$ & $100-09$ & $-110+00$ & ORR.LI I & 503 \\
\hline 349 & & 5 & & - ORO+ne & $i 500=01$ & & $.700=09$ & $.150-00$ & $\cap R r, L$ IR & 594 \\
\hline 41 & Cs & 6 & & $.140+03$ & $\because$ & $\begin{array}{l}300-02 \\
300-01\end{array}$ & $\begin{array}{r}500-0 ? \\
400-01\end{array}$ & $\begin{array}{l}130=00 \\
400=00\end{array}$ & CRerLIT & $\begin{array}{l}505 \\
590\end{array}$ \\
\hline 51331 & $\mathrm{cs}$ & R & & & & & & $.927-01.12+00.30-00$ & DRFLIH & 597 \\
\hline & & & $.130-00$ & $.14 n+03$ & $.400-00$ & $.300-10$ & $.400-00$ & $.200-00$ & OPCLIR & 508 \\
\hline 349 & CS & & $.13 n=00$ & & & & & 0.092 & ORroOOI & 440 \\
\hline & cs & & $.130=0 n$ & & & & & 0.011 & OR & 449 \\
\hline 341 & $c^{52}$ & & $.130=00$ & & & & & 0.093 & $O R \cap \cap 01$ & $\triangle 42$ \\
\hline 51341 & $\mathrm{CS}_{2}$ & & $\cdot 130=0 n$ & & & & & $0 \cdot 0.3$ & ORP.0OS & 443 \\
\hline & Cs & 1 & $-1 \ln n+10$ & $.700+112$ & $100+09$ & $.750-00$ & $=100+01$ & $.060-01$ & ORPLIR & 500 \\
\hline 35 & Cs & 3 & $.110+i 0$ & $42^{0+0} ?$ & $: 100-01$ & $.750-02$ & $.100-01$ & .660 .01 & ORPLLIR & 600 \\
\hline 35 & $\operatorname{cs}$ & 4 & $.110+10$ & $000+0 ?$ & $.7 n n=01$ & $.5^{00-01}$ & $.7^{n 0-0} 01$ & $.060-01$ & ORPLIR & 601 \\
\hline & Cs & 5 & $.110+10$ & $.020+02$ & $.500=0 ?$ & $.380-02$ & $.500-02$ & .060 .01 & CReLIB & 602 \\
\hline & CS & 6 & $.1 \ln +10$ & $140+n 3$ & $400-01$ & $.300-01$ & $.400-01$ & $.330-00$ & OPrLIIS & 003 \\
\hline $\begin{array}{l}55135 \\
55135\end{array}$ & & & $\begin{array}{l}110+10 \\
.110+10\end{array}$ & $: \begin{array}{l}140+n^{3} \\
140+03\end{array}$ & $\begin{array}{l}300=0 ? \\
400=00\end{array}$ & $\begin{array}{l}230=02 \\
300=00\end{array}$ & $\begin{array}{l}300-02 \\
400=00\end{array}$ & $\begin{array}{l}.660-01 \\
.660-01\end{array}$ & $\begin{array}{l}\text { ORPLIIR } \\
\text { ORTLIIB }\end{array}$ & $\begin{array}{l}604 \\
605\end{array}$ \\
\hline & $\csc$ & & $11 n+1 n$ & & & & & 0.060 & 020,001 & $\Delta \Delta \Delta$ \\
\hline 5135 & Cs? & & $.11 n+10$ & & & & & 0.060 & $\cap 2,001$ & 445 \\
\hline 5135 & Cs? & 2 & $.110+10$ & & & & & 0.060 & $0 R, 001$ & $\Delta \Delta t$ \\
\hline & $\csc$ & & $.110+10$ & & & & & 0.060 & OPro001 & 447 \\
\hline & CS & 1 & $.13 n+n ?$ & $700+12$ & $10 n+01$ & $.750-00$ & $.100+01$ & $.650-00$ & OPRLIR & 606 \\
\hline & CS & 3 & $.13 n+n ?$ & $.42 n+n 2$ & $=100-n 1$ & $.750-0 ?$ & $.100-01$ & $.200-00$ & ORPLLIA & 607 \\
\hline & cs & 4 & $.130+0 ?$ & $900+n 2$ & $: 7 n 0-n 1$ & $.500-01$ & $.700-01$ & $.350-00$ & ORRLLIA & 608 \\
\hline & C5 & 5 & $-13 n+n 2$ & $=920+n 2$ & $=5^{0} 0=0 ?$ & $.320-02$ & $.500-0 ?$ & $.290=00$ & ORRLLIB & 600 \\
\hline & cs & h & $.13 n+n 2$ & $.140+03$ & $40 n=01$ & $.300-01$ & $.400-01$ & $.720-00$ & ORTLLIB & 610 \\
\hline 55130 & CS & 8 & $.130+n 2$ & $140+03$ & $300-0 ?$ & $.230-02$ & $.300-02$ & $.350=00$ & ORCLI I & 611 \\
\hline & CS & & $.130+0 ?$ & $.140+03$ & $.400-00$ & $.300=00$ & $. \triangle 00-00$ & $.650-00$ & DRPLIIR & 012 \\
\hline & $\csc$ & & $.13 n+n 2$ & & & & & 0.35 & ORFOOI & 448 \\
\hline & $C \leqq 2$ & & $.13 n+0 ?$ & & & & & 0.65 & QPFO 001 & $4 \Delta 9$ \\
\hline & C 52 & 2 & $.130+n ?$ & & & & & 0.24 & ORP 001 & 450 \\
\hline & $\operatorname{cs}$ ? & & $.130+12$ & & & & & 0.24 & ORחOח & $45 !$ \\
\hline & Cs & 1 & $.11 n+n 5$ & $7 n 0+n ?$ & $10 n+01$ & $.750=00$ & $.100+01$ & $.500=00$ & CRPLIR & 613 \\
\hline 37 & Cs & 3 & $.11 n+n 5$ & $u ? 0+n ?$ & $.100-01$ & $.750-02$ & $.100-01$ & $.370-00$ & ORr,LIR & 014 \\
\hline & cs & 4 & $.11 n+05$ & $900+n 2$ & $700-\cap 1$ & $.500-01$ & $.700=01$ & $.490-00$ & ORTLLIA & 615 \\
\hline & Cs & 5 & $.11 n+05$ & $980+n ?$ & $.500-0 ?$ & $.380-0 ?$ & $.500-0 ?$ & $.370-00$ & ORELIA & 016 \\
\hline 5137 & Cs & 6 & $.110+05$ & $.140+n 3$ & $.4 n \cap-n 1$ & $.300=01$ & $.400-09$ & $.140+01$ & ORPLIA & 097 \\
\hline 137 & $C 5$ & R & $.11 n+05$ & $.140+03$ & $.300-02$ & $.230-02$ & $.300-02$ & .410 .00 & $O R=L I B$ & 618 \\
\hline
\end{tabular}




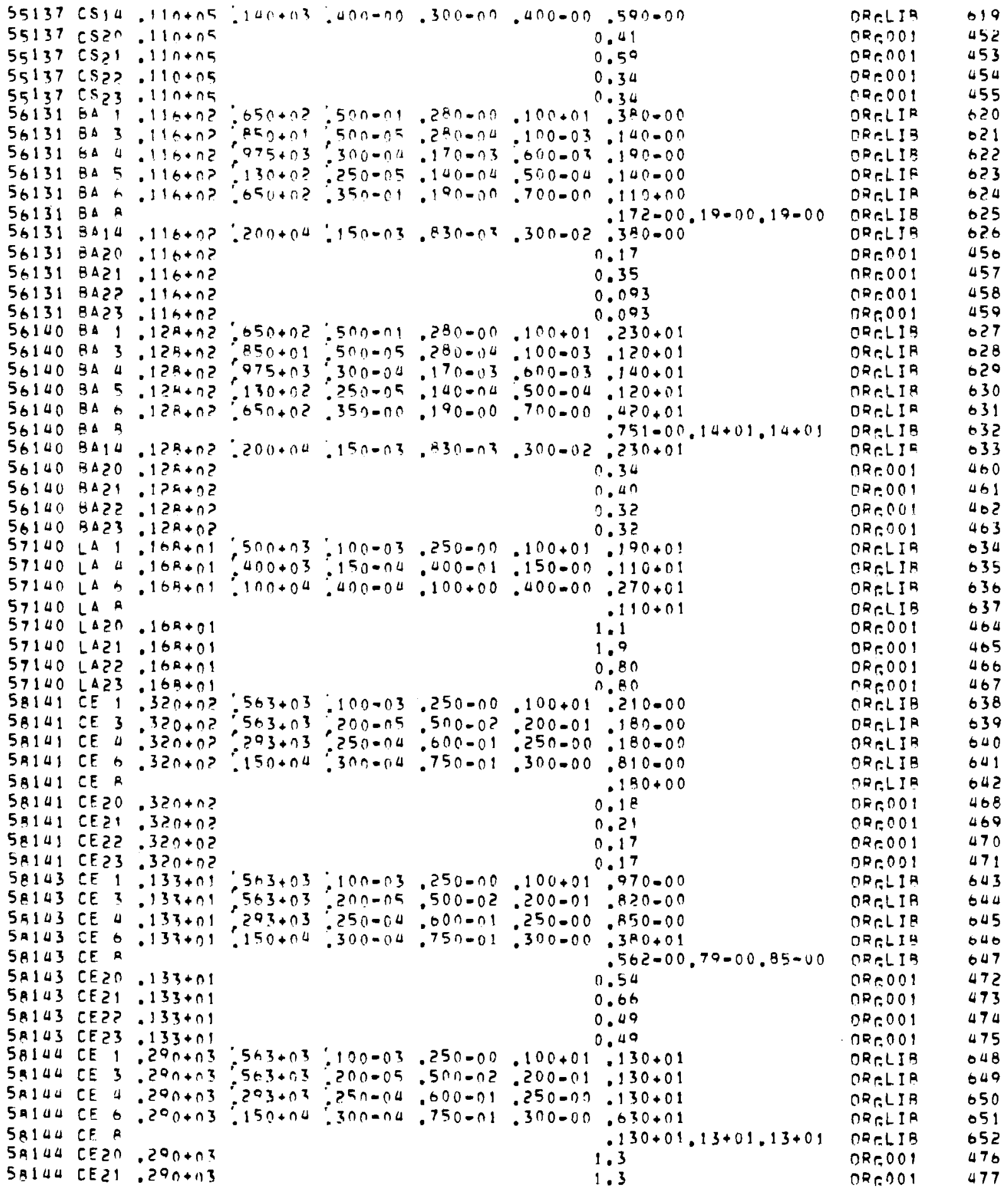




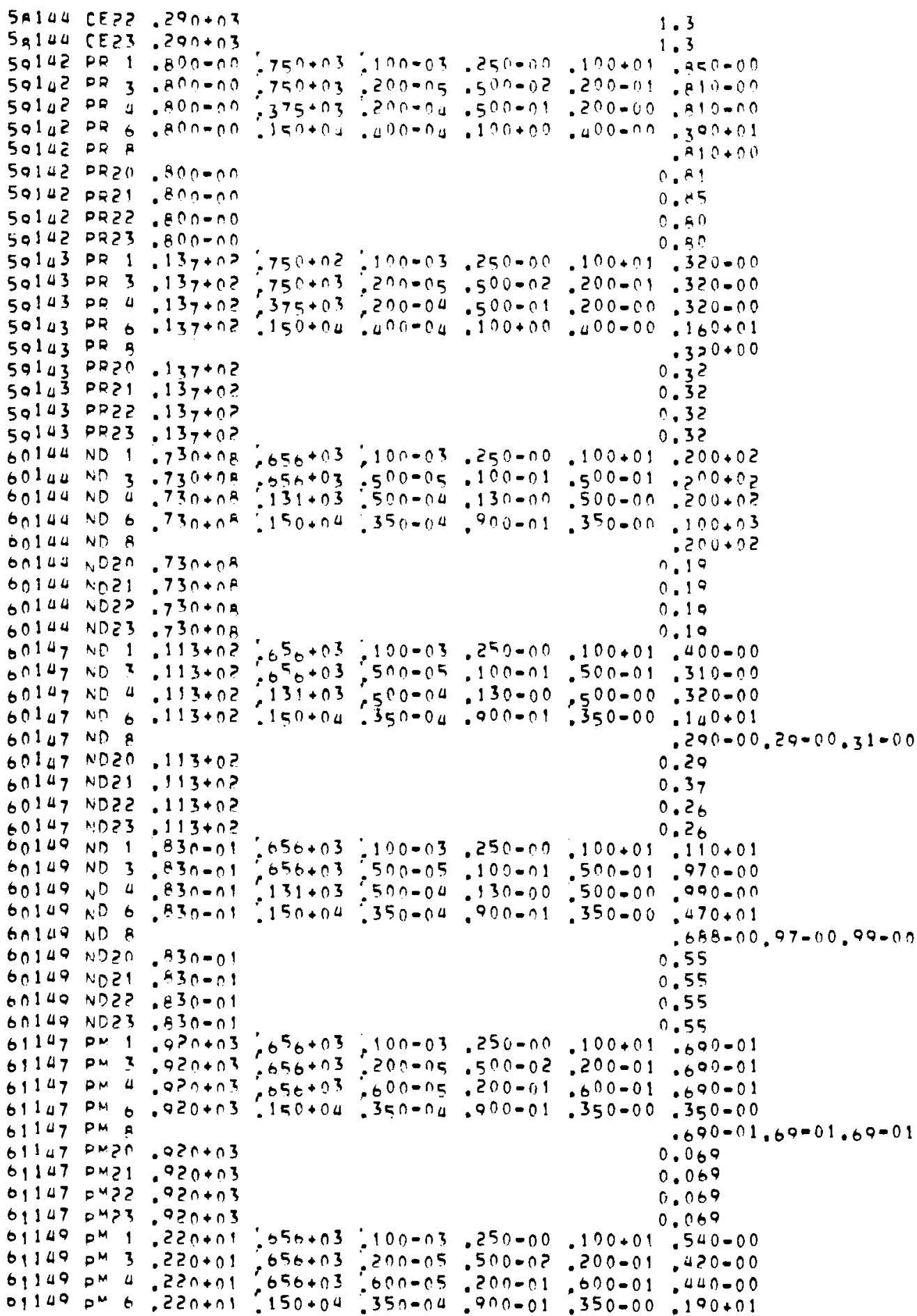

ORroOO!

ORrOOI

ORPLIR

MPR.LIA

OPRLIB

OPrLI I

ORELIA

OProO 01

ORroO

oReons

ORP 001

ORRLIB

ORrLLIE

ORPL I I

OFCLIS

ORPLIA

OP.001

$0 R$ r. 001

QRe.001

OR $=001$

ORPLIR

ORr.LIA

MPrLI I

ORPLIA

orrith

oronol

ORroO

$O R=001$

CRenOI

CRrLII

ORPLIS

ORrLLIB

OPr.LIB

DReLI I

ORr.00!

ORr.001

ORron

ORr.001

ORrLLIP

ORCLIA

OPR.LIR

ORRLIS

ORELIS

ORroO

DRe, 001

OR $=001$

ORFOOI

ORTLIR

OORLIA

ORRLIB

ORPLIR

oretis

ORFOOI

ORroO 01

OProol

TREOOI

ORRLIB

ORPLIA

ORPLIB

ORCLIB
478

470

653

050

055

650

057

480

पन 1

पहर

483

658

659

600

$06 !$

bot

पB口

485

$\triangle 86$

487

063

064

065

066

667

498

480

400

401

668

669

670

071

072

492

493

404

495

673

674

675

076

677

490

407

408

499

678

679

680

OB 1

682

500

501

502

503

683

O84

685

686 


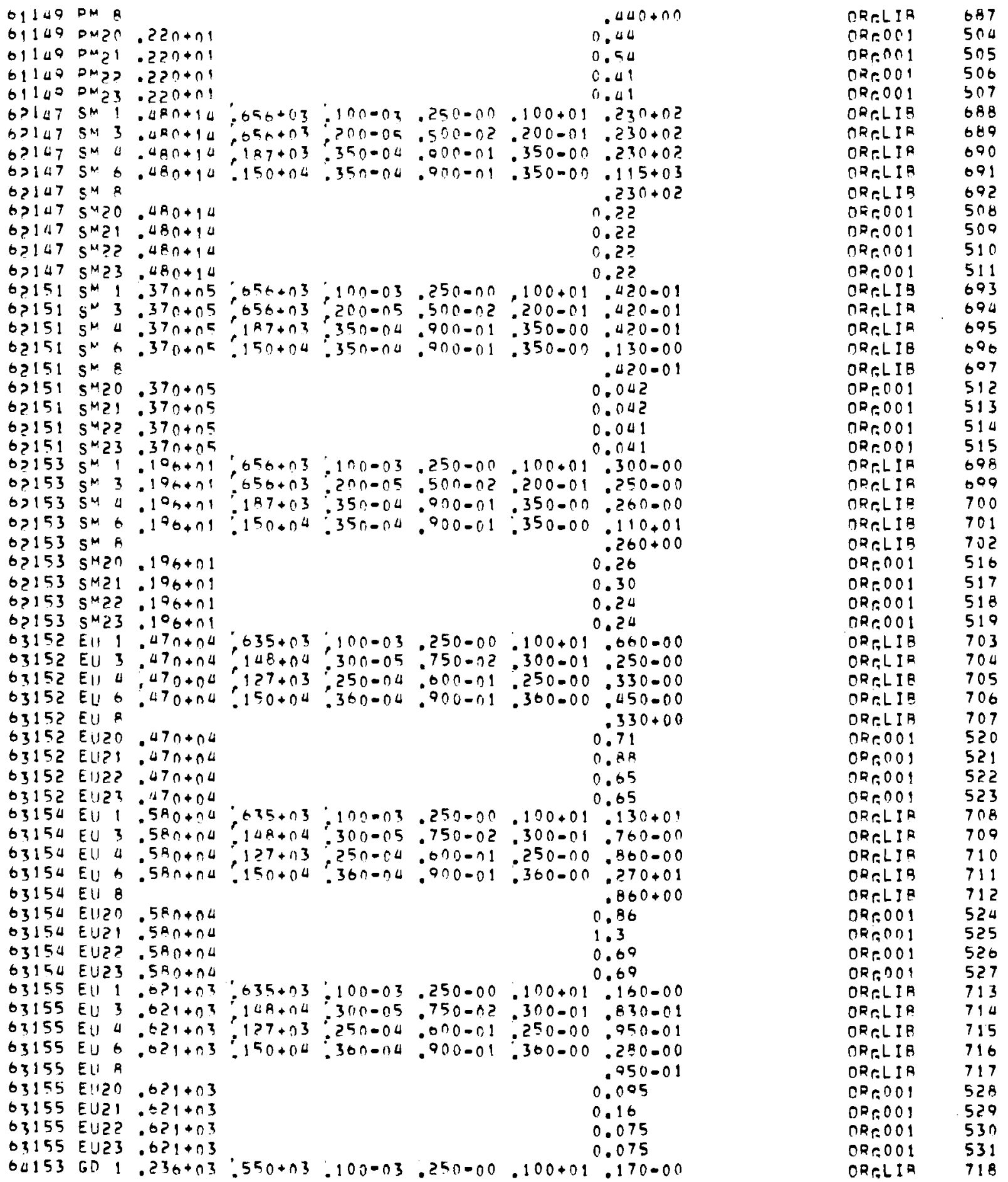




\begin{tabular}{|c|c|c|c|c|c|c|c|c|c|c|c|}
\hline $\begin{array}{l}64153 \\
h \triangle 153\end{array}$ & 60 & 4 & $.236+03$ & $: 460+03$ & $: 12 n=00$ & - $300-01$ & $-120+00$ & $.000-01$ & & ORr.LIP & 710 \\
\hline $\begin{array}{l}64153 \\
64153\end{array}$ & $\begin{array}{l}\text { GD } \\
\text { GD }\end{array}$ & $\frac{6}{8}$ & $.23 t+n 3$ & $.10 n+04$ & $.450 \cdot 04$ & $.110+00$ & $.450-0 n$ & $\begin{array}{l}.230-00 \\
.000-01\end{array}$ & & $\begin{array}{l}\text { ORPLLIA } \\
\text { ORRLISE }\end{array}$ & $\begin{array}{l}720 \\
721\end{array}$ \\
\hline 60151 & GD2 & & $.23 n+n 3$ & & & & & 0.000 & & ORr.00I & 532 \\
\hline 60153 & 602 & & $.236+03$ & & & & & 0.17 & & $n R_{r} 001$ & 533 \\
\hline 0153 & 602 & & $.236+13$ & & & & & 0.072 & & nor,nol & 534 \\
\hline 60153 & $\ln 5$ & & $.23 n+n 3$ & & & & & $0.07 ?$ & & DRe. 001 & 535 \\
\hline $415^{\circ}$ & GD & 1 & $.750=00$ & $550+113$ & $\cdot 1^{n \cap 0}=3$ & $.250-00$ & $-100+0_{1}$ & $.300-00$ & & nRRLI IR & 722 \\
\hline 159 & & 4 & $.750-00$ & $.460+n 3$ & $i>n=0 u$ & $.300-01$ & $.120+00$ & .330 .00 & & ORRLLIE & 723 \\
\hline $15^{\circ}$ & GD & b & $.750=00$ & $.100+n$ & $.450-n a$ & $.110+00$ & .050 .00 & .750 .00 & & DPrLIR & 724 \\
\hline 4150 & 60 & A & & & & & & $.330+00$ & & OPR.LIR & 725 \\
\hline $\begin{array}{l}159 \\
159\end{array}$ & $\begin{array}{l}6 D 2 \\
60 ?\end{array}$ & & $\begin{array}{r}750=00 \\
750=00\end{array}$ & & & & & 0.33 & & 080.001 & $\begin{array}{l}536 \\
537\end{array}$ \\
\hline 0159 & 602 & & $.750-00$ & & & & & $\begin{array}{l}0.36 \\
0.32\end{array}$ & & $\begin{array}{l}\text { ORr. } 001 \\
0 R r .001\end{array}$ & $\begin{array}{l}331 \\
538\end{array}$ \\
\hline 459 & GD2 & & $.750-00$ & & & & & 0.32 & & $0 R$ r. 001 & 530 \\
\hline $\begin{array}{l}65160 \\
65160\end{array}$ & & & $\begin{array}{l}.730+n ? \\
.73 n+n ?\end{array}$ & $\begin{array}{r}670+03 \\
.700+03\end{array}$ & $\begin{array}{l}100=02 \\
300-05\end{array}$ & $\begin{array}{r}250=00 \\
750=02\end{array}$ & $\begin{array}{l}100+09 \\
300=09\end{array}$ & $\begin{array}{r}850-00 \\
000-00\end{array}$ & & $\begin{array}{l}\text { ORrLIIE } \\
\text { ORrLLIR }\end{array}$ & $\begin{array}{l}726 \\
727\end{array}$ \\
\hline 5160 & $T^{B}$ & 6 & $.73 n+n 2$ & $100+04$ & $\therefore 0 \cap 0-00$ & $.150=00$ & $.600-00$ & $.110+01$ & & TRRLLIR & 728 \\
\hline 5160 & TH & 8 & & & & & & $.450+100$ & & DRr.LIH & $7 ? 9$ \\
\hline 5160 & 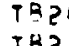 & & $.730+02$ & & & & & 0.42 & & ORe 001 & 540 \\
\hline $\begin{array}{l}65160 \\
65160\end{array}$ & TB? & & $.73 n+02$ & & & & & 0.85 & & $\cap R=001$ & 501 \\
\hline $\begin{array}{l}65160 \\
65160\end{array}$ & $\begin{array}{l}\text { Thर } \\
\text { Tिर }\end{array}$ & & $\begin{array}{l}.73 n+n 2 \\
.73 n+n 2\end{array}$ & & & & & $\begin{array}{l}0.34 \\
0.34\end{array}$ & & $\begin{array}{l}0 \times 00 \\
0 R+0099\end{array}$ & $\begin{array}{l}542 \\
543\end{array}$ \\
\hline 06165 & DY & 1 & $.97 n-n 1$ & $.7 n n+n 3$ & $: 100=03$ & $.250-100$ & $.100+01$ & $.510-00$ & & OR-LIF & 730 \\
\hline 165 & $u^{y}$ & 4 & $.97 n-01$ & $5 n n+n 3$ & $\operatorname{nonn-n5}$ & $2 \geq 00-0 !$ & $.300-01$ & $.300-00$ & & ORTLIF & 731 \\
\hline 105 & DY & 6 & $.0711-n 1$ & $.9 n n+n d$ & $a n n=0 \mathrm{~J}$ & $.15 n=0 n$ & $.000=0 n$ & $.150+01$ & & OPRLIA & 732 \\
\hline 165 & & a & & & & & & $.300+00$ & & חPR.LIE & 733 \\
\hline 165 & DY2 & & $.970-01$ & & & & & 0.39 & & $O R+001$ & 544 \\
\hline 165 & $\begin{array}{l}\text { DY? } \\
\text { DY? }\end{array}$ & & $.970-01$ & & & & & 0.51 & & nRP.001 & $\begin{array}{l}545 \\
540\end{array}$ \\
\hline $\begin{array}{l}165 \\
165\end{array}$ & DY? & & $\begin{array}{r}97 n-01 \\
.970-01\end{array}$ & & & & & $\begin{array}{l}0.34 \\
0.34\end{array}$ & & $\begin{array}{l}\text { ORP. } 001 \\
\text { ORGOOS? }\end{array}$ & $\begin{array}{l}546 \\
547\end{array}$ \\
\hline 6166 & DY & & $.300+01$ & $900+03$ & $: 100-03$ & $.250-00$ & $.100+01$ & $.790-00$ & & ORCLID & 734 \\
\hline $6 ! 66$ & DY & 4 & $-3 a n+01$ & $500+03$ & $\because 690-05$ & $.200-01$ & $.000-01$ & $.790-00$ & & DRr.LIR & 735 \\
\hline 6100 & OY & & $.340+01$ & $.100+03$ & $.600-00$ & $.150-00$ & $.600-00$ & $.390+01$ & & ORr.LIR & 730 \\
\hline 6166 & DY & 8 & & & & & & $.423=00$ & $77-00,78=00$ & DPC.LIA & 737 \\
\hline 6165 & DY? & & $.340+n 1$ & & & & & 0.004 & & $0 \times 0001$ & 548 \\
\hline 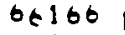 & $0 \times 2$ & & $.340+01$ & & & & & 0.094 & & nProO 01 & 549 \\
\hline 6166 & $0 \times 2$ & & $.34 n+n 1$ & & & & & 0.004 & & ORPOOI & 550 \\
\hline 6166 & DYZ & & $.300+01$ & & & & & $0.09 \mathrm{~s}$ & & ORron 1 & $55 !$ \\
\hline 7106 & wo & & - $11^{n+n} 1$ & $.75 n+n 3$ & $=1^{0 n-n} 3$ & $.25^{11}=00$ & $.100+1.1$ & .700000 & & ORPLIS & 738 \\
\hline 100 & HD & 3 & - ilnoni & $a^{n} n+03$ & $=200-05$ & $.500-n ?$ & $.200-01$ & $.69(1-00$ & & OER LIA & 739 \\
\hline 1166 & & $山$ & $.1 ! n+01$ & $.275+03$ & $.600-05$ & . $2 \cap 0=01$ & $.600-01$ & $.600-00$ & & OPCLIA & 740 \\
\hline 7160 & wO & & $.110+01$ & $.100+14$ & $.600-00$ & $.160=00$ & $.040-0 n$ & $.340+01$ & & ORPLLID & 741 \\
\hline 7166 & +0 & & & & & & & $.690+00$ & & $D R p ! I R$ & 742 \\
\hline 7160 & $\mathrm{HOC}$ & & $.11 n+n 1$ & & & & & $0.6^{\circ}$ & & $08+001$ & 552 \\
\hline 160 & $\mathrm{HO}_{2}$ & & $.110+01$ & & & & & 0.70 & & $02+001$ & 553 \\
\hline 67166 & $\mathrm{HO}_{2}$ & & $.190+01$ & & & & & $0.6^{\circ}$ & & $n=0.001$ & 554 \\
\hline $67 ! 60$ & $\mathrm{HO}_{2}$ & & $.110+01$ & & & & & $0.6^{\circ}$ & & ORPOOOI & 555 \\
\hline 671661 & $1 \mathrm{HO}$ & 1 & $4.3^{A} F 5$ & 750. & .0001 & .25 & 1. & .81 & & ORPLIB & 743 \\
\hline 671661 & I HO & 3 & U. 3RES & 800. & $? \cdot E-6$ & .005 & .02 & .32 & & ORPLIR & 744 \\
\hline 71661 & & 4 & $4.3^{A E} 5$ & A 75. & 6. E-6 & .02 & .06 & .37 & & OR P.LIA & 745 \\
\hline 1601 & HO & 6 & 4.3855 & 1000. & $6.4 E-5$ & .10 & .64 &.$\Delta$ & & OR, L I I & 740 \\
\hline & $I_{0}$ & A & UIRES & & & & & $: 37$ & .37 & OR RLLIR & 747 \\
\hline 1601 & IHO? & & $.432+n t$ & & & & & 0.37 & & $02 r_{9} 001$ & 556 \\
\hline 716011 & $1 \mathrm{HOC}$ & & $.438+06$ & & & & & 0.81 & & $\cap R, 001$ & 557 \\
\hline 716611 & 1002 & & $.+32+n 6$ & & & & & 0.20 & & $0 R r_{0} 001$ & 558 \\
\hline $\begin{array}{l}6716611 \\
68169\end{array}$ & $\begin{array}{l}H_{0} D^{2} \\
E \mathrm{~L}\end{array}$ & & $\begin{array}{r}4.3^{2}=5 \\
0 a_{n}+0 i\end{array}$ & $050+03$ & $.100-03$ & $.250-00$ & $.100+01$ & .25 & & $\begin{array}{l}\text { ORPCOOO } \\
\text { ORFLLIR }\end{array}$ & 749 \\
\hline 2160 & $E R$ & 3 & $.20 n+01$ & $650+03$ & $200-05$ & $.500-0 ?$ & $.200-01$ &.$: 0.3=0 n$ & & ORPLI IR & 750 \\
\hline 8100 & ER & 4 & $.94 n+n 1$ & $.433+03$ & $.3 n 0-05$ & $.750-02$ & $.0 \cap 0-01$ & $.220-100$ & & ORPLIIR & 751 \\
\hline
\end{tabular}




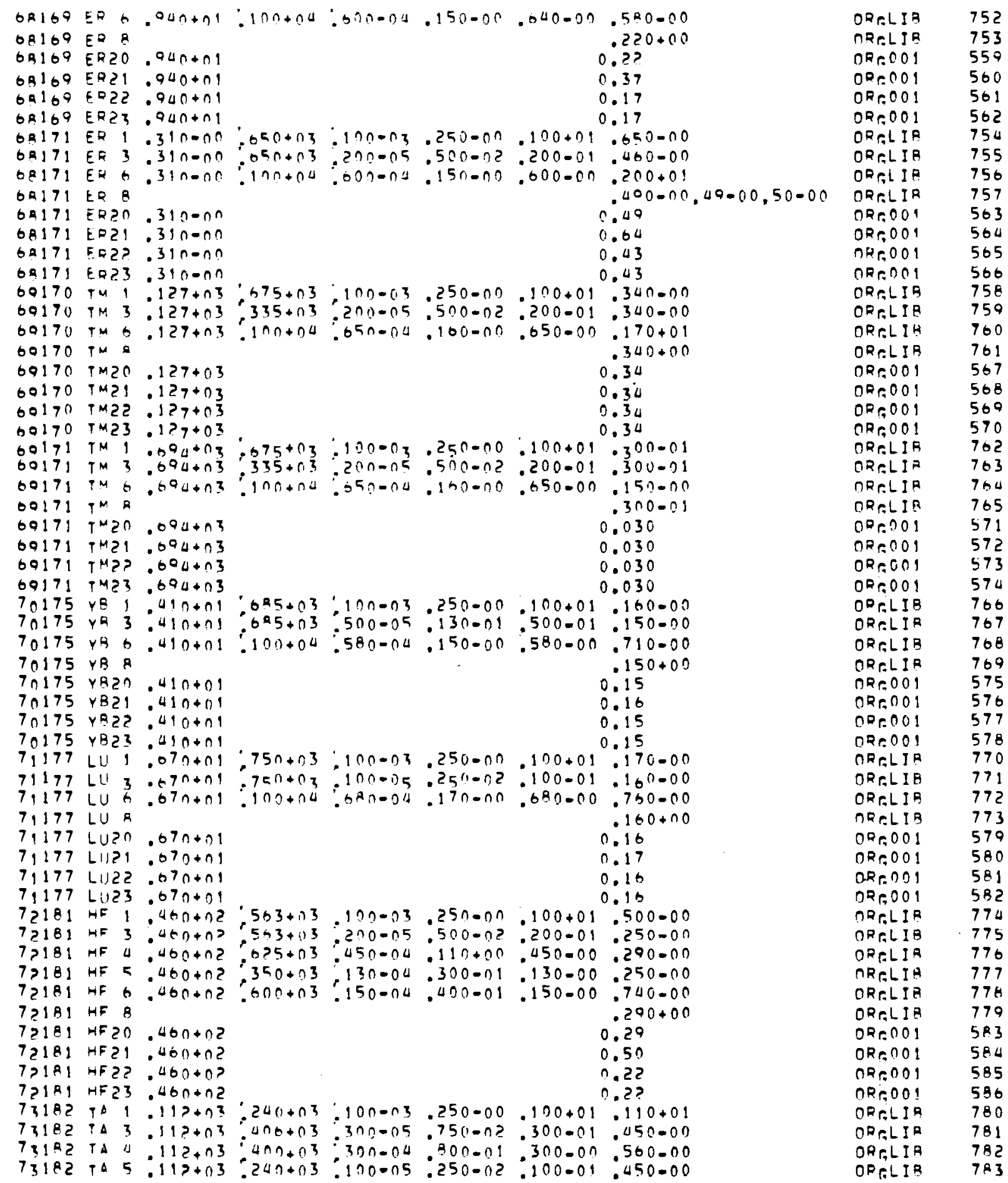




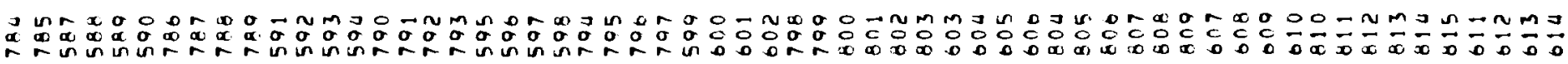

a

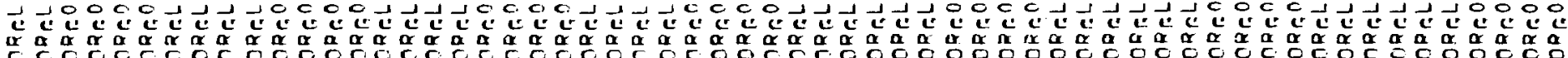

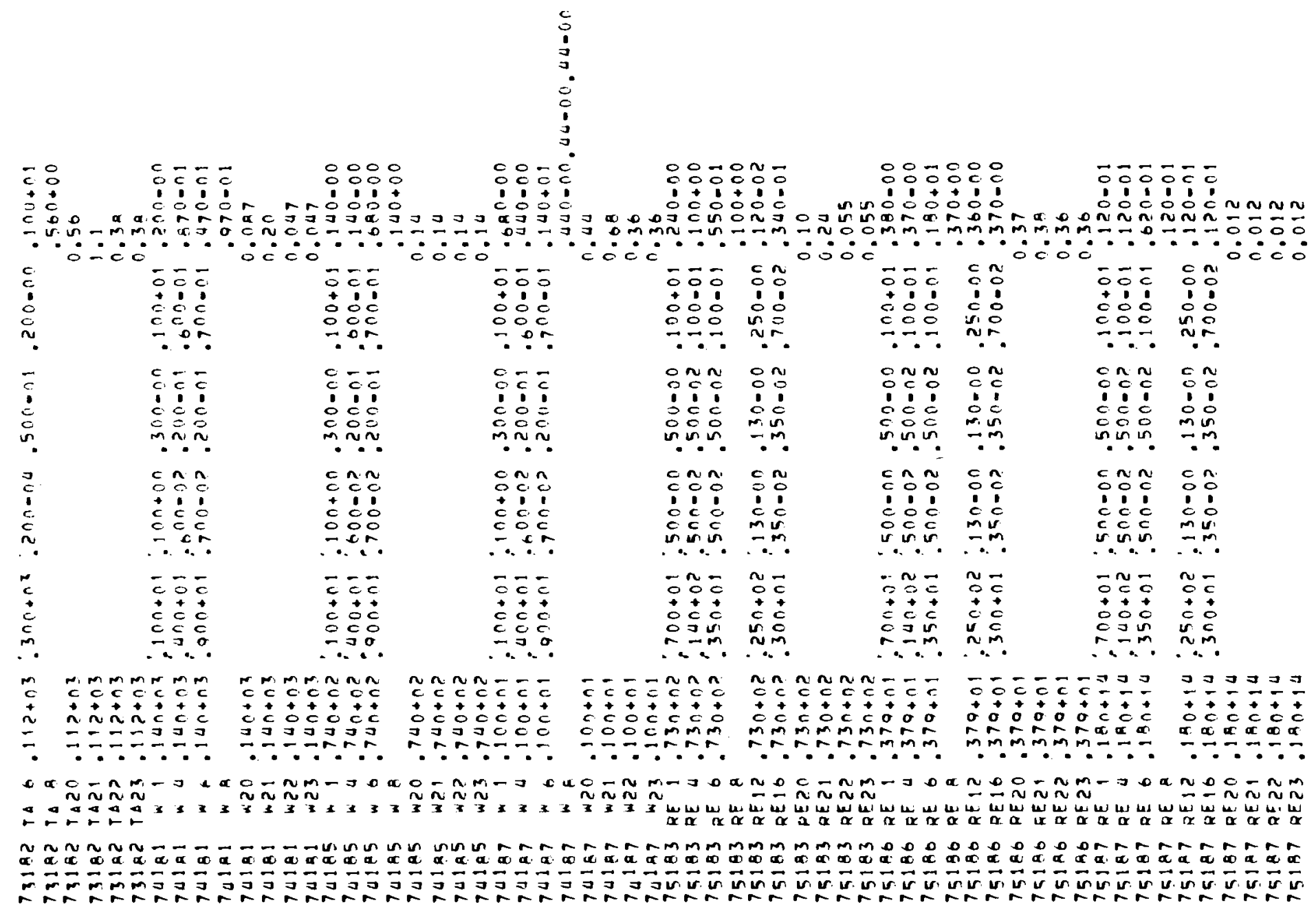




\begin{tabular}{|c|c|c|c|c|c|c|c|c|c|}
\hline $\begin{array}{l}75188 \\
75188\end{array}$ & $\begin{array}{ll}\text { RE } & 1 \\
\text { RE } & 4\end{array}$ & $\begin{array}{l}.710=0 n \\
.710=00\end{array}$ & $\begin{array}{l}700+n ! \\
100+0 ?\end{array}$ & $\begin{array}{l}.5 n 0=00 \\
500=0 ?\end{array}$ & $\begin{array}{l}.500=00 \\
.500=0 ?\end{array}$ & $\begin{array}{l}.100+119 \\
.100-01\end{array}$ & $\begin{array}{l}.940=00 \\
.850=00\end{array}$ & $\begin{array}{l}\text { ORCLIIR } \\
\text { ORPCLIIR }\end{array}$ & $\begin{array}{l}816 \\
817\end{array}$ \\
\hline $\begin{array}{l}75188 \\
75188\end{array}$ & RE 6 & $\begin{array}{l}710=00 \\
710=00\end{array}$ & $\therefore 350+01$ & $500=0 ?$ & $\begin{array}{l}.51000 \\
500-02\end{array}$ & $\begin{array}{l}100-01 \\
100-01\end{array}$ & $\begin{array}{l}.850=00 \\
390+01\end{array}$ & ORGLIA & 815 \\
\hline 75188 & RF 2 & & & & & & $.850+00$ & ORP,LIR & 819 \\
\hline 5198 & RF 12 & $.7 ! n=00$ & $.250+102$ & $13 n=0 n$ & $.130-00$ & $.250-00$ & $.790-00$ & ORCLIB & 820 \\
\hline 75198 & REIS & $.710-00$ & $300+01$ & $350=0 ?$ & $.350-12$ & $.700-02$ & $.8 \cap 0=00$ & OPCLIB & 821 \\
\hline 75188 & QF.2n & $.71 n=0.0$ & & & & & 0.85 & ORPO0 01 & 015 \\
\hline 75188 & RE2 I & $.710=0 n$ & & & & & 0.94 & $O R=001$ & 616 \\
\hline 75188 & REลे? & $.710=00$ & & & & & 0.82 & $C R \cap \cap 01$ & 017 \\
\hline 75186 & RE23 & $.710=0 n$ & & & & & 0.82 & RR, 001 & 618 \\
\hline 6185 & os 1 & $.950+02$ & $2 n 0+01$ & $\therefore 00+00$ & $.3 n 0=00$ & $.100+01$ & .510 .00 & ORC,LIR & 822 \\
\hline 76185 & 053 & $.95 n+n ?$ & $.500+01$ & $.500-0 ?$ & $.200-01$ & $.500-01$ & $.250-00$ & ORTLLIB & 823 \\
\hline 66185 & 054 & $.050+12$ & $.550+01$ & $40 n-n ?$ & $.100-01$ & $.400-01$ & $.290-00$ & $O R_{r}$ L I I & 824 \\
\hline 76185 & os 9 & & & & & & $.290+00$ & ORPLIR & 825 \\
\hline 76185 & 0520 & $.950+0 ?$ & & & & & 0.20 & $O R=001$ & 619 \\
\hline 76185 & OS21 & $.05 n+02$ & & & & & 0.51 & $O R+001$ & 620 \\
\hline 76185 & $052 ?$ & $.050+12$ & & & & & 0.23 & ORP.001 & 021 \\
\hline $76 ! 85$ & 0523 & $.050+0 ?$ & & & & & 0.23 & ORPOOOI & 022 \\
\hline 76191 & os ? & $.16 n+0 ?$ & $.200+01$ & $.100+00$ & $.300=0 n$ & $.100+01$ & $.160-00$ & ORPLIB & 826 \\
\hline 76191 & os 3 & $.16 n+02$ & $.500+01$ & $.500-0 ?$ & $.200-01$ & $.500-01$ & $.110+00$ & ORPLIIR & 827 \\
\hline 16191 & OS 4 & $.16 n+n ?$ & $.550+01$ & $.40 n-02$ & $.100-n 1$ & $.400-01$ & $.120+00$ & $O R P L I R$ & 828 \\
\hline 76191 & & & & & & & $.120+00$ & ORP.LIB & 629 \\
\hline $\begin{array}{l}76191 \\
7109\end{array}$ & $\begin{array}{l}0.520 \\
052,\end{array}$ & $-16 n+n ?$ & & & & & 0.12 & OR r. 001 & $\begin{array}{l}623 \\
620\end{array}$ \\
\hline $\begin{array}{l}76101 \\
76191\end{array}$ & $\begin{array}{l}0521 \\
052 ?\end{array}$ & $\begin{array}{l}-160+0 ? \\
.160+0 ?\end{array}$ & & & & & $\begin{array}{l}0.16 \\
0.10\end{array}$ & 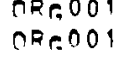 & $\begin{array}{l}626 \\
625\end{array}$ \\
\hline 76191 & 0523 & $.100+n ?$ & & & & & 0.10 & OProO 01 & 626 \\
\hline 761911 & $05_{1}^{1}$ & $.580-00$ & $200+01$ & $100+00$ & $.300=00$ & $.100+01$ & $.000-01$ & OR R L I E & 830 \\
\hline $\begin{array}{l}761011 \\
761011\end{array}$ & $\begin{array}{ll}05 \\
05 & 4\end{array}$ & $\begin{array}{l}.580=00 \\
580=00\end{array}$ & $\begin{array}{l}.500+01 \\
55^{n+01}+01\end{array}$ & $\begin{array}{l}500-0 ? \\
400-0 ?\end{array}$ & $\begin{array}{l}-200-01 \\
100-01\end{array}$ & $\begin{array}{l}.500-01 \\
400-01\end{array}$ & $\begin{array}{l}.300-01 \\
400-01\end{array}$ & $\begin{array}{l}\text { ORPLLIB } \\
\text { ORGLIR }\end{array}$ & $\begin{array}{l}831 \\
832\end{array}$ \\
\hline 761011 & 1058 & $.500-100$ & $.55+111$ & & & & $.251=01,11+00.13=00$ & ORTLLIB & 833 \\
\hline $\begin{array}{l}761011 \\
761911\end{array}$ & $\begin{array}{l}0520 \\
0521\end{array}$ & $\begin{array}{l}.580=00 \\
.580=00\end{array}$ & & & & & $\begin{array}{l}0.098 \\
0.042\end{array}$ & $\begin{array}{l}\text { ORrOOOI } \\
\text { ORROOOI }\end{array}$ & $\begin{array}{l}027 \\
028\end{array}$ \\
\hline 61911 & 10522 & $.580=00$ & & & & & 0.097 & ORPOOOI & 629 \\
\hline & 10523 & $.580=00$ & & & & & 0.007 & ORP 001 & 630 \\
\hline 76103 & OS i & $.131+91$ & $200+01$ & $: 100+10$ & $.300=00$ & $.100+01$ & $.380-00$ & ORPLI I & 834 \\
\hline $\begin{array}{l}76103 \\
76103\end{array}$ & os 3 & $\begin{array}{l}131+01 \\
131+01\end{array}$ & $\left\{\begin{array}{l}500+01 \\
550+01\end{array}\right.$ & $\left\{\begin{array}{l}500-02 \\
400-0 ?\end{array}\right.$ & $.200-01$ & $\begin{array}{r}500=09 \\
400=01\end{array}$ & $.380-00$ & ORCLI IB & $\begin{array}{l}835 \\
836\end{array}$ \\
\hline $\begin{array}{l}76193 \\
76193\end{array}$ & $\begin{array}{l}0.5 \\
0520\end{array}$ & $.131+n 1$ & & - Ontia ve & $.100=(10)$ & $.000=01$ & $\begin{array}{l}380+00 \\
0.38\end{array}$ & 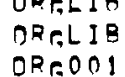 & $\begin{array}{l}837 \\
839 \\
631\end{array}$ \\
\hline 76103 & $\mathrm{OS}_{2} 1$ & $.131+01$ & & & & & $n \cdot 3^{2}$ & QR P O O I & 632 \\
\hline $76: 93$ & OS? ? & $.131+n 1$ & & & & & 0.38 & DRe001 & 633 \\
\hline 76193 & 0523 & $.131+01$ & & & & & 0.38 & $O R+001$ & 630 \\
\hline 77100 & 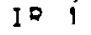 & $.120+02$ & $-5^{00+0}$ & $=100+00$ & .300000 & $.100+01$ & $.370-00$ & ORTLIR & 838 \\
\hline $77 \pm 00$ & IP 3 & $.120+02$ & $1500+0$ ह & $450-02$ & $.1_{4} 0-01$ & $.450-01$ & $.120+00$ & OR C.LI $B$ & 839 \\
\hline $77^{190}$ & 124 & $.120+02$ & $270+0 ?$ & $.230-01$ & $.700-01$ & $.230=00$ & $.160=00$ & OR RLL I B & 840 \\
\hline 79190 & IR 5 & $.12 n+n ?$ & $.5^{n 0+02}$ & $.200-02$ & $.600-02$ & $.200-01$ & $.120+00$ & ORPLIA & $8 \cup 1$ \\
\hline $\begin{array}{l}77190 \\
77100\end{array}$ & IR 8 & & & & & & $.160+00$ & ORCLIIA & 642 \\
\hline $\begin{array}{l}77100 \\
77100\end{array}$ & IP2n & $.120+02$ & & & & & 0.16 & $0 R r, 001$ & 635 \\
\hline 79100 & $12 ? 1$ & $1 \geq 0+0 ?$ & & & & & 0.37 & $O R=001$ & 036 \\
\hline 77190 & IR2? & $.120+02$ & & & & & 0.087 & 025001 & 637 \\
\hline 79190 & $I_{1} 23$ & $.12 n+n ?$ & & & & & 0.087 & ORPOOI & 638 \\
\hline 79192 & IR I & $.745+12$ & $.200+02$ & $.100+00$ & $.300=00$ & $.100+01$ & $.110+01$ & ORPLI I & 843 \\
\hline 77192 & I 3 & $.745+0 ?$ & $: 500+02$ & $450-0 ?$ & $.100-01$ & .450 .01 & $.500-00$ & ORPLI I & 844 \\
\hline 77192 & If & $.745+0 ?$ & $: 270+02$ & $230=01$ & $.700-01$ & .230000 & $.600+00$ & DReLI I & 805 \\
\hline 77192 & IR 5 & $.745+n 2$ & $.500+02$ & $.200-02$ & $.000-02$ & $.200-01$ & $.500+00$ & ORRLI IR & 846 \\
\hline 77102 & IR $R$ & & & & & & $.000+00$ & ORCLI IB & 847 \\
\hline 77102 & $\operatorname{IR20}$ & $.745+0 ?$ & & & & & 0.60 & ORP,001 & 639 \\
\hline 77192 & If I & $.745+02$ & & & & & 1.1 & $0 R+001$ & 040 \\
\hline 77192 & I $22 ?$ & $.745+02$ & & & & & $0.4 ?$ & ORPOOO! & 641 \\
\hline 77192 & 1023 & $.745+10 ?$ & & & & & 0.42 & 02,001 & 042 \\
\hline
\end{tabular}




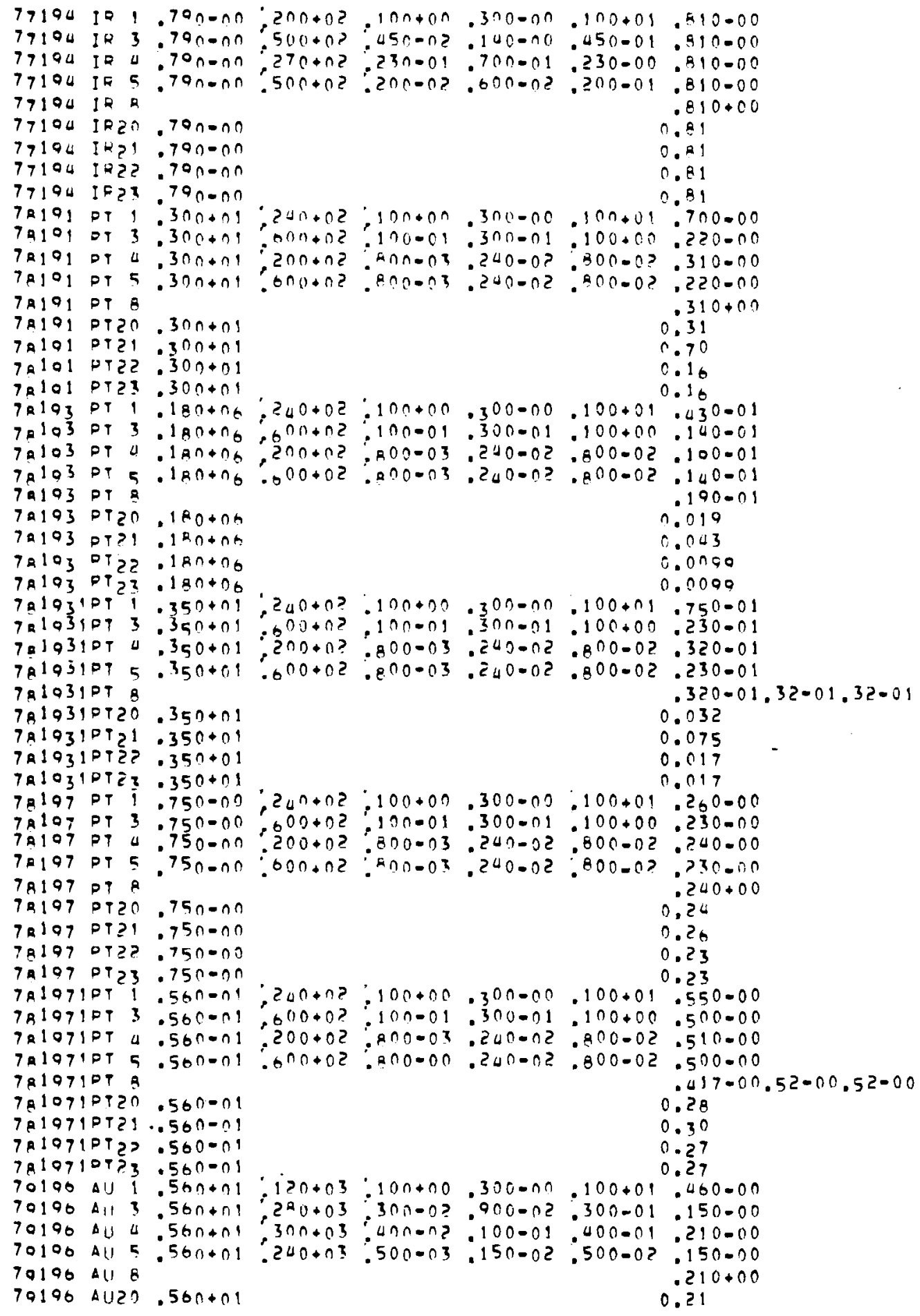

ORCLIT

ORTLLIA

OERLIR

ORTLIIR

ORTLLIR

ARr,0O?

ORFCOI

OFr.001

narong

CRTLLIP

Cartia

ORFLIID

ORPLI:A

ORTLII

ORFOOI

ORPOOOI

OR 0001

OR $=001$

ORTLIA

ORTLIA

CR CLII

ORTLIA

CQRELIA

ORFOOI

ORr.00

CQROOS

OR=OOA

ORCLIR

$O=$ C.L IA

OPCLLIA

ORPLIE

ORTLII

ORFOOS

CRFOOOS

OR 009

OR.001

ORPLIIA

ORPLII

ORPLIS

ORRLI I =

ORELII

$0 R=003$

ORPOOOI

ORFO01

ORPOOI

ORRLIS

DRELIR

ORTLIIS

ORPLIR

ORPLIR

ORrOONI

ORPOOI

DRr.00?

ORPOO:

ORPL IP

ORTLIB

ORPL I A

ORrLLI IE

ORPLIIR

ORFOOI
848

849

850

451

852

o 43

oud

605

040

853

854

855

850

657

047

048

549

050

858

859

800

501

8h?

051

05 ?

053

654

863

804

865

860

867

055

650

657

658

868

660

670

871

872

050

660

061

662

873

874

875

870

877

663

6od

605

660

878

879

850

8.

882

667 


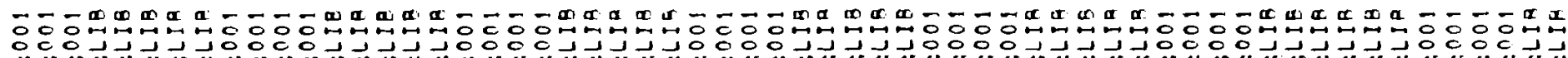

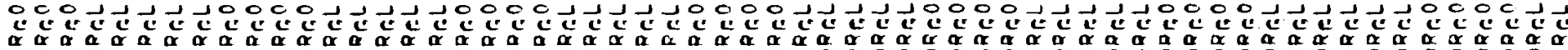

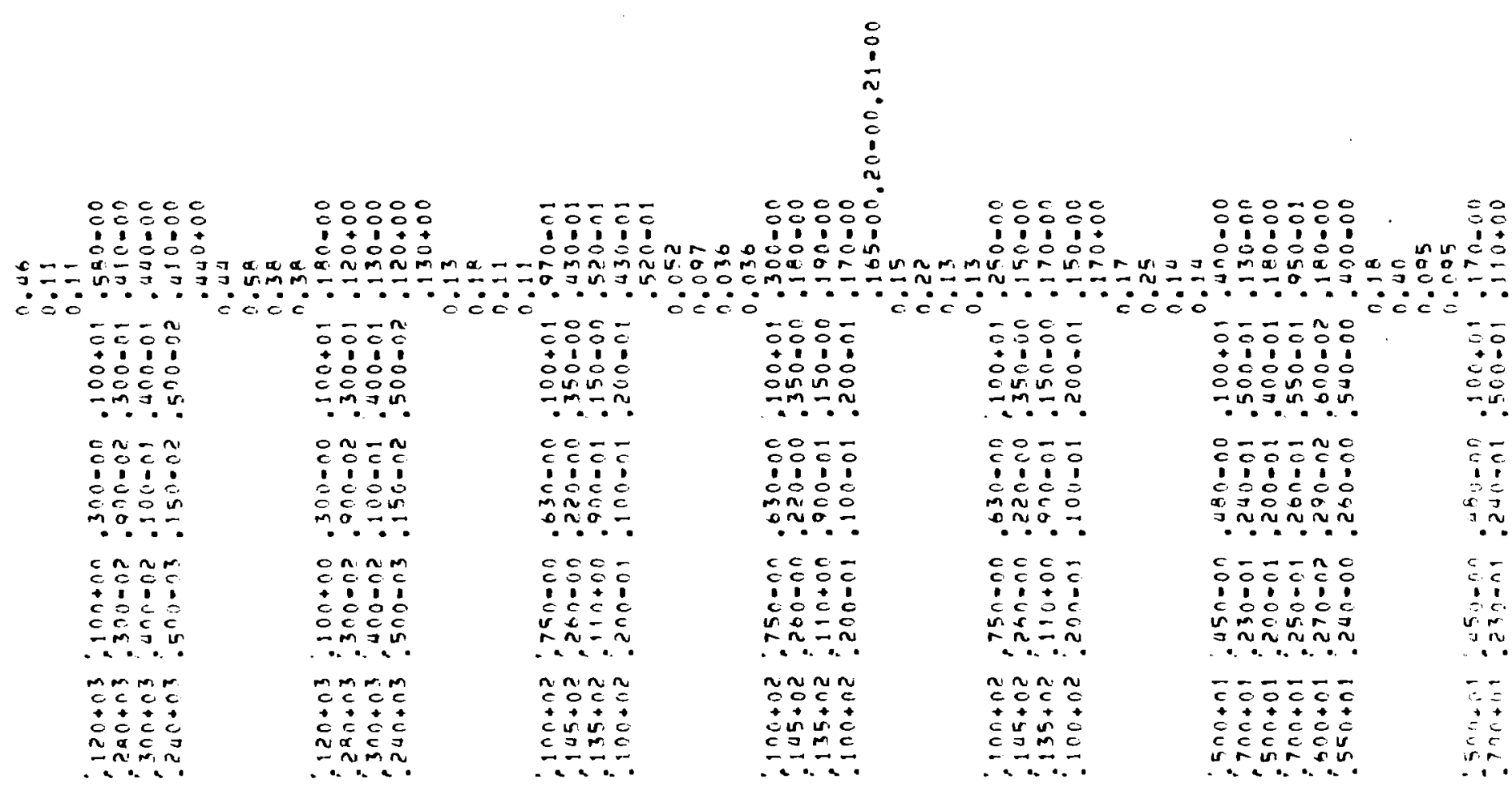

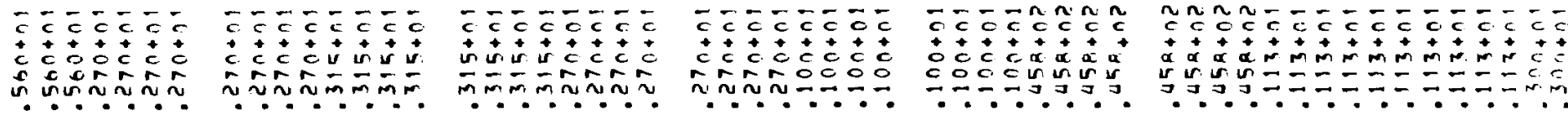

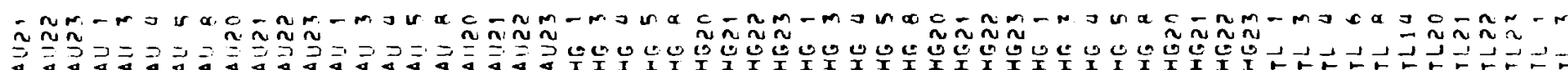

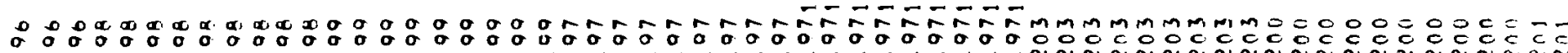

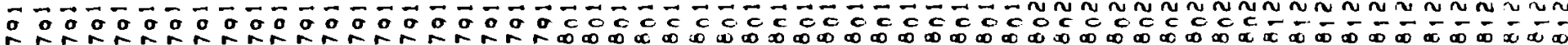




\begin{tabular}{|c|c|c|c|c|c|c|c|c|c|}
\hline 8,201 & 114 & . $3110+801$ & $=5: x+1$ & $20 n=01$ & $.2^{2 n}=-51$ & $.0 \cap 0-1$ & $.129+00$ & $n \theta$ TIP & 010 \\
\hline $8, \geq n 1$ & & $.3 n n+n 1$ & $7 n n+11$ & $.251-11$ & $.20 ?-01$ & $.550-01$ & $\triangle \Delta C=0$ & $O=R: L$ & 017 \\
\hline 1201 & & $30 n+01$ & $000+01$ & $279=0 ?$ & $.29 n-n ?$ & $.0 \times 0-0 ?$ & $.120+00$ & ARPLIR & $0: 8$ \\
\hline 1201 & TLAU & $30_{0}+n 1$ & $: 55 n+01$ & $2+0=00$ & $.260-00$ & $.5+0-00$ & $.170-00$ & ORPLIN & 010 \\
\hline 81201 & $T L 2 n$ & $.3 n n+n 1$ & & & & & 0.12 & CRrons & 695 \\
\hline 81201 & $T L \geq 1$ & $.300+01$ & & & & & 0.17 & ORP.001 & 090 \\
\hline 81201 & TL2? & $.3 n n+n 1$ & & & & & 0.10 & ORroO: & 507 \\
\hline 81201 & $P L 2^{2}$ & $.30 n+n 1$ & & & & & 0.10 & OR r 001 & 098 \\
\hline 81202 & & $.120+n 2$ & $.500+01$ & $.450-0 n$ & $.420=00$ & $.100+0 !$ & .3801000 & ORFLIIF & 920 \\
\hline $\begin{array}{l}81202 \\
81202\end{array}$ & $\begin{array}{ll}\text { TL } & 3 \\
\text { TL } & 4\end{array}$ & $\begin{array}{l}1 \geq 0+n ? \\
12 n+n ?\end{array}$ & $: \begin{array}{l}700+01 \\
=00+01\end{array}$ & $\begin{array}{l}23 n=01 \\
200=01\end{array}$ & $\begin{array}{l}500-01 \\
500-01\end{array}$ & $\begin{array}{r}500=09 \\
400=09\end{array}$ & $\begin{array}{r}.240-00 \\
270-00\end{array}$ & ORr:LIB & $\begin{array}{l}921 \\
925\end{array}$ \\
\hline 81202 & & $1 ? 0+n 2$ & $=700+01$ & $25 n-01$ & $.260-n 1$ & $.550-01$ & $.0 a n-00$ & ORTLIIA & $\begin{array}{l}922 \\
923\end{array}$ \\
\hline $8120 ?$ & TL \& & $120+n ?$ & $: 600+01$ & $270 \cdot 0 ?$ & $.2^{\circ} 0-0 ?$ & $.000=0 ?$ & $.270-00$ & ORRLIR & 924 \\
\hline 8,202 & TLIO & $.120+02$ & $.550+01$ & $.24 n=0 n$ & $.200-00$ & $.540-00$ & $.380-00$ & ORr.LIB & 925 \\
\hline $\begin{array}{l}81 \geq 02 \\
81 \geq 02\end{array}$ & IL.2n & $-120+02$ & & & & & 0.27 & $02 r 001$ & $\begin{array}{l}699 \\
700\end{array}$ \\
\hline 81202 & TLEZ & $.120+n ?$ & & & & & $\begin{array}{l}0.34 \\
0.23\end{array}$ & $\begin{array}{l}\text { ORr. } 009 \\
\text { OProO } 009\end{array}$ & 701 \\
\hline 1202 & $T L 23$ & $.12 n+n ?$ & & & & & 0.23 & DRPOOO1 & 702 \\
\hline 8,204 & TL 1 & $.11 n+n \|$ & $500+01$ & $: 450=00$ & $.480=n 0$ & $100+01$ & .250 .00 & ORPLIZ & 026 \\
\hline 8,204 & TL & $.110+n !$ & $.700+01$ & $.23 n=01$ & $.240=01$ & $.500-01$ & $.250-00$ & ORPLII & 927 \\
\hline 81204 & TL & $.11 n+n d$ & $.500+01$ & $? \cap n=01$ & $.200-01$ & $.400-01$ & .250 .00 & ORPLIB & 928 \\
\hline 8,204 & & $.110+n d$ & $7 \cap 0+0 !$ & $250-01$ & $.260-01$ & .550 .01 & $.130+01$ & ORTEL I & 020 \\
\hline $\begin{array}{l}3,204 \\
8,204\end{array}$ & $\begin{array}{ll}\text { TL } \\
\text { TL }\end{array}$ & 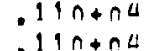 & $.600+01$ & $\begin{array}{l}27 n=0 ? \\
240-0 n\end{array}$ & $\begin{array}{r}290-112 \\
200-10\end{array}$ & $\begin{array}{r}.600-02 \\
540-00\end{array}$ & $\begin{array}{r}250=00 \\
250-00\end{array}$ & ORraLIE & $\begin{array}{l}930 \\
031\end{array}$ \\
\hline 81204 & TLEO & $.110+n a$ & & & & & 0.25 & ofanos & 703 \\
\hline 81200 & TL 21 & $11 n+n \Delta$ & & & & & 0.25 & $02000^{\circ}$ & $7: 4$ \\
\hline 81204 & PLZZ & $.110+04$ & & & & & 0.25 & OReOO: & 705 \\
\hline 81204 & $T L 23$ & $.110+0 \Delta$ & & & & & 0.25 & DRroos & 700 \\
\hline $8 \geq 203$ & $p^{R} !$ & $.217+01$ & $140+00$ & $R \cap 0-n 1$ & $.290-0.0$ & $.100+01$ & $.220-00$ & ORRLIIS & 932 \\
\hline $8>203$ & $D R$ & $.217+01$ & $531+03$ & $.100-01$ & $.400-01$ & $.140=00$ & $.690-01$ & $O A r_{A} L I B$ & 933 \\
\hline 203 & $P^{A}$ & $.217+01$ & $195+04$ & $.640-02$ & $.230-01$ & $.800-01$ & $.000-01$ & DARLIP & 934 \\
\hline & PQ & $.217+01$ & $.365+04$ & $200-01$ & $.800-01$ & $.280-00$ & .510 .01 & OREL: : & 835 \\
\hline 82203 & FE & & & & & & $.9 \Delta 0.01$ & ORrLLIA & 930 \\
\hline 82203 & $P$ F 20 & $.217+01$ & & & & & 0.004 & 000001 & 707 \\
\hline 82203 & PA21 & $.297+n 1$ & & & & & 0.22 & $\because R r=00$ ? & 708 \\
\hline 82203 & PQZ2Z & $.217+01$ & & & & & 0.051 & ORFOON1 & 709 \\
\hline $8 ? 203$ & D.23 & $.217+01$ & & & & & 0.051 & ORrOOOI & 710 \\
\hline $8 \geq 210$ & $F B$ & $.91 n+n u$ & $106+04$ & $.900-01$ & $.280-00$ & $.100+01$ & 0.01 & ORRLLIR & 937 \\
\hline 82210 & $P P$ & $.710+04$ & $.53 !+0,3$ & $100-01$ & $.400-01$ & $.140=000$ & $.100+02$ & APrit? & 038 \\
\hline $8>210$ & $D R$ & $.710+0 \mathrm{~d}$ & $195+04$ & $640-0 ?$ & $.230-01$ & .800 .01 & $.100+02$ & ORELIA & 939 \\
\hline $8 ? 210$ & $O E$ & $.710+104$ & $.305+04$ & $200=01$ & $.8 \cap 0-01$ & $.280-00$ & $.290+02$ & ORRELIR & 940 \\
\hline $8 \geq 210$ & DF $R$ & & & & & . & $.157-00.10+0 \varepsilon .43+07$ & ORTIII & $2<1$ \\
\hline $\begin{array}{l}8 \geqslant 210 \\
8 \geqslant 210\end{array}$ & $\begin{array}{l}\text { DA2n } \\
\text { DEZI }\end{array}$ & $.710+04$ & & & & & $\begin{array}{l}0.027 \\
0.045\end{array}$ & 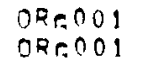 & $\begin{array}{l}7: 1 \\
712\end{array}$ \\
\hline $8 ? 210$ & PA2? & $.71 n+04$ & & .. & & & 0.010 & 020001 & 713 \\
\hline 82210 & $P R 23$ & $.71 n+n 4$ & & & & & 0.019 & ORr, 001 & 714 \\
\hline 85212 & $D A$ & $.4 \Delta 0=00$ & $.146+04$ & $200=01$ & $.290-0 n$ & $.100+01$ & $.820+02$ & CRTLLIR & 942 \\
\hline $8 \geqslant ? 15$ & $P R$ & $. \Delta \Delta n=n n$ & $.531+03$ & $.100-01$ & $.400-01$ & .140 .00 & $.810+02$ & ORr.LIR & 943 \\
\hline 82212 & $D R$ & $.4 \Delta n=n n$ & $105+04$ & $640=03$ & $.230-01$ & $800-01$ & $830+02$ & DRrLIB & 940 \\
\hline 82.212 & $P A$ & $.440-n n$ & $.365+104$ & $20 n=n 1$ & $.804-01$ & $.2^{2} 0-00$ & $.410+03$ & $8 / 18 / 70$ & \\
\hline 82212 & $P B \&$ & & & & & & $.799+02.83+02.83+02$ & ORRLLIB & 940 \\
\hline 82212 & DR? O & $.64 n=n n$ & & & & & 0.24 & $0 R r 001$ & 715 \\
\hline $8>212$ & $F \geq 21$ & $.4 \Delta 0=0 n$ & & & & & 0.29 & $n 0,001$ & 710 \\
\hline & PBZZ & $.4 \Delta 0=n n$ & & & & & 0.22 & ORROOOI & 717 \\
\hline $8 \geq 212$ & $P 423$ & $.4 \Delta 0-0,0$ & & & & & $0.2 ?$ & $0 R+001$ & 718 \\
\hline 83206 & QI 1 & $.04 n+n 1$ & $5^{000+04}$ & $.190-01$ & $.200-00$ & $.100+01$ & $.180+01$ & ORRELIR & 947 \\
\hline & BI & $.0^{4} n+0^{1}$ & & $.30 n-0 ?$ & . $800=01$ & .300 .00 & $.580-00$ & ORFLIA & $9 \angle A$ \\
\hline & BI & $.04 n+n 1$ & $15 n+n ?$ & $15 n-02$ & $.400=01$ & .150 .00 & $\triangle \cap \cap 0=0 ?$ & ORELIR & $\rightarrow \cup 9$ \\
\hline $\begin{array}{l}8 \div 200 \\
8 \div 200\end{array}$ & $\begin{array}{ll}81 & 5 \\
\text { e I } & 6\end{array}$ & $\begin{array}{l}.040+0 ! \\
.040+0 !\end{array}$ & $: \begin{array}{l}100+02 \\
133+02\end{array}$ & $\begin{array}{l}100=03 \\
300-03\end{array}$ & $\begin{array}{l}.260-02 \\
.970-02\end{array}$ & $\begin{array}{l}100=01 \\
300=01\end{array}$ & $\begin{array}{l}580=00 \\
430-00\end{array}$ & ORFLIR & $\begin{array}{l}950 \\
951\end{array}$ \\
\hline
\end{tabular}




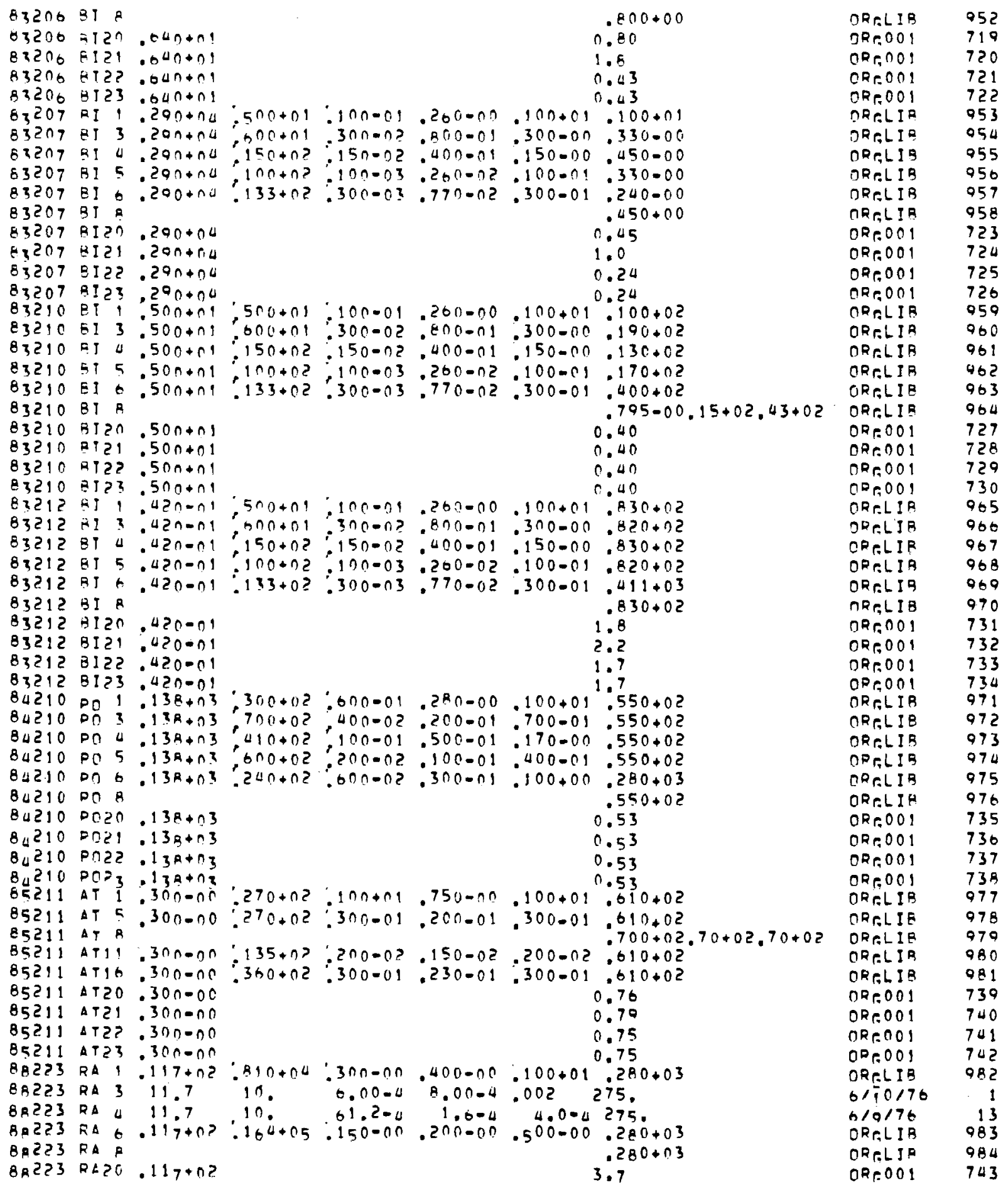




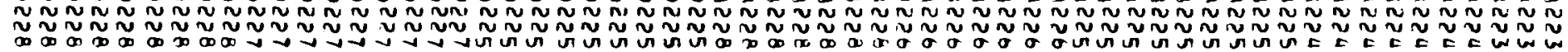

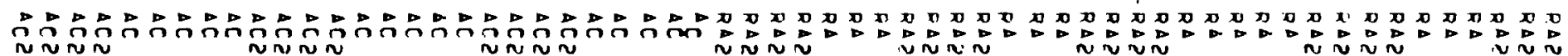

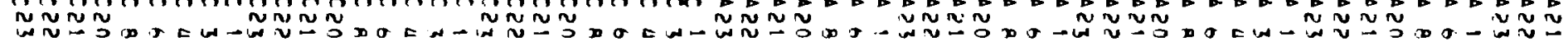

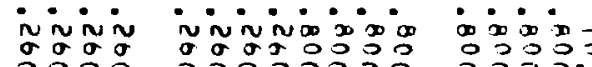
vivis Nininin

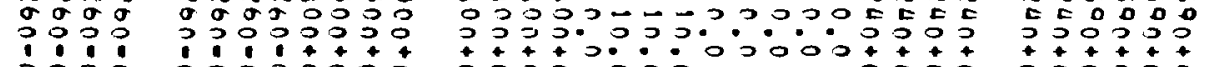
官家:

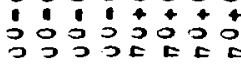
iviñ

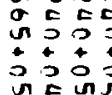
bis

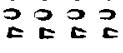

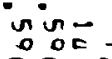

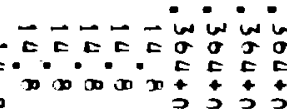

inis:

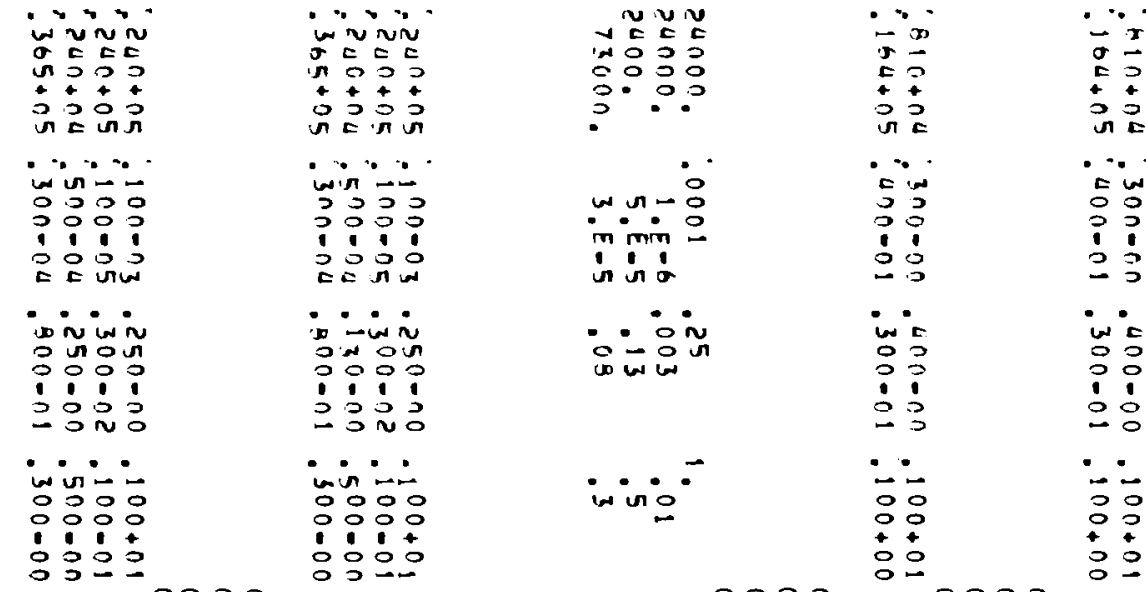

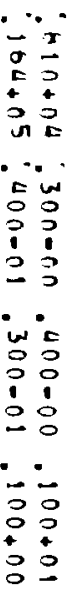

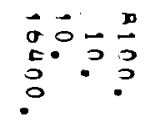

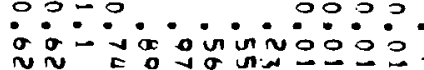

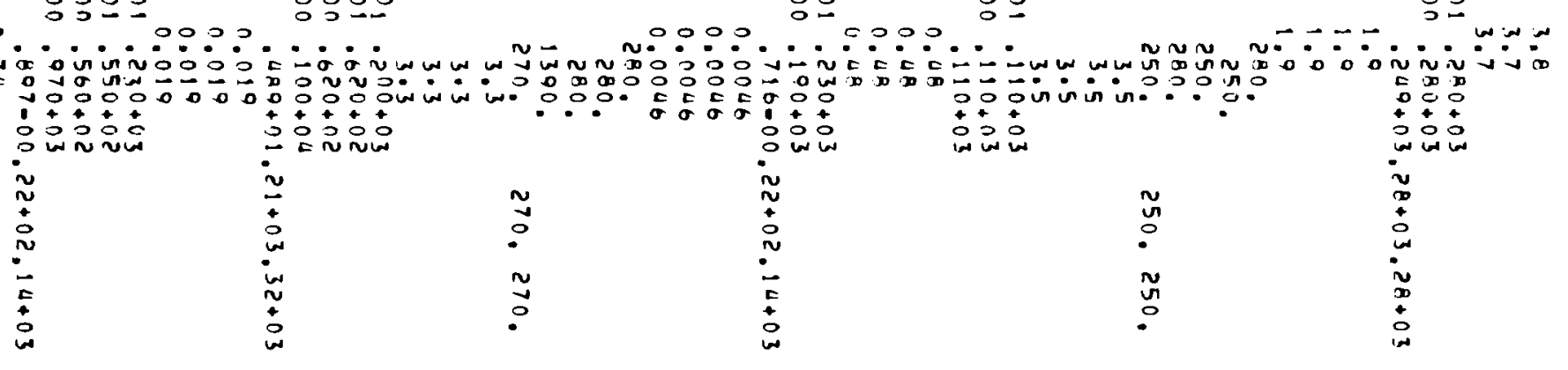

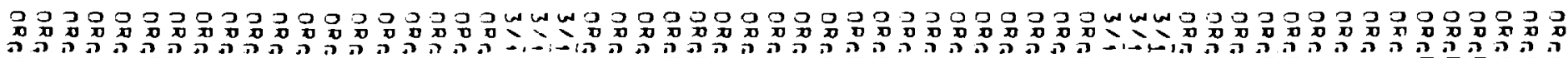

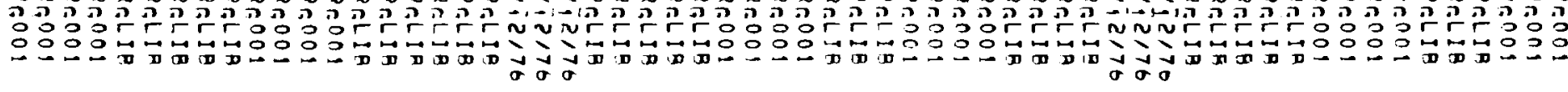

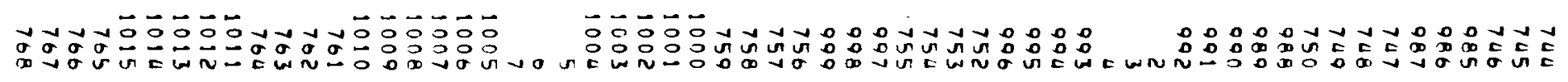




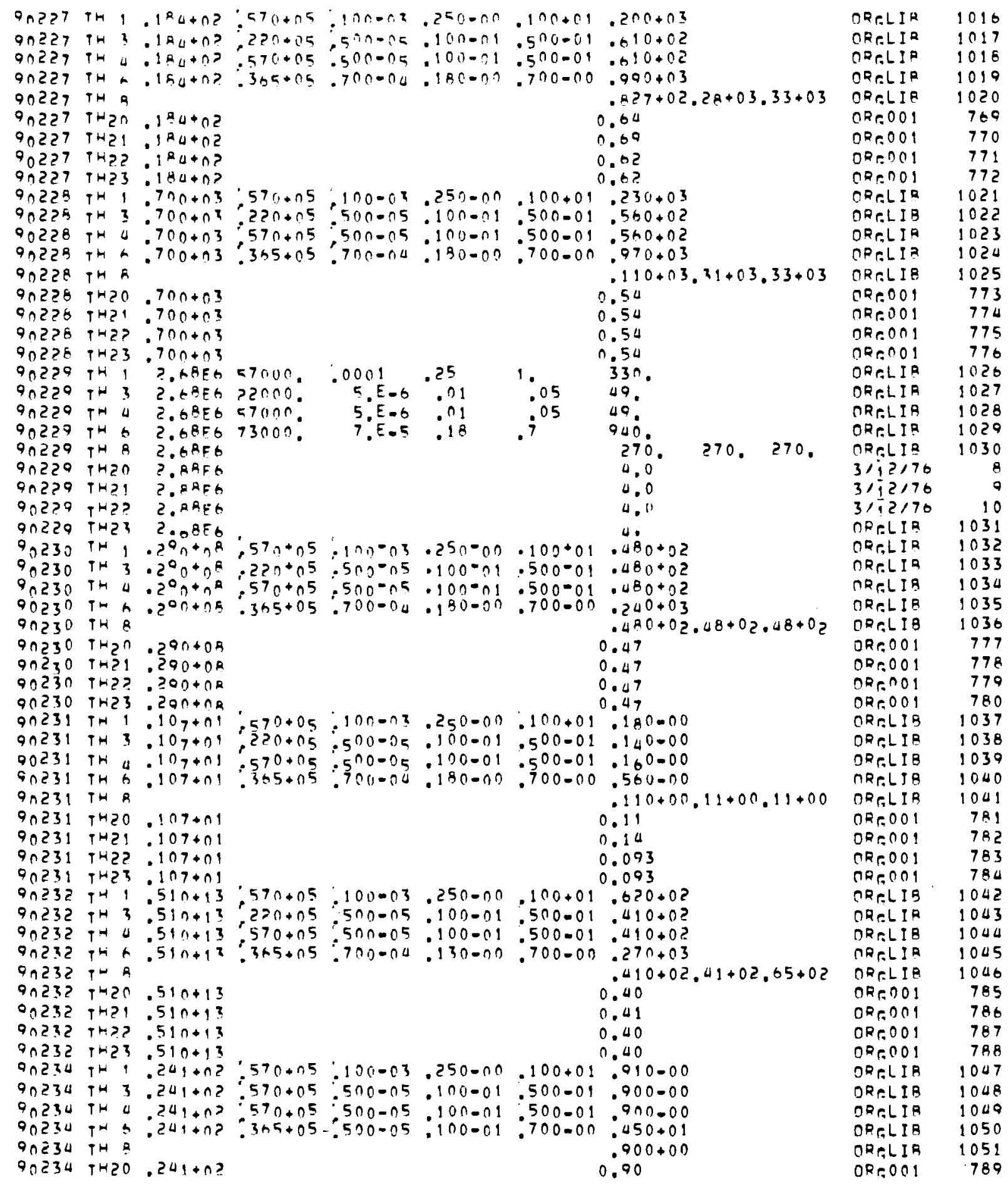




\begin{tabular}{|c|c|c|c|c|c|c|c|c|c|}
\hline $9 \cap 234$ & $1+21$ & $.241+n 2$ & & & & & 0.01 & ORrnOI & 700 \\
\hline $0 \cap 230$ & $T+2 ?$ & $.241+n ?$ & & & & & 0.00 & OReoni & 701 \\
\hline 00233 & TH23 & $.241+n 2$ & & & & & 0.00 & orenni & 702 \\
\hline $91 \overline{20}$ & $F \Delta 1$ & $.177+02$ & $: 410+05$ & $1 \cap n=0 x$ & $.250-10$ & $.100+01$ & $.670-01$ & ORCLIA & 1052 \\
\hline 91270 & FA 3 & $177+n ?$ & $.510+05$ & $\triangle \cap \cap \cap \cap 5$ & .10 rien! & $.000=01$ & $.310=01$ & ORP,LIa & 1053 \\
\hline 9,230 & $=\Delta \theta$ & $\cdot 177+n ?$ & $.365+05$ & $.450-02$ & $.110+n n$ & $.450=00$ & $110+00$ & OQRLIT & 1054 \\
\hline 91230 & & & & & & & $.320+01.50+02.0 A+02$ & OHRLIR & 1055 \\
\hline 0,230 & $P \Delta \geq 0$ & $.177+n ?$ & & & & & 0.042 & QREODO & 703 \\
\hline 91230 & 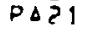 & $.177+07$ & & & & & 0.064 & OPr. 001 & 794 \\
\hline 91230 & $D \Delta 22$ & $.177+n ?$ & & & & & 0.035 & ORrOOOI & 795 \\
\hline 91270 & $P A 23$ & $.177+0 ?$ & & & & & 0.035 & $0 R$ r. OO & 796 \\
\hline 9,231 & PA 1 & $.13 n+0 a$ & $410+05$ & $10 n=03$ & $.250=00$ & $.100+01$ & $.140+03$ & ORPLIS & 1050 \\
\hline 9,231 & D 3 & $.13 n+05$ & $\therefore 510+05$ & inn-05 & $.100=n 1$ & $.400-01$ & $.70^{\circ} 0+02$ & ORRLI I & 1057 \\
\hline 31 & 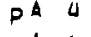 & $.130+0^{2}$ & $.580+05$ & $: 500-05$ & $.130=01$ & $.500-01$ & $.630+02$ & ORELIS & 1058 \\
\hline 91231 & PS 6 & $.13 n+.08$ & $.365+05$ & $.450-04$ & $.110+00$ & $\because 450=00$ & $.750+03$ & OR riLIB & 1059 \\
\hline $9 ! 5$ & PD 8 & & & & & & $.510+02.52+02,70+02$ & nRrLIB & 1060 \\
\hline 91231 & $P \Delta ? 0$ & $.130+0^{8}$ & & & & & 0.60 & 000001 & 797 \\
\hline 91231 & $D \Delta 21$ & $.130+12$ & & & & & $0.7 n$ & DRP.0OI & 798 \\
\hline $9 ! 231$ & Pम Q? & $.13 n+09$ & & & & & 0.56 & 090001 & 799 \\
\hline 91231 & $D \Delta 23$ & $.130+0 A$ & & & & & 0.56 & 020001 & 800 \\
\hline 91233 & $D \Delta 1$ & $.274+12$ &, $410+05$ & $100=03$ & $0=00$ & $.100+01$ & $.320-00$ & ORPLIB & 1001 \\
\hline 91233 & $\begin{array}{ll}\text { PA } & 3 \\
0 A & 4\end{array}$ & $.270+0 ?$ & $.510+05$ & $400=05$ & $.100=01$ & - $400=01$ & $.150=00$ & CRPLL I R & 1002 \\
\hline 9,233 & PD 0 & $-270+0 ?$ & $.580+95$ & $=5 n 0-05$ & $-150=n 1$ & $.590-01$ & $.180=00$ & ORriLis & 1063 \\
\hline 9,233 & $D \Delta$ & $\cdot=10+n e$ & $.563+03$ & $.450-00$ & $.110+n(1)$ & $.450=00$ & $.410=00$ & ARthlis & 1004 \\
\hline 1233 & $\Delta \Delta ? 0$ & $.270+102$ & & & & & $0.18=0+18$ & 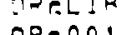 & 1005 \\
\hline 91233 & $P \Delta ? 1$ & $.270+n ?$ & & & & & 0.32 & 0 acond & 802 \\
\hline 91233 & $P A 2 ?$ & $.270+n ?$ & & & & & 0.13 & OREOOI & 803 \\
\hline 9,233 & $p \Delta>3$ & $.274+0 ?$ & & & & & 0.13 & 006,001 & $80 \Delta$ \\
\hline & $\begin{array}{ll}11 & 1\end{array}$ & $.20 \mathrm{R}+n ?$ & $100+03$ & $10 n=03$ & $.250-00$ & $.1 n_{0}+01$ & $.350+03$ & CRrLIE & 1066 \\
\hline 922 & $\cup 3$ & $.20 R+02$ & $150+0 ?$ & $.110=04$ & $.250-01$ & $.110+00$ & $.350+03$ & ORPLIP & 1067 \\
\hline 925 & 116 & $.208+0 ?$ & $.300+03$ & $.110-04$ & $.280-01$ & $.110+00$ & $.180+04$ & $n R r_{i}: R$ & 1068 \\
\hline 92230 & U 5 & $\cdot$ & & & & & $.348+03.35+03.35+03$ & ORCLIIA & $16 t^{2}$ \\
\hline 922 & U20 & $.20 R+\cap 2$ & & & & & 3.4 & $O R$ r. 001 & 805 \\
\hline 0 & บ2 1 & $.20^{2}+05$ & & & & & 3.4 & ORpoos & 806 \\
\hline 92230 & U22 & $.20 R+02$ & & & & & 3.4 & $O R=001$ & 807 \\
\hline $\begin{array}{l}9 ? 230 \\
9 ? 232\end{array}$ & $\begin{array}{l}423 \\
41\end{array}$ & $\begin{array}{l}.205+02 \\
270+05\end{array}$ & $: 100+03$ & $100-03$ & $.250-00$ & $100+01$ & 3.4 & ORCOOOI & $\begin{array}{r}608 \\
1070\end{array}$ \\
\hline $9 ? 232$ & 113 & $.270+15$ & $150+0 ?$ & $\therefore 110-0 \mathrm{a}$ & $.280-01$ & $.110+00$ & $.110+03$ & OReLI & 9071 \\
\hline & U 6 & $.270+05$ & $.300+03$ & $.110-04$ & $.290-01$ & $.110+00$ & $.120+04$ & nophje & $907 \bar{c}$ \\
\hline $9>232$ & U & & & & & & $.552+02.76+02.19+03$ & ORRLIB & 1073 \\
\hline 9,232 & 1120 & $.27 n+0.5$ & & & & & 0.54 & ofenol & 807 \\
\hline $9>232$ & 1121 & $.270+05$ & & & & & 0.54 & 020001 & 810 \\
\hline $9 ? 2$ & 1122 & $.270+05$ & & & & & 0.53 & 020009 & BI: \\
\hline 92232 & U23 & $.270+05$ & & & & & 0.53 & CHe.001 & 812 \\
\hline & U1 1 & $.590+08$ & $100+03$ & $.100-03$ & $.250=00$ & $.100+01$ & $.500+02$ & ORPLLIR & 1074 \\
\hline 92 & $\cup 3$ & $.500+08$ & $150+02$ & .110004 & - $Z R O=01$ & $.110+00$ & $.5 \cap 0+012$ & OR PLI I & 1075 \\
\hline & U 6 & $.500+n 8$ & $.3 \cap 0+03$ & $.110=04$ & $.250-01$ & $.110+00$ & $50+03$ & ORPLIA & 1076 \\
\hline 922 & $11 A$ & & & & & & $.500+02$ & ORPLIB & 1077 \\
\hline 922 & U20 & $.500+08$ & & & & & 0.49 & 02 r. 001 & 813 \\
\hline & แอ 21 & $.590+\cap A$ & & & & & 0.49 & DRP, 001 & 814 \\
\hline & U2? & $.50 n+n 8$ & & & & & 0.49 & $0 R 0001$ & 815 \\
\hline $9 ?$ & บ?3 & $.500+0 R$ & & & & & 0.49 & $O R=001$ & 810 \\
\hline & U 1 & $.010+\cap_{B}$ & $100+n 3$ & $.100=03$ & $.250-00$ & $.100+01$ & $.490+02$ & ORrLLIA & 1078 \\
\hline 922 & U 7 & $.010+n 8$ & $\therefore 5 n+n ?$ & $.110-04$ & $.200-01$ & $.110+00$ & $.490+02$ & OR RLI I & 1070 \\
\hline $9>2$ & 196 & $.910+.98$ & $.300+03$ & $.110-04$ & $.290-01$ & $.110+00$ & $.240+0,3$ & CRrLLIB & $10 R 0$ \\
\hline $9 ? ?$ & UI $A$ & & & & & & $.400+02$ & OPrLIB & 1081 \\
\hline & 1) 20 & $.910+08$ & & & & & 0.48 & 00001 & 817 \\
\hline & U2! & $.910+0 R$ & & & & & 0.49 & $0 Q 0001$ & 818 \\
\hline & U2 2 & $.910+n e$ & & & & & 0.48 & $0 R+001$ & 819 \\
\hline
\end{tabular}




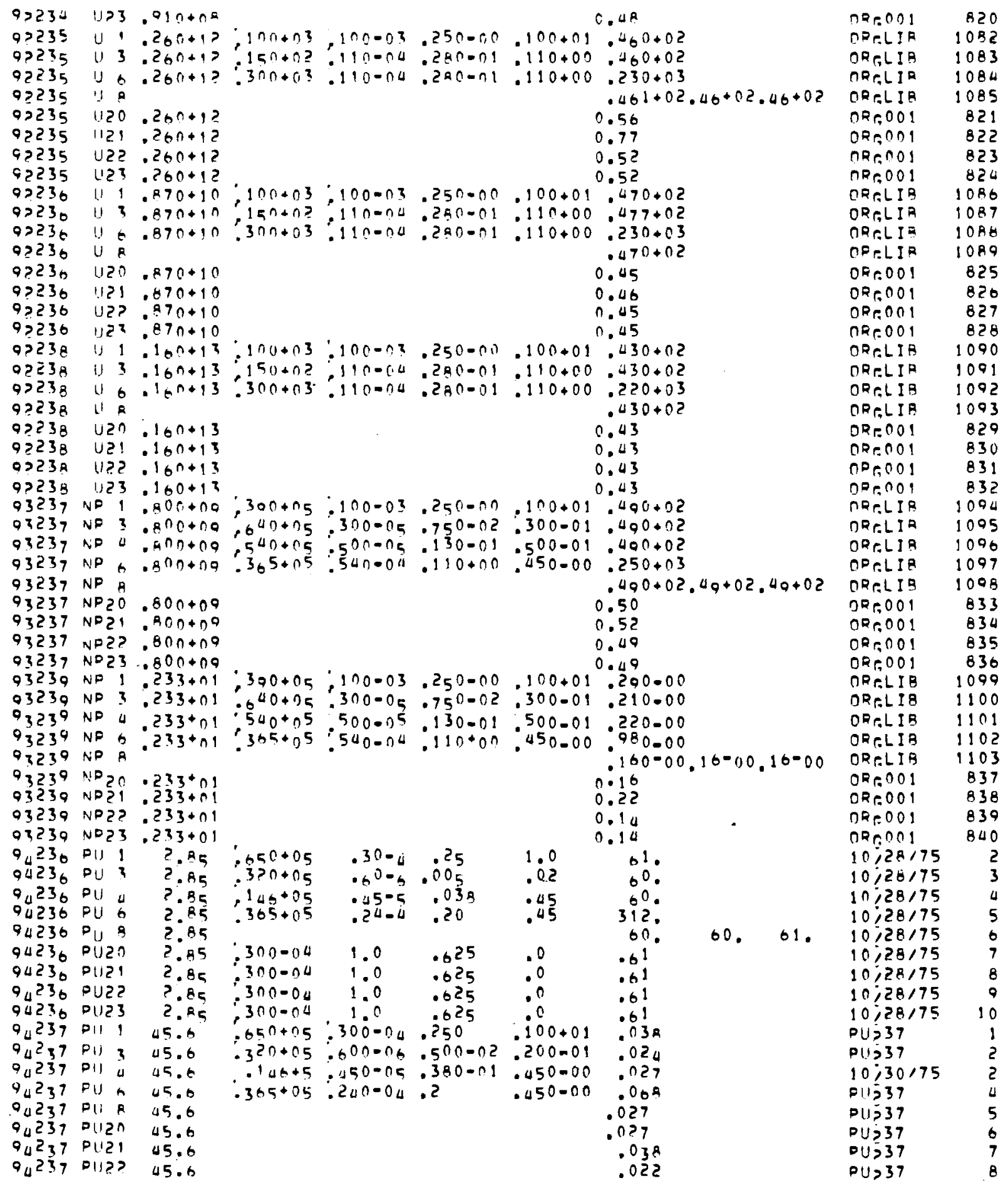




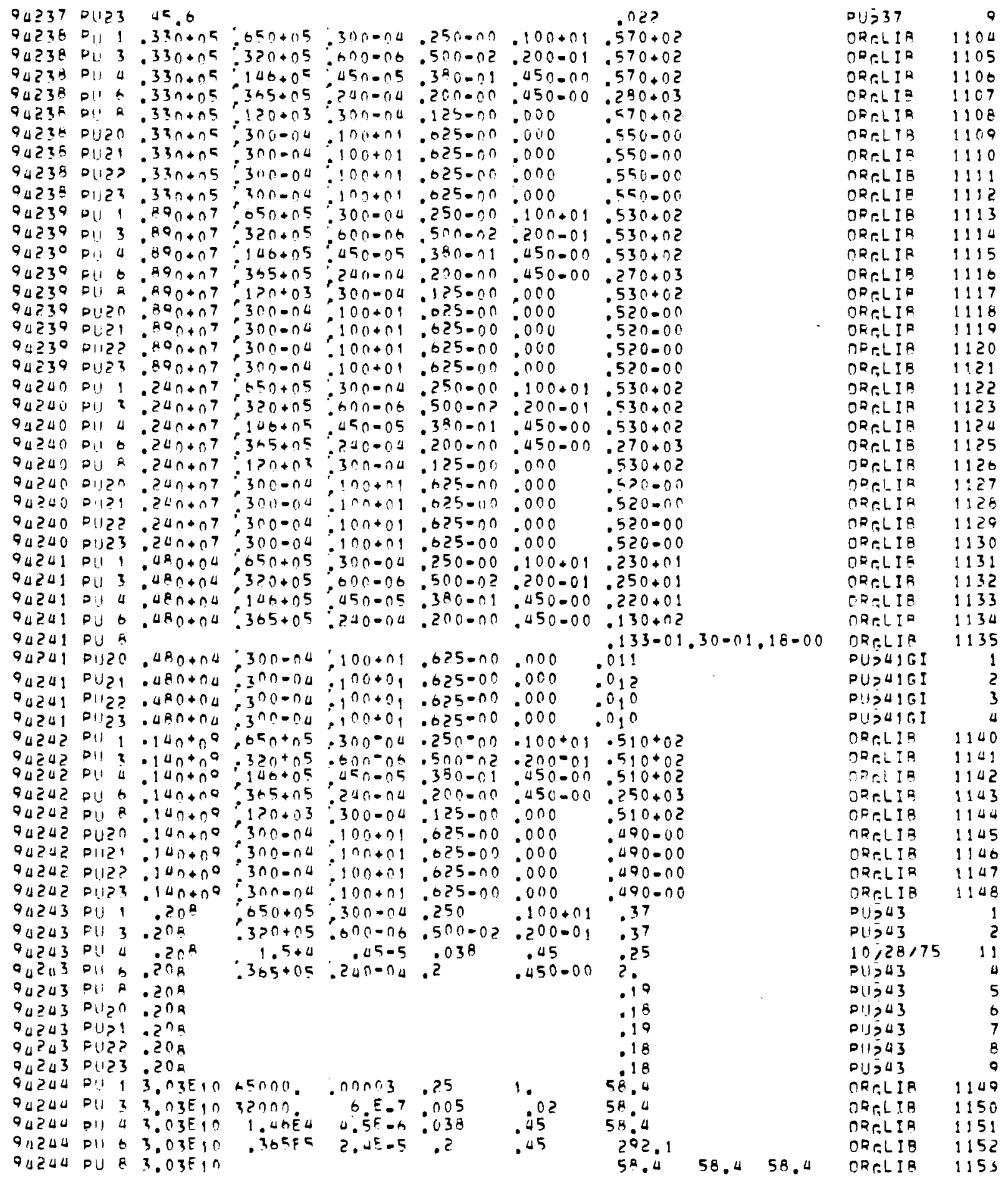




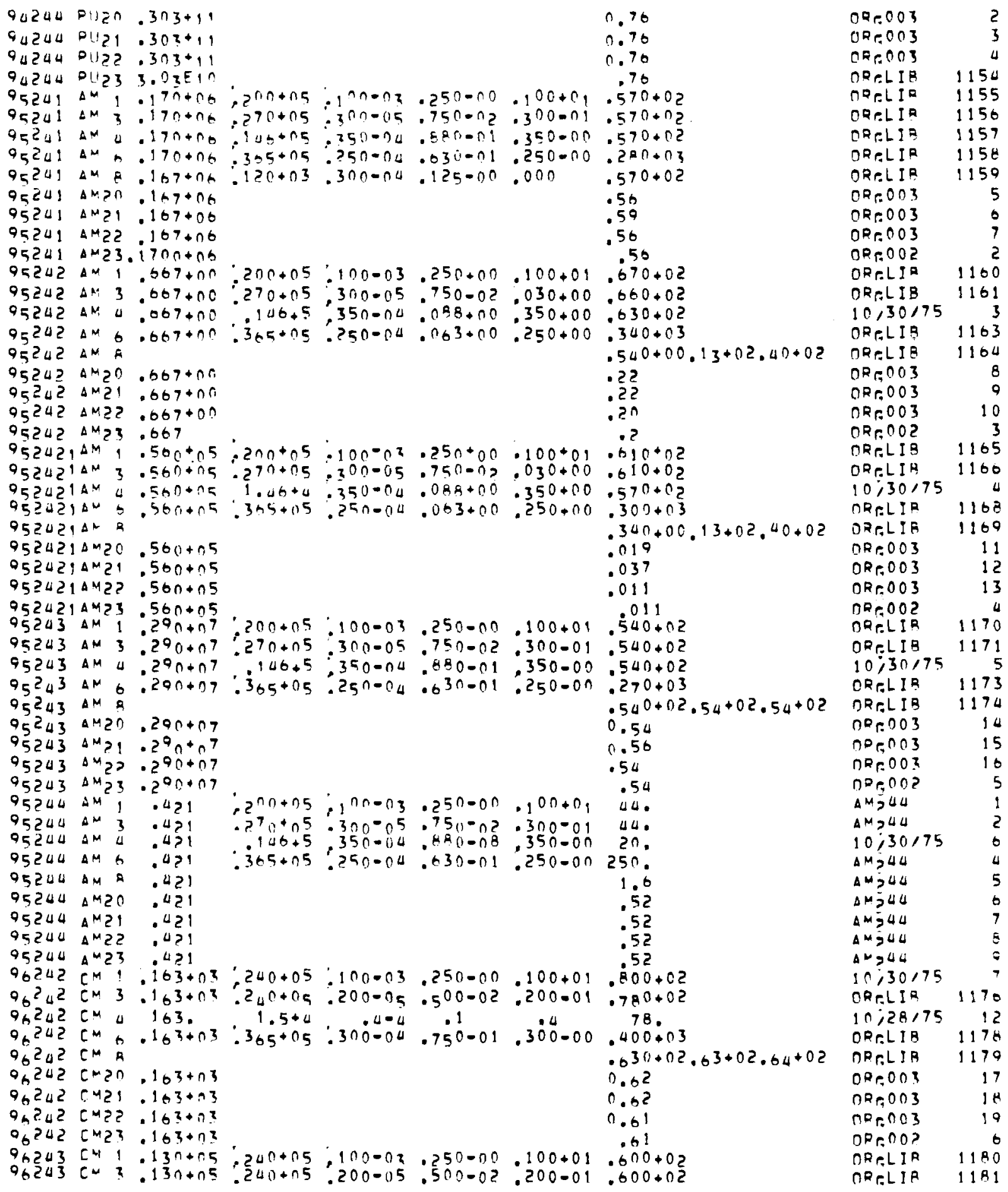




\begin{tabular}{|c|c|c|c|c|c|c|c|c|c|}
\hline 96243 & & $: 13+5$ & $1.5+4$ & .0 .4 & $: 1$ & .4 & 00 & $10 ; 28 / 75$ & 13 \\
\hline 96243 & $C^{4}$ & $.13 n+05$ & $.365+05$ & $300-114$ & $.75 n-n 1$ & $.3 n=00$ & $.3 \cap 0.03$ & CRr.LIE & 1983 \\
\hline $\ln 203$ & CM & & & & & & $.000+02.00+02.00+02$ & AR r.LIA & 1184 \\
\hline $6^{2}+3$ & $C^{M} 20$ & $.130+05$ & & & & & 0.04 & noenO & 20 \\
\hline 76243 & $C^{M} ?$ ! & $.13 n+05$ & & & & & 0.71 & $O R=003$ & 21 \\
\hline 96243 & $C^{4} 52$ & $.130+05$ & & & & & 0.61 & $0+0003$ & 22 \\
\hline 6243 & {$[M ? 3$} & $-13 n+n 5$ & & & & & .61 & $02 \div 002$ & 7 \\
\hline $66^{2} a 4$ & CM 1 & $.67 n+104$ & $: 2_{4} n+n \leq$ & $: 100-03$ & $.250-00$ & $.100+0 !$ & $.600+02$ & OR RLIA & 1185 \\
\hline $62 u d$ & [M 3 & $.67 n+04$ & $.24 n+05$ & $.200-05$ & $.500-0 ?$ & $.200-01$ & $.000+02$ & ORRLIR & 1186 \\
\hline $\begin{array}{l}96204 \\
96244\end{array}$ & CM 4 & in $7+4$ & $1.5+0$ & $\cdot 3000-4=4$ & $i=0$ & $\therefore: 4$ & $\begin{array}{ll}60 \\
310+03\end{array}$ & $10 ; 25 / 75$ & 140 \\
\hline $9_{6}^{9} 240$ & Con & $.670+00$ & $.565+15$ & $.300-00$ & $.750 \cdot 01$ & $.500=0 n$ & $.600+02.50+02.60+02$ & OACLIS & 1189 \\
\hline 96244 & C4 10 & $.070+04$ & $100+00$ & & & .0005 & $.600+02$ & ORPLII & 1190 \\
\hline 96344 & C4I1 & $.570+n 4$ & $.190+00$ & & & .0001 & $.600+02$ & DRCLIS & 1191 \\
\hline 6240 & CM2O & $.67 n+04$ & & & & & .59 & 020003 & 23 \\
\hline $\begin{array}{l}96204 \\
96204\end{array}$ & $\begin{array}{ll}C M S T \\
C M S !\end{array}$ & $\begin{array}{l}.07 n+n 4 \\
.07 n+n 4\end{array}$ & & & & & .50 & $\begin{array}{l}025003 \\
080003\end{array}$ & $\begin{array}{l}24 \\
25\end{array}$ \\
\hline $9+244$ & $C M>3$ & $.070+15$ & & & & & .58 & ORro0? & 8 \\
\hline $\begin{array}{l}96205 \\
96205\end{array}$ & $C^{N}$ & $\begin{array}{l}.730+07 \\
.730+07\end{array}$ & $\begin{array}{l}240+05 \\
240+05\end{array}$ & $\begin{array}{l}100-1) 3 \\
.200=05\end{array}$ & $\begin{array}{l}.250=00 \\
.500=02\end{array}$ & $\begin{array}{l}.100+01 \\
.200-01\end{array}$ & $\begin{array}{l}.560+02 \\
.560+02\end{array}$ & $\begin{array}{l}\text { ORFLIIE } \\
\text { TRPLIB }\end{array}$ & $\begin{array}{l}1192 \\
1193\end{array}$ \\
\hline 96245 & $C+1$ & $.73+7$ & $.1 .5+4$ &., $0=0$ & .1 & $0^{4}$ & So. & $10 ; 28,75$ & 15 \\
\hline 96245 & $C^{m}$ & $.73 n+07$ & $.3+5+05$ & $.300-04$ & $.750-01$ & $.300-00$ & $.230+03$ & CPRLIIB & 1195 \\
\hline 96205 & $\begin{array}{l}C M \\
C N 20\end{array}$ & $.730+07$ & & & & & $.550+02.55+02.55+02$ & OROLIA IA & 1196 \\
\hline $0_{6} 2,15$ & $C+21$ & $\begin{array}{l}.730+07 \\
.73 n+.07\end{array}$ & & & & & $\begin{array}{l}.57 \\
.01\end{array}$ & 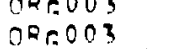 & $\begin{array}{l}20 \\
27\end{array}$ \\
\hline $0 n^{2} \cup 5$ & $6+2 ?$ & $.730+07$ & & & & & .50 & 020003 & 28 \\
\hline$q_{n} 245$ & $C N=3$ & $.730+17$ & & & & & .55 & ORrooz & 9 \\
\hline 96240 & [M ! & $.240+07$ & $200+05$ & $100=03$ & $.256-00$ & $.100+01$ & $.560+02$ & OFPLIE & 1197 \\
\hline 96200 & {$\left[\begin{array}{ll}m & -1 \\
2 & 3\end{array}\right.$} & $.240+n 7$ & $.240+05$ & $.200-05$ & $.500=02$ & $.200-01$ & $.560+02$ & OR日 L IR & 1198 \\
\hline 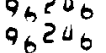 & $c^{2}$ & $.240+07$ & $.3 .5+0$ & $: 3 n i=04$ & $.7 \dot{0}=01$ & $3 \dot{0} 0=0$ & $\begin{array}{l}56 . \\
280+03\end{array}$ & $\begin{array}{l}10 / 28 / 75 \\
00 r_{R} L I R\end{array}$ & 1199 \\
\hline $9+200$ & CM & & & & - J & & $.560+02$ & ORRLIA & 1200 \\
\hline 96206 & $\operatorname{CM} 20$ & $.240+0^{7}$ & & & & & .54 & ORr,003 & 29 \\
\hline 96200 & CM21 & $.200+07$ & & & & & .54 & ORr,003 & 30 \\
\hline 96240 & $c^{M} 22$ & $.240+07$ & & & & & .54 & $\cap R r, 003$ & 31 \\
\hline 96206 & $C^{M}{ }^{4} 3$ & $-240+07$ & & & & & .54 & 020003 & 32 \\
\hline $\begin{array}{l}96267 \\
96207\end{array}$ & $\cos 1$ & $\begin{array}{l}5.62=9 \\
5.62 F 0\end{array}$ & $\begin{array}{l}5,000 . \\
54000\end{array}$ & $\begin{array}{l}=0 \cap 01 \\
? . E-6\end{array}$ & .25 & 1.02 & $\begin{aligned} 55 \\
55\end{aligned}$ & $\begin{array}{l}\text { OPRLLIF } \\
\text { ORCLLIA }\end{array}$ & $\begin{array}{l}1201 \\
1202\end{array}$ \\
\hline 96207 & $C * 4$ & $5.62+0$ & $1.5+4$ & $4=4$ & $\div 1$ & & 570 & $10 / 28 / 75$ & 17 \\
\hline 96207 & {$[+4$} & $5 \cdot 6^{2}=0$ & $.365 E 5$ & $.0 \mathrm{NOO}_{3}$ & .075 & $\cdot 3$ & 55. & ORFL I B & 1204 \\
\hline $\begin{array}{l}47 \\
47\end{array}$ & $\begin{array}{ll}C^{N} & R\end{array}$ & $\begin{array}{l}5.6250 \\
5.6250\end{array}$ & & & & & 55. & OPRLIB & 1205 \\
\hline $\begin{array}{l}96247 \\
96267\end{array}$ & 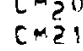 & $\begin{array}{l}5.6 ? 5^{\circ} \\
5.6 ? 50\end{array}$ & & & & & $\begin{array}{l}0.53 \\
0.53\end{array}$ & $O R=001$ & 841 \\
\hline 96247 & & 5.6259 & & & & & $\begin{array}{l}0.53 \\
0.53\end{array}$ & $\begin{array}{l}\text { ORenOl } \\
\text { OReOOOLI }\end{array}$ & 843 \\
\hline 96247 & $(4 ? 3$ & $5.62 E 9$ & & & & & 0.53 & 50004 & 15 \\
\hline 96248 & {$[+1$} & 1.7 CE & 54000. & .0001 & .25 & $1 \cdot$ & 453.3 & $10 ; 30 / 75$ & B \\
\hline 95248 & CM & 1.7052 & $>400 n$. & ?. E-6 & .005 & .02 & 453.3 & $10,30 / 75$ & 9 \\
\hline 96208 & CM 4 & $1.70 F \mathrm{~A}$ & $.146+5$ & $.40-5$ & & & 453.3 & $10 ; 30 / 754$ & 1 \\
\hline 962 & EM & $1.70 E^{8}$ & $.365 E^{5}$ & .00003 & .075 & .3 & 2244. & $10,30 / 75$ & 11 \\
\hline 962 & CM $R$ & 1.7058 & & & & & 453.3 & $10 ; 30 / 75$ & 12 \\
\hline $96 ?$ & $C M \geq n$ & $1.70 \mathrm{FA}$ & & & & & 11.05 & $10,30 / 75$ & 13 \\
\hline$\Delta Q$ & CM? & 1.7058 & & & & & 11.45 & $10,30 / 75$ & 14 \\
\hline $9+246$ & [M?? & 1.705 .8 & & & & & 11.45 & $10,30 / 75$ & 15 \\
\hline 965 & $C 423$ & 1.7058 & & & & & 11.45 & $10,30 / 75$ & 16 \\
\hline 97249 & PK & $.290+n 3$ & $.050+05$ & $.300-0 a$ & $.250-00$ & $.100+01$ & $.380+01$ & ORPLLIR & 1213 \\
\hline 97209 & $5 x$ & $\cdot 2^{9} n+n^{3}$ & $.3+5+05$ & .240 .04 & $.200-00$ & $.800=00$ & $.200+02$ & OPCLIB & 1214 \\
\hline 09 & $B \times \&$ & & & & & & $.264-01.04-01.20-00$ & DRPLIE & 1215 \\
\hline 97249 & $9 \times 20$ & - $29 n+n 3$ & & & & & 0.32 & OR:O0 01 & 647 \\
\hline & RK? & $.200+03$ & & & & & 0.32 & $O R E 001$ & $B \Delta \mathrm{H}$ \\
\hline 97249 & $8 \times 22$ & $.200+03$ & & & & & 0.32 & $09 p 001$ & 849 \\
\hline
\end{tabular}




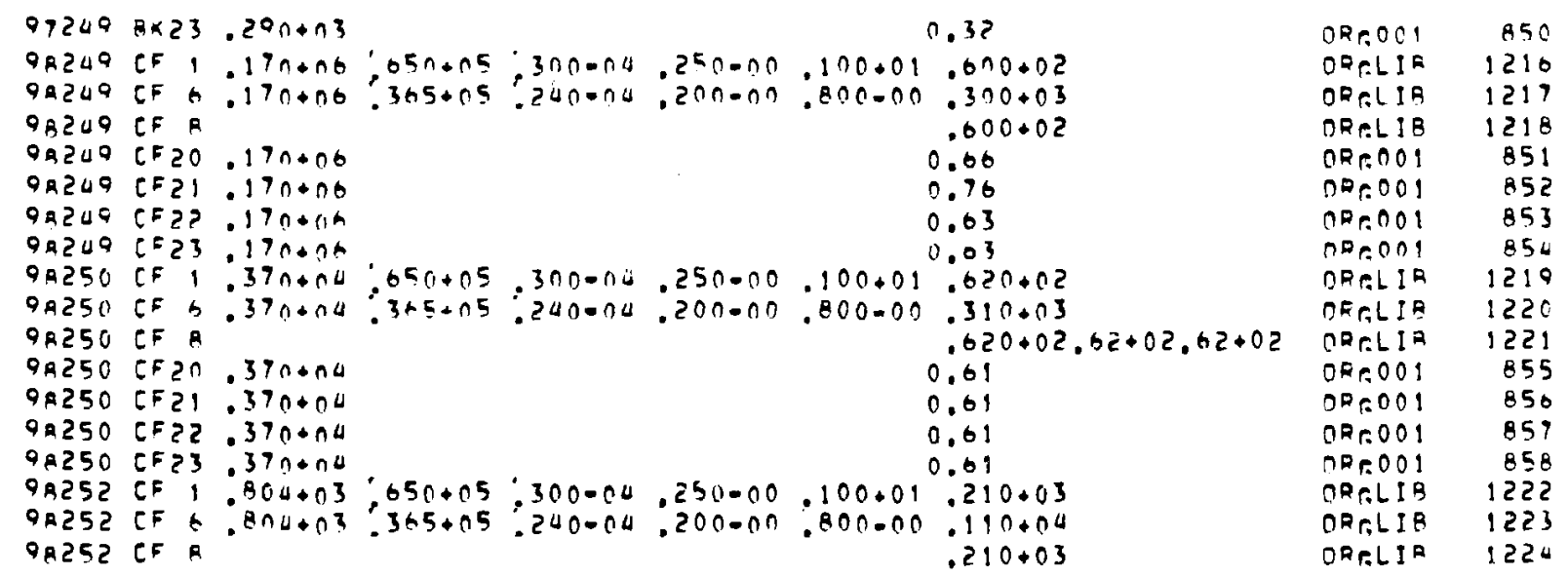




\section{REFERENCES FOR APPENDIX D}

1. The International Commission on Radiological Protection, Report of Committee II on Permissible Dose for Internal Radiation. ICRP Publication 2, Pergamon Press, 0xford, 1972.

2. The International Commission on Radiological Protection, Recommendations of the International Commission on Radiological Protection. ICRP Publication 6, Pergamon Press, 0xford, 1962.

3. The International Commission on Radiological Protection, The Metabolism of Compounds of Plutonium and Other Actinides. ICRP Publication 19, Pergamon Press, Oxford, 1972. 
APPENDIX E

PROGRAM LISTING 


\section{PROGRAM LISTING}

A FORTRAN Tisting of the entire REDIQ program is shown in Figure E-1. The order of the modules is given below.

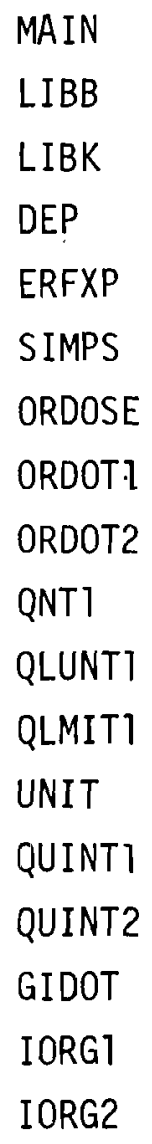


FIGURE E-1. FORTRAN Listing of REDIQ 


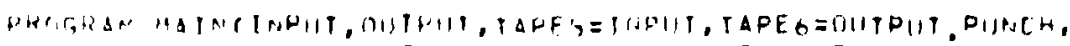

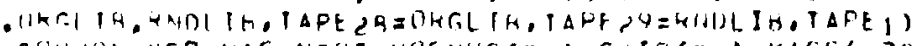

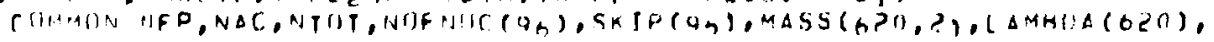

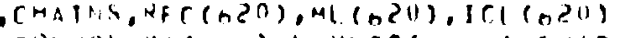

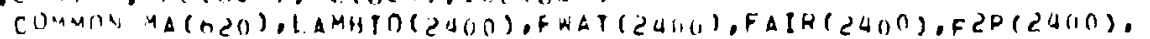

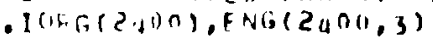

(ilumion

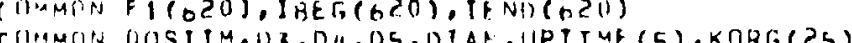

COMmON TITLCz(B), TLN, ILH

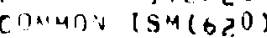

(IIIACIN TPAGE,ORGAN(z,10)

COMMON/NAM/ORGIVAM(2, 2S)

RE $\triangle L$ I. AMFIOI,LAMBDA,MASS

INIERF.R CHAINS, SKIP

IOFICAL FISPRD, ACTPRD

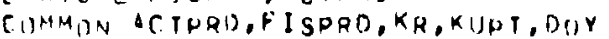

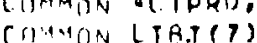

DIMENSITIN DILN(S), DTLH(5), UIRGANS (IU)

INTFF,ER REC,ORTIANS

DIMFASION NIME (ODO), M(OOO)

$0 I_{M F N S I O N}\left[T_{1} H(10), C I L N(10), 15 L(600)\right.$

DIMFNSION IARY (S)

CIIMMONN/RISK/RL (25), RWE

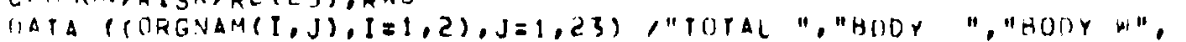
I"ATER ", KION", "EYS ", LTV", "ER ", "SPIE", "EM

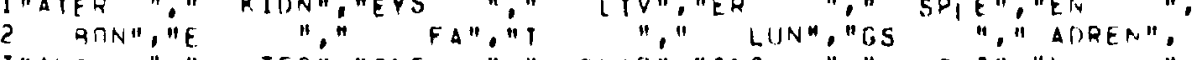

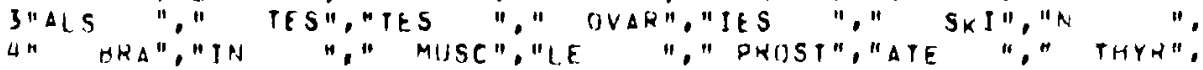
4" HRA", "TA " " MUSC", "LE ", " PKIST", "ATE ", "THYA",

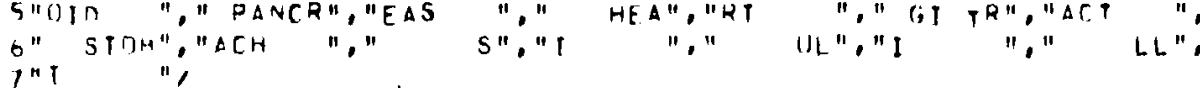
inI

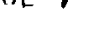
"." LL",

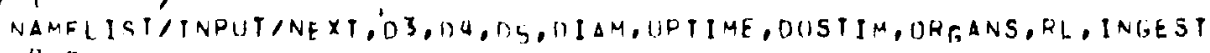
, HAR

(INTT $2 Q$ IS FOR RIBD LIMRARY. USE LUGICAL FILE NAME ATD PERMANENT FILE NAIG IIF ORIRLIB- ON ATYACH CAHI),

IJNIT 2 IS IS FUR THE ORGAN DAIA LHRAGY, USE LOGICAL and PERMANENT FILF NAME UIF ORGLIB- OIN ATTACH CARO.

$1 \triangle R Y(1)=0$

$1 A_{K} Y(P)=0$

[DI SYSIEMC ( I:5, IARY)

CALL DATE (DOY)

DOSTTM $=1,5779 E 9$

$1 E_{R}=0$

IPACE $=1$

IOO REAO I1150, 11IL:

If. $K=0$

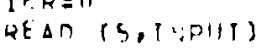

\begin{tabular}{|c|c|}
\hline $\begin{array}{l}M \triangle I N \\
8 / 25 / 76 \\
\text { COMNA }\end{array}$ & 2 \\
\hline REIII & \\
\hline COMNA & \\
\hline COMNH & \\
\hline COMNH & \\
\hline REDID & \\
\hline REOIO & \\
\hline $8 / 23 / 10$ & \\
\hline $\operatorname{COMN}$ & \\
\hline $\operatorname{COMN}$ & 10 \\
\hline $\operatorname{COMN}$ & 11 \\
\hline $\operatorname{COMN}$ & 12 \\
\hline $\operatorname{COMN}$ & is \\
\hline $\operatorname{COMN}$ & 14 \\
\hline $9 / 9,74$ & 3 \\
\hline $8 / 23 / 76$ & s \\
\hline MAIN & B \\
\hline $\operatorname{MAIN}$ & 10 \\
\hline MAIN & il \\
\hline SYSIC & 1 \\
\hline $1011117 \mathrm{n}$ & 0 \\
\hline$M A I N$ & 24 \\
\hline MaIP.] & 25 \\
\hline MAIN & 20 \\
\hline Malis & ? \\
\hline MAIN & 28 \\
\hline $3 / 5 / 75$ & 3 \\
\hline $1 / 23 / 75$ & 4 \\
\hline $1 / 23 / 75$ & 5 \\
\hline REDIN & 50 \\
\hline $\begin{array}{l}10 / 11 / 7 n \\
M \triangle I N\end{array}$ & $\begin{array}{r}7 \\
34\end{array}$ \\
\hline$M A I N$ & 35 \\
\hline$M \triangle I N$ & 30 \\
\hline$M A I N$ & 37 \\
\hline $\operatorname{MAIN}$ & 39 \\
\hline$M \perp \mathbb{I}$ & 39 \\
\hline SYSTC & 2 \\
\hline SYSTR & 3 \\
\hline SYSTC & 4 \\
\hline$M \triangle I N$ & 40 \\
\hline REDIN & 50 \\
\hline$M A I N$ & 41 \\
\hline $4 \triangle I N$ & 43 \\
\hline MAIN & 44 \\
\hline JULY! & 1 \\
\hline $14 I N$ & 45 \\
\hline
\end{tabular}




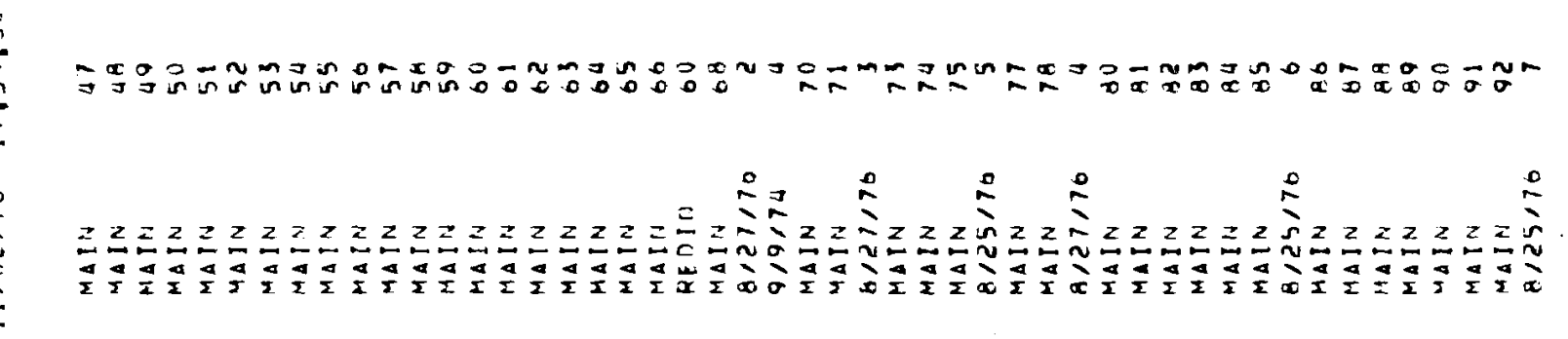

0
$y$
3
$\vdots$
$\vdots$
$z$
2
4

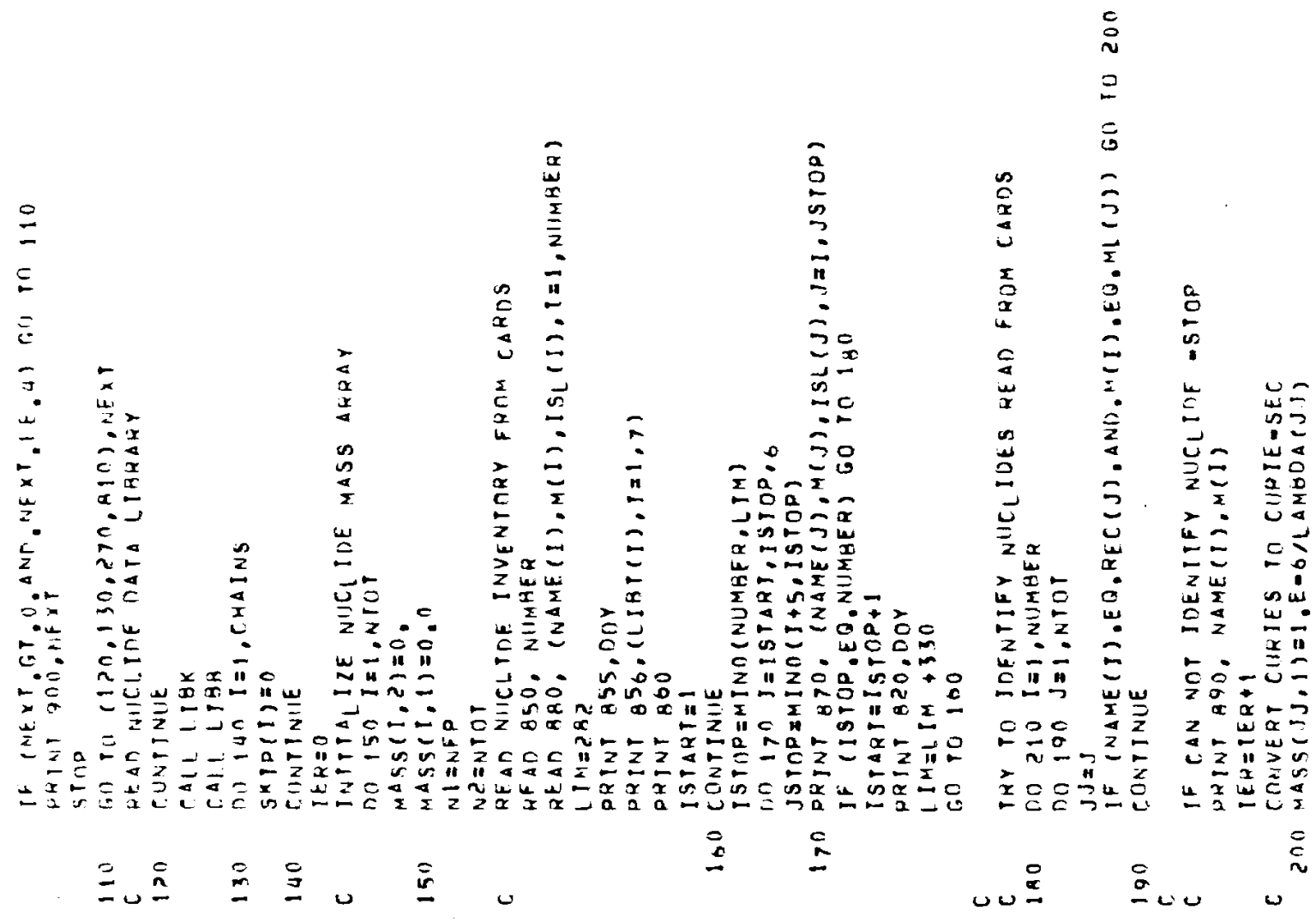

(1)

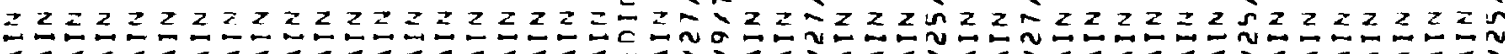

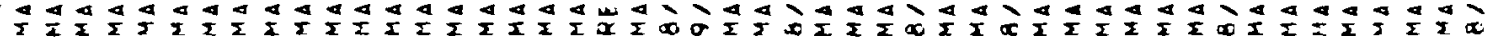



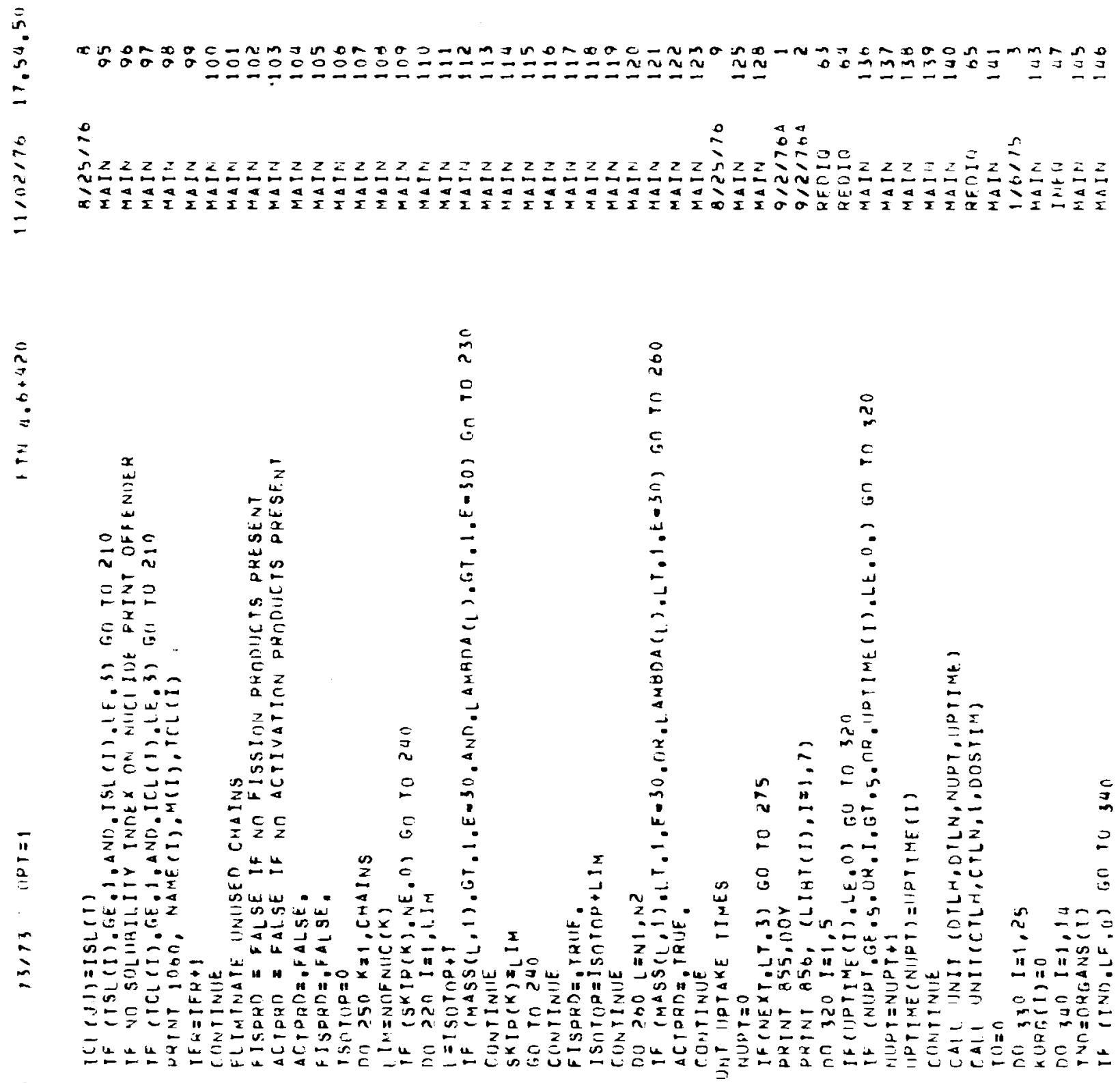

$\frac{2}{3}$

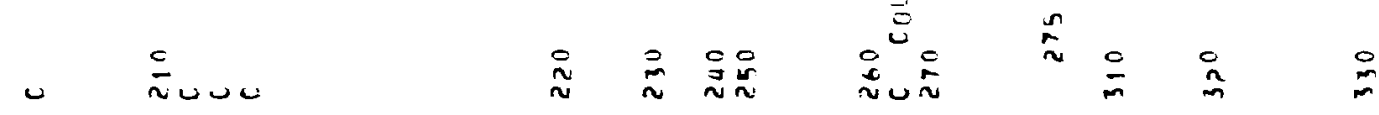

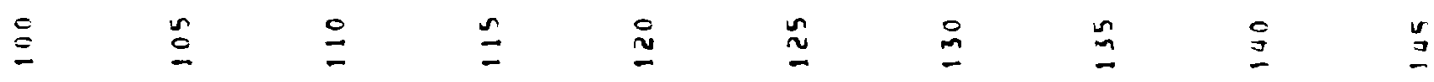




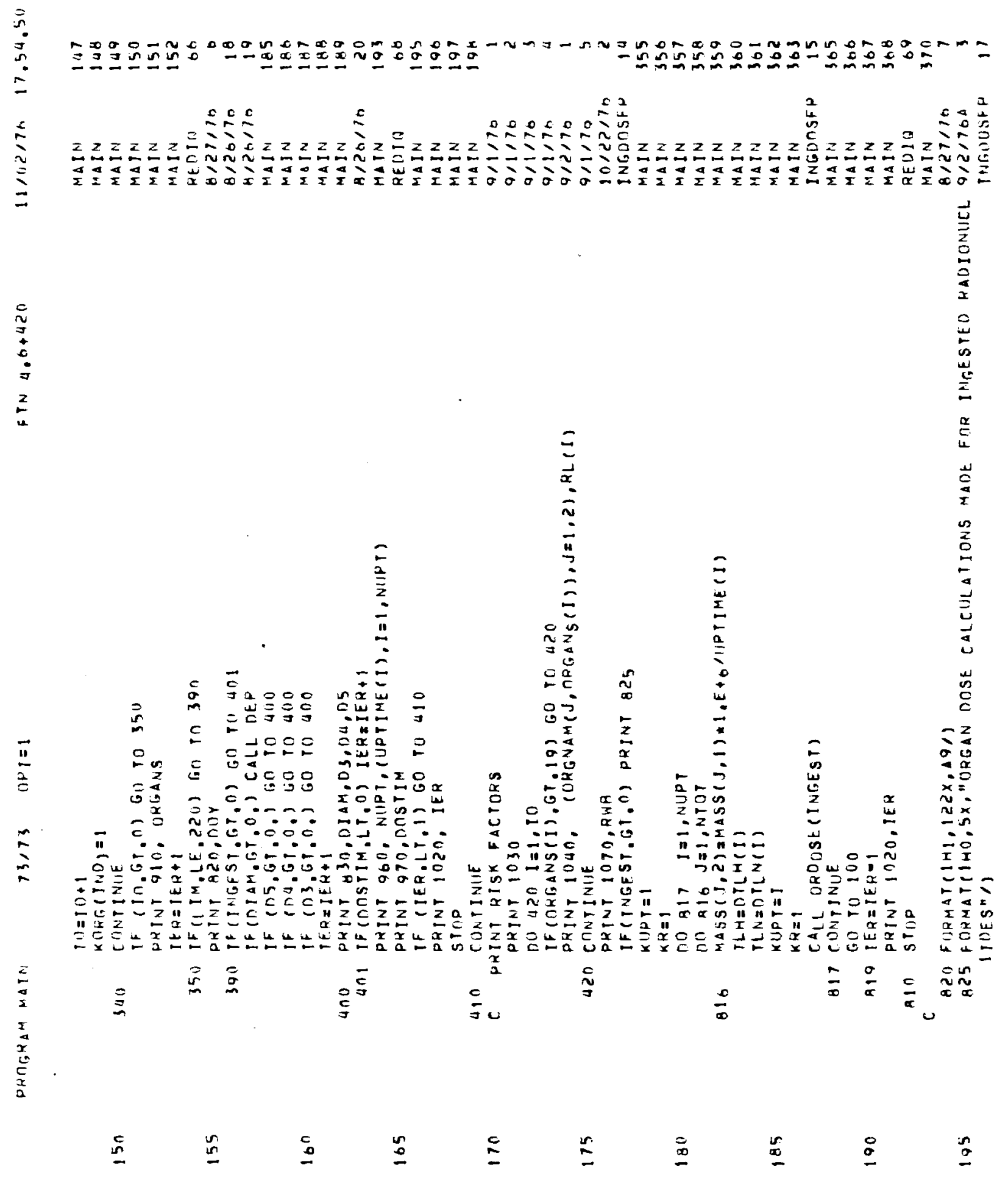




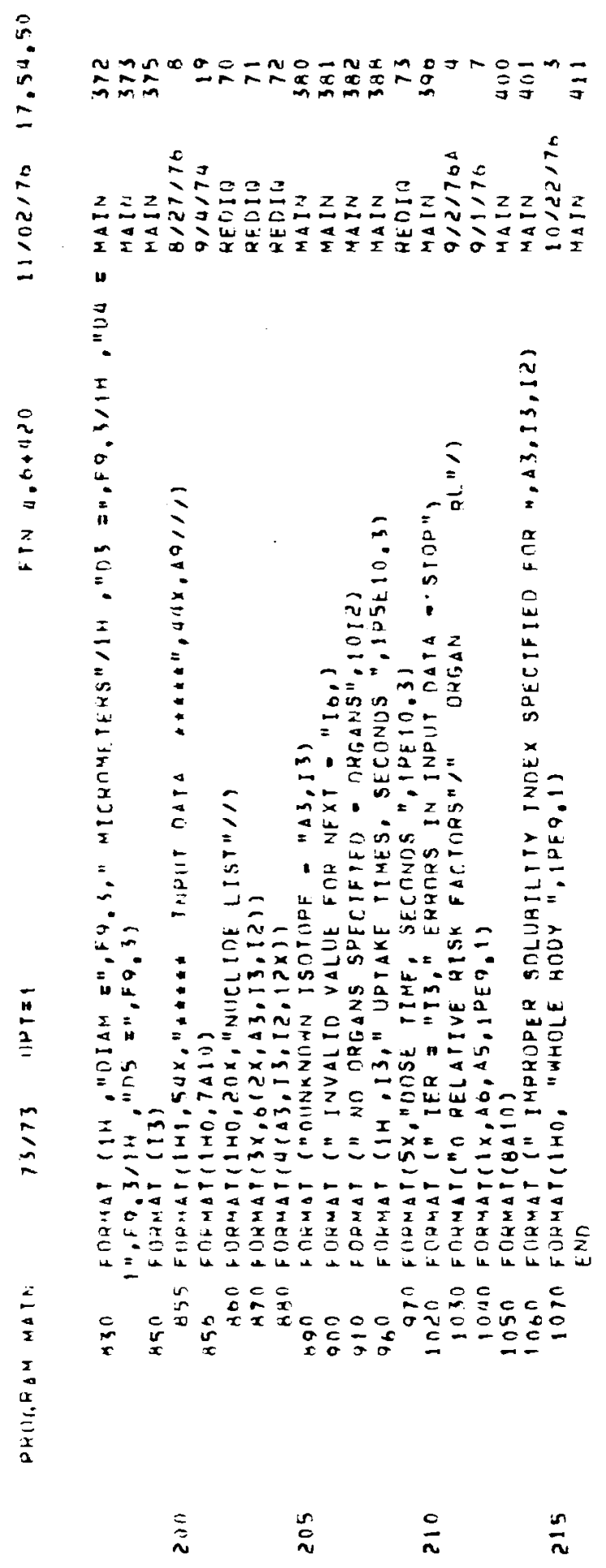




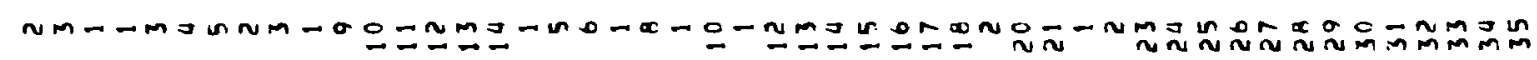

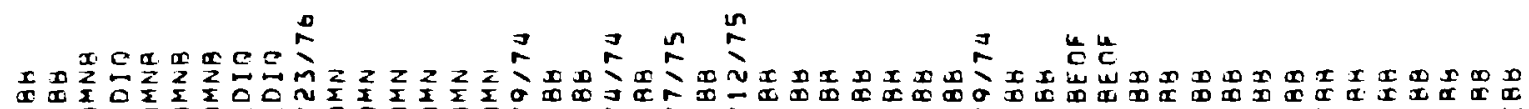

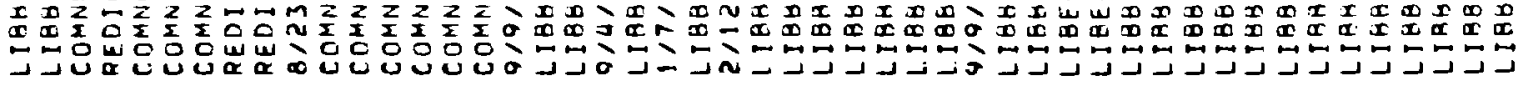

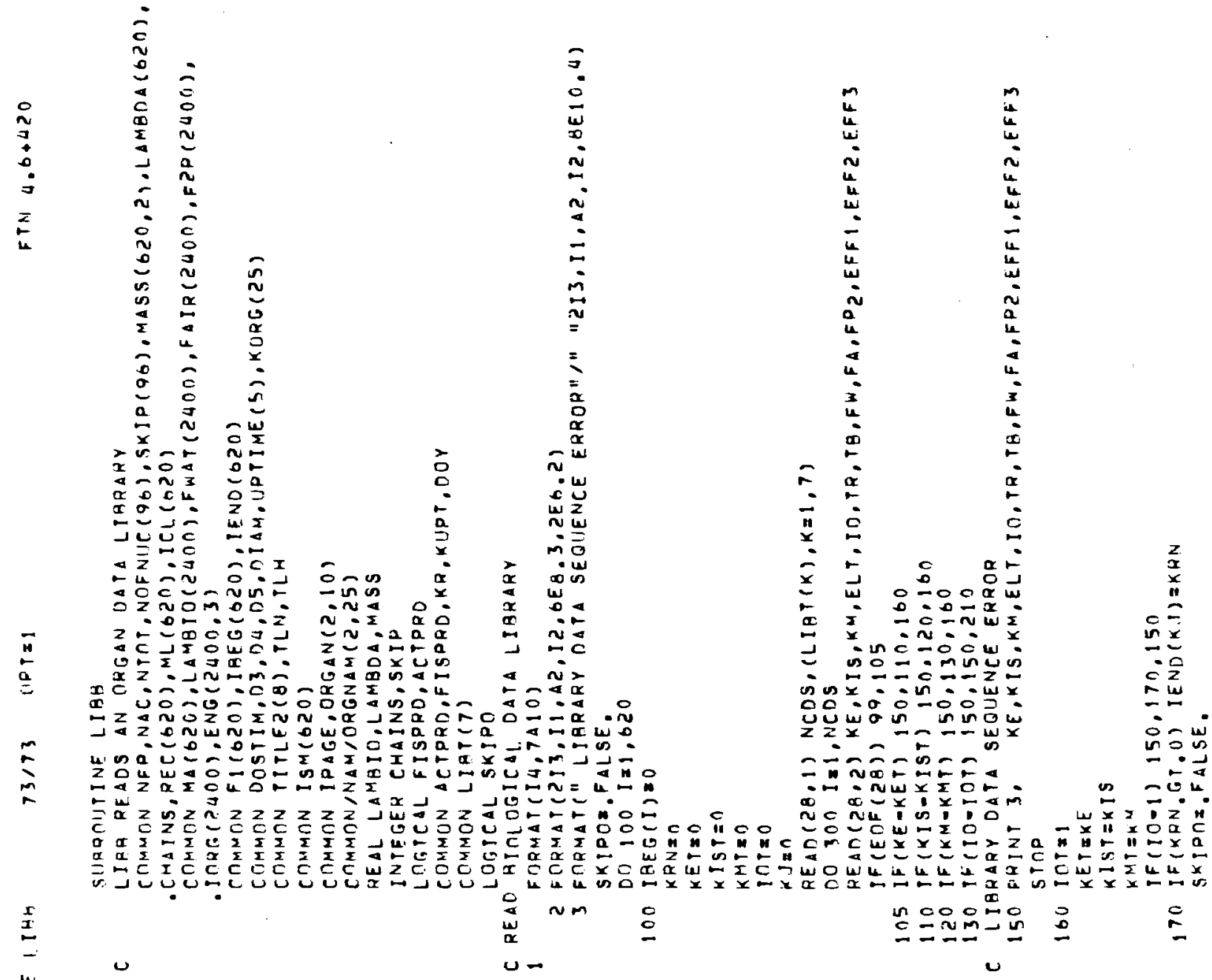

$\frac{1}{2}$ 


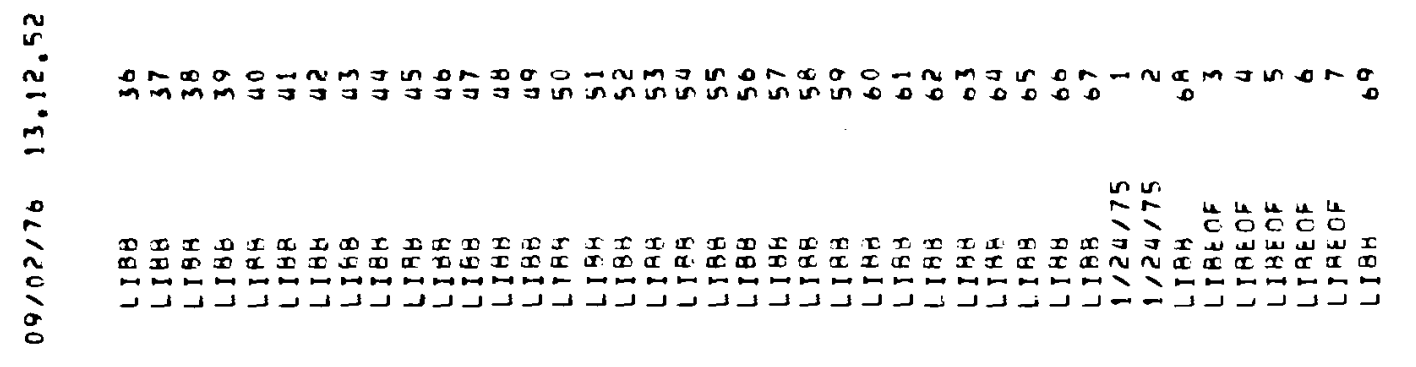

0
0
+
0
$\vdots$
$z$
2

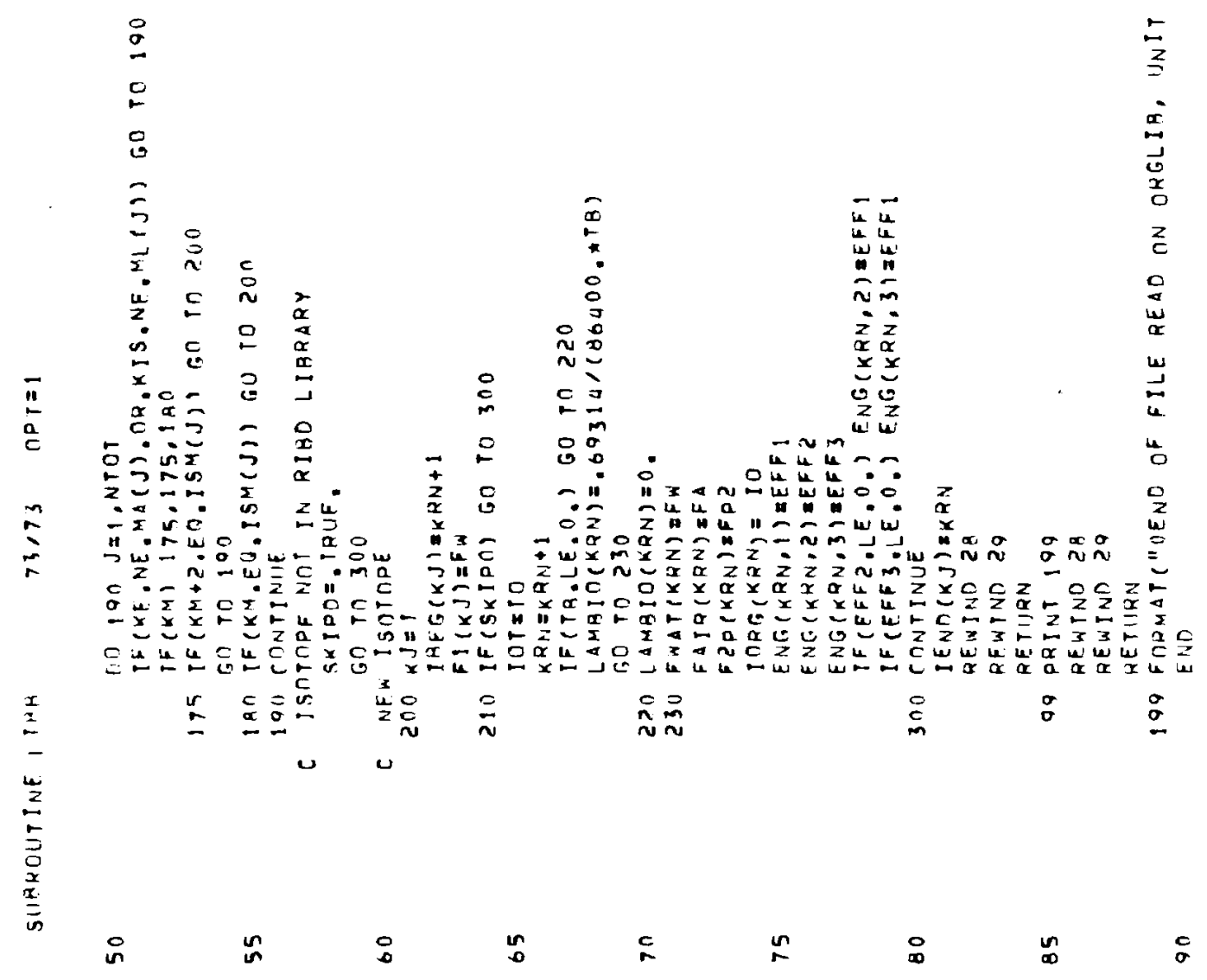




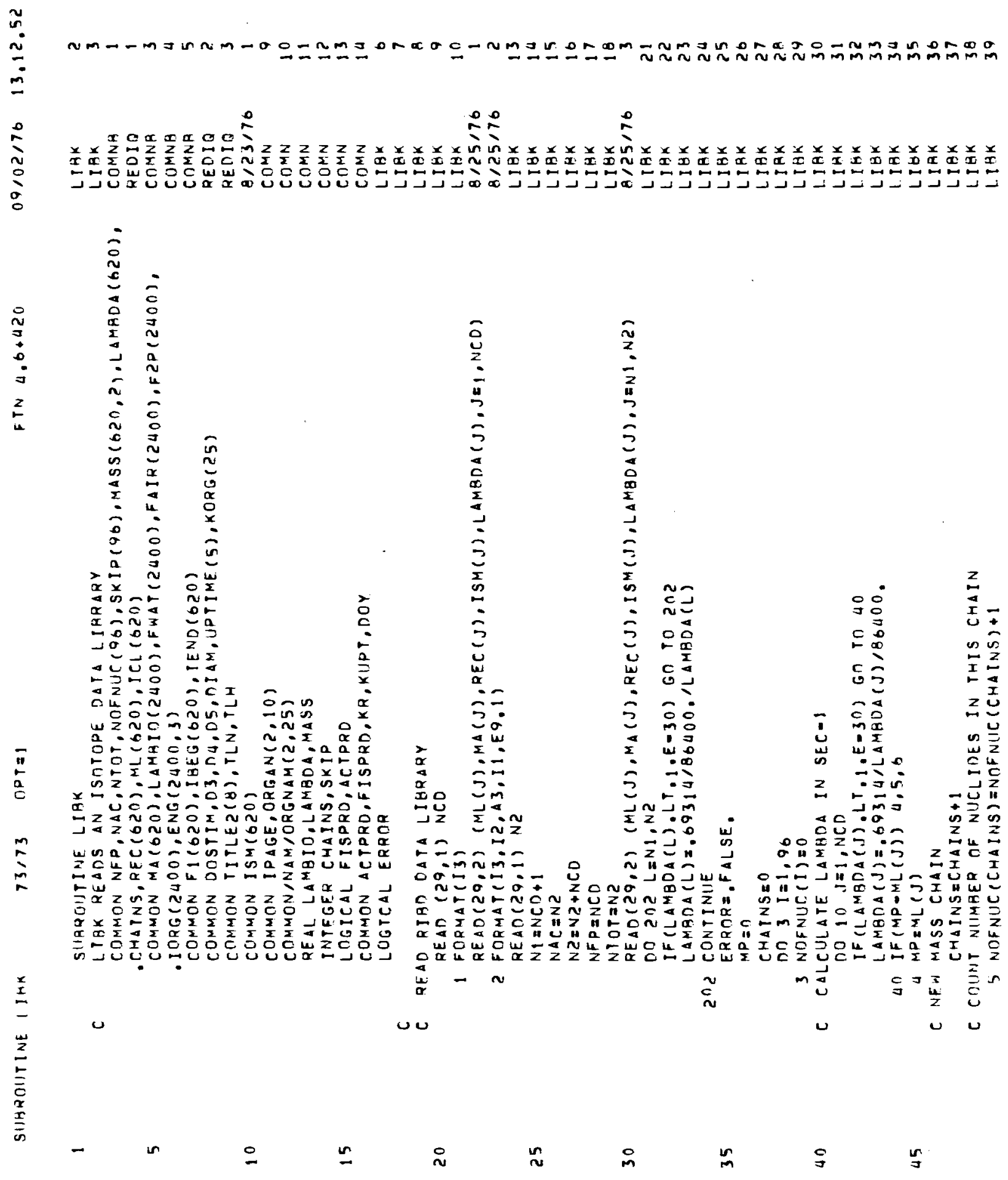




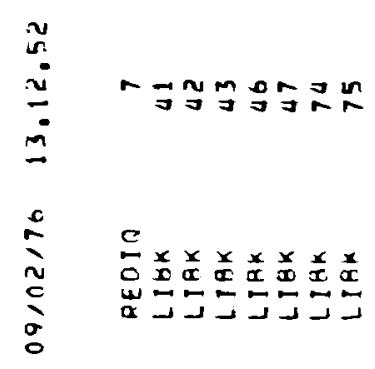

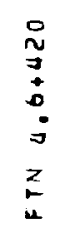

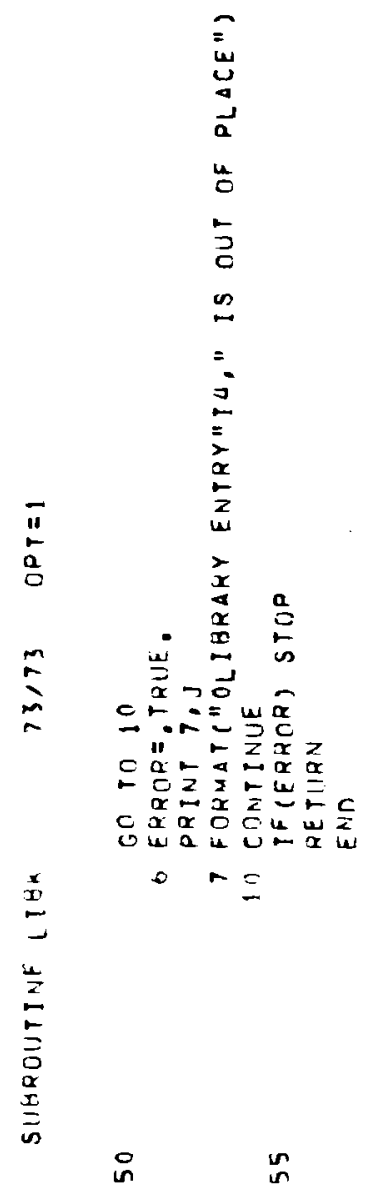



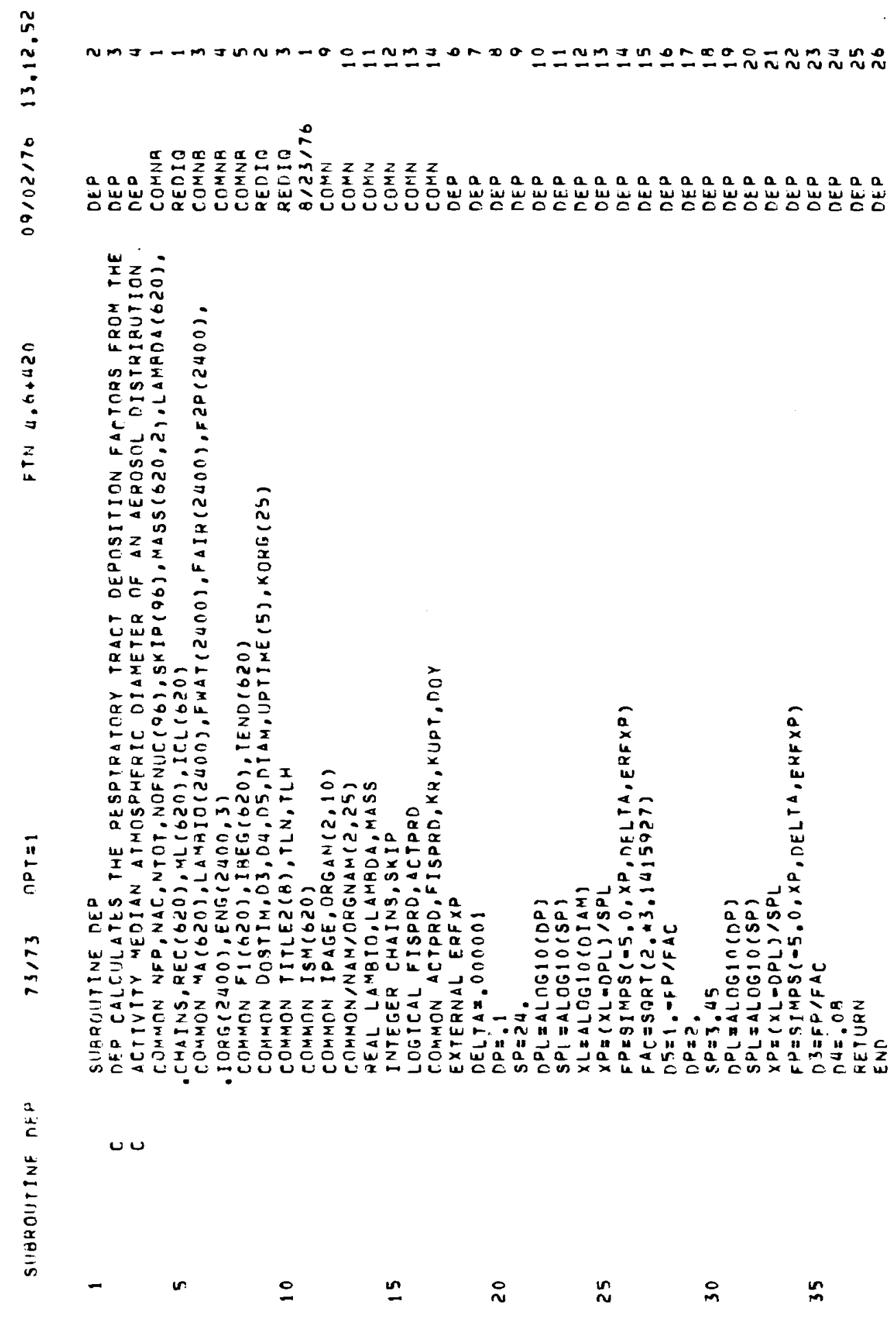

$\stackrel{\circ}{\sim}$



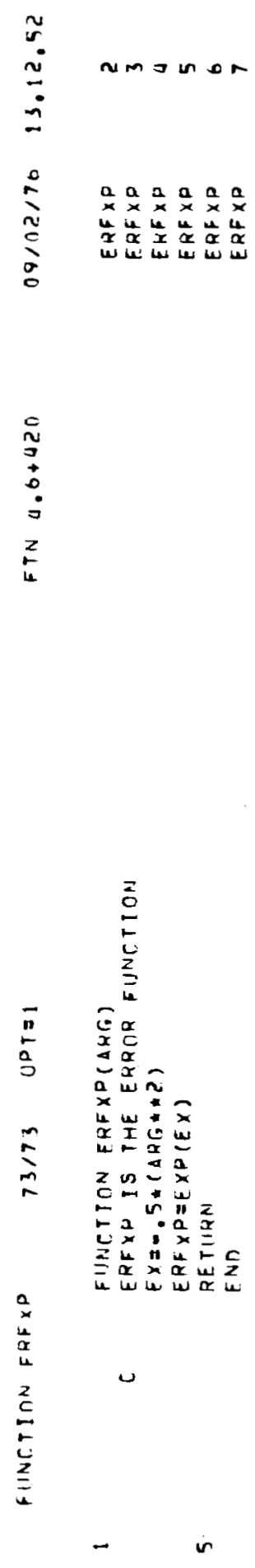


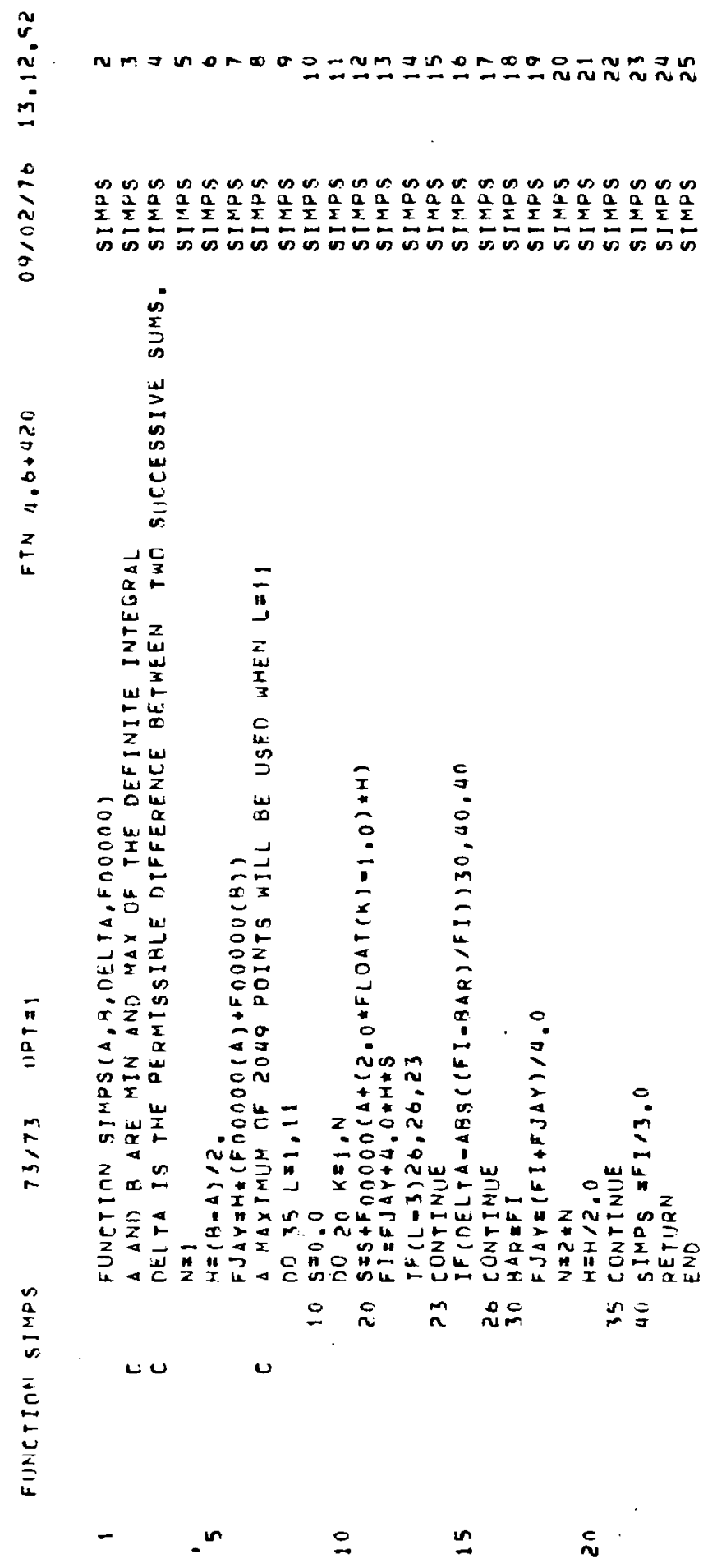




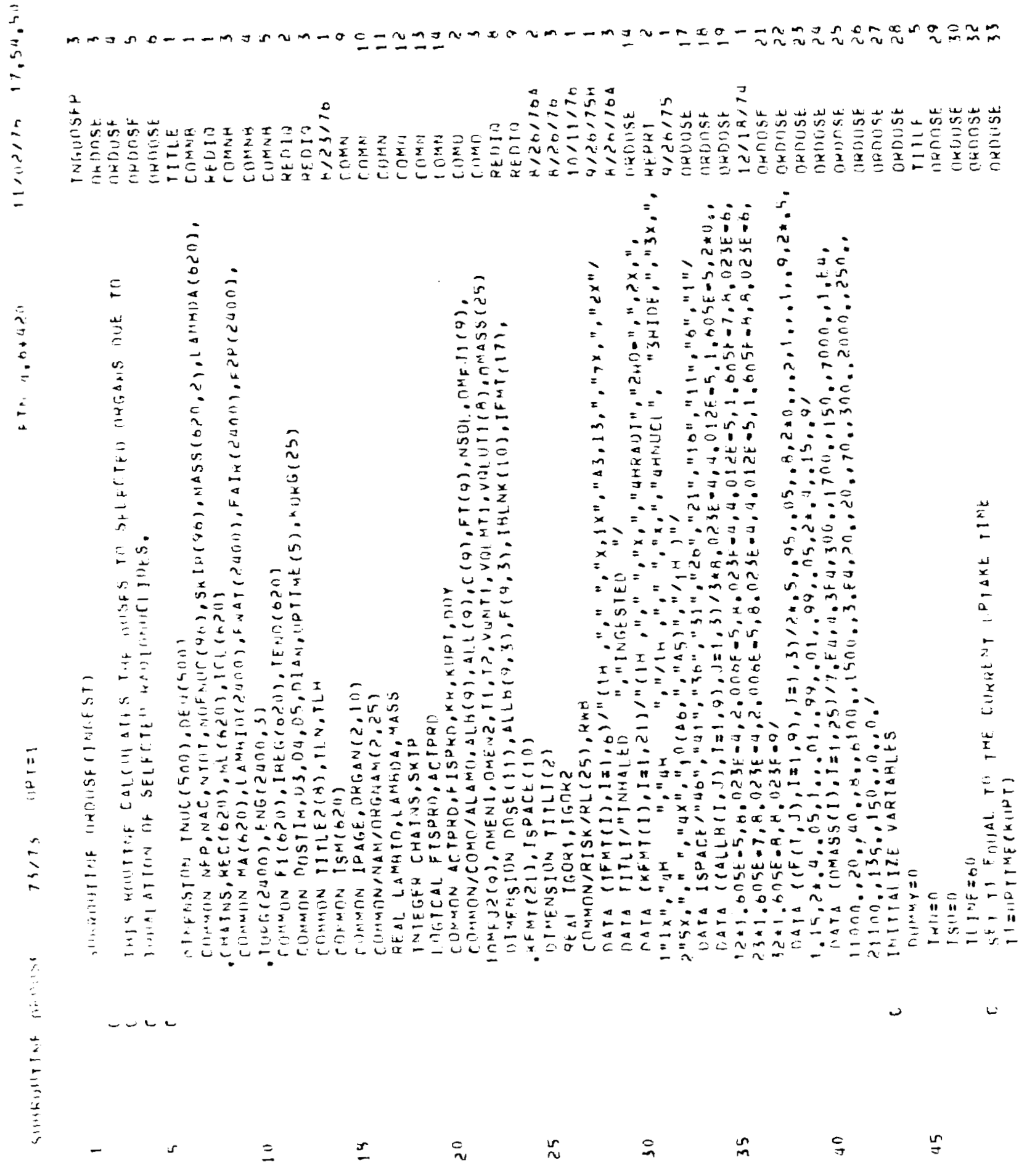




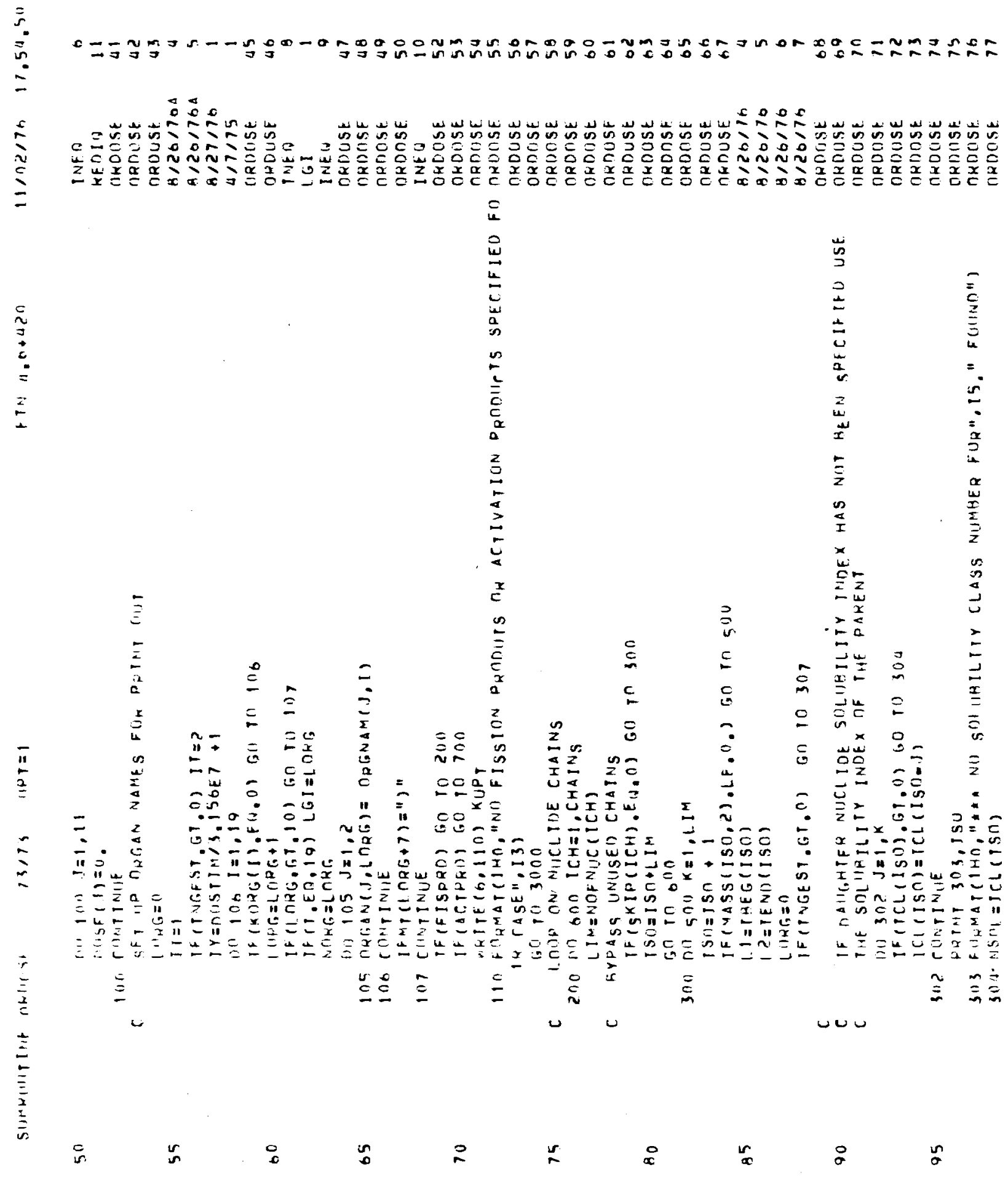




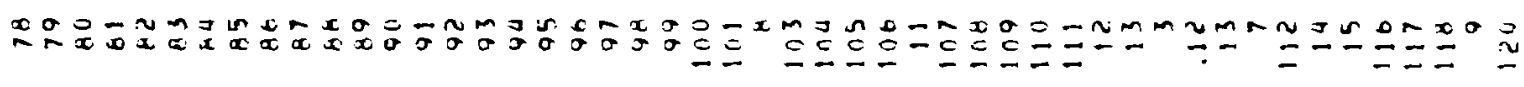

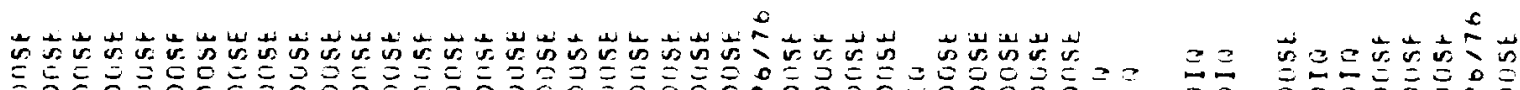

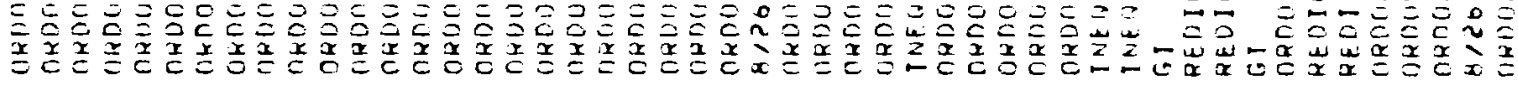

$\vdots$
$\vdots$
$\vdots$
$\vdots$
$\vdots$

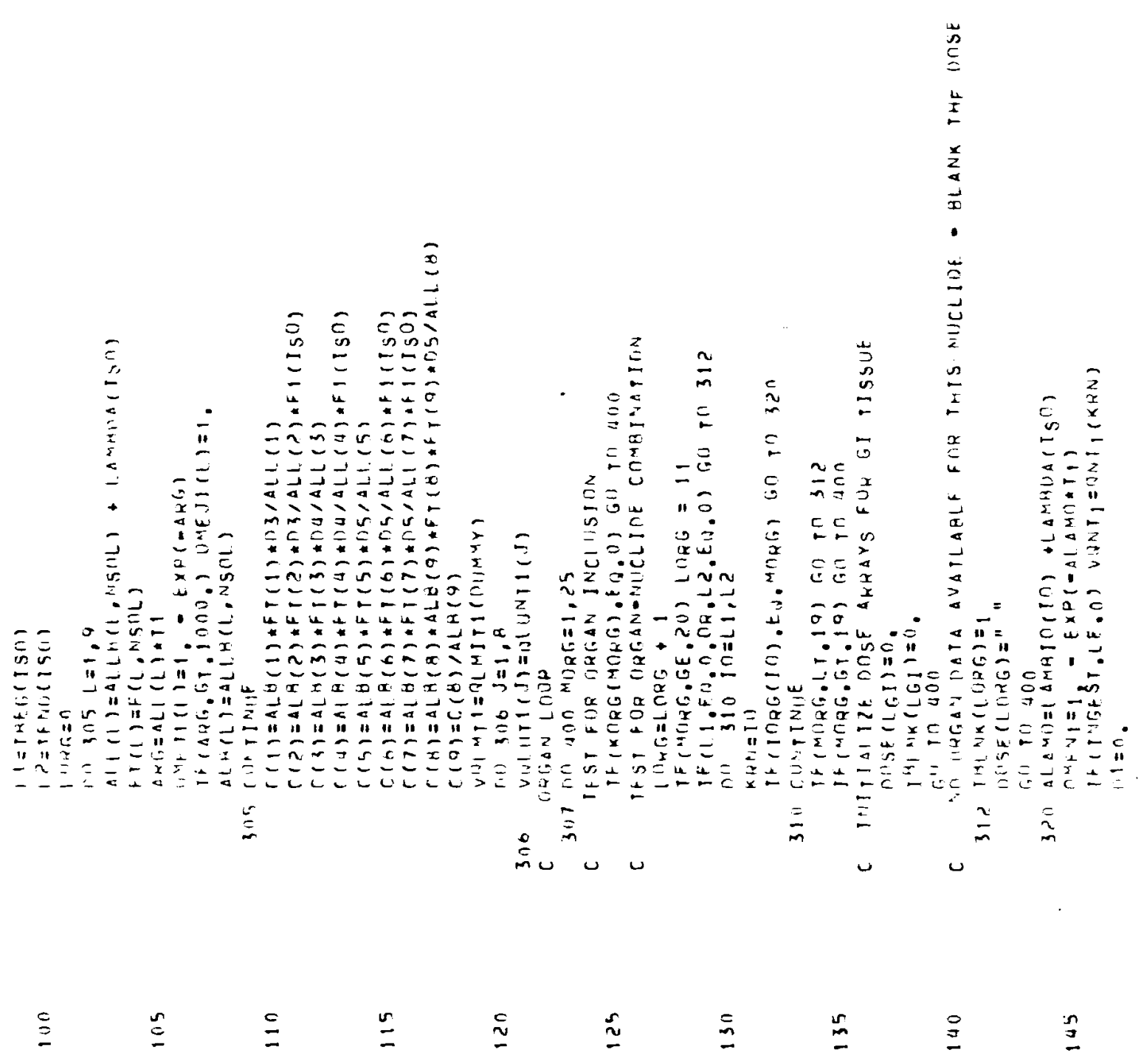



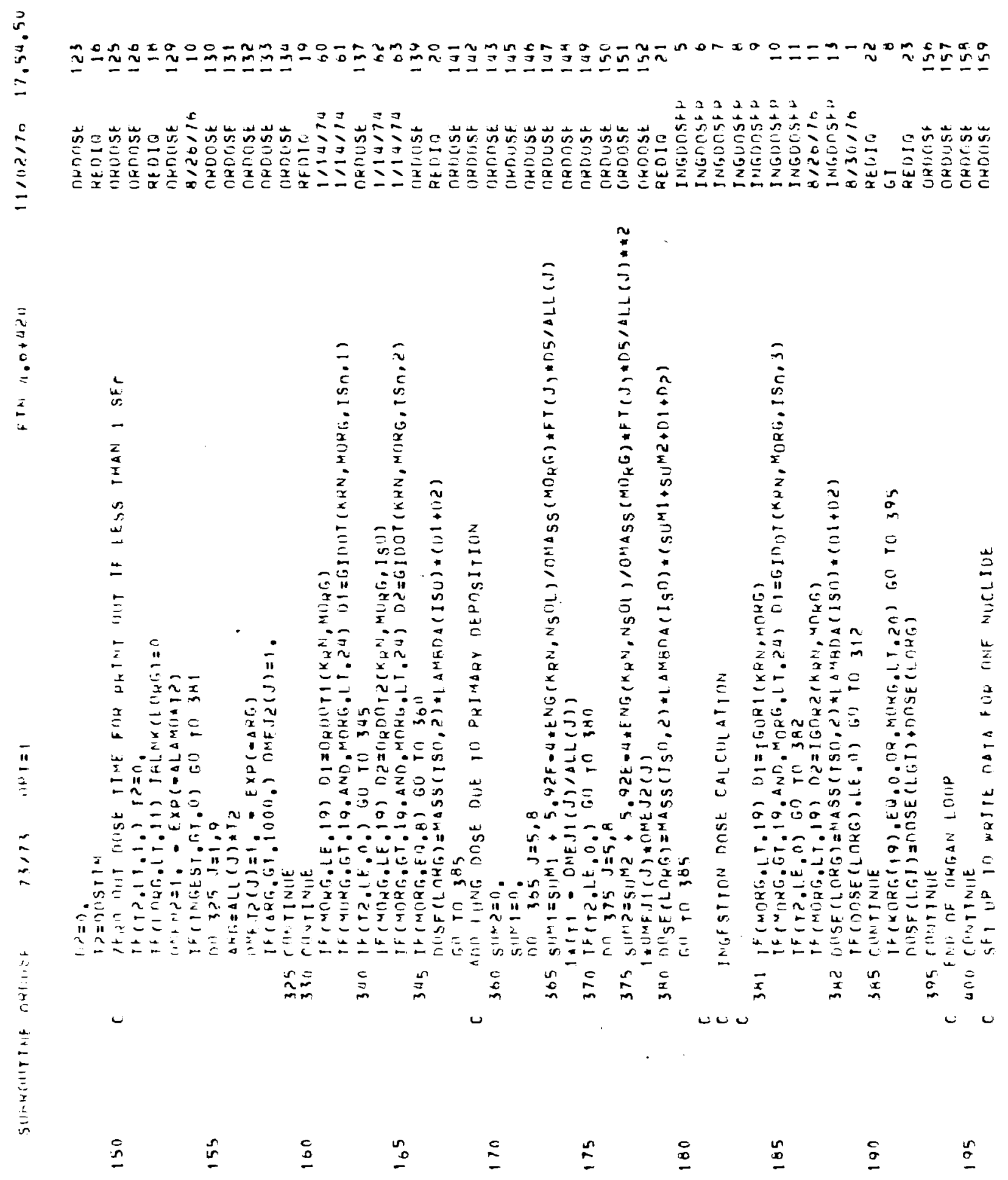


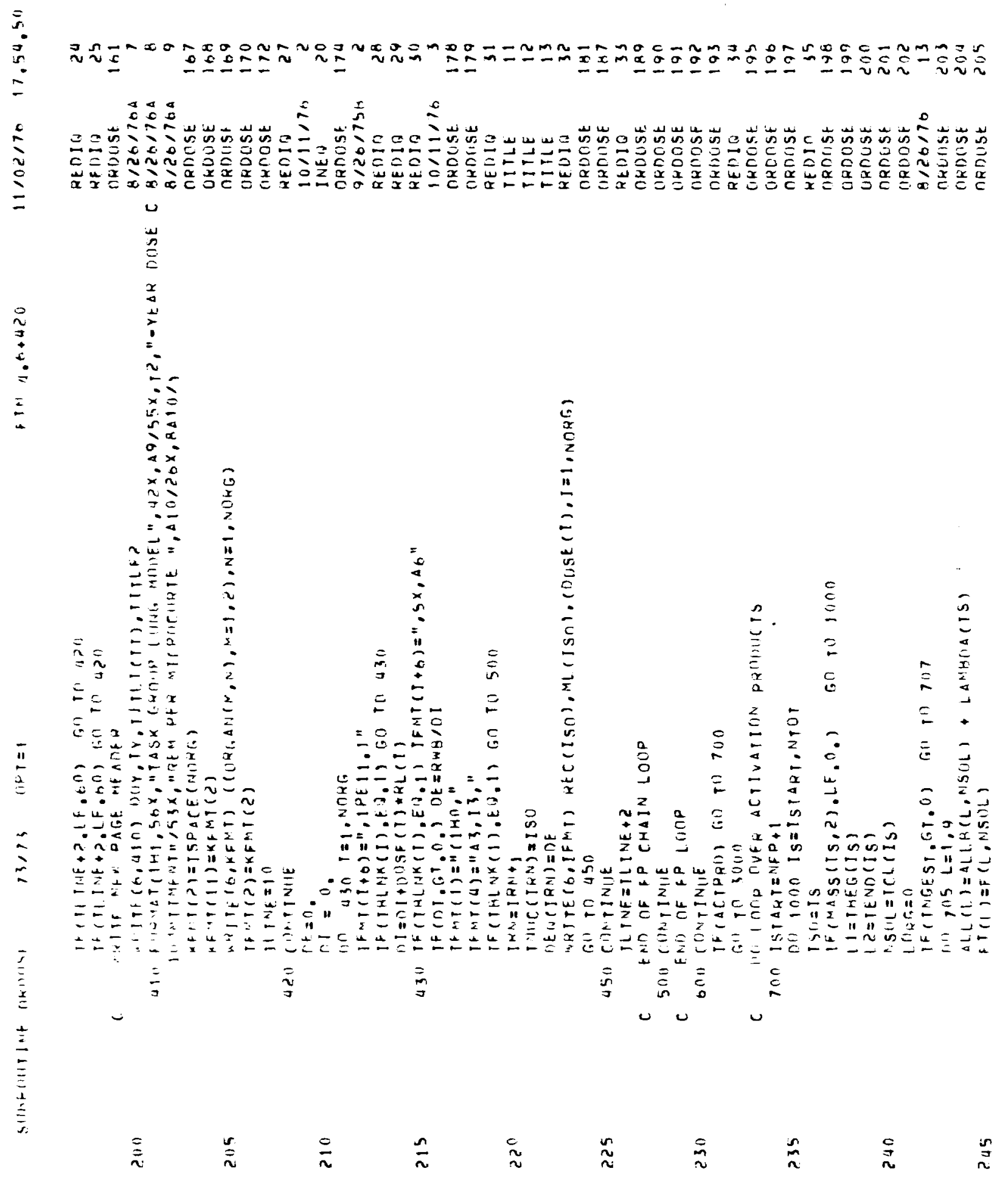




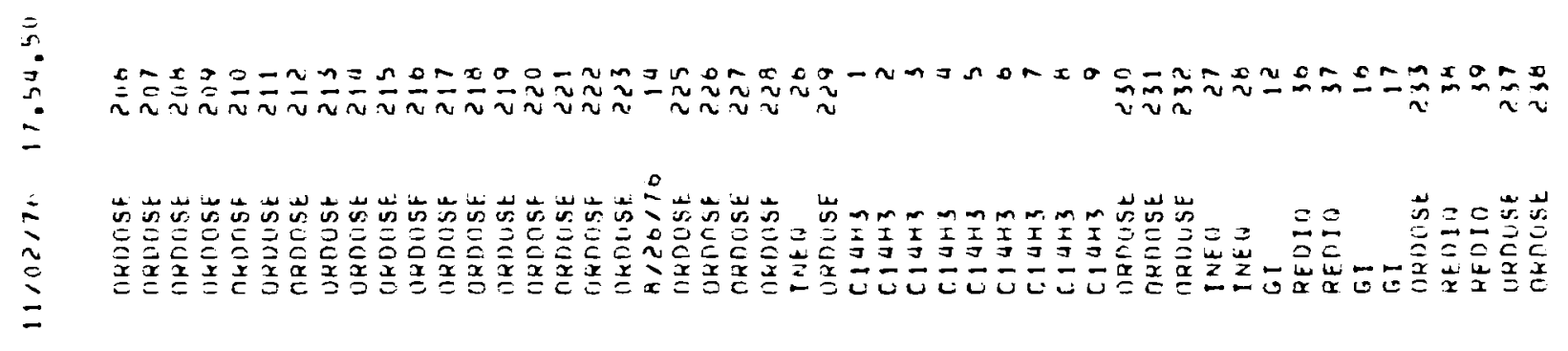

$=$
5
$\vdots$
$\vdots$
$\vdots$
5

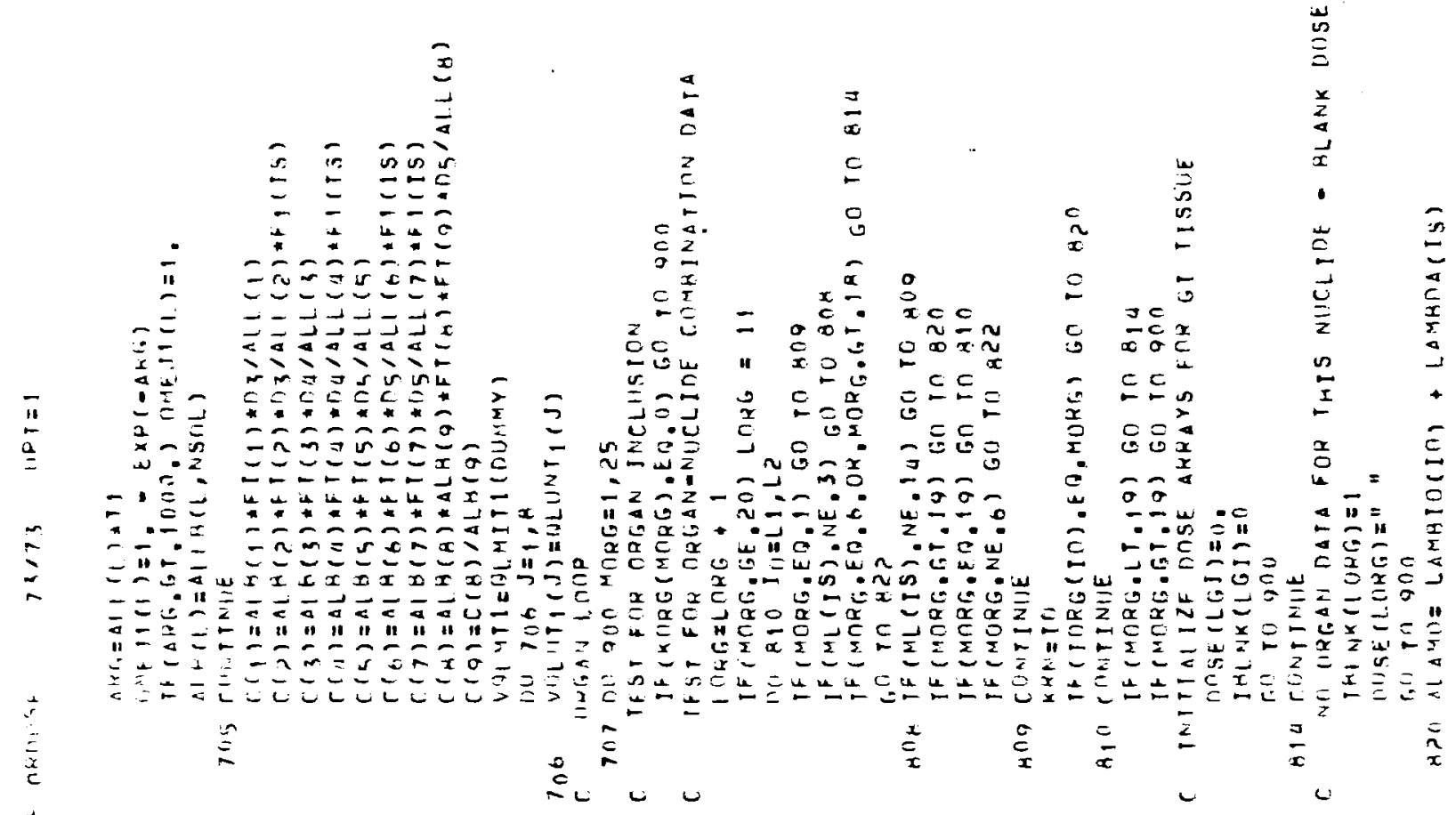
ก)
$\stackrel{n}{n}$
$\stackrel{0}{0}$
$\underset{n}{n}$
$\stackrel{2}{n}$
$\frac{n}{n}$
$\begin{array}{ll}c & n \\ x & \infty\end{array}$
$\bar{\sigma}$ 


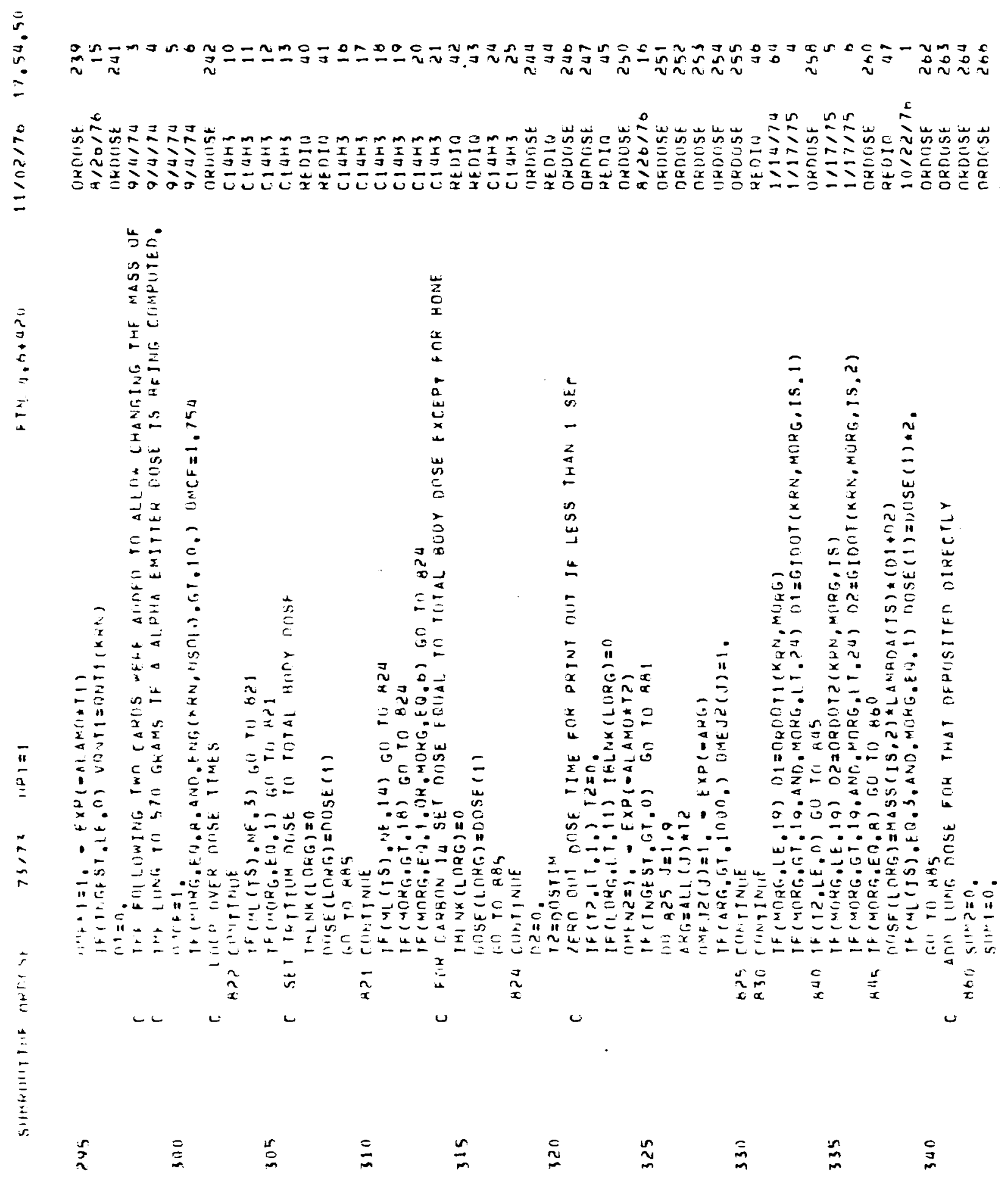




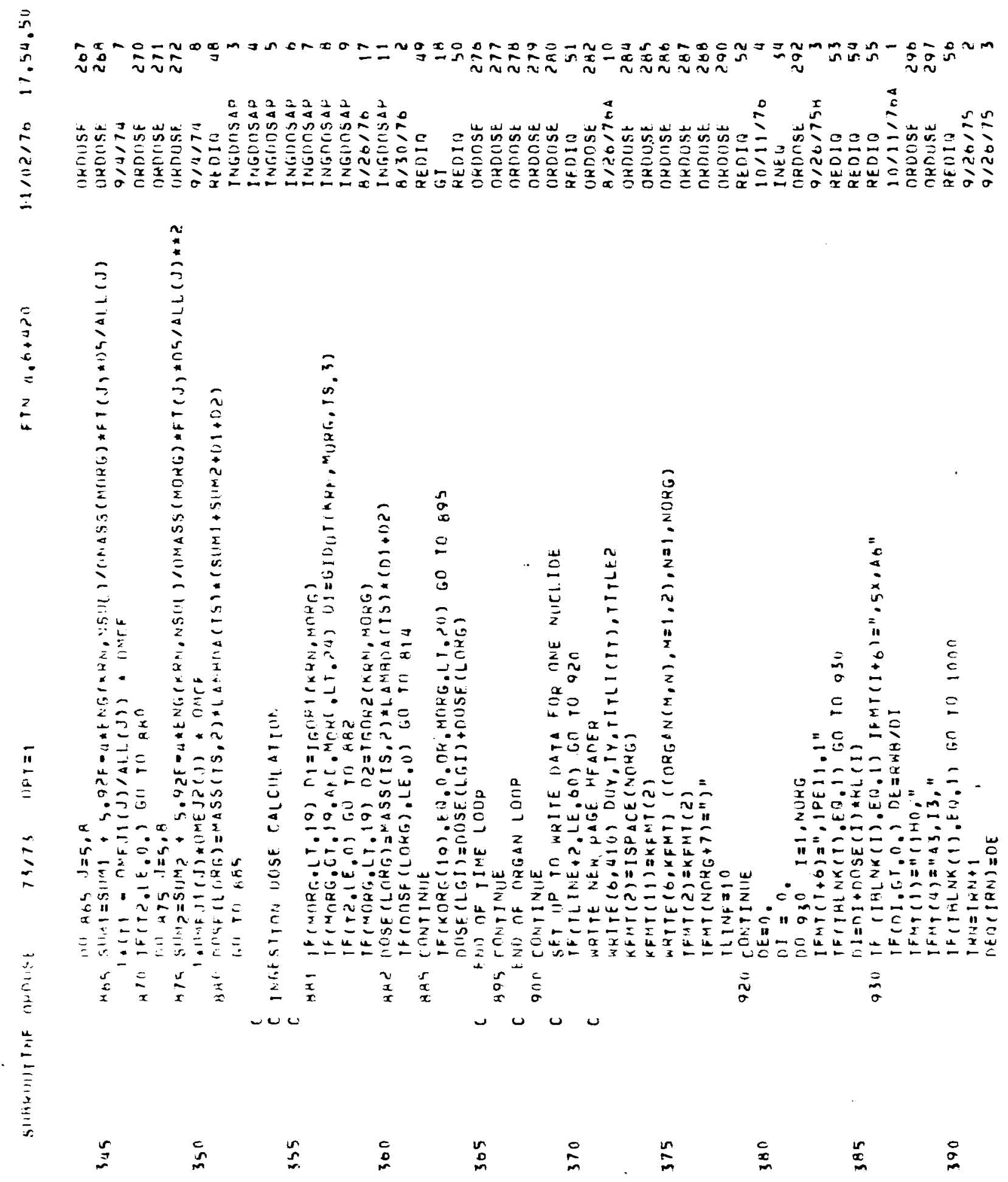




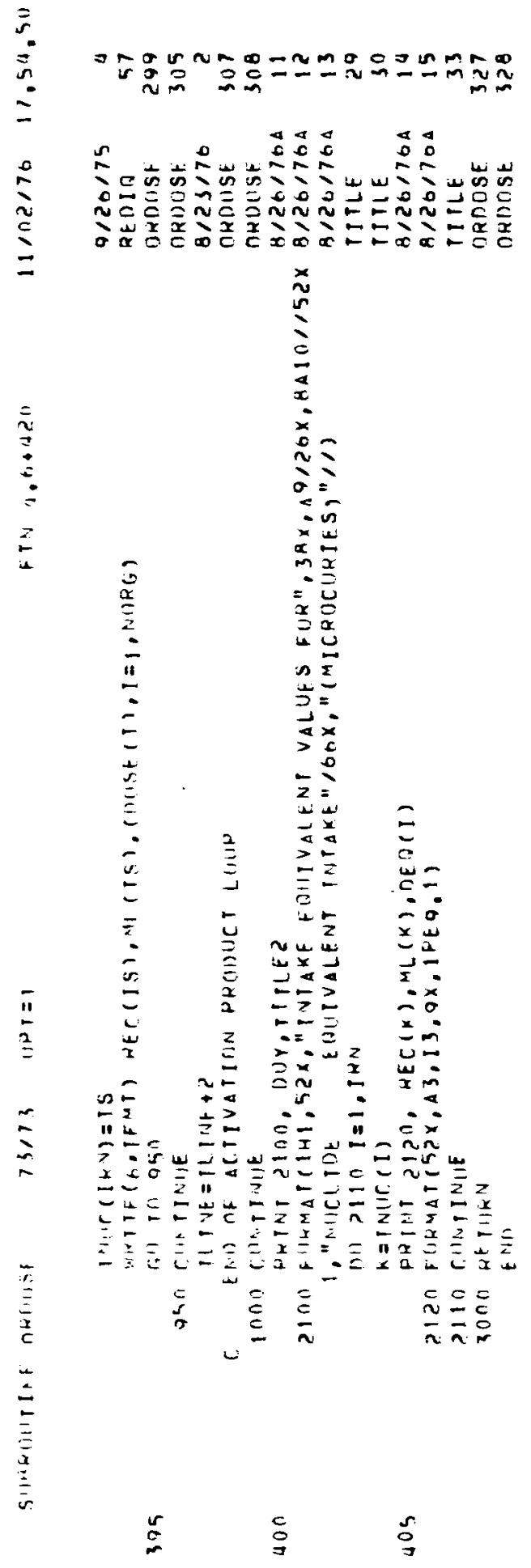


$n$
$\vdots$
0
0
0
0
0
0
0

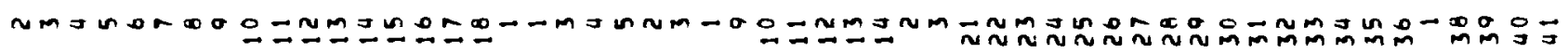

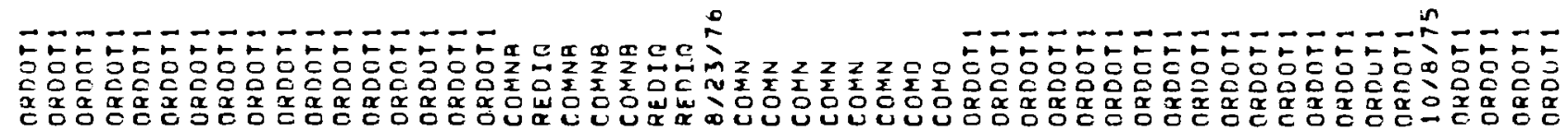

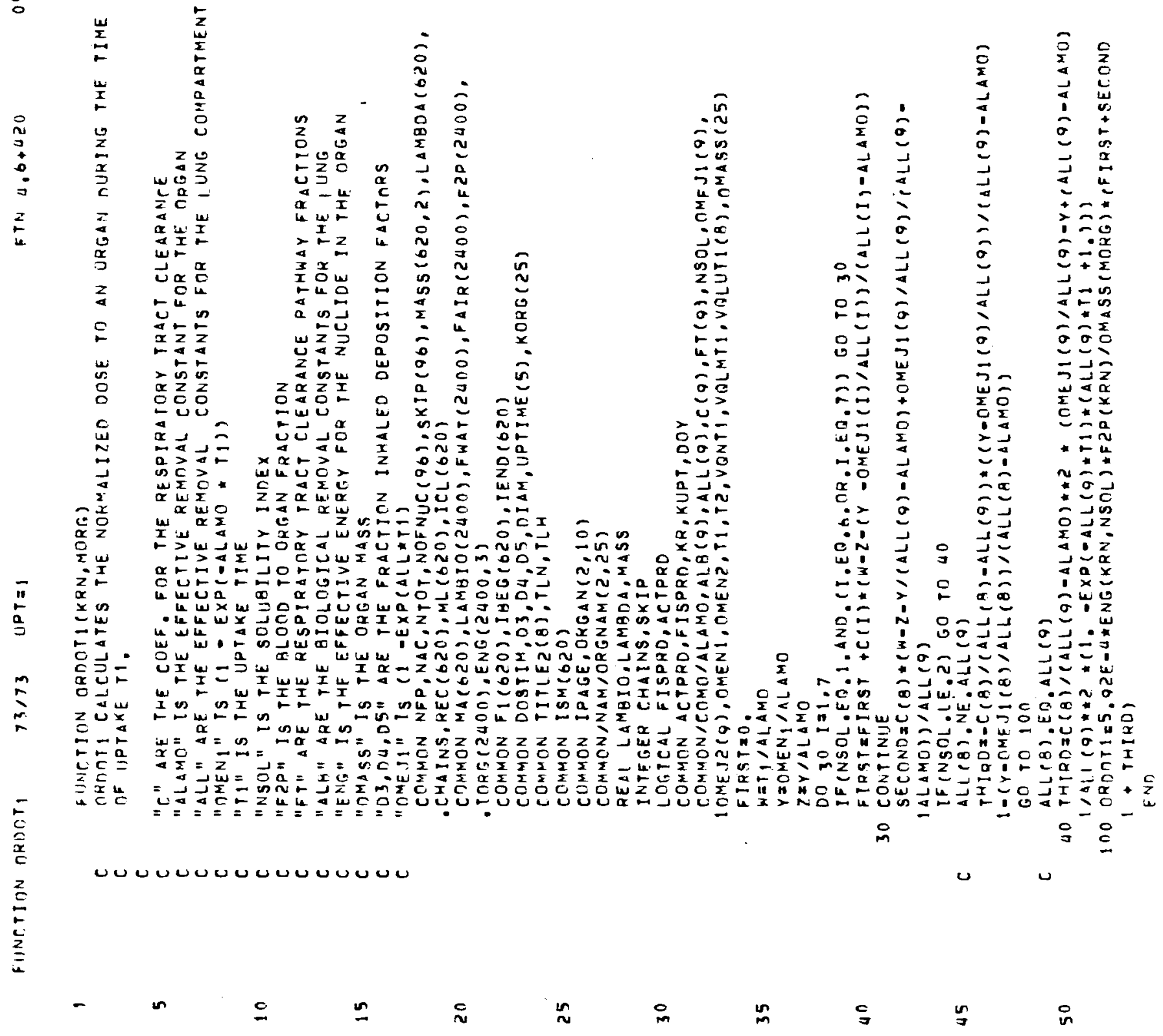


2

nma nor 0 o - -

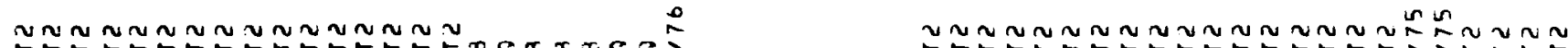

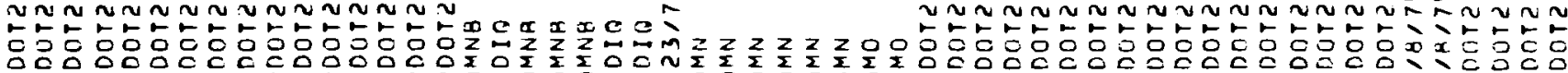

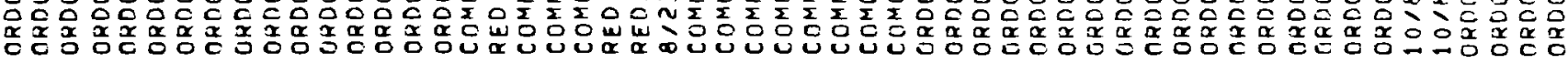

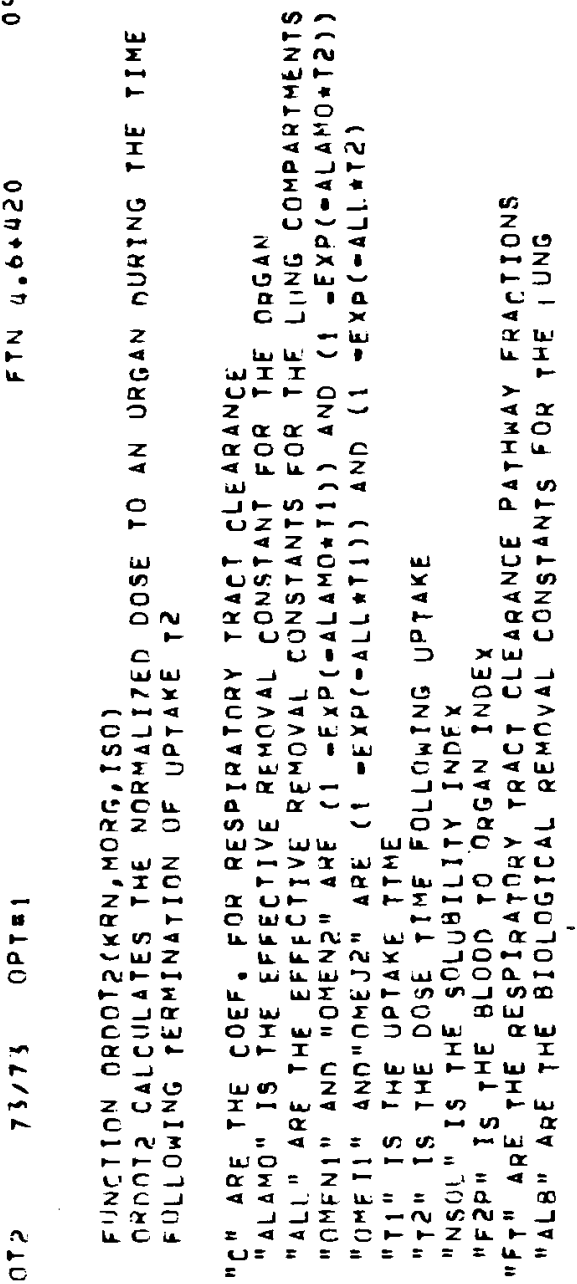

טง

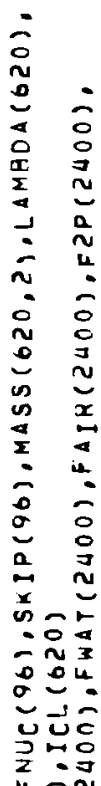

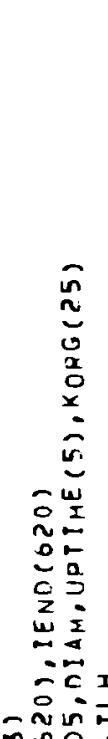

C.

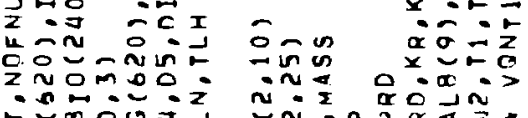

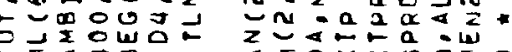

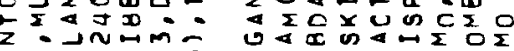

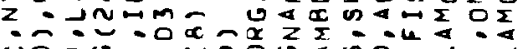

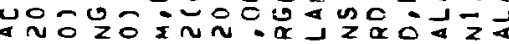

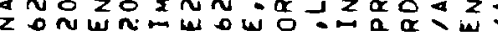

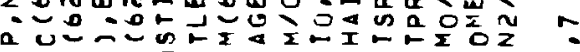

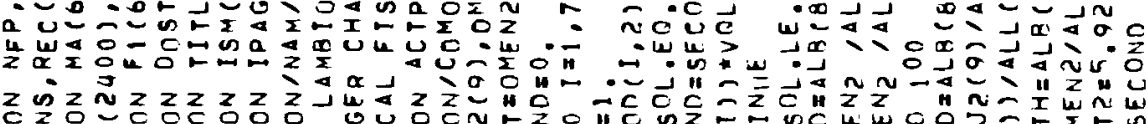

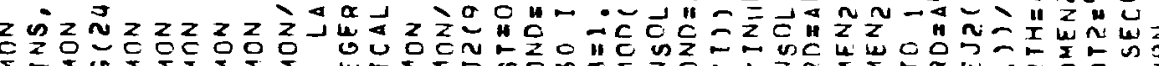

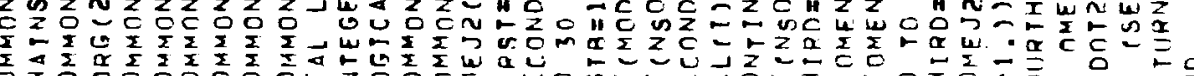

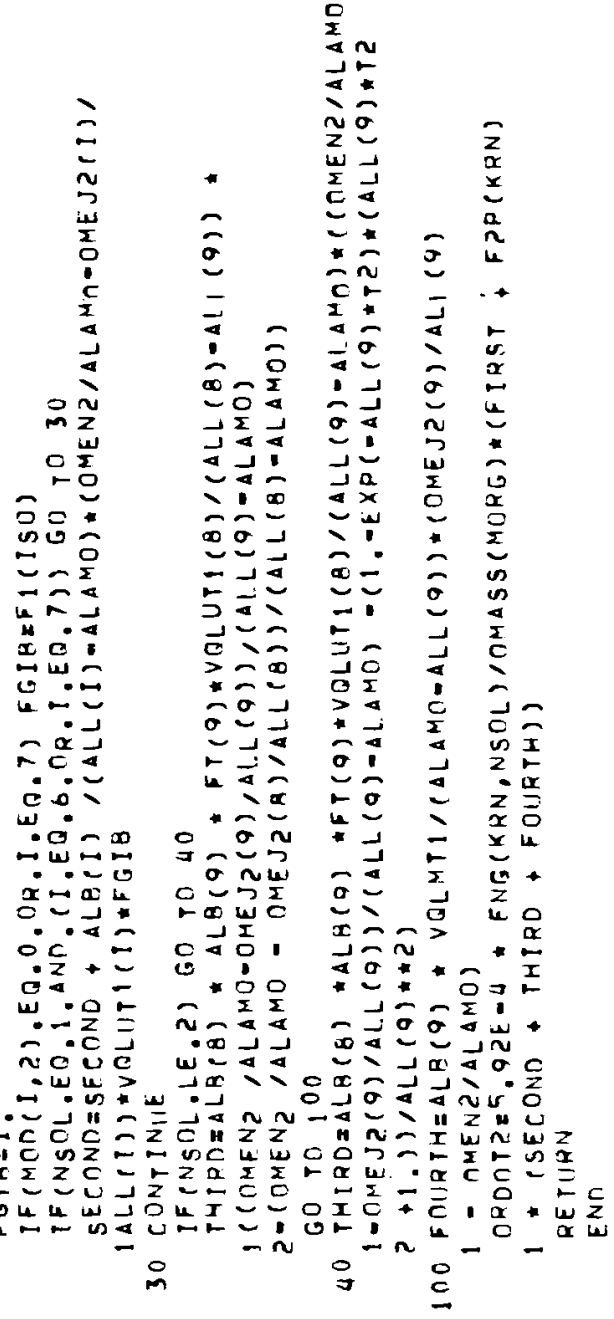

$\underset{c}{z}$

\begin{tabular}{|c|c|c|c|c|c|c|c|c|c|c|}
\hline- & in & $\subseteq$ & $\stackrel{n}{m}$ & $\stackrel{c}{\sim}$ & $\tilde{n}$ & $\stackrel{c}{m}$ & $\stackrel{n}{m}$ & $\stackrel{0}{9}$ & $\underset{a}{n}$ & $\stackrel{c}{n}$ \\
\hline
\end{tabular}




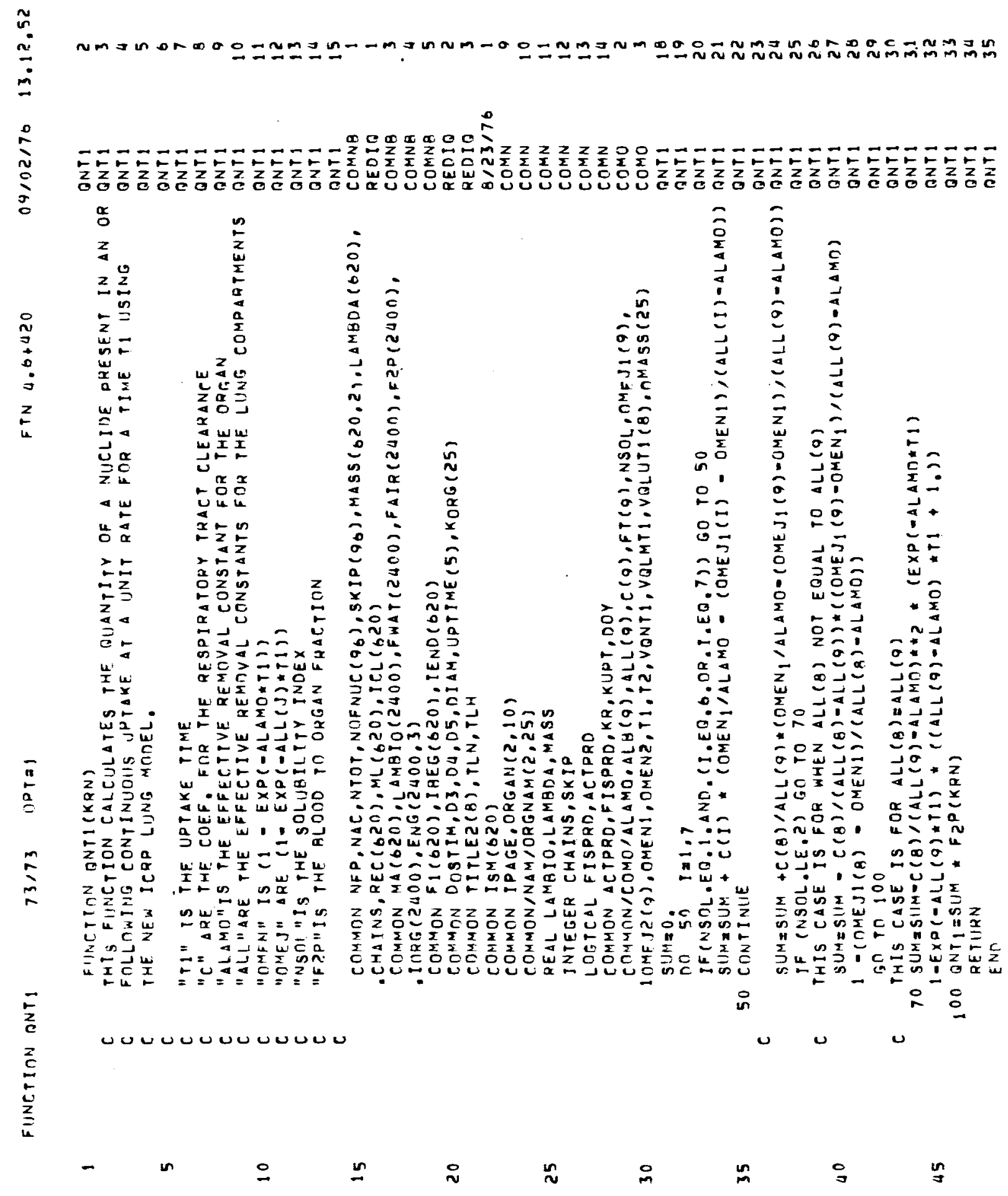


FUNCTION OLIINTISI)

THIS FUNCTION CALCULATES THE DUANTTTY OF A NUCLIDE PRESENT IN EACH OF THE LUNG SUG COMPARTMENTS FOLLOWING CONTINIIOUS INHALATION AT A UNIT RATE FDR A TIME TI ISING THE NEW ICRP LINAG MODEL.

"FT" are tHe respiratory tract ClearaneE pathway fractions

"I) 3.04, DS" ARE THE LUNG DEPOSITION FACTORS

"OMEJI" IS (I - EXP(-ALL\#TI)

"AlL" are the efFective removal constants for the ling compartments

COMMON NFP, NAC, NTOT, NUFNUL $(96), 5 K I P(96), M A S S(620,2), L A M B O A(620)$ - CHATAS, REC (620), ML (620), IPL (620)

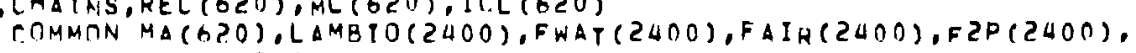
- IURT, (2400), ENG(2400,3)

COMMON FI(6?0), IBEG(620), IEND(O20)

COMMON DOSTIM,OJ,DG,D5,DIAM,UPTIME (5), KORG(25)

COMMON TITLEZ(8), TLN, TLH

COMPON ISM(6ZO)
COMMON IPAGE,ORGAN $(2,10)$

COMMON/NAM/ORGNAM(2, 25)

REAL LAMBIO,LAMBOA,MASS

INTFGFR CHAINS, SKIP

LOGICAL FISPRO, ACTPRD

COMMIN ACTPRD,FISPRD, KR, KUPT, DOY

COMMON /COMO ALLAMO.ALB $(9)$, ALL $(9), C(0), F T(\theta), N S O L, O M F J 1(9)$,

1 OMEJZ(9), OMEN1, OMENZ,T1,T2,VQNT1, VOLMT1, VOLUTI (B), חMASS (25)

G $0,0(10,10,20,20,30,30,30,30)$, I

10 OLLNTI = FP(I) OB OMEJI(T)/ALL(I) GO in 100

20 OLINTI $=$ FT(I) D DU*OMEJI (I)/ALL (I) GD TO 100

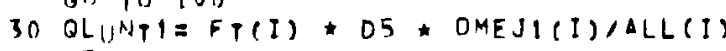
1 DO RETIIRN

END

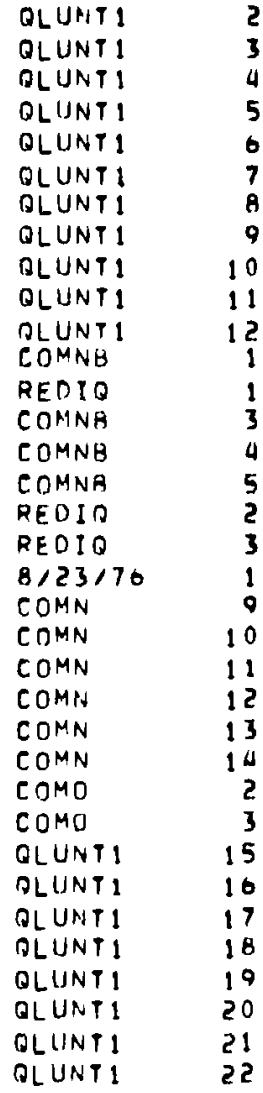


5

plint tion olmitig(j)immy)

THIS FUNCTION CALCIILATES THE QUANTITY OF NULLIDE PRESEAT IN THE LYMPH THAT IS REMOYARLE, FOLLOWING EONTINUOUS IIPTAKF AT A UNIT RATE FOR a TIME TI USING THE NEW LUNG MODEL.

"ALL" ARE tHe REMOVAL CONSTANTS FUR THE RESPIRATORY TRACT "OMEJI" ARE (I - EXP(-ALL(J)*T1)) 

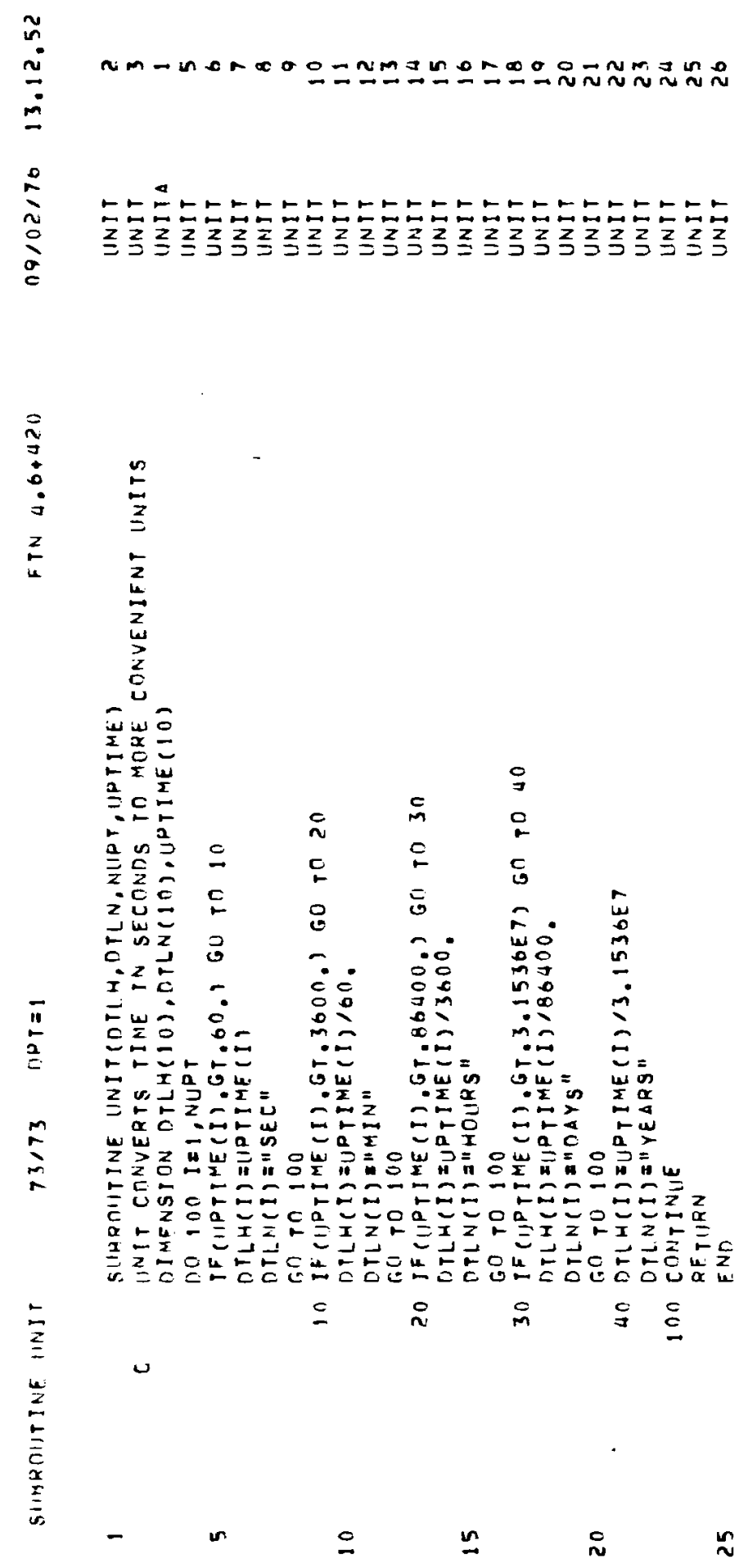

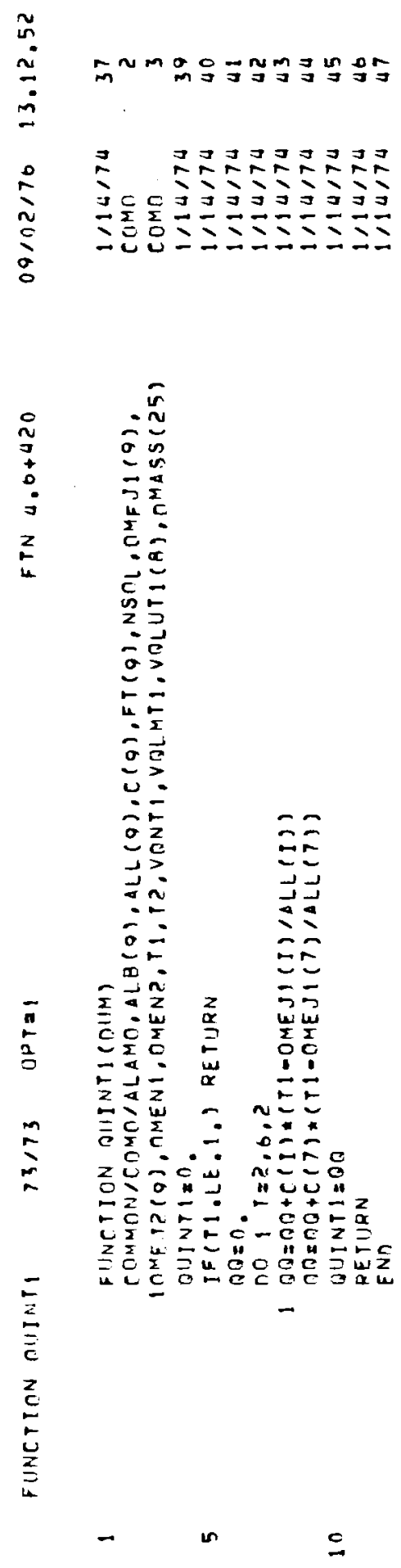

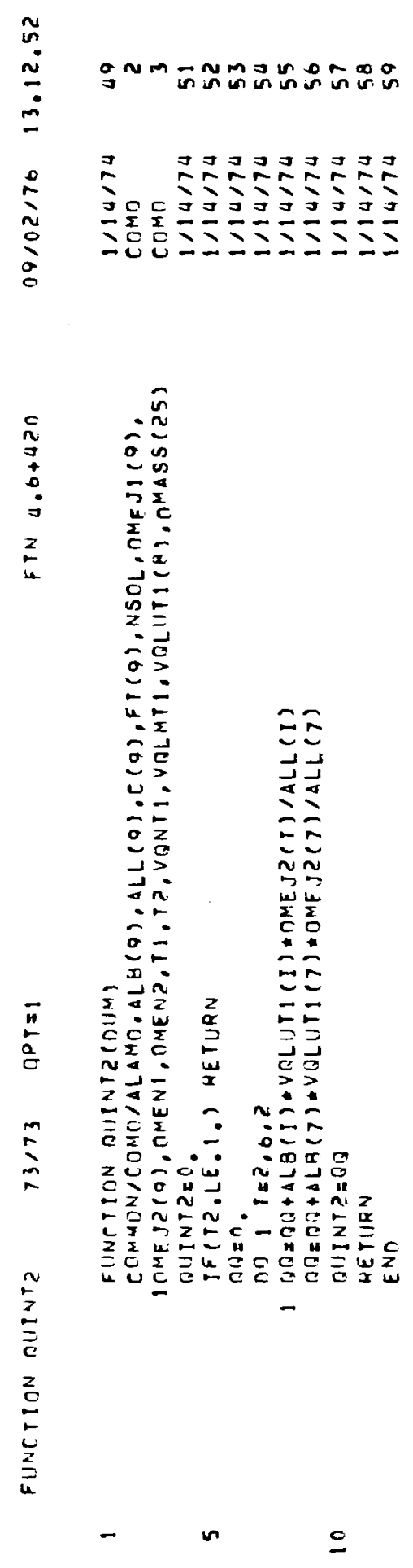


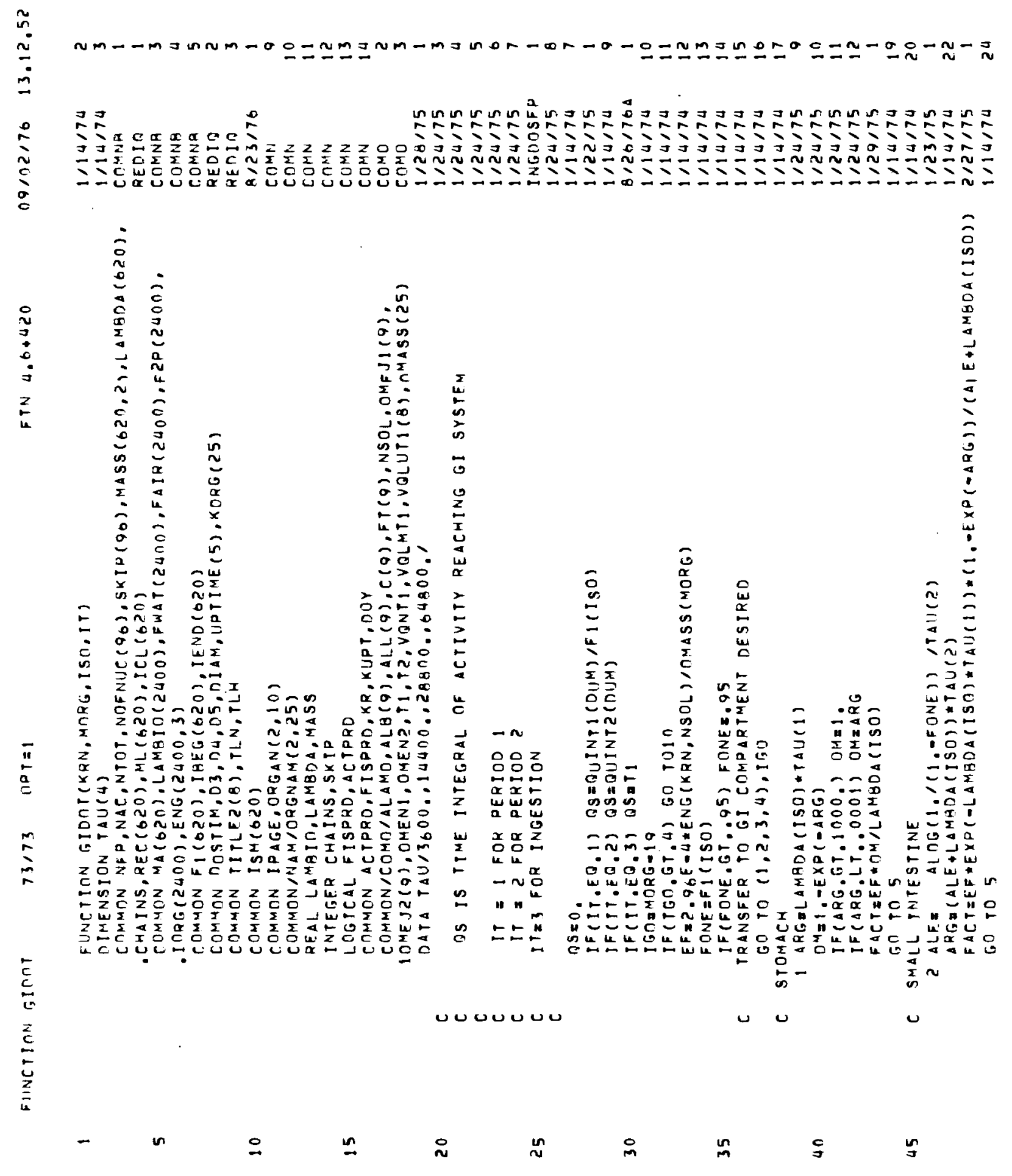




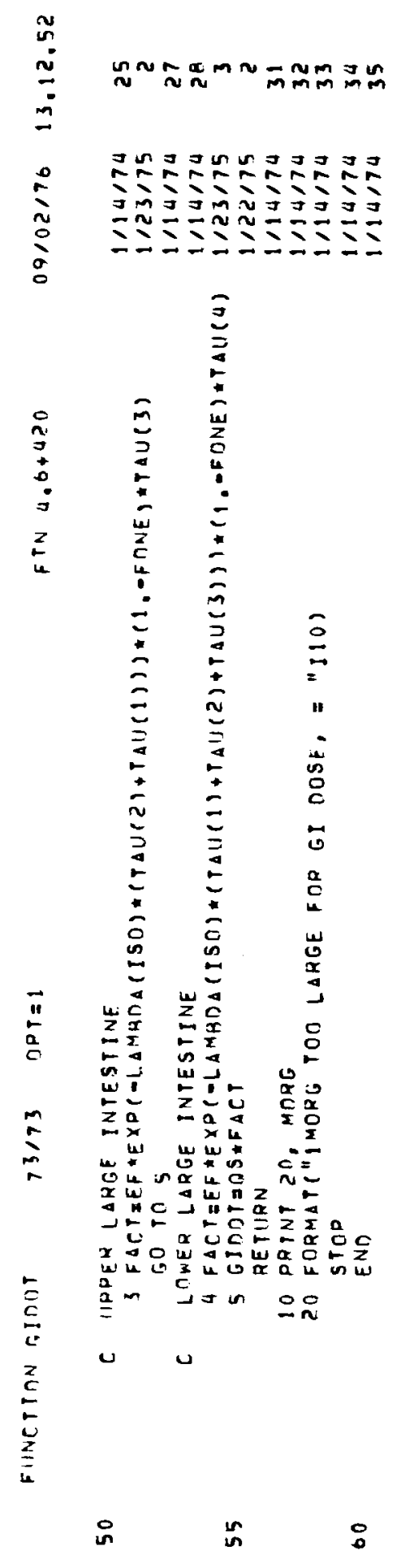


a

NmJ

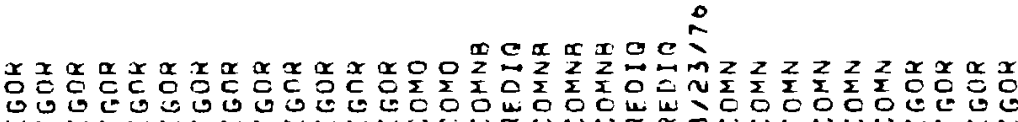

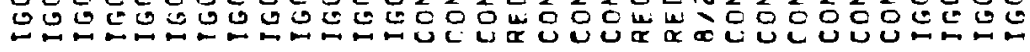

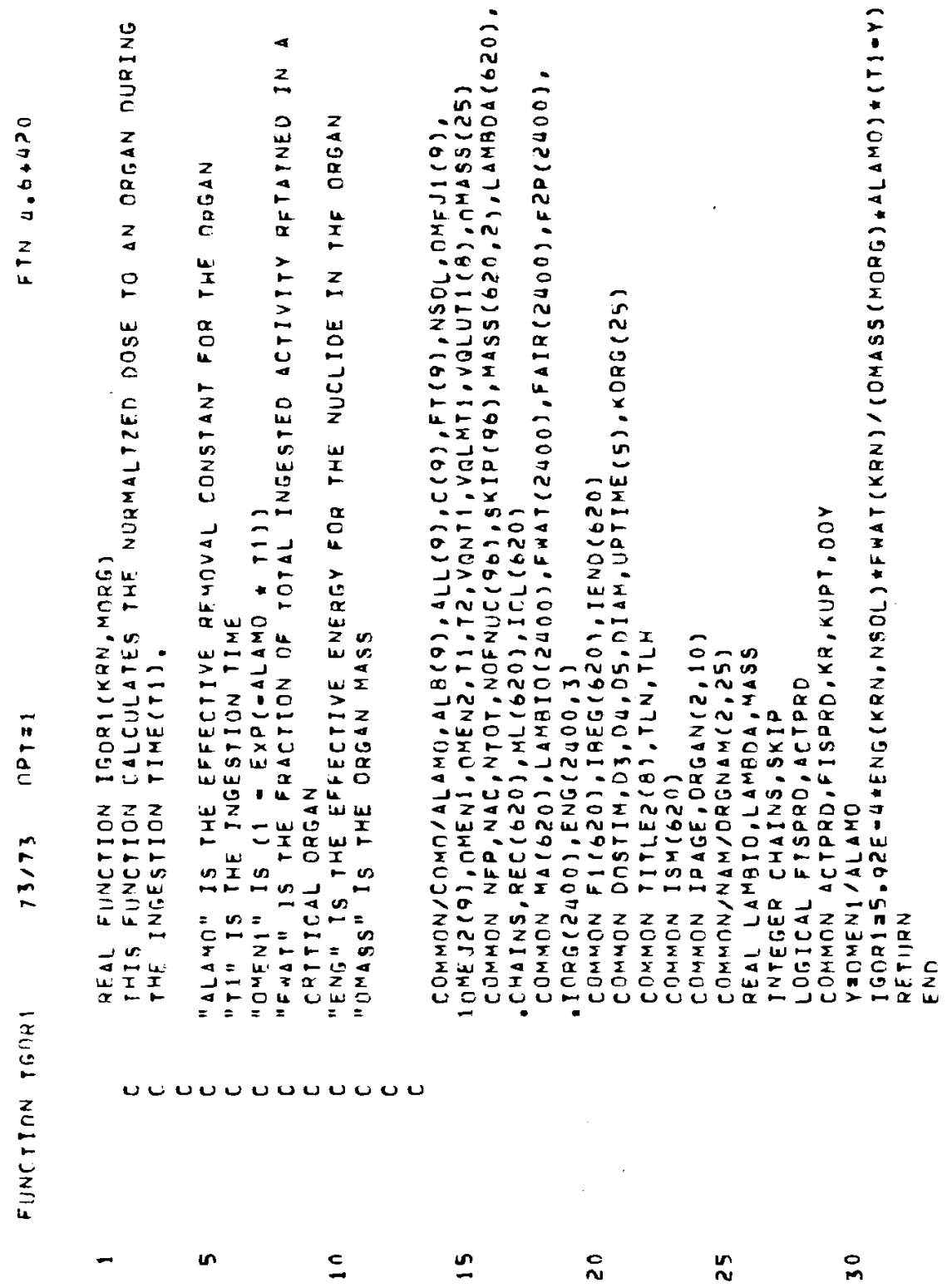


1

FEAL FIJNCTION IGORZ (KPN, MORG)

$8 / 20 / 76$

PHIS FIINCTIOIN CALCULATES THE NORMALIZED DOSE TO TN ORGAN DURING

PHE TIME FOLLOWIMG THE TERMINATION OF INGESTION(T?),

"ALAMO" IS THE EFFECTIVE REMOVAL CONSTANT FOR THE nRGAN

IGnR

I GOH

IGOR

IGOR

"TZ" IS THE TIME FOLLOWING THE TERMINATION OF INGESTION

"OMENI" IS (1 - EXP(-ALAMO TI)

"OMENZ" IS (1 - EXP(-ALAMO - T2)

"Il" IS THE INGESTION TIME

IGOR

IGOR

TGR

CRITICAL ORGAN

"ENG" IS THE EFFECTIVE ENERGY FOR THE NUCLIDE IN THE ORGAN

"OMASS" IS THE ORGAN MASS

IGOR

IGOR

I $R O R$

IGOR

COMMON/COMO/ALAMO,ALB( $(9), A L L(9), C(9), F T(9), N S O L, O M F J I(9)$, IOME I $2(9), O M E N 1, O M E N 2, T 1, T 2$, VONTI, VOLMTI, VOLUTI (B), OMASS (2S)

COMMON NFP, NAC, NTOT. NOFNUC $(96), 5 K I P(96)$, MASS $(620,2), L A M B O A(620)$, CHAINS, REC (620), ML (620), ICL (620)

CDMMON MA 620$)$, LAMBIO(240O), FWAT $(2400)$, FAIR $(2400)$, F2P(2400).

COMO

IORT(2400), ENG(2400,3)

COMMON $1(620)$, IAEG (620), IENO(620)

COMMON DOSTIM,D 3, D4, D5, DI IM,UPTIME (5), KORG (25)

COMMON TITLEZ $(\theta)$, TLN,TLH

COMMON ISM(62O)

COMMON IPAGE, ORGAN(2,10)

COMMON/NAMIORGNAM(2,25)

REAL. LAMBIO,LAMBOA, MASS

INTEGER CHAINS, SKIP

LOGICAL FISPRD, ACTPRD

COMMGN ACTPRD,FISPRD,KR, KUIPT, DOY

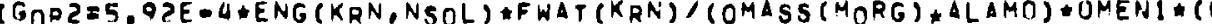

MEN 2/ALAMN

RETHRN

COMNB

REDIO

COMNA

COMNB

COMNA

REOIO

REDIO

$8 / 23 / 76$

COMN

COMN

COMN

CDMN

COMN

COMN

IGOR

IGOR 
APPENDIX F

INPUT PREPARATION 


\section{INPUT PREPARATION}

The input data needed for the calculations fall into two general categories: (1) program control variables, and (2) parameters associated with the organ dose calculation. Most of the data required by the code are contained in two data libraries (see Appendix D), thus eliminating much time-consuming preparation of input.

Program control variables consist of parameters to control the reading of the data libraries, the optional printing of some input and intermediate data, the relative risk factor for each organ specified, and the type of dose calculation to be performed (i.e., inhalation or ingestion).

The remainder of this appendix describes in detail the input variables, their use, and the manner in which they are supplied to the program.

DATA CARD DESCRIPTIONS

CARD 1 - Title Card

$\frac{\text { COLUIMN }}{1-72} \quad \frac{\text { FORMAT }}{12 A 6} \quad \frac{\text { VARIABLE }}{\text { TITLE 2 }}$

USE

Words entered here are reprinted as a title on the summary page. Each case requires a title card or blank card.

CARDS 2 to $\mathrm{N}$ - Namelist Data Cards (one or more namelist cards).

The minimum data for each case consist of one title card (Card 1) and one or more cards using the Namelist format (Cards 2 to $N$ ). The first Name1ist card (Card 2) must have a blank in Column 1, \$INPUT in Columns 2-7, and at least one blank following, before entry of data items. Data items are separated by commas, and the last item must be followed by a $\$$. Each data item must have one of the three following forms:

1. Variable name $=$ constant, where the variable name may be either subscripted or not. 
2. Array name $=$ set of constants (separated by commas). The number of constants must not exceed the number of elements in the array and they must be in the same order as the array is in storage, i.e., the first subscript changes most rapidly.

3. Subscripted variable $=$ set of constants (separated by commas). This form results in the set of constants being placed consecutively in an array, starting with the element designated by the subscripted variable.

The Namelist variables retain their values throughout the execution of the program and need not be respecified unless a change is wished. Namelist input variables are shown in Table F-1.

When the Namelist variable NEXT has a value of 1 or 2 , cards are read that select nuclides for which calculations are to be performed. The first of these cards $(\mathrm{N}+1)$ gives the number of nuclides to be input, while the rest $(\mathrm{N}+2$ to $\mathrm{M})$ give the nuclide identification parameters.

CARD N+1 - Number of Radionuclides Card

$\frac{\text { COLUMN }}{1-3} \quad \frac{\text { FORMAT }}{13} \quad \frac{\text { VARIABLE }}{\text { NUMBER }}$

USE

Controls the number of radionuclides (maximum: 500) to be read from subsequent input cards

CARDS $\mathrm{N}+2$ to $\mathrm{M}$ - Radionuclide Cards

\begin{tabular}{|c|c|c|c|}
\hline COLUMN & FORMAT & VARI ABLE & USE \\
\hline $1-3$ & A3 & NAME & $\begin{array}{l}\text { Names an element selected from the } \\
\text { Radionuclide Data Library }\end{array}$ \\
\hline $4-6$ & 13 & $M$ & $\begin{array}{l}\text { Gives the mass number of the selected } \\
\text { radionuclide }\end{array}$ \\
\hline $7-8$ & 12 & ISL & $\begin{array}{l}\text { Gives solubility class of the nuclide } \\
(1=D, 2=W, 3=Y)\end{array}$ \\
\hline $9-20$ & $12 x$ & -- & $\begin{array}{l}\text { Blank space before next radionuclide } \\
\text { entry }\end{array}$ \\
\hline
\end{tabular}

The format shown may be repeated 4 times on each card, starting in columns 21,41 , and 61 for additional nuclides. 


\section{TABLE F-1. Namelist Variables for Cards 2 to $\mathrm{N}$}

VARIABLE

I. PROGRAM CONTROL VARIABLE

NEXT

(1)

Next case options

II. ORGAN DOSE VARIABLES

D3

04

05

(1)

DIAM

UPTIME (I)

DOSTIM

ORGANS (I)

ORGANS(I)

\begin{abstract}
Fraction of inhaled aerosol deposited in nasal passages
\end{abstract}

Fraction of inhaled aerosol deposited in trachea and bronchia

Fraction of inhaled aerosol deposited in pulmonary region

Mass median aerodynamic diameter of inhaled material

The length of time during which inhalation intake takes place

The length of time following the termination of inhalation intake for which the dose is to be calculated

Selects the organs for which the dose is to be calcuitu?d. NOTE: Each calculation mist use total body as the fi.st organ, and supply other organs in increasing index order. (See Table F-2.)

\section{VALUE UNITS}

None

1 to 4

Non

0 to 1

None

0 to 1

None

0 to 1

$\mu m$

$\geq 0$

$\sec$

$>0$

sec

$>0$

None

1 to 18

(integer)

III. DOSE MODEL CONTROL VARIABLE

INGEST

(1)

Bypasses inhalation dose model

None

o or 1 and calculates ingestion dose. (Default $=0=$ inhalation model)

IV. RELATIVE RISK FACTORS

$\mathrm{RL}$ ( I )

RWB
Sets the relative risk factor for each organ specified (listed in the same order as the organs)

Sets the relative risk factor for external whole-body irradiation
Events per $\quad>0$

Rem

Events per $>0$ Rem 


\section{NAMELIST VARIABLE EXPLANATION}

NEXT is a variable controlling the dose calculations. It tells the program what to do after the Namelist data have been read, and controls library reading and the input of the radionuclide identification list. There are 4 options, corresponding to NEXT $=1,2,3,4$.

NEXT $=1$ Reads in libraries and a set of nuclide identification cards.

NEXT $=2$ Reads in a new set of nuclide identification cards; Namelist variables may be changed.

NEXT = 3 Namelist variables may be changed.

NEXT $=4$ End of job. No further calculations are done. Provides for normal exit.

Any of the Namelist variables may be changed when NEXT $=1,2$ or 3 . NEXT must be specified as 1 in the first case so the libraries will be read.

\section{ORGANS}

Table F-2 shows the list of possible organs used in the REDIQ code, with their numerical indices.

TABLE F-2. Numerical Index of Organs

\begin{tabular}{llcl}
\multicolumn{1}{c}{ INDEX } & \multicolumn{1}{c}{ ORGAN } & \multicolumn{1}{c}{ ORGAN } \\
\cline { 2 - 4 } 1 & Total body & 12 & Skin \\
2 & Body water & 13 & Brain \\
3 & Kidneys & 14 & Muscle \\
4 & Liver & 15 & Prostate \\
5 & Spleen & 16 & Thyroid \\
6 & Bone & 17 & Pancreas \\
7 & Fat & 18 & Heart \\
8 & Lungs & 19 & GI tract \\
9 & Adrenals & 20 & Stomach \\
10 & Testes & 21 & Small intestine \\
11 & Ovaries & 22 & Upper 1arge intestine \\
& & 23 & Lower large intestine
\end{tabular}

Index 19 causes the sum of doses to the GI compartments to be printed. 


\section{RL, RWB}

Values for risk factors must be supplied by the user in the same order that the organs are specified, with RWB corresponding to whole body external irradiation. The risk factors must all be related to the same biological effect. Typical units for risk factors are events per rem. At least one non-zero value must be given for organs (other than total body) for which nuclide data is given in the data library. 
APPENDIX G

SAMPLE PROBLEM 


\section{SAMPLE PROBLEM}

A sample problem is presented here to illustrate use of the computer program. The inhalation and ingestion intake equivalents are calculated for seven transuranium nuclides based on relative risk factors for cancer deaths. The inhalation dose calculation is performed for exposure to aerosols with activity median aerodynamic diameters (AMAD) of $0.05,0.1,1.0$ and $5.0 \mu \mathrm{m}$. Inhalation of $\mathrm{Class} \mathrm{W}$ and $\mathrm{Class} Y$ compounds is considered. The run cons ists of eight cases for inhalation (four particle sizes times two translocation classes) and one case for ingestion. The order of the cases is indicated below. The uptake time for each case is 1 minute (UPTIME $(1)=60$ ).

\begin{tabular}{|c|c|c|}
\hline Case & Intake Mode & Parameters \\
\hline 1 & Inhalation & $\begin{array}{l}\text { NEXT }=1, \text { DIAM }=0.05, \\
\text { Translocation Class } w\end{array}$ \\
\hline 2 & Inhalation & $\begin{array}{l}\text { NEXT }=3, \text { DIAM }=0.1, \\
\text { Translocation Class } W\end{array}$ \\
\hline 3 & Inhalation & $\begin{array}{l}\text { NEXT }=3, \text { DIAM }=1.0, \\
\text { Translocation Class } \mathrm{W}\end{array}$ \\
\hline 4 & Inhalation & $\begin{array}{l}\text { NEXT }=3, \text { DIAM }=5.0, \\
\text { Translocation Class } \mathrm{W}\end{array}$ \\
\hline 5 & Inhalation & $\begin{array}{l}\text { NEXT }=2, \text { DIAM }=0.05, \\
\text { Translocation Class } Y\end{array}$ \\
\hline 6 & Inhalation & $\begin{array}{l}\text { NEXT }=3, \text { DIAM }=0.1 \text {, } \\
\text { Translocation Class } Y\end{array}$ \\
\hline 7 & Inhalation & $\begin{array}{l}\text { NEXT }=3, \text { DIAM }=1.0, \\
\text { Transiocation Class }\end{array}$ \\
\hline 8 & Inhalation & $\begin{array}{l}\text { NEXT }=3, \text { DIAM }=5.0, \\
\text { Translocation Class } Y\end{array}$ \\
\hline 9 & Ingestion & NEXT $=3, \quad$ INGEST $=1$ \\
\hline 10 & End of Run & NEXT $=4$ \\
\hline
\end{tabular}

The relative risk values used in this sample problem were developed by Strom and Watson $(1)$ based on data presented in the BEIR Committee report. (2) 
The following was taken from the report by Strom and Watson.

"There are no adequate data for estimating the risk of cancer in man from inhalation of any of the transuranics. The BEIR Committee estimates of the risk of excess deaths from cancer in the United States population from exposure to ionizing radiation are interpreted in this report in terms of risk of death per person per unit dose for several organs of reference. Described in these terms, the assumption of dose-effect linearity is implied. The linear extrapolation of effects at doses where effects have been observed to effects at lower doses remains unresolved. The estimates of absolute risk given in Table XIV for those 10 years of age and over have been used in the estimation of equivalent risks that might result from whole-body irradiation or from the inhalation of transuranium elements. Risk estimates provided by the BEIR Committee are not applicable to several organs of reference, e.g. liver and kidneys. Thus, for these organs risk estimates have been assumed that seem to be reasonable in light of comparable values provided in the BEIR Committee's report."

(Table XIV mentioned above is Table 3.2 of Appendix II of the BEIR Committee report.) The values of risk estimates suggested by Strom and Watson are given in Table G-1. These values are used in the sample problem for inhalation and ingestion intake (Namelist variable RL). A listing of input cards is given in Figure G-1. The nuclides considered are ${ }^{236} \mathrm{Pu},{ }^{238} \mathrm{Pu},{ }^{239} \mathrm{Pu}$, ${ }^{240} \mathrm{Pu},{ }^{241} \mathrm{Pu},{ }^{242 \mathrm{Pu} \text { and }}{ }^{241} \mathrm{Am}$. A listing of the output from the sample problem is given in Figure $\mathrm{G}-2$.

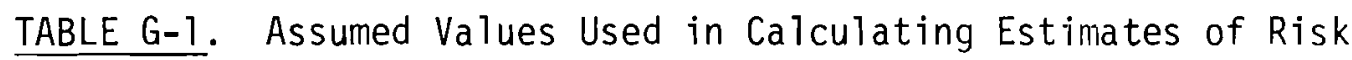

Type of Cancer

GI tract including stomach

Lungs

Bone

Kidneys

Liver

A11 other (total body)
Excess Cancer

\begin{tabular}{c} 
(deaths $\left./ 10^{6} / \mathrm{a} / \mathrm{rem}\right)$ \\
\hline $1.0^{(\mathrm{a})}$ \\
$1.3^{(\mathrm{a})}$ \\
$0.2^{(\mathrm{a})}$ \\
$0.5^{(\mathrm{b})}$ \\
$0.5^{(\mathrm{b})}$ \\
$2.5^{(\mathrm{c})}$
\end{tabular}

(a) Value from BEIR Committee report.

(b) Estimated equipartition of risks provided in BEIR Committee report from all cancers other than leukemia, breast, lung, GI tract, stomach, and bone.

(c) Estimated as sum of leukemia and breast cancer risks as provided in BIER Committee report. 
TRANSITCATTON CLASS W O.RE MICRON PARTICLFS

\$INPUT NEXT =1, DI $\triangle M=.05$, UDTIME $(1)=60 .$, ORGANS $(1)=1,3,4,0,8,19,20,21$. $22,23, R L(1)=2.5^{F}-6, .5 F-6, .5 F-6, .2 F-6,1,3 E-6,1, F-0, D W R=2.5 E-065$

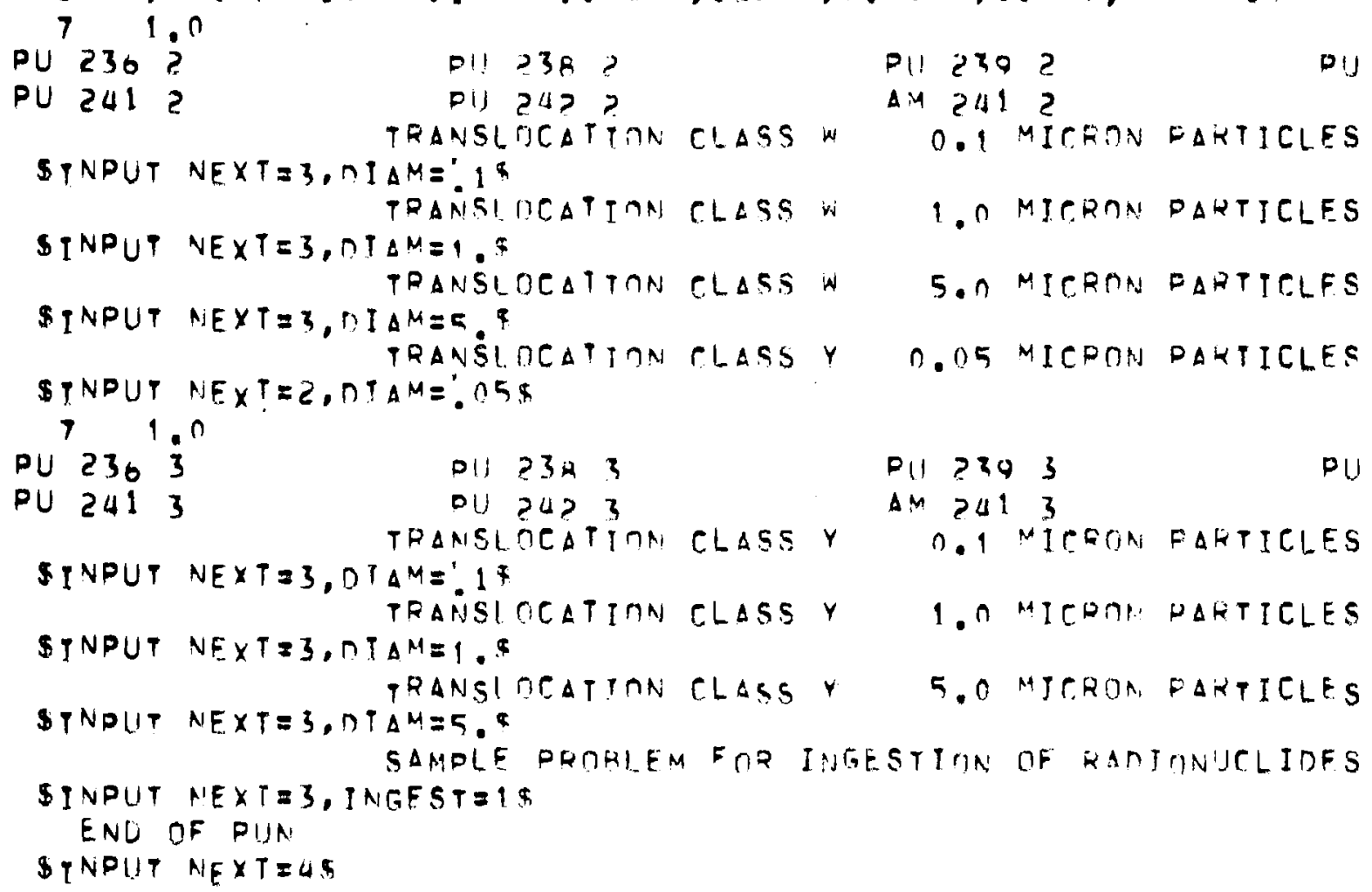

FIGURE G-1. Input Card Listing for Sample Problem 
FIGURE G-2. Sample Problem Output 

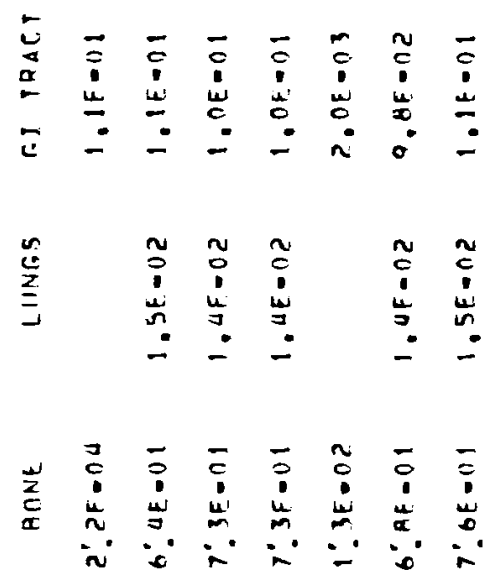

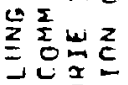

눙

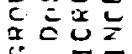

* $x^{2} x$

c. $\frac{x}{2}$

- : 0

品:

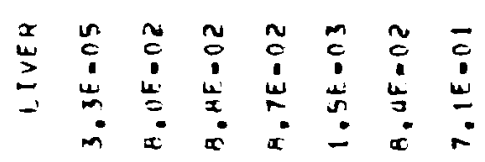

荘
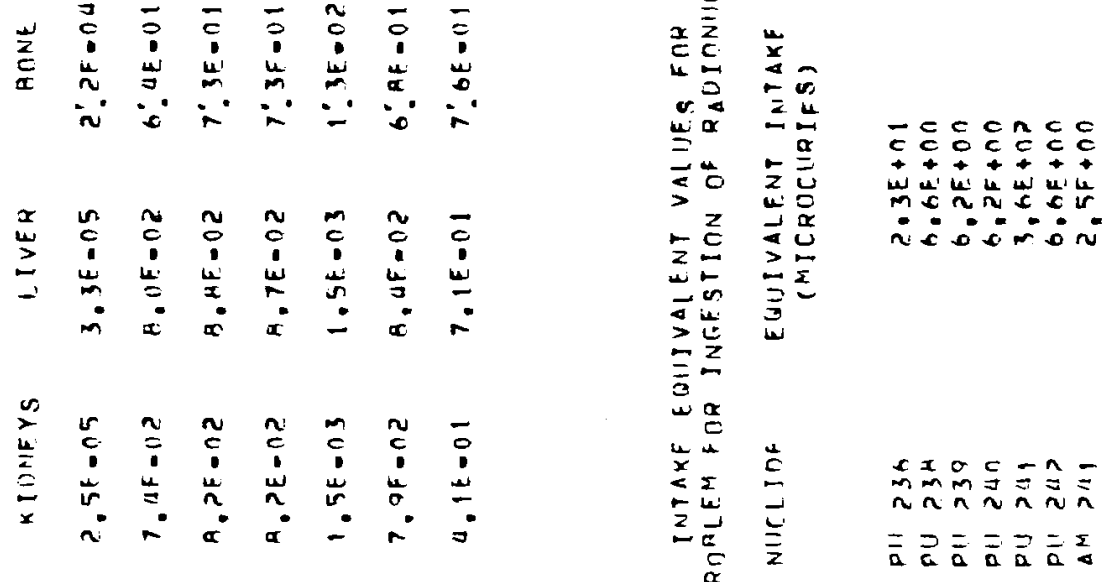

$\underset{0}{a}$

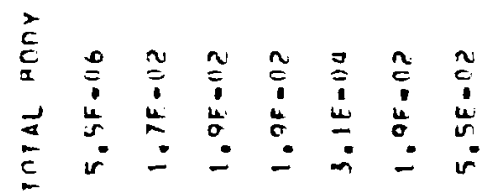

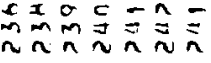

言灵言言言言五

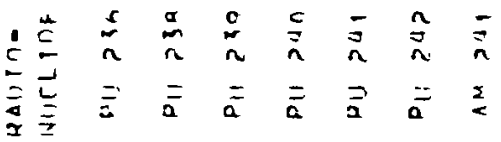



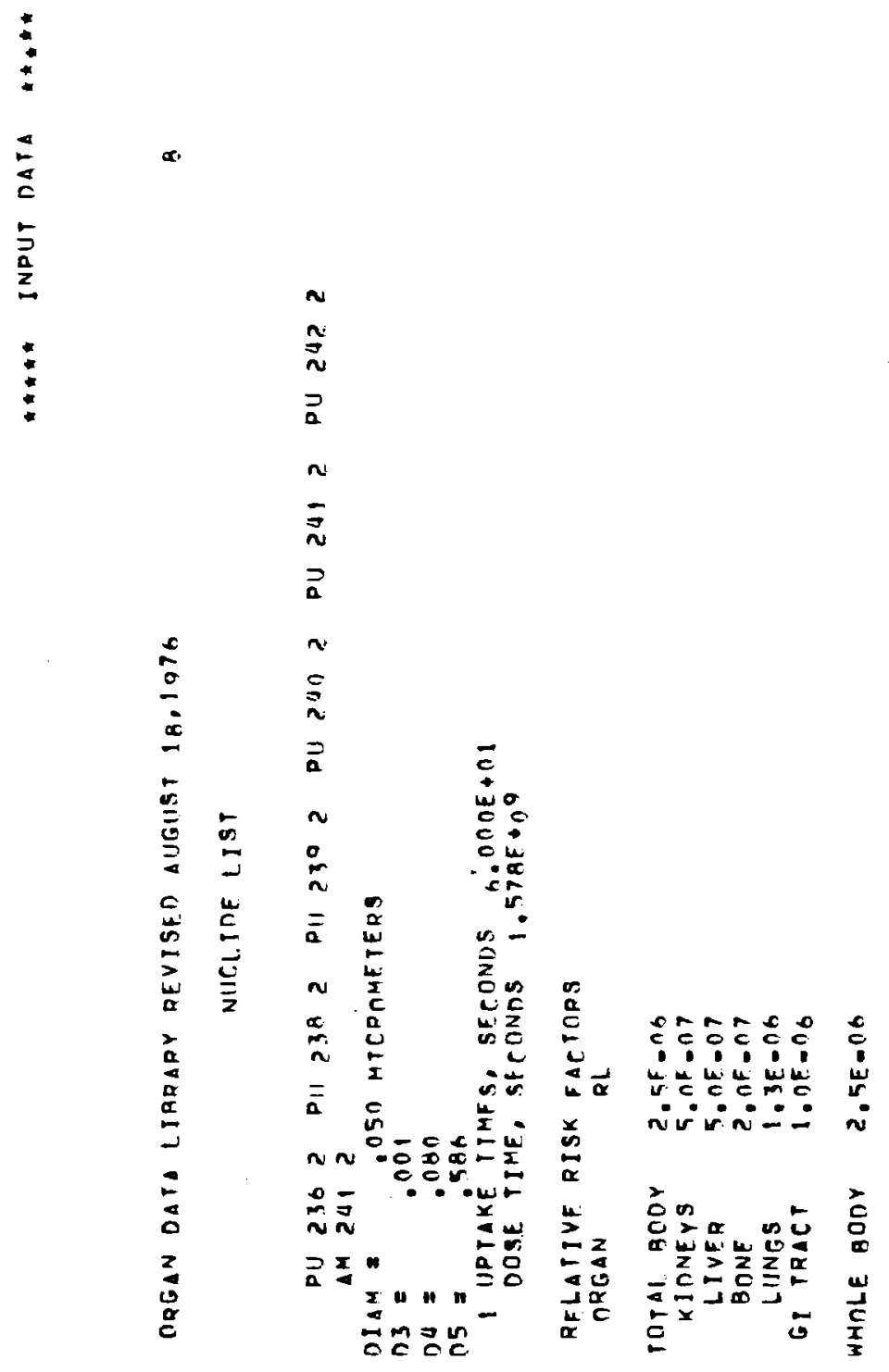


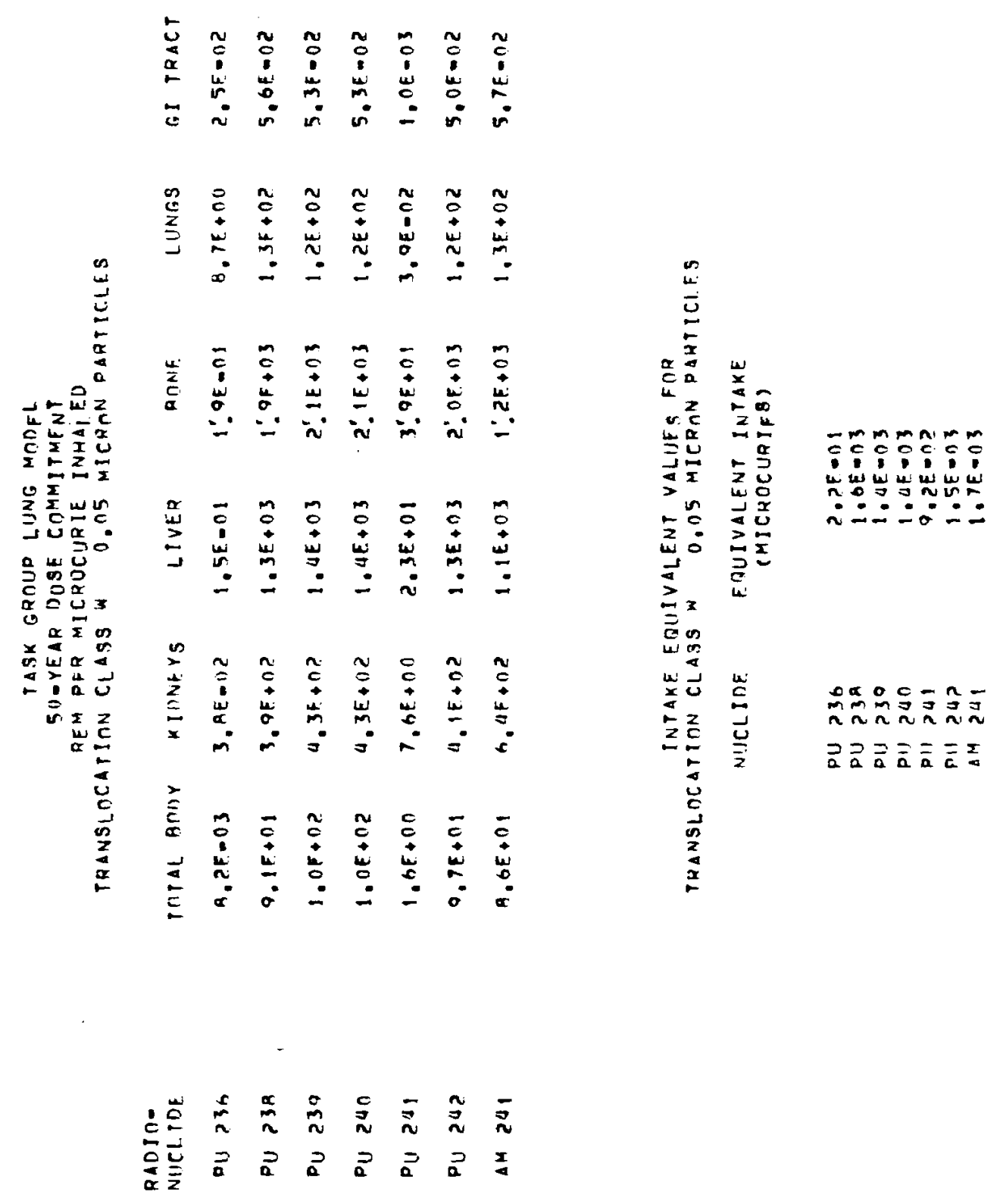




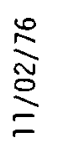
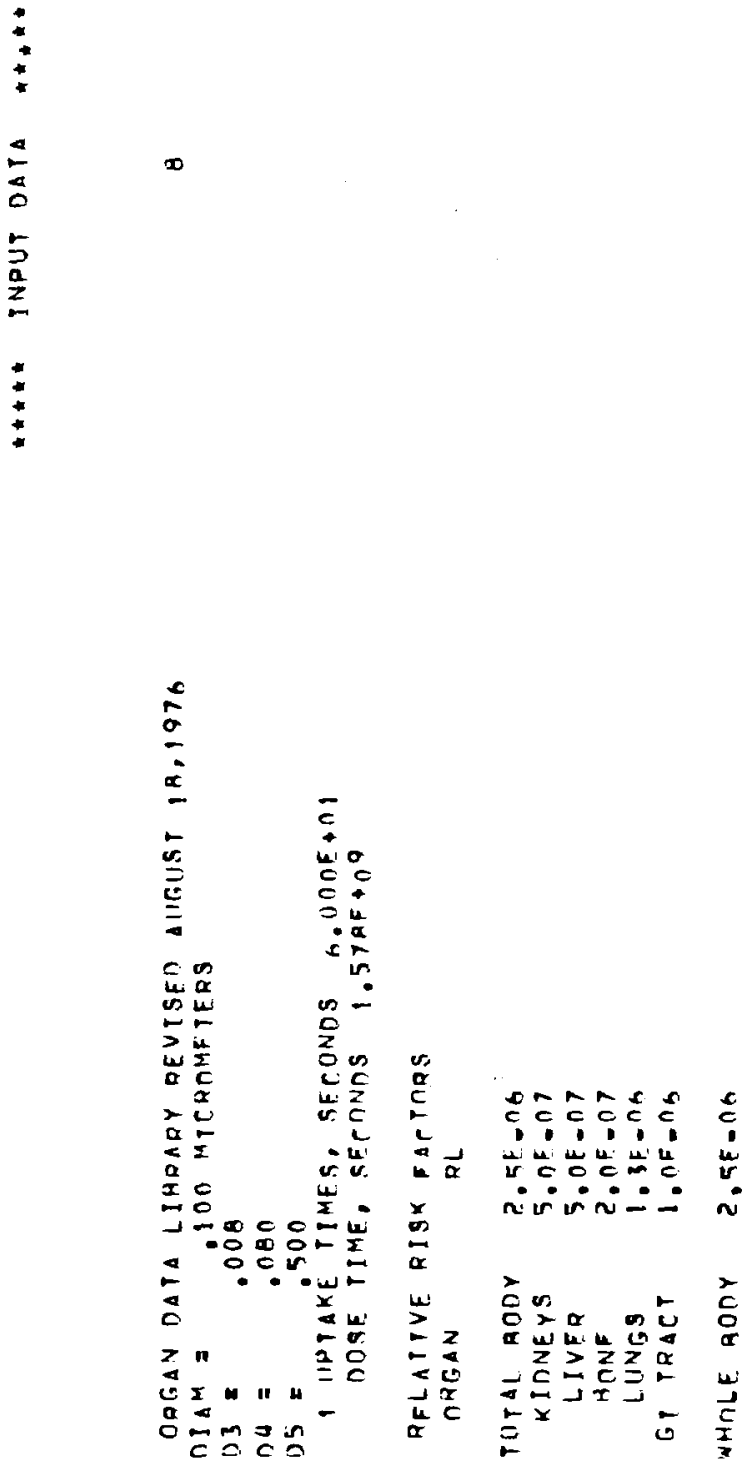

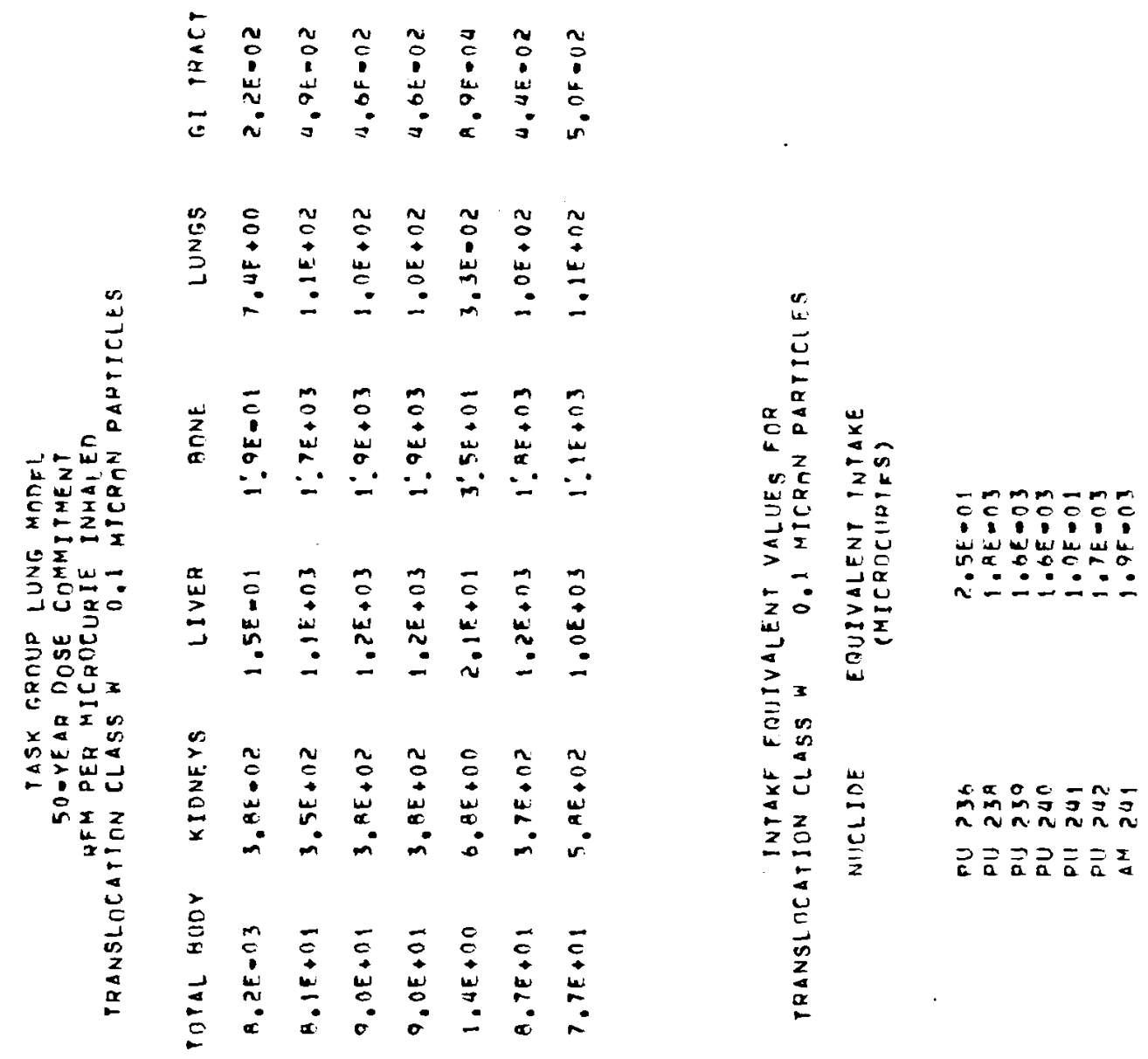

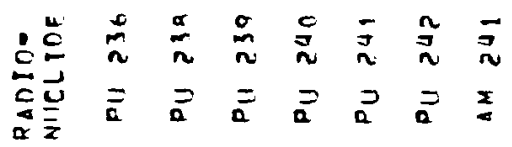


$\stackrel{\infty}{\stackrel{N}{\Xi}}$
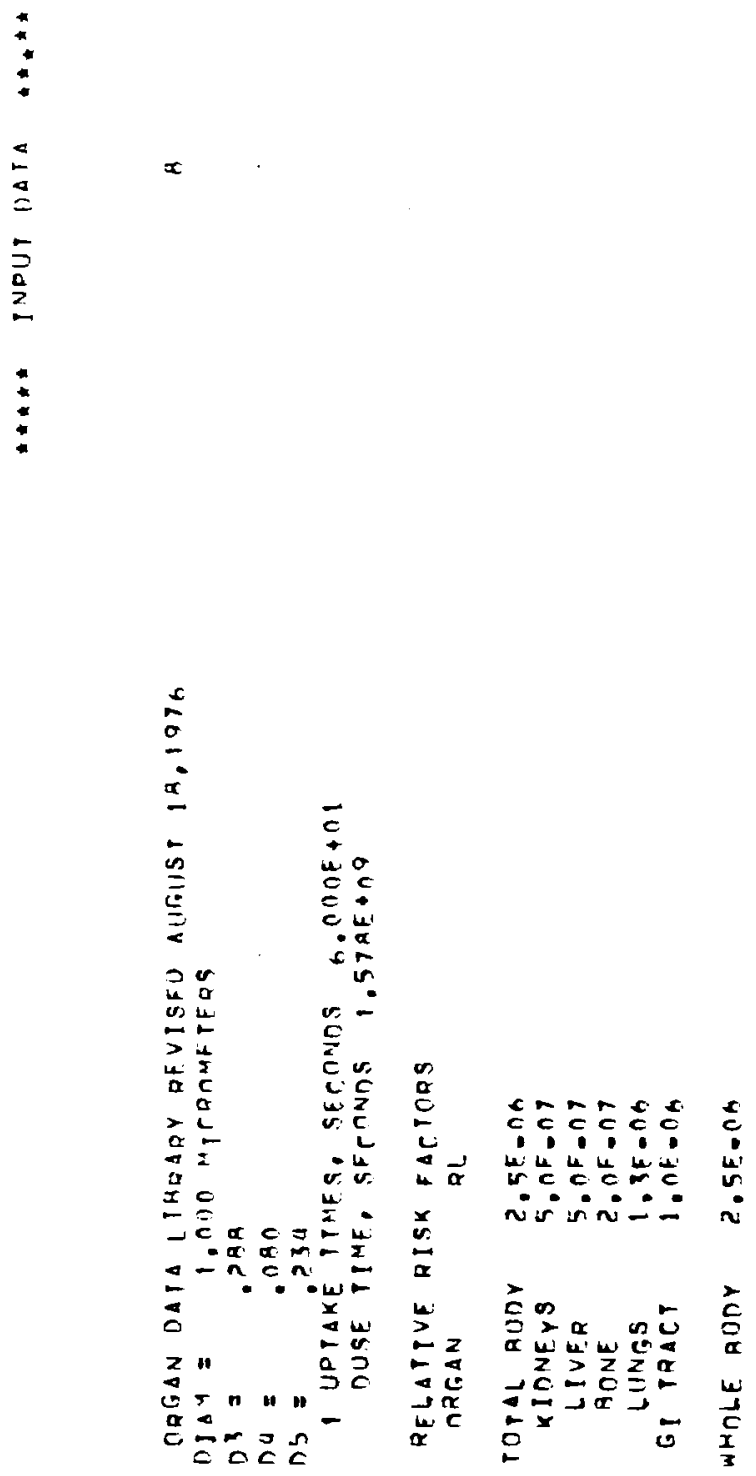


\section{$\stackrel{2}{\vdots}$}

$\stackrel{c}{\vdots}$
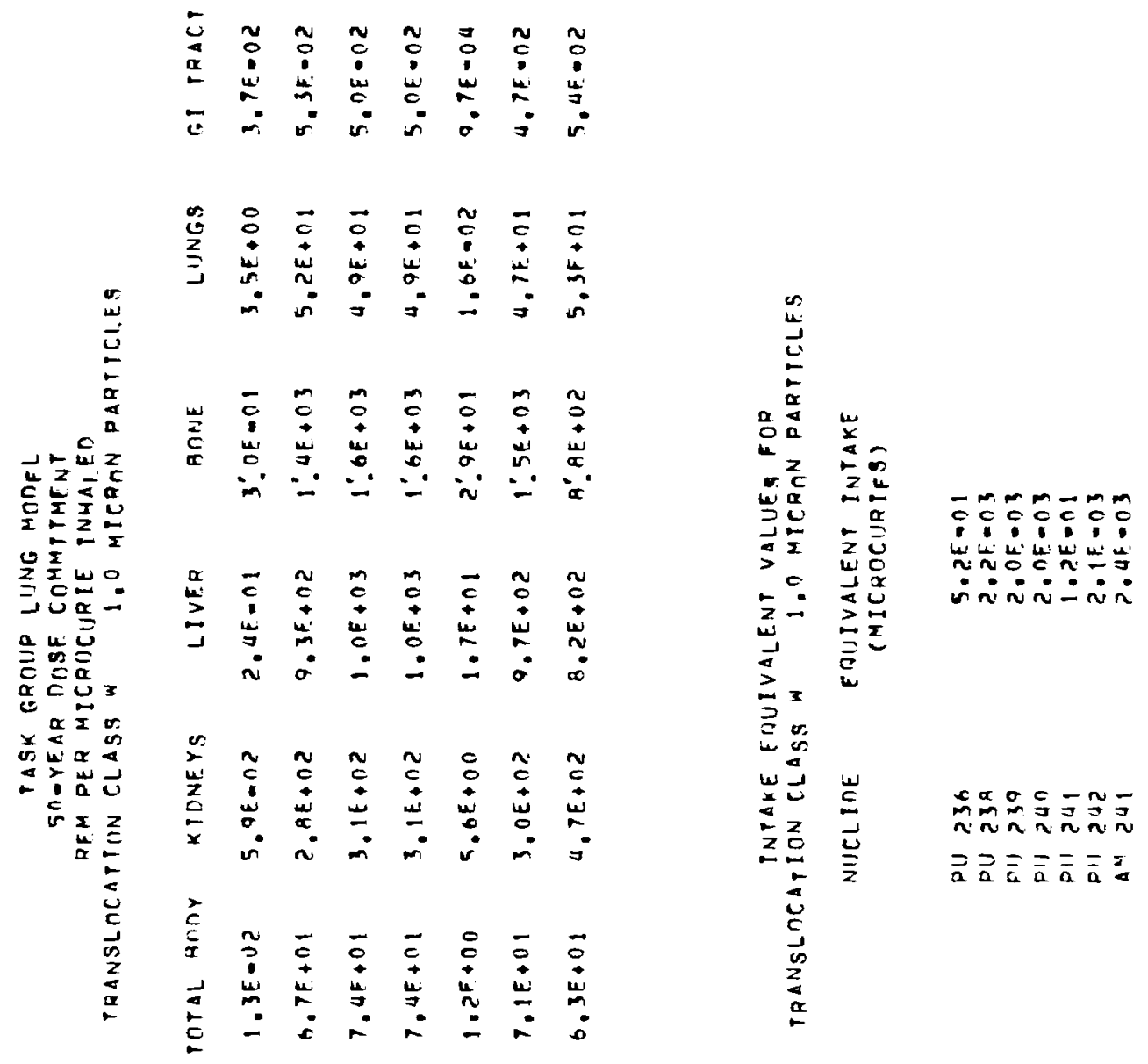

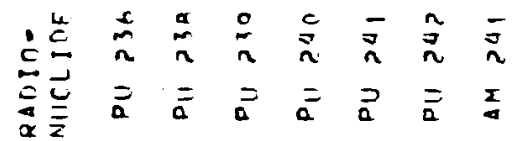




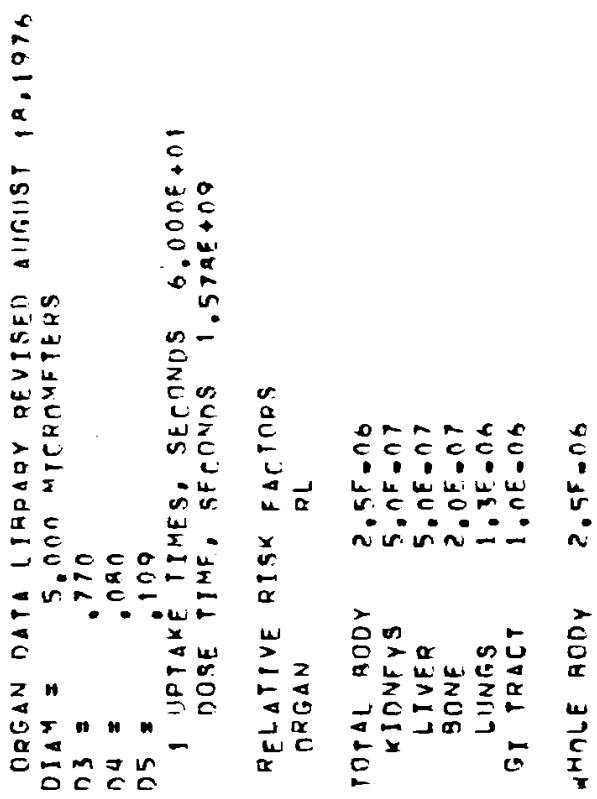




\section{$\stackrel{2}{\vdots}$}
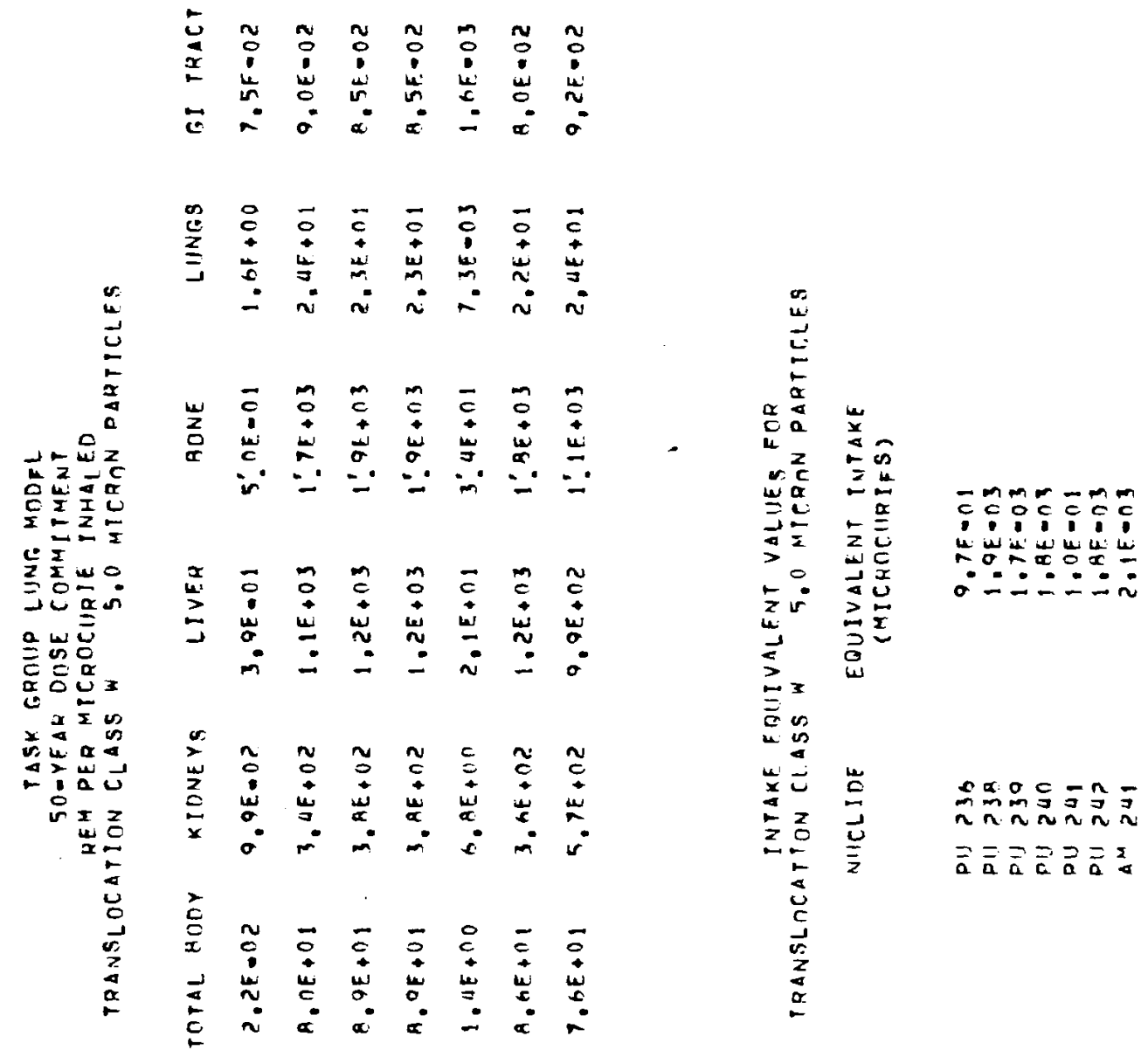

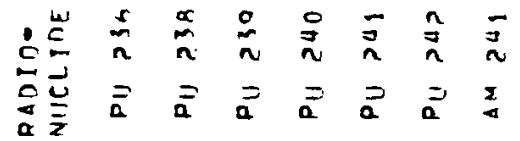


$\stackrel{ }{\stackrel{ }{ }}$

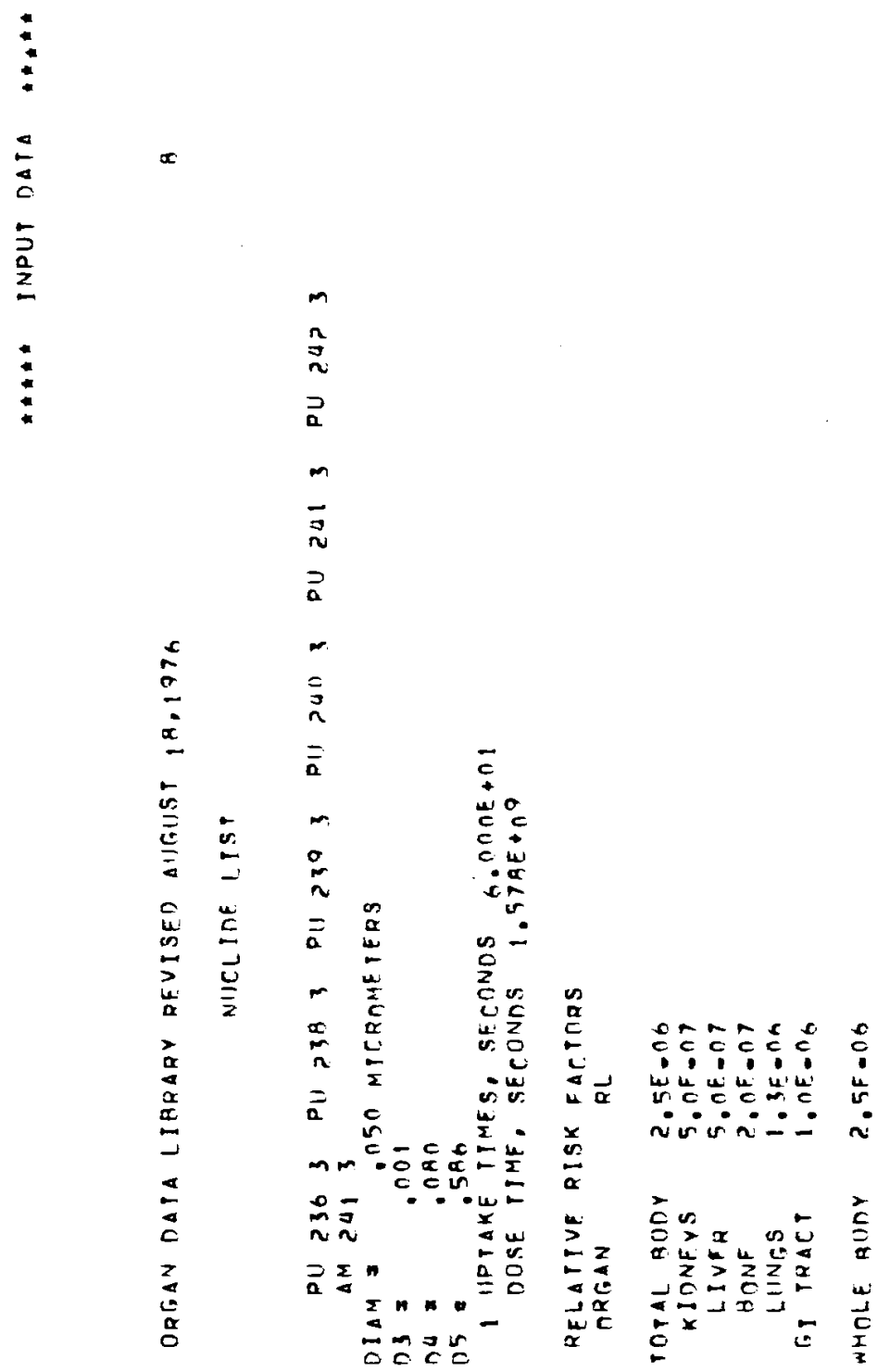


$\stackrel{0}{\vdots}$

$\stackrel{c}{\Sigma}$

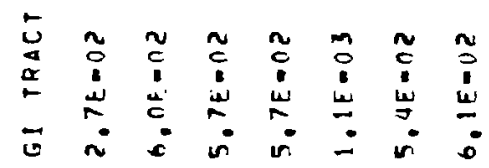

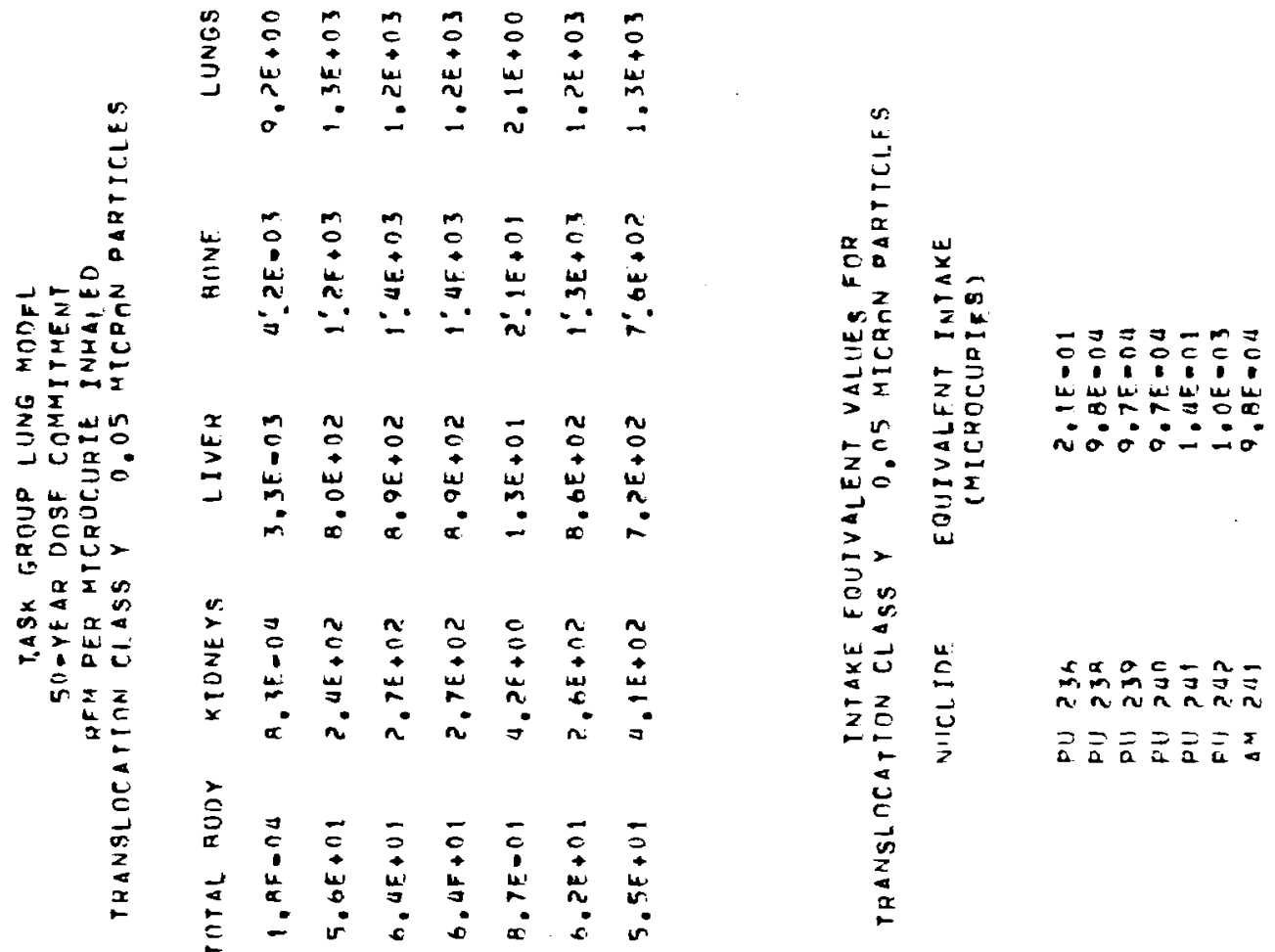

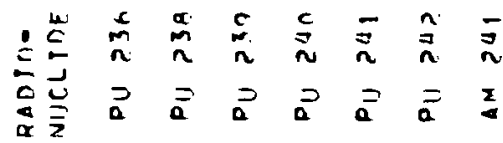




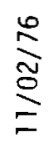
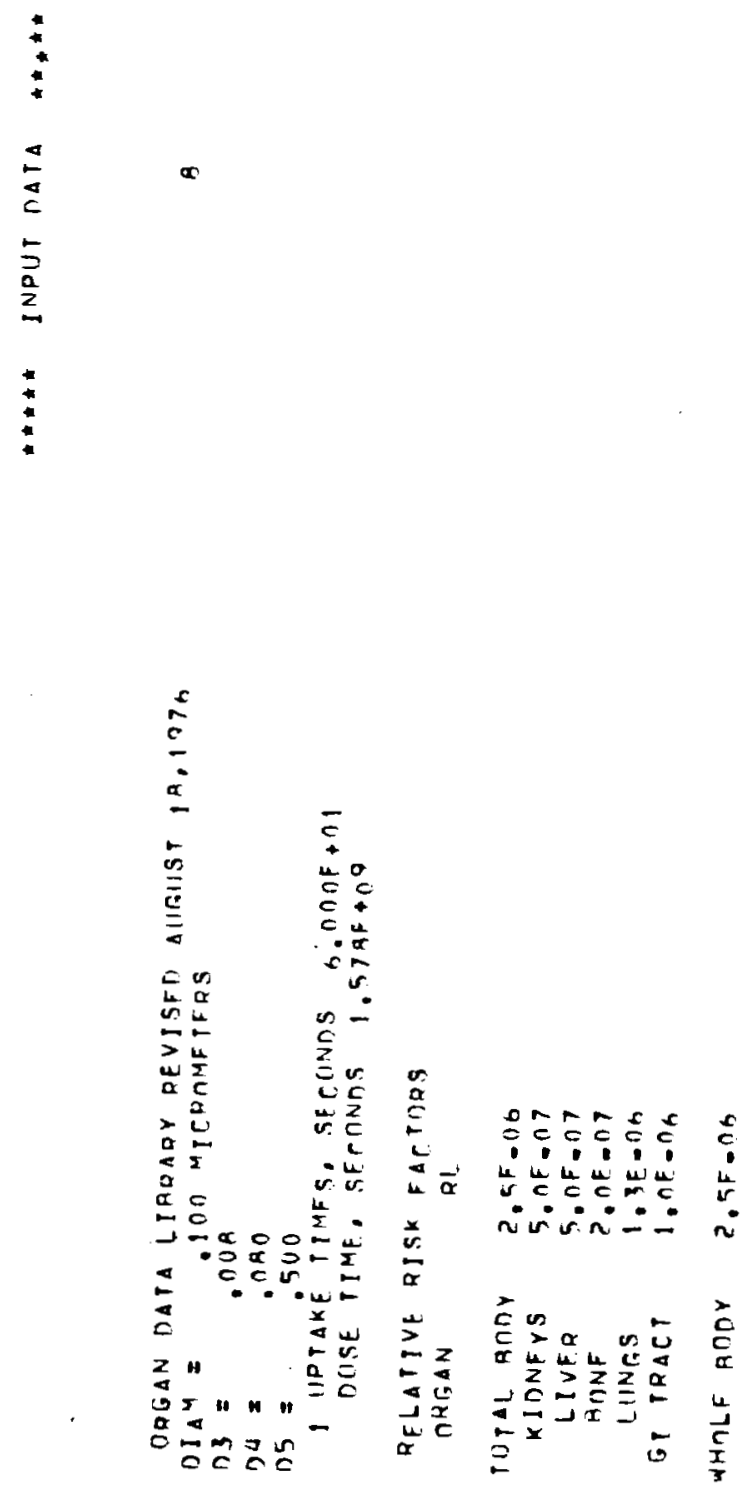

G. 15 

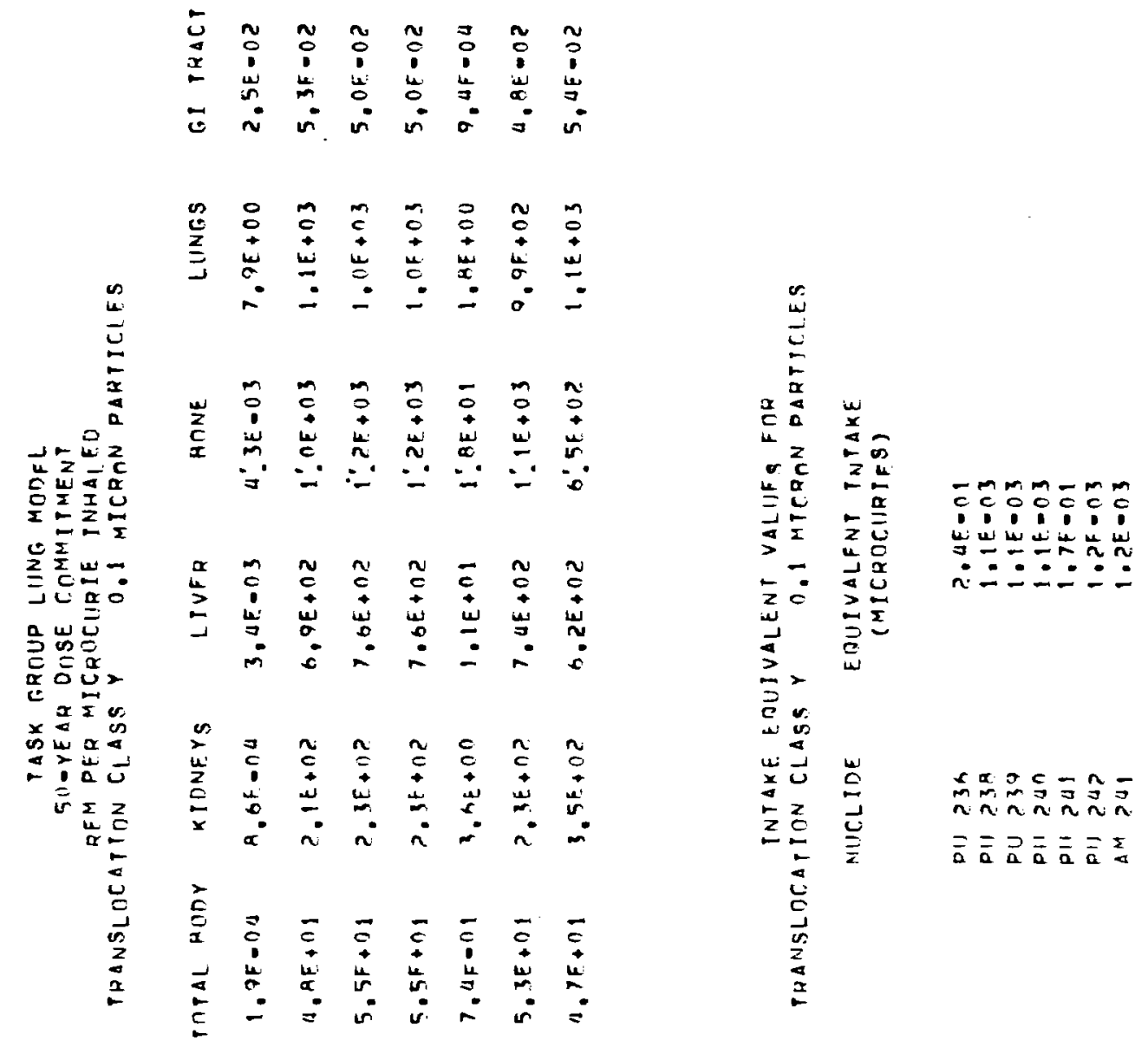

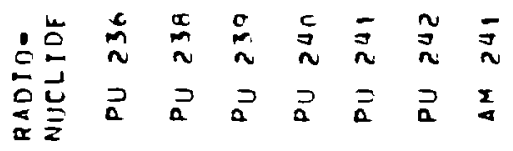


$\stackrel{Ð}{ٍ}$
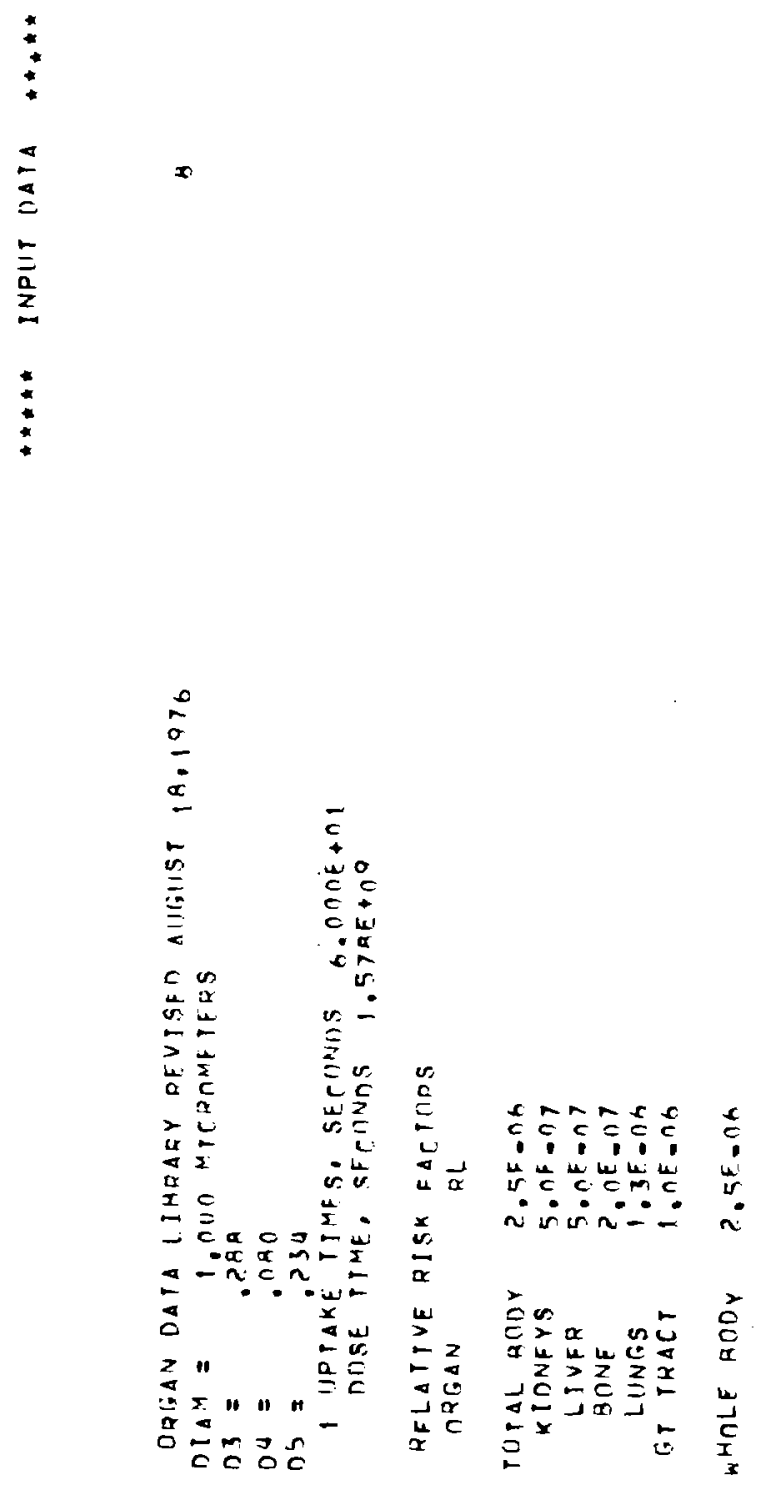

G. 17 
$c$
$\vdots$
0
$=$

5
$\vdots$
$\vdots$

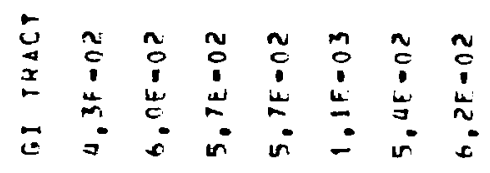

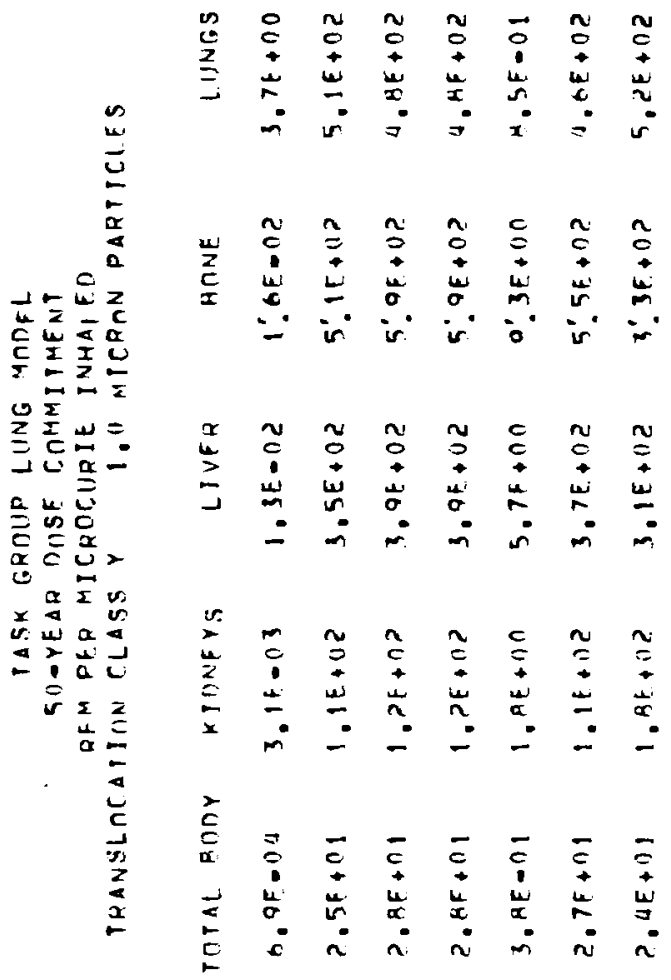

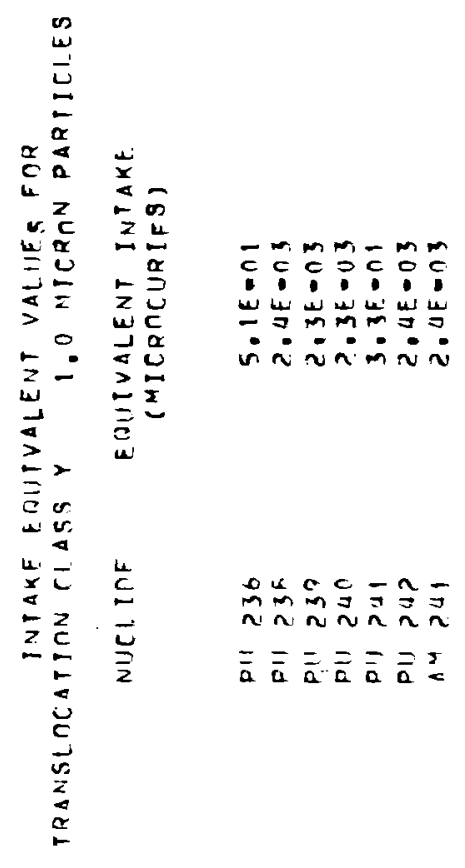

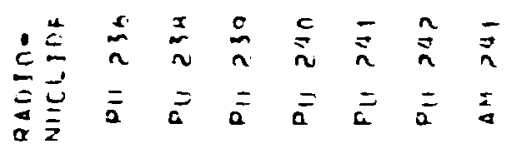



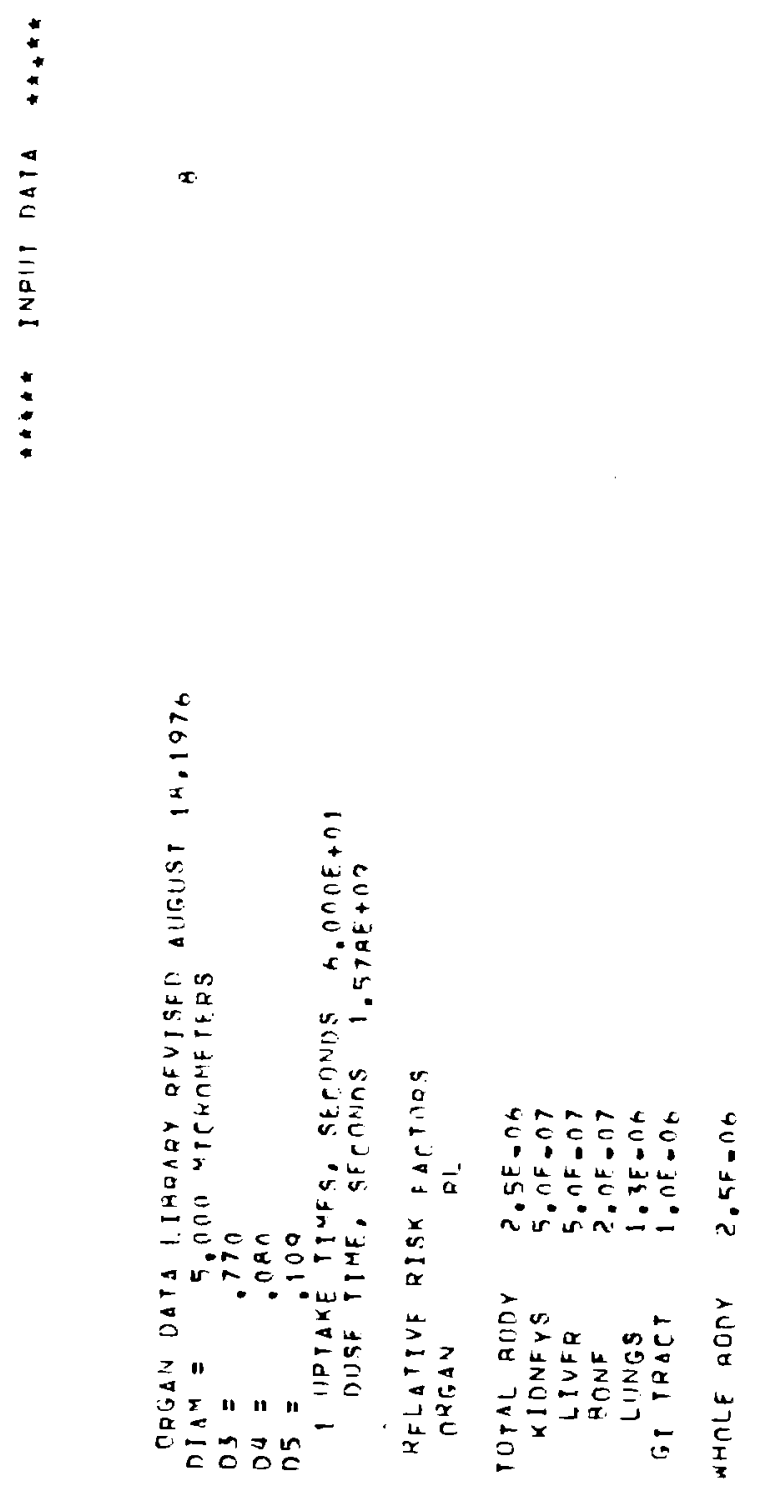

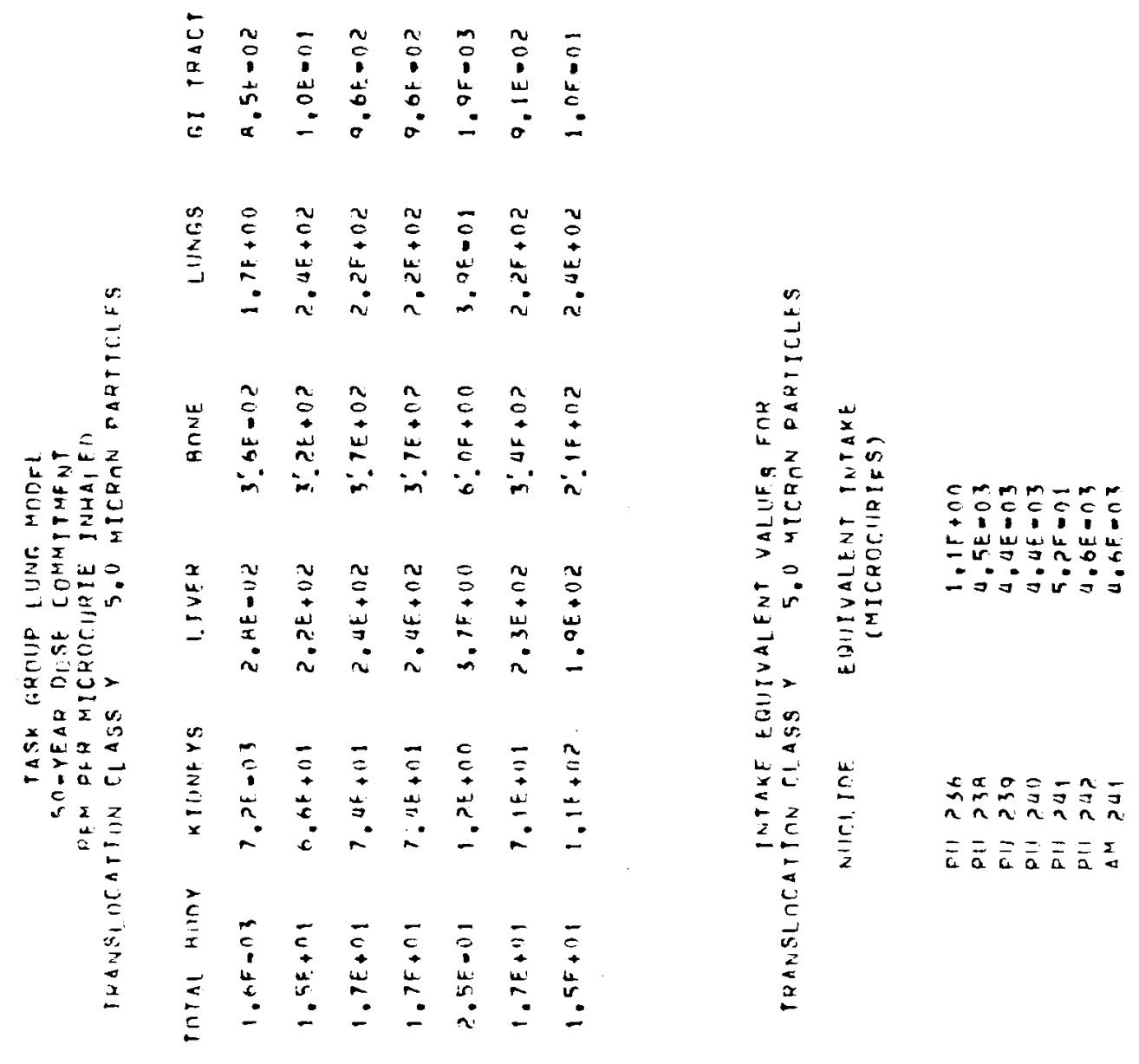

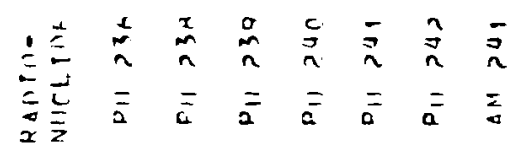



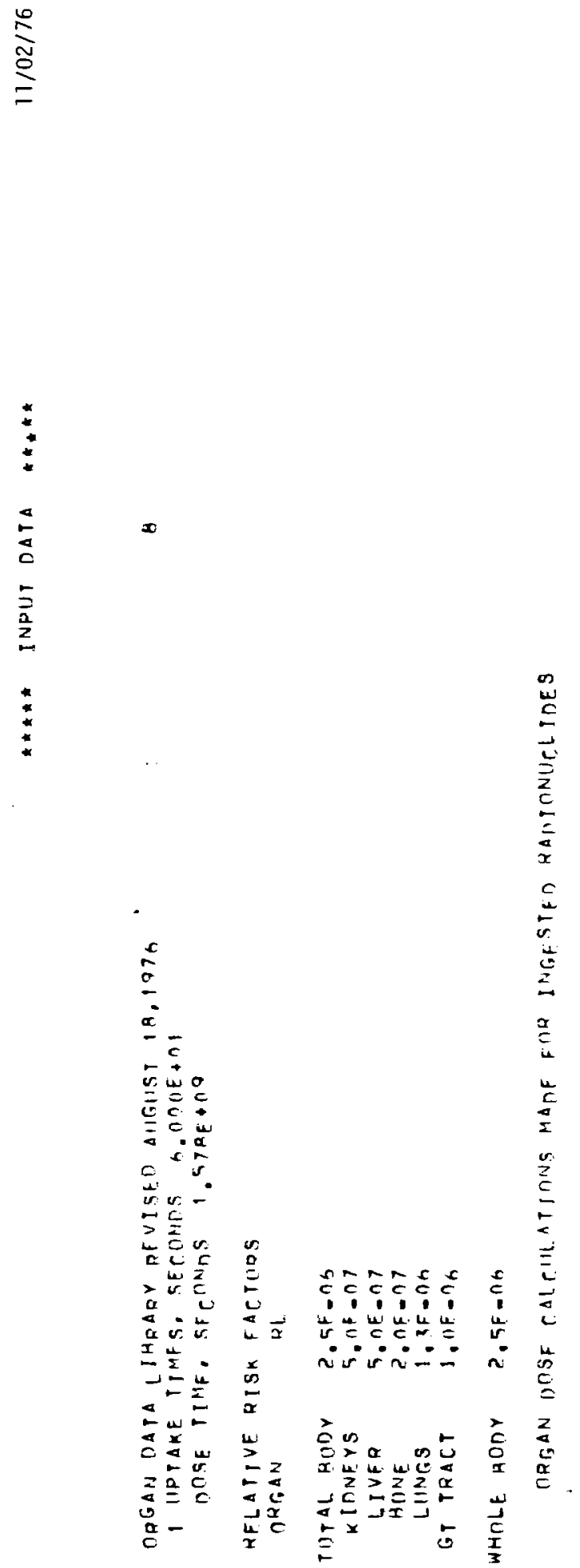


\section{REFERENCES FOR APPENDIX G}

1. P. 0. Strom and E. C. Watson, "Calculated Doses from Inhaled Transuranium Radionuclides and Potential Risk Equivalence to Whole-Body Radiation." Transuranium Nuclides in the Environment, IAEA-SM-199/114, Vienna, 1976.

2. The Advisory Committee on Biological Effects of Ionizing Radiation, The Effects on Populations of Exposure to Low Levels of Ionizing Radiation. National Academy of Sciences - National Research Council, Washington, DC 20006, 1972. 
BNWL -2110

NRC -1

\section{DISTRIBUTION}

No. of

Copies

OFFSITE
A. A. Churm

ERDA Chicago Patent Group

9800 South Cass Avenue

Argonne, IL 60439

3 M. Jinks, Chief Mail and Files

USNRC Central Files

Washington, DC 20555

245 ERDA Technical Information Center

For basic distribution under NRC-1

P. G. Voilleque

ERDA Health Services Laboratory

Idaho Falls, ID 83401

5 H. T. Peterson

USNRC Office of Standards Development 58 Washington, DC 20555
No. of

Copies

ONSITE

ERDA Richland Operations office

P. G. Holsted

Atlantic Richfield Hanford Company

G. E. Backman

United Nuclear Industries, Inc.

A. E. Engler

Hanford Engineering Development Laboratory

G. D. Carpenter

Battelle Northwest
WJ Bair

KR Heid

JR Houston

WE Kennedy (10)

HV Larson

RC Li ikala

KJ Schneider

JM Selby

JK Soldat

DL Strenge (20)

RC Thompson

CM Unruh

LD Williams

EC Watson (10)

Technical Information Files (5)

Technical Publications (2) 